\title{
Cash for consideration? An examination of academics, demographics, and student socioeconomics in the provisioning of institutional aid.
}

\author{
Matthew G. Matyasovsky \\ mgmatyasovsky@mix.wvu.edu
}

Follow this and additional works at: https://researchrepository.wvu.edu/etd

Part of the Higher Education Commons

\footnotetext{
Recommended Citation

Matyasovsky, Matthew G., "Cash for consideration? An examination of academics, demographics, and student socioeconomics in the provisioning of institutional aid." (2019). Graduate Theses, Dissertations, and Problem Reports. 7395.

https://researchrepository.wvu.edu/etd/7395

This Dissertation is protected by copyright and/or related rights. It has been brought to you by the The Research Repository @WVU with permission from the rights-holder(s). You are free to use this Dissertation in any way that is permitted by the copyright and related rights legislation that applies to your use. For other uses you must obtain permission from the rights-holder(s) directly, unless additional rights are indicated by a Creative Commons license in the record and/ or on the work itself. This Dissertation has been accepted for inclusion in WVU Graduate Theses, Dissertations, and Problem Reports collection by an authorized administrator of The Research Repository @ WVU. For more information, please contact researchrepository@mail.wvu.edu.
} 
"Cash for consideration? An examination of academics, demographics, and student socioeconomics in the provisioning of institutional aid."

\author{
Matthew G. Matyasovsky
}

A dissertation submitted to the College of Education and Human Services at West Virginia University in partial fulfillment of the requirements for the degree of Doctor of Philosophy

\author{
Rodney Hughes, Ph.D., Chair \\ Nathan Sorber, Ph.D. \\ Erin McHenry-Sorber, Ph.D.
}

Robert Duval, Ph.D.

Department of Curriculum and Instruction/Literacy Studies

\author{
Morgantown, WV
}

2019

Keywords: Higher Education, Finance, Organizational Behavior, Enrollment Management Access, Institutional Aid

Copyright 2019 Matthew G. Matyasovsky 


\title{
ABSTRACT \\ Cash for consideration? An examination of academics, demographics, and student socioeconomics in the provisioning of institutional aid.
}

\author{
Matthew G. Matyasovsky
}

This dissertation is an empirical investigation of student level observations of 11 cohorts of first-time full-time freshmen from a public, land-grant, research university in Appalachia. Complete with student financial aid offerings, socioeconomic status, and pre-college academic characteristics such as standardized test scores and high school GPA, I investigate the data to examine institutional behavior constrained by resource dependence. The variable of interest is institutional financial aid. Institutional financial aid awards are monetary concessions presented to students as a means to discount the overall price a student pays to enroll. As institutional aid is a direct mechanism through which the institution can influence a student's decision to attend, I argue it is a mechanism through which researchers can shed light on institutional priorities and goals in the context of a resource dependent institution of higher education. As this data spans twelve years and provides both pre and post-recession (2009-10) observations, I gain great leverage in examining institutional aid awards longitudinally. I use multivariate regression and summary statistics to evaluate my research questions guided by a theoretical framework supported by extant financial aid literature. 


\section{TABLE OF CONTENTS}

Abstract

List of Tables

List of Figures

Acknowledgements

Chapter 1: Introduction

Chapter 2: Literature Review

Chapter 3: Methodology

Chapter 4: Results

Chapter 5: Discussion and Conclusion

References

Appendix
Page ii

Page iv

Page v

Page vii

Page 1

Page 28

Page 91

Page 105

Page 140

Page 166

Page 174 


\section{Chapter 1}

\section{Table List}

Table 1.1 Summary Statistics of Appalachian Household by County or Independent City Budget

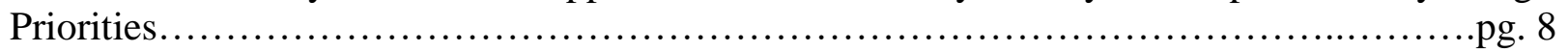

Table 1.2 Percent Change in State Appropriations by State............................pg. 15

\section{Chapter 4}

Table 4.1 Comparison Table of Summary Statistics for 2005-06 and 2015-06 FTFTF by

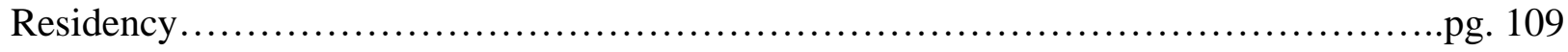

Table 4.2 Proportion and Mean Need of Students With Demonstrated need by Residency pg. 112 Table 4.3 Frequency Distribution of Institutional Awards by Institutional Aid Typology pg. 114

Table 4.4 Benchmarking of Integrated Post-Secondary Education Data System Values and Dissertation Values............................................................ 117

Table 4.5 Longitudinal Comparison of Pooled Regression Results - (ME) Probabilities...pg. 120

Table 4.6 Longitudinal Comparison of Pooled Regression Results - Marginal Effects......pg. 120

Table 4.7 Tobit Pooled Aggregate Aid Regression Results - Marginal Effects on the Probability of Receiving an Aid Award pg. 127

Table 4.8 Tobit Pooled Aggregate Results - Marginal Effects on the Average Institutional Aid Award.

Table 4.9 Tobit Pooled Need-Meeting Aid Regression Results - Marginal Effects on the Probability of Receiving an Aid Award.

Table 4.10 Tobit Pooled Need-Meeting Aid Regression Results- Marginal Effects on the Average Institutional Aid Award. .pg. 130

Table 4.11 Tobit Pooled Non-Need-Meeting Aid Regression Results - Marginal Effects on the Probability of Receiving an Aid Award.

Table 4.12 Tobit Pooled Non-Need-Meeting Regression Results - Marginal Effects on the Average Institutional Aid Award. .pg. 132 


\section{Chapter 1}

\section{Figure List}

Figure 1.1 Total U. S. Coal Production from 1949 to 2017 by Combined Method and Region

\section{Chapter 4}

Figure 4.1: Institutional Enrollment by Year and Residency .pg. 108

Figure 4.2: Proportional Total Enrollment by Year and Residency pg. 108

Figure 4.3 Actual Increases by Year and Residency. pg. 111

Figure 4.4 Percentage Increases to Tuition and fees by Year and Residency - Adjusted for Inflation ..pg. 111

Figure 4.5 Mean Student Need by Year and Residency. .pg. 111

Figure 4.6 Mean Student EFC by Year and Residency.... pg. 111

Figure 4.7 High School GPA of FTFTF by Residency. .pg. 111

Figure 4.8 Mean SAT Score by Year and Residency.... .pg. 111

Figure 4.9 Mean Concorded ACT Score by Year and Residency.... .pg.111

Figure 4.10 Mean Student Quality Index Score (SQIS) by Year and Residency..... .pg. 111

Figure 4.11 Institutional Aid Recipients by Year and Residency.... .pg. 112

Figure 4.12 Aggregate Institutional Aid by Year and Residency.... .pg. 112

Figure 4.13 Need-Meeting Institutional Aid by Year and Residency.... pg. 112

Figure 4.14 Non-Need-Meeting Institutional Aid by Year and Residency.... .pg. 112

Figure 4.15 SQIS Quartile 4: Marginal Effects for Aggregate Institutional Aid Award....pg. 133 Figure 4.16 Student Need: Marginal Effects for Aggregate Institutional Aid Award......pg. 133 Figure 4.17 Nonresidents: Marginal Effects for Aggregate Institutional Aid Award......pg. 133 Figure 4.18 Underrepresented Minorities: Marginal Effects for Aggregate Institutional Aid Award. .pg. 133 
Figure 4.19 SQIS Quartile 4: Marginal Effects on the Probability of Receiving an Institutional Aid Award (Aggregate). .pg. 134

Figure 4.20 Student Need: Marginal Effects on the Probability of Receiving an Institutional Aid Award (Aggregate). .pg. 134

Figure 4.21 Nonresidents: Marginal Effects on the Probability of Receiving an Institutional Aid Award (Aggregate). .pg. 134

Figure 4.22 Underrepresented Minorities: Marginal Effects on the Probability of Receiving an Institutional Award (Aggregate). .pg. 134

Figure 4.23 SQIS Quartile 4: Marginal Effects of Need-Meeting Institutional Aid Awards for SQIS Quartile 4 Students... .pg. 135

Figure 4.24 Student Need: Marginal Effects for Need-Meeting Institutional Aid Awards .pg. 135

Figure 4.25 Nonresidents: Marginal Effects for Need-Meeting Institutional Aid Awards .pg. 135

Figure 4.26 Underrepresented Minorities: Marginal Effects for Need-Meeting Institutional Aid Awards. pg. 135

Figure 4.27 SQIS Quartile 4: Marginal Effects for Need-Meeting Institutional Aid Awards .pg.136

Figure 4.28 Student Need: Marginal Effects for Need Meeting Institutional Aid Awards ..pg. 136

Figure 4.29 Nonresidents: Marginal Effects for Need-Meeting Institutional Aid Awards .pg. 136

Figure 4.30 Underrepresented Minorities: Marginal Effects for Need Meeting Institutional Aid Awards. .pg. 136

Figure 4.31 SQIS Quartile 4: Marginal Effects for Non-Need-Meeting Institutional Aid Awards

Figure 4.32 Student Need: Marginal Effects for Non-Need-Meeting Institutional Aid Awards .pg. 137

Figure 4.33 Nonresidents: Marginal Effects for Non-Need-Meeting Institutional Aid Awards .pg. 137 
Figure 4.34 Underrepresented Minorities: Marginal Effects for Non-Need-Meeting Institutional

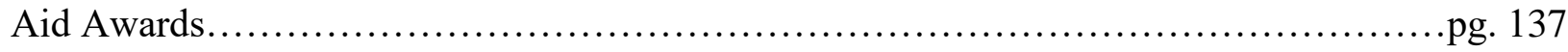

Figure 4.35 SQIS Quartile 4: Probability of Receiving a Non-Need-Meeting Institutional Aid Awards. .pg. 138

Figure 4.36 Student Need: Probability of Receiving a Non-Need-Meeting Institutional Aid Awards .pg. 138

Figure 4.37 Nonresidents: Probability of Receiving a Non-Need-Meeting Institutional Aid



Figure 4.38 Underrepresented Minorities: Probability of Receiving a Non-Need-Meeting

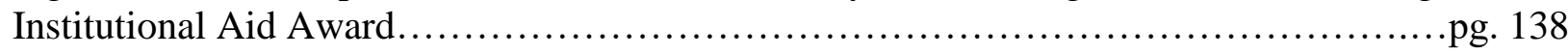

\section{Chapter 5}

Figure 5.1 Aggregate Institutional Aid Discount Rate by Year and Residency .pg. 145 


\section{$\underline{\text { Acknowledgements }}$}

Since entering college as an undergraduate, I have felt as though the first-generation college student label was branded on my forehead. In retrospect, it was a brand of honor. As I reflect on this reality later in life, I'm in awe of what it means. It meant my parents worked hard and committed themselves to my future without having this benefit themselves. For that, I am grateful, thankful, and forever indebted to you.

To my wife and children. Countless times I have said to you, "I'll be out in a minute..." For whatever reason it may have been, know that the work presented here could not have been possible without your unwavering love and support. You are the reasons I write, read, and commit myself to a higher education. The joys you have given and shown me in the small amount of time I have been your husband and father inspire within me the highest sense of self and purpose to which I am truly grateful. I'm simply not possible without you. I love you.

To Dr. Dana Cook Baer, thank you for helping me understand that "balance" is a key to understanding both the law and life. I would also like to thank Dr. Daniel Adamski and his approach to holding students accountable for their own learning and the critical reading and writing skills he instilled in me as an undergraduate.

To my chair, Dr. Rodney Hughes, thank you for your tireless assistance in helping me debug approximately 10,000 lines of SAS code, another 5,000 lines of STATA code, two renditions of results, hundreds of excel files, parse hundreds of facts, figures, and tables, countless phone calls, late night texts, exhausting wall-of-text emails, citation suggestions, text edits and all of this in addition to your classroom teaching. Our working relationship over the past 18 months have positively redefined what I consider to be a close working relationship.

To Dr. Robert Duval, I'm very grateful for the foundations of knowledge you provided to me in your quantitative methods courses. Your suggestions and input have been extremely valuable to both the approach and results of this dissertation. I would also like to thank you for your ability to make even the most complex of concepts, approaches, and methods accessible to the greenest of rookie graduate students - the true essence of a great teacher.

To Dr. Nathan Sorber, the phone call we had in the Fall of 2015 that placed me under your advisement and into the WVU Higher Education program was one of the most positive and lifealtering moments in my higher education career. You helped me realize my future in higher education.

To Dr. Erin McHenry-Sorber, you are one of the best classroom teachers I have ever had. Seeking your approval of my writing was always something that made me hyper-focused. Not making it up on your weekly spotlights of student writing was always difficult for me to swallow, but it made me work harder the following week. Thank you for your thoughtful contributions to this dissertation.

Finally, to graduate students and people everywhere who struggle with any type of mental, psychological, or physical challenges, I urge you to find your breakthrough and carry on to see the betterment in the world that only you can bring. Remember: You belong. You can do it. 


\section{Chapter 1: Introduction}

In the pages that follow, I will provide for an argument that the national landscape for higher education finance is changing through continued state disinvestment, particularly among those states in Appalachia, and how those changes inform institutional aid. I begin with a discussion of how state budgets have still not fully recovered from the recession of 2009-10 and how those realities impact higher education funding in Appalachia. Further complicating regional economic problems and state revenue projections, budgeting, and support of higher education, I move to a discussion of how the economic engine that has traditionally supported the Appalachian region for generations, coal mining, is also experiencing a dearth of growth due to changing energy policies and priorities in the United States.

As a result of the combination of regional economic difficulties, net population losses, competing state interests, and stagnating supporting industries, I argue that Appalachian state governments have been disinvesting from their institutions of higher education - a national trend as well. As higher education institutions who have received government support in the past attempt to hedge against those funding losses, I argue that institutional aid is a mechanism through which we can understand aspects of institutional enrollment management strategies to replace lost funds and stabilize resources necessary to the organization. It is this very resource dependence that drives the behavior of the institution and, I argue, that institutional aid is a lens through which we can observe and evaluate those behaviors.

Further complicating the matter, as institutions contend with continued disinvestment, higher education institutions are also facing a coming decade of problematic enrollment projections as indicated by the Western Interstate Commission for Higher Education's (WICHE) report: Knocking at the College Door. The report demonstrates near stagnant growth of overall 
high school graduates from 2019 to 2023 with a brief upward trend from 2024 to 2025 - the highest point recorded since 2001 - only to spiral downward and leveling off to a new low not seen since circa 2008. As a result, institutions will be faced with the potential for contending not only with continued government disinvestment, but a decreased ability to increase revenue from volume enrollment strategies over the long-term and this signals the potential for greater competition in and among schools to recruit students. While it is clear that institutions need students, it is not always entirely clear as to which students the institutions prefer? I argue that institutional aid awards are a means through which we can understand institutional preferences for various student constituencies as they pertain to academic, socioeconomic, and demographic dimensions.

One of the contributions I will make with this dissertation is the data set I use to examine my research questions. Data for this dissertation stems from a public, land-grant, research university in Appalachia containing 11 cohorts of incoming fall first-time full-time freshmen (FTFTF) from 2005-06 to 2015-16. The longitudinal nature of this dataset allows for an ample timeline to study institutional aid awards with student-level observations from both pre and post2009 recession years. To investigate the data, I will use numerous statistical tools, such as regression analysis and summary statistics, to uncover relationships between institutional aid recipients while also controlling for student financial need, academic aptitude, and socioeconomic and demographic dimensions of individual students. Through institutional aid award data, I can uncover statistical relationships to demonstrate preferred institutional student constituencies in an effort to shed light on the institution's response to resource dependency aggravated by government disinvestment. 
Potential relationships between institutional aid awards and student characteristics are many. If the institution is awarding institutional aid to those students high in need, it may demonstrate the institution's desire to provide greater equity in access to higher education for students of financial need. If the institution is preferential of its aid awards to students of high academic aptitude, the institution may be attempting to, among many other possibilities, capitalize on building a strong student body to increase its ranking reputation, provide greater shares of students necessary for the institution to compete in ventures of academic capitalism, or increase its ability and reputation for providing quality graduates ready to enter industry. The institution may also offer institutional aid awards in an attempt to expand access to previously underrepresented minorities. Institutions may also attempt to maximize their net-tuition calculation to ensure the highest rate of return for a myriad of reasons from financial solvency, to increase capabilities to competitively engage in the higher education marketplace, or in advancing goals of visionary growth brought on by administrative or organizational ambition. In short, institutions provide institutional aid for many reasons. Who receives those funds helps us understand their goals.

\section{The Appalachian Context}

As the institution of study is located within the Appalachian region, a greater understanding of that region helps to contextualize how regional economics and demographics influence resources available to higher education institutions from their host governments. Appalachia provides a unique contextual lens through which this study gains greater leverage in controlling for various economic and demographic factors, such as paradigm-shifting industrial change, population migration, and competing state interests that act upon institutions of higher education by constraining resources available to the state. 
This dissertation uses the definitions and descriptions of the Appalachian region and subregions as those provided by the Appalachian Regional Commission (ARC). Established through an Act of Congress in 1965, the ARC is comprised of the Governors from the Thirteen Appalachian states (Alabama, Georgia, Kentucky, Maryland, Mississippi, New York, North Carolina, Ohio, Pennsylvania, South Carolina, Tennessee, Virginia, and West Virginia), a federal co-chair appointed by the president, and is bolstered with local representation from within the Appalachian Region's 420 counties (ARC, 2019). The ARC defines the Appalachian Region as a "205,000-square-mile region that follows the spine of the Appalachian Mountains from Southern New York to Northern Mississippi” (ARC, 2019, p. 1).

Using data from 2012-16 American Community Survey, the ARC demonstrated that 25.6 million people lived in Appalachia and the Appalachia population has grown by $1 \%$ whereas the national population has grown by 4.5\% (Pollard and Jacobsen, 2019). Southern Appalachia which includes northern Alabama, northern Georgia, northeastern Mississippi, western North and South Carolina, as well as central and northeastern Tennessee have experienced an overall growth of 4.7\% since 2010 (Pollard and Jacobsen, 2019). Although the ARC (2019) minority status within the Appalachian region has increased since 2019 from $16.4 \%$ to $18.2 \%$, data from the American Community Survey indicated that the overall share of minorities in the national population is 38.7\% up from 36.2\% in 2010 (Pollard and Jacobsen, 2019).

Although the ARC has recognized that the Appalachian region has had positive economic shifts in the past 55 years, those benefits have been shared by regions whose economies have adapted. For example, the ARC suggested that the "number of high-poverty counties in the region (those with poverty rates more than 1.5 times the U. S. Average) declined from 295 in 1960 to 93 over the 2012-2016 period" (Pollard and Jacobsen, 2019). However, this growth has 
occurred in areas where the industries supporting local economies have adapted and diversified over time away from industries that have been traditionally supportive of the region. Although the ARC does not specially indicate how the regions have adapted, one can infer that adaptation refers to a region's ability to respond to changes in the economy. For example, As the ARC indicates, the Appalachian region has been historically dependent upon mining, forestry, agriculture, as well as chemical and heavy industry (Pollard and Jacobsen, 2019). Regions experiencing economic success as a result of adaptation have either modified their industrial capabilities to compete profitably or have shifted their industrial focus to meet more contemporary economic needs. For my purposes, this dissertation is focused on North Central Appalachia where coal-mining has been the dominant industry where the unemployment rate for working age adults is $5.6 \%$ (Pollard and Jacobsen, 2019). As the coal industry continues to face declining demand and political support, its ability to provide family sustaining jobs has become severely limited. As a result, the scarcity of state resources is further exacerbated by competing public policy priorities as they gain greater shares of state fiscal and legislative agendas leaving even less resources for institutions of higher education.

\section{State Budgets and Economic Industry}

According to the National Conference of State Legislatures (NCSL), state budgets are still in relative disarray since the Great Recession of 2009 (MacKellar, 2017). Although many 2017 state budgets are relatively stable, many other states, particularly those that enact two-year budgets, indicated the need to address a budgetary shortfall in 2017 - eight years post-recession (Quinn, 2017). Although states have partially restored higher education cuts, Mitchell, Leachman, and Masterson (2017) demonstrated that, nationally, states spent approximately $16 \%$ less per student between 2008 and 2017 with only five states increasing their per-student 
funding: Indiana, Montana, Nebraska, North Dakota, and Wyoming. The authors also stated that some cuts were austere with eighteen states decreasing spending by $20 \%$ per student with eight of those states slashing spending by up to $30 \%$ and a highly austere Arizona cutting spending by approximately $50 \%$.

Research from Bowen, Christiadi, Deskins, and Lego (2018) demonstrated that coal production fell by nearly $45 \%$ in central Appalachia and represented a rate of decline over double that of the national average of $21 \%$. The authors noted that the main reason for this decline stems from a "perfect storm of three major national factors" including the declining cost of competing natural resources such as natural gas, a hostile regulatory environment, and declining international demand (p. 4). As large-scale industries leave and alternative employment is limited, displacement and diffusion of the labor force is likely as individuals attempt to find work elsewhere. As these individuals are forced to leave the state in search of adequate employment, the state tax base is also degraded, resulting in further jeopardy for the economic stability of the state. Furthermore, individuals who attempt to wait out job-loss also stress the state unemployment system causing further complications to fiscal planning for state policymakers.

The decline of coal mining in the Appalachian region is a relevant example as government regulation and global economics have constrained the profitability and growth of mining operations in the U.S. The following graphic (see Figure 1.1) was provided by the U. S. Energy Information Administration (Table ES-1) and demonstrates the relative decline of U.S. Coal production since 2009. The difference between the Eastern and Western regions of the Mississippi - with Appalachia being east of the Mississippi - help to demonstrate that economic disparity in the coal industry is not monolithic. Even individual state shares of U.S. coal 
production differ widely among Appalachian states. For example, the West Virginia share of the average national coal production has shrunk from $13.5 \%$ in 2008 to less than $11 \%$ in 2016 whereas other coal basins, like those in Western Indiana and Western Kentucky, have seen their Figure 1.1

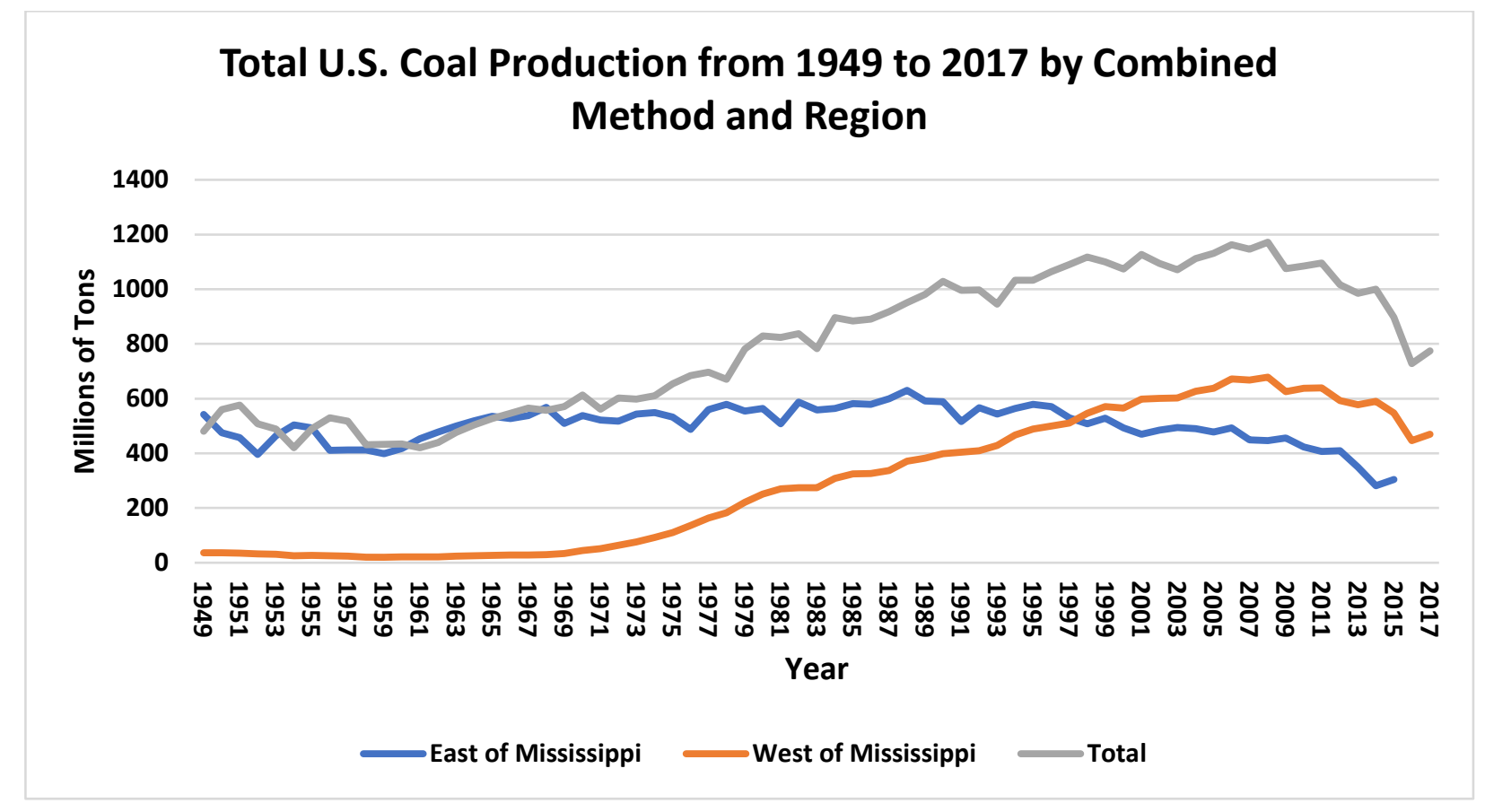

Source: U. S. Energy Information Administration, Table ES-1 Coal Production.

overall share of the national average increase by as much as $4 \%$ points (Lego and Deskins, 2017). As a result, some regions in Appalachia are experiencing reasonable growth, whereas others are stagnant. According to the U.S. Census Bureau, Kentucky is projected to have a $2.6 \%$ increase in their 2017 overall population, Tennessee $+5.8 \%$, Virginia $+5.8 \%$, Pennsylvania of $+.8 \%$. Population growths paint a telling picture. Estimates from the US Census Bureau, from 1980 to 1990 , indicate West Virginia has lost approximately $8 \%$ of its total population, with slow growth of approximately $.8 \%$ in the 2000 census, $+2.5 \%$ in the 2010 census and a 2017 projected decrease of $-2 \%$ and is, demonstrably, the region hardest hit by economic change and population migration in Appalachia. 
Coal mining jobs provided above average earnings opportunities for Appalachian households. According to the Bureau of Labor Statistics (BLS), as of May 2017, national estimates for the coal mining industry demonstrate a mean hourly wage of \$28.32 and an annual mean wage of $\$ 58,910$. Loading machine operators and underground miners earn a mean hourly wage of $\$ 24.89$ with a mean annual salary of $\$ 51,780$ nationally. West Virginia is among the top five states in pay for coal mining, according to the BLS, as its mean hourly wage is $\$ 27.19$ with a mean annual wage of $\$ 56,560$ and has the highest level of employment for loading machine Table 1.1:

\begin{tabular}{|c|c|c|c|c|c|c|c|c|c|c|}
\hline \multicolumn{11}{|c|}{$\begin{array}{r}\text { Summary Statistics of Appalachian Households by County or Indepe } \\
\text { In Ascending Order by } 2017 \text { Median Household Income }\end{array}$} \\
\hline & OBS & Median & Mean & STDV & OBS & & edian & & Mean & STDV \\
\hline Kentucky & 54 & 26.3 & 27.6 & 7.0 & 54 & $\$$ & 33,526 & $\$$ & 33,937 & 6068 \\
\hline Mississippi & 24 & 22.8 & 22.2 & 4.1 & 24 & $\$$ & 36,479 & $\$$ & 37,335 & 3780 \\
\hline Virginia*** & 33 & 17.4 & 18 & 5.1 & 33 & $\$$ & 39,003 & $\$$ & 41,448 & 7868 \\
\hline Tennessee & 52 & 18.3 & 18.5 & 3.9 & 52 & $\$$ & 40,359 & $\$$ & 40,494 & 5957 \\
\hline West Virginia*** & 55 & 18.1 & 19.05 & 5.0 & 55 & $\$$ & 40,509 & $\$$ & 41,217 & 7658 \\
\hline North Carolina & 29 & 16.8 & 16.9 & 2.8 & 29 & $\$$ & 41,443 & $\$$ & 42,823 & 4994 \\
\hline Alabama & 37 & 17.5 & 17.9 & 3.9 & 37 & $\$$ & 41,456 & $\$$ & 43,472 & 8184 \\
\hline Ohio & 31 & 15.1 & 17.5 & 3.5 & 31 & $\$$ & 44,729 & $\$$ & 44,955 & 4267 \\
\hline South Carolina & 6 & 15.2 & 15 & 2.5 & 6 & $\$$ & 46,575 & $\$$ & 46,734 & 5473 \\
\hline Georgia & 37 & 15.4 & 15.2 & 3.7 & 37 & $\$$ & 46,634 & $\$$ & 49,894 & 12775 \\
\hline Maryland & 3 & 13.2 & 14.4 & 2.4 & 3 & $\$$ & 46,710 & $\$$ & 48,687 & 5254 \\
\hline Pennsylvania & 52 & 13.7 & 13.6 & 2.9 & 52 & $\$$ & 47,484 & $\$$ & 48,960 & 5996 \\
\hline New York & 14 & 15.2 & 15.7 & 2.1 & 14 & $\$$ & 49,981 & $\$$ & 49,082 & 3885 \\
\hline All Appalachia & 41 & 19.6 & 20.0 & 4.6 & 41 & $\$$ & 38,968 & $\$$ & 40,104 & 6358 \\
\hline All U.S. & 3142 & 14.9 & 15.9 & 6.3 & 3142 & $\$$ & 47,589 & $\$$ & 49,522 & 12887 \\
\hline
\end{tabular}

*Data Source: US Census Bureau Small Area Income and Poverty Estimates 2017 (SAIPE)

** Includes cities: Bristol, Buena Vista, Covington, Galax, Lexington, Martinsville, Norton, and Radford

***All counties in WV are considered a part of Appalachia according to the ARC

$* * * *$ All ARC Identified counties can be found here:

https://www.arc.gov/appalachian_region/countiesinappalachia.asp 
operators and underground mining. According to 2016 U.S. Census Bureau data (see Table 1.1), the median household income in Appalachia (in 2016 dollars) was $\$ 42,137$ with a mean of 17.5 percent of all-aged individuals living in poverty by county. For the U.S. nationally in 2016, the median household income was $\$ 60,309$ and climbed by 1.8 percent from the previous year (Fontenot, Semega, and Kollar, 2018). Although the median household income in Appalachia are well below the national median household income, the coal mining occupations described above earn well above the regional median poverty rate as well as the national poverty rate. However, the Bureau of Labor Statistics projection for some of these occupations such as, continuous mining machine operators, is expected to decrease by $3.7 \%$ from 2016 to 2026 as well as shares for mine shuttle car operators by $21.9 \%$.

Although new market opportunities, such as the Marcellus Shale boom (see Pless, 2012) manifest and offer potential substitutes for job losses in one industrial sector, they do come with their own set of potential problems. Natural gas extraction through proprietary hydraulic fracturing or "fracking", for example, is politically controversial and has been banned outright in three different states as of January 2018. Reasons for bans are numerous, but states have been under tremendous pressure from environmental groups and industry to expand or contract legislative rules regarding the practice of fracking. At the genesis of the Marcellus Shale boom circa 2012, nine states had introduced new legislation regulating various segments of the shale industry with a total of twenty-six new bills focusing on mitigation of potential environmental hazards caused by fracking and the required disclosure of fracking fluid components (Pless, 2012). Some states have successfully moved to ban the practice all together. Vermont stands as the first state to ban fracking in 2012 a move which has been coined as symbolic because Vermont has insignificant reserves of shale gas (Gram 2012). Citing public health as the impetus 
for the ban, The Cuomo administration in New York banned fracking in New York via executive order (Kaplan 2014). Maryland, the third state to ban fracking, enacted legislation directly forbidding the practice (Wood 2017).

Although industries may enter and exit the market, in the interim, however, population migrations are likely to occur as individuals previously eligible to enter an occupation (e.g. coal mining) vastly outnumber the positions available. Without an immediate alternative to coal mining with similar pay, benefits, and available jobs, migration of state population is likely occur as individuals search for better economic opportunities. As a net loss of population through migration occurs, state revenues are also negatively affected as the revenues from sales, corporate, and income taxes coincide with industry, occupational, and population losses. As these issues extend over a period of time and are proportionally different among the affected regions, the issues systemic to one region become compounded over time with some regional losses disproportionately higher than others - especially within the Appalachian regions discussed above.

As these jobs decrease and a lack of alternative employment opportunities exists, individuals will either be forced out of state to find suitable employment or they may be forced to enroll in public assistance until better opportunities are available to them. As these complementary pressures mount, state resources will be constrained and the discretion of policymakers to invest in policies or institutions that do not promote the public welfare in meaningful ways will also be highly constrained.

In light of declining state resources, higher education institutions must constrict their spending to save or find other avenues through which they can replace the lost revenue. Institutions may seek to increase tuition or find other sources of revenue to offset the government 
disinvestment. Jaquette and Curs (2015) suggest that institutions who receive decreased funding from their state government, often change their recruitment behavior to enroll more out of state students to gain more net-tuition as revenue. As institutional behavior demonstrates institutional goals and preferences, this dissertation analyzes the distribution of student financial aid packages, socioeconomic data, and academic aptitude - with specific attention to institutional aid - to identify potential preferences of the institution and the goals it seeks.

State budgets, particularly in Appalachia, have been uncertain or depressed and policymakers have been faced with tough decisions on where to allocate even more limited resources to competing state interests. In the following subsection, I will describe how competing budgetary priorities operate in West Virginia and how the longitudinal disinvestment in higher education has occurred and which budgetary domains have concomitantly increased in their share of the state budget.

\section{State Budget Priorities}

According to the West Virginia Center on Budget and Policy, the West Virginia State Budget has six major domains: Health and Human Services, Public Education, Judicial, Legislative and Administration, Military Affairs and Public Safety, Higher Education, and Other. Health and Human services contains all appropriations to the Department of Health and Human services to provide various governmental programs from immunizations and nutrition assistance to cervical cancer screenings and child speech therapy. Education contains expenditures for the State Department of Education, school lunch programs, schools for the deaf and blind, vocational divisions, the state Future Farmers of America (FFA) and Future Homemakers of America (FHA), and others. The judicial, legislative, and administrative sector of the budget contains allocations for the operations of the West Virginia House and Senate as well as joint ventures 
between the chambers and includes member and staff salaries along with other administrative costs. Military Affairs and Public Safety includes appropriations for the secretary of Military Affairs, the Adjutant General for the State Militia and an Adjutant General Military Fund and Corrections. Higher education appropriations include all appropriations made to community colleges, public colleges, and public universities for both institutional and administrative costs. However, appropriations made to four-year colleges on the basis of institutional and administrative costs may be disaggregated from the higher education budget. The final category "Other", contains appropriations for state departments such as commerce, the environment, revenue, transportation, veterans, senior services, as well as a mix of miscellaneous boards and commissions to serve the common good.

In the aggregate, initial data from the center suggested that West Virginia State spending experienced modest growth from FY2005 to FY2016 of 1.8\%. However, when the same period is adjusted for inflation (Perrins and Nilsen, 2010) using the Consumer Price Index (CPI) the state's budgetary growth gains greater perspective. Transforming the data to adjust for inflation demonstrated that the West Virginia State budget has experienced an overall average growth of 0.0\% from FY2005 to FY2016. When adjusting for inflation, aggregate State spending on higher education has, on average, decreased by .6\% with high years of investment occurring FY2008 from FY2007 at 14.7\% and 12.2\% from FY2011 to FY2012. Years demonstrating the largest amounts of disinvestment was FY2010 at a 7.8\% overall reduction in spending to state higher education institutions from FY2011 and a 7.5\% decrease in spending to the same in FY2015 from FY2014. Furthermore, from FY2013 to FY2016, state disinvestment has averaged a 5.3\% reduction in higher education funding, as a percentage of total expenditures, each year. According to IPEDS data and adjusting for inflation, institutional appropriations from West 
Virginia have averaged $4.52 \%$ of total West Virginia state expenditures from 2005 to 2016. However, from FY2013 to FY2016, the overall share of the state's higher education budget has been on a downward trajectory averaging $4.16 \%$ of overall state expenditures further indicating its falling share as a state budgetary priority.

Using IPEDS data, I can drill down further to investigate annual state appropriations to the institution over time. After adjusting the state budget totals for each year to account for inflation I can calculate the share of the institutional appropriation relative to the state's total budget the institution receives over time. In FY 2005, the institution received approximately $4.7 \%$ of the state's total budget. In FY2016, the institution received approximately $4.0 \%$ of the state's total budget. As the overall inflation-adjusted budget has not grown or decreased, the overall share of higher education as a part of the state budget have declined. The highest shares the institution received were $4.8 \%$ in $2008,4.9 \%$ in 2009 , and $4.8 \%$ in 2010 . After the Great Recession began to fully affect state budgets, the clawback of state appropriations becomes observable as appropriations from FY2011 forward begin to wane, ending with an institutional share of $4.0 \%$ in 2016 and an institutional average of $4.3 \%$ overall. Overall, statewide drawbacks of higher education appropriations occurred from FY2005 to FY2016 as the inflation adjusted share of appropriations to non-community and technical colleges was $10.5 \%$ in FY2005 sliding to $7.51 \%$ in 2016 averaging an overall rate of disinvestment of $3.5 \%$.

In inflation adjusted dollars, the state has also greatly curtailed its administrative spending as well as judicial and legislative spending of an average of $8.2 \%$ from FY2005 to FY2016. General education expenditures have decreased, on average, by .02\% and the state is spending less on education in FY2016 then it did in FY2005 in 2016 dollars. The Health and Human Services spending for West Virginia has experienced the largest amount of relative 
growth as its expenditures have averaged 3.0\% growth from FY2005 to FY2016. High investment years in Health and Human services have included 11.9\% in FY2013, 5.1\% growth in FY2014, and 14.8\% in FY2015. Disinvestment years in Health and Human services occurred in FY2010 at $11.6 \%, 2.7 \%$ in FY2011, and 9.0\% in FY2016.

Military Affairs and Public Safety have experienced 1.4\% growth with high investment in FY2009 at 12.0\% and higher than average growth in FY2011 at 3.2\% and 3.1\% in FY2012. Within this budgetary domain, high growth is observable in correctional units. In FY2005, the adjusted share of the state budget for correctional units was 3.1\%. However, over the next 11 years, the Department of Corrections, specifically appropriations made for correctional units, increased by an average of 5\% from FY2005 to FY2016 and increased as a total share of the adjusted overall state budget each year - except for FY2011 and FY2011 where it stayed the same at $3.8 \%$ - ending in 2016 as $4.3 \%$ of the overall state budget. This represents a $28 \%$ overall increase in FY2016 spending on correctional units from FY2005.

\section{Problem and Purpose}

\section{Government Disinvestment}

Although the immediate effects of state budget cuts affect nearly every aspect of a state's economic and public-sector dependent upon state appropriations, cuts to higher education have wide-ranging effects. Institutions faced with government disinvestment present an intriguing puzzle to higher education finance. As governments have historically invested in higher education to support an educated citizenry and provide for equity in the opportunity for economic and social mobility, those higher order goals become threatened when states pull back their financial support because institutions tend to pass those cuts onto the student (Webber, 2017) which may also limit access to students on the fringes of higher education affordability. 
The Grapevine Survey of Illinois State University's Center for the Study of Education Policy and the State Higher Education Executive Officers Association provides yearly analysis of state funding for higher education. The Grapevine's editor and Professor of Higher Education at Illinois State University, James Palmer, suggests that higher education experienced "anemic growth" of only 1.6 percent from 2017 to 2018 in the national annual percent changes to state fiscal support for higher education; a sharp decline from the previous cycle of $4.2 \%$ (Seltzer 2018). According to Seltzer (2018), Palmer further suggests: "the fiscal capacity [of states] to

\section{Table 1.2:}

\begin{tabular}{|c|c|c|c|}
\hline \multicolumn{4}{|c|}{ Percent Change In state Appropriations by State } \\
\hline & Total & & \\
\hline State & $\begin{array}{c}\text { Support, } \\
2017-18 \\
\text { (dollars) }\end{array}$ & $\begin{array}{l}\text { 1-Year } \\
\text { Change }\end{array}$ & $\begin{array}{l}\text { 5-Year } \\
\text { Change }\end{array}$ \\
\hline Alabama & $1,618,261,945$ & $3.90 \%$ & $15.00 \%$ \\
\hline Georgia & $3,423,355,485$ & $6.60 \%$ & $30.40 \%$ \\
\hline Kentucky & $1,173,159,100$ & $0.20 \%$ & $-1.20 \%$ \\
\hline Maryland & $1,992,867,551$ & $0.60 \%$ & $23.20 \%$ \\
\hline Mississippi & $900,155,014$ & $-11.20 \%$ & $-2.70 \%$ \\
\hline North Carolina & $4,020,836,353$ & $1.20 \%$ & $7.20 \%$ \\
\hline Ohio & $2,300,904,761$ & $-0.10 \%$ & $12.20 \%$ \\
\hline Pennsylvania & $1,651,732,000$ & $-2.40 \%$ & $1.20 \%$ \\
\hline South Carolina & $1,097,979,545$ & $0.30 \%$ & $20.60 \%$ \\
\hline Tennessee & $1,844,857,699$ & $6.50 \%$ & $26.80 \%$ \\
\hline Virginia & $2,013,572,522$ & $-1.90 \%$ & $17.60 \%$ \\
\hline West Virginia & $470,910,031$ & $-2.70 \%$ & $-14.50 \%$ \\
\hline New York & $5,860,223,303$ & $1.90 \%$ & $14.60 \%$ \\
\hline
\end{tabular}

Source: Inside Higher Ed, Seltzer (2018)

increase funding for colleges and universities doesn't seem to be there" (Seltzer, 2018, 4).

According to the data provided by Grapevine and presented in Seltzer's article, if we disaggregate Appalachian states from the list (see Figure 1.2), the one-year increase shrinks to a meager .22\% signaling the Appalachian region is experiencing even slower funding increases 
relative to rest of the U.S. higher education system. However, government disinvestment is only part of the problem facing higher education financial stability.

\section{Changing Supply of Higher Education Students}

The Knocking report produced by the Western Interstate Commission for Higher Education (WICHE) projects modest growth of U.S. high school graduates with brief upticks in enrollments from 2024 to 2026. The trend of graduates declines, sharply, from 2027 onward to a new plateau not seen since 2007 indicating a coming dearth of high-school eligible students when compared to current enrollments. As the share of college-eligible students declines rapidly, it is likely that this shift will affect higher education demand - signaling revenue problems for higher education institutions. Further complicating higher education financial constraints is the systematic dialing back of state appropriations to higher education institutions. This presents a puzzle: If the flow of eligible college students lessens and there is continued and compounded government disinvestment, revenue for enrollment dependent institutions will likely continue to decrease. As some institutions are enrollment dependent, what are these universities to do in light of government disinvestment and a shrinking market for potential students if the cost of providing a higher education remains flat or increases?

As potential enrollments decline and the cost of providing a higher education remains flat or increases, it is likely that institutions will adopt strategies to offset the potential loss or prospects of losses to enrollment - particularly for those resource-dependent institutions that require net-tuition maximization strategies (McPherson and Schapiro, 1998) to stay in business and pursue their goals. Net-tuition maximization strategies may indicate that there is a preferred student constituency that meets a particular set of attributes the institution finds valuable and may include a mix of socioeconomic and academic aptitude measures. 
The continued trend of state disinvestment and system-wide disruptions to the flow of college-eligible high school graduates, presents several problems to both higher education institutions and potential students. First, students with lesser ability to pay may face greater financial obstacles to higher education even when controlling for academic quality through high school performance and standardized test scores. For example, even if lower-income students have the requisite academic profile to achieve success and are deemed desirable by the institution recruiting them, extant literature (Hoxby and Avery, 2013; Singell and Stone 2002; Heller and Laird 1999) suggests merit-based aid still favors students of higher socioeconomic status. Second, although the federal government is still the dominant player in the provisioning of financial aid, particularly need-based aid, higher education institutions have also become major players in the financial aid calculus through the provisioning of institutional aid (The College Board 2017). Institutions are now providing low to no-cost loans, grants, tuition discounts, and other monies to students using criteria developed internally and not always readily available to the public. As institutions dole out funds based upon criteria they deem appropriate, it suggests that financial aid or other cash awards for consideration are a variable that institutions find valuable or fruitful in carrying out their goals. For this dissertation, tuition discounting is the means through which institutional aid is distributed to students.

\section{Institutional Aid and Discount Rates in Higher Education}

Baum and Ma (2010) define the undergraduate tuition discount rate as: "the ratio of institutional grant aid to published tuition and fee charges" (p. 1). This "tuition discounting" process is also stratified by institution with tuition waivers averaging $10 \%$ less for public twoyear institutions, $20 \%$ less for public four-year institutions, and 33\% for private non-profit fouryear colleges and universities (Baum, Ma, and Lapovsky 2010). The authors also found that 
discounts provided to students who could afford higher education to be about $5 \%$ to $6 \%$ of gross tuition revenues. These findings cause the authors to call for a "public policy" discussion to address the allocation of financial aid to students who, according to their financial profile, can already afford college without aid.

The growth of institutional financial aid is substantial when compared to other popular grant programs. In fact, the total dollar amount of institutional aid amounts ( $\$ 37.9$ billion) is actually higher than the total of Pell grants ( $\$ 33.7$ billion) indicating its rising share in the overall makeup of student financial aid packages (Cheslock, Hughes, Frick Cardelle, and Heller 2018; Baum and Payea, 2014). However, scholarly discussion of institutional aid - in general - and in the context of resource dependency remains underdeveloped. Although the federal government has been the primary means through which students have afforded a higher education through student loans and grants, institutions have become active participants in the financing of college and changes to the system that mitigate demand will likely cause institutions to change their behavior.

\section{Resource Dependence and Institutional Aid - Challenges of Institutional Aid}

As I will discuss, institutions are constrained by their environment, their goals, and their need to accumulate resources external to the organization. In this specific case, we can think of students as resource providers through their tuition, academic aptitude, and the culture they can potentially generate for a university. Institutions have always competed for the best students and they will continue to compete for the best students. As institutions have become more reliant on external resources (e.g. net-tuition revenue from students) through competitive enrollment and decreasing state appropriations - a reality that will only be exacerbated through extensive decreases to the college-going population as indicated by the WICHE report - I argue that 
institutions will engage in "market or marketlike efforts to secure external moneys" (Slaughter and Leslie, 1997, p. 8) in what has commonly termed: academic capitalism. Although the full purview of academic capitalism is broad and contains the behavior of nearly all agents and fiefdoms of the institution, particularly faculty, my focus on academic capitalism is concerned with how institutions secure external resources, chiefly tuition, through the provisioning of financial aid - a key variable that nearly all students require to attend college.

Institutional ability to capitalize on external resources, or the recruiting of students, will be highly constrained if there are fundamental changes to the supply of the resource itself. For example, as the dearth of high school graduates limits the effectiveness of volume-enrollment strategies, it is likely that institutions will be forced to adjust their enrollment strategies to maximize net-tuition revenue per student. This reality is exacerbated by government disinvestment. Previous evidence suggests that many institutions tend to raise tuition when government disinvestment occurs (Jaquette and Curs 2015; Webber, 2017). Jaquette and Curs (2015) demonstrated how large research universities tend to increase their out-of-state enrollment to offset revenue losses from state disinvestment. Citing evidence from the National Postsecondary Student Aid Survey (NPSAS), they argue: "public universities derive more nettuition revenue from each nonresident freshman than each resident freshman" (p. 542). Consequently, the authors argue further that this behavior is consistent with academic capitalism because it is a direct attempt to "monetize students" (Jaquette and Curs, 2015, p. 558). I agree with their assertion and would add that this is an enrollment management decision to maximize revenues.

Their findings demonstrate the potential to investigate further institutional behaviors aimed at maximizing revenues. It may also be possible that institutions may recognize specific 
student constituencies as more financially tenable to the institution; much like what they suggest through increased out-of-state enrollment in light of state appropriations losses. To further the findings of Jaquette and Curs (2015), I would argue that institutional aid is a direct mechanism through which the institution can encourage a student to enroll - suggesting a potential link between out-of-state status and institutional aid offerings. Data gathered for this dissertation will allow for a systematic investigation of aid packages to control for student academic quality, student financial strength, and tuition revenue to tease out these potential relationships. Although this behavior is not necessarily problematic from an out-of-state access perspective, it can conflict with institutional mission to educate a local populace (i.e. the land-grant mission) if recruiting and institutional aid is prioritized to those students who pay a higher price.

On the one hand, the argument may be that in-state students have earned the privilege of paying in-state rates to attend their state's university - through state income taxes - whereas outof-state students pay the premium (i.e. increased tuition) to attend a state taxpayer-funded university and that institutional aid is the mechanism through which these universities defray the cost for desired students. On the other hand, as the institution is partially financed through state tax revenue and when institutional aid is produced to help offset the cost of out-of-state students to attend the state university, problems of agency and institutional mission are introduced especially when institutional aid is formulated through taxpayer revenues. Are state taxpayers served by subsidizing students from other states? This is not to say that the institution is not delivering on their mission to educate a citizenry, only that state residents may be subsidizing out-of-state residents. From a return on investment standpoint, however, the institutional aid dollars offered to entice out-of-state students are returned to the institution - through increased net-tuition per out-of-state students - at higher rates for out-of-state students than for in-state 
students. Out-of-state students may also possess valuable inputs (racial and ethnic diversity, high academic aptitude, etc.). As a result, it is potentially rational to pursue nonresidents for purposes of increasing net-tuition per student as well as to recruit desirable student constituencies that go beyond issues of access. Also, as institutions attempt to put together the best class possible that mixes issues of access and merit, out-of-state students may, inherently, a necessary constituency to achieve those goals regardless.

\section{Conceptual Challenges to the Supply of Higher Education Students}

Although state disinvestment is a serious challenge to higher education fiscal planning, its ripple effects go beyond institutional sticker price and these cuts threaten higher education access to future generations of students - especially to those where higher education affordability is already a concern. As massification of the higher education system ramped up after World War II (Geiger 2014), the assumption has been that an ample supply of college graduates is waiting in the wings from year to year where demand has remained, relatively, the same or increased. Previous research conducted by Geiger (2004) also asserts that while the market for full-time freshmen has been "remarkably stable" since the 1970s, the population of eligible highschool students has not been concomitantly stable as high school graduates have fluctuated from 3.2 million to 2.3 million while rebounding back to 2.8 million in 1998 - suggesting that enrollments are not related to the pool of eligible high school students. At first glance, Geiger's (2004) findings would suggest that higher education demand is not entirely explained by the

eligible pool of high school graduates. Instead, the author suggests that the "supply of places" (or seats) greatly explain higher education demand.

However, Geiger (2004) suggests that while "[t]he supply of four-year colleges is not limited to high school graduates", evidence from the stability of enrollments suggests that 
freshmen enrollments "are in the aggregate largely determined by the supply of places" (Geiger, 2004, p. 20). Geiger (2004) also suggests "the supply of students for four-year colleges is not limited to recent high school graduates" because an "immense pool of students, nearly 4 million in 1997, attends degree programs at two-year colleges either full- or part-time.” (p. 20). However, he adds the following caveat: "Only a small portion of these students makes the transition to baccalaureate-granting institutions, but they more than compensate for attrition among freshman at those colleges" (p. 20). Missing from the discussion of supply of places, however, are institutional behaviors. Institutional behavior, strategy, and goal orientation are also important to consider as these institutions must secure external resources to hedge against government revenue losses to which Geiger (2004) describes - along with endowment revenue as fundamental to higher education's ability to operate in a mixed, not market, economy where they are somewhat independent from traditional market pressures. Therefore, higher education demand is a function of both the supply of places and institutional behaviors. As will be discussed in the framework for this dissertation, the very notion that traditional market pressures do not operate on the institution is fundamentally linked to the assumption that there is a institutional government revenue stream. As the link between the institution and the government is weakened through continued divestment of public tax dollars, the privatization of the institution increases, resulting in changes to institutional behavior that may influence enrollment management decisions previously linked to the supply of places.

Geiger (2004) also suggests that institutions will raise tuition in response to government disinvestment in order to gain greater independence from the government as a resource-provider. Consequently, goal orientation of the institution will then inform the relationship between the institution and its new resource providers if government disinvests. As the government disinvests 
and the institution becomes more dependent upon external funds, such as net-tuition, the institution will seek to align itself with the wants and needs of its new primary resource-provider: the student as consumer.

As a consequence, resource dependence theory informs the resource relationship between higher education institutions and their host governments. Resource dependence theory suggests that institutions will respond to those organizations that provide it with resources (Jaquette and Curs 2015; Pfeffer and Salancik 1978). There are many conventional avenues through which institutions attempt to increase their potential revenue streams which include, but are not limited to, increasing tuition and fees, fundraising, overheard from contracts and grants, patenting, copyrighting, international student enrollment, corporate partnerships, enrollment strategies to maximize net-tuition, and institutional advancement offices. This dissertation will attempt to highlight how preferred enrollment constituencies - gleaned through an empirical examination of regression coefficients of longitudinal institutional aid recipients - inform institutional behavior. For example, as the states disinvest from their higher education institutions, resource dependence theory suggests that the institution will course-correct and realign itself with the interests of the new providers (Jaquette and Curs 2015; Pfeffer and Salancik 1978).

According to Jaquette and Curs (2015), the out-of-state student constituency, became the preferred constituency that institutions would tap to counter state disinvestment. The out-of-state resource-stream would act as a buffer against state disinvestment while also forging relationships with the constituency to limit its uncertainty and gain predictability (Parsons 1956). Geiger (2004) might also suggest this behavior is an attempt by the institution to gain independence from its resource providers. If predictability is a primary concern, this behavior will also be consistent, or increase, over time. I endeavor to take on Jaquette and Curs' (2015) call for future 
research to: "examine the effect of state appropriations on nonresident tuition price and the amount of institutional aid awarded to resident versus nonresident students (p. 558).

Institutional goals are likely to include other goals beyond net-tuition maximization. Goals also include population education and the provisioning of equity in the pursuit of opportunity for social and economic mobility - goals that are threatened by tuition maximization strategies as wealth is not distributed equally. For example, the preference of recruiting out-ofstate students at a state supported, public, research university introduces potential problems of social and class isolation for underrepresented minority students thus threatening lessening social and economic mobility for those individuals. Research by Jaquette, Curs, and Posselt (2016) demonstrated that the growth in the proportion of nonresident students resulted in the decline in the proportion of low-income students as well as the proportion of underrepresented minorities. As the proportion of low-income and underrepresented minorities shrinks, the ability for these constituencies to access social and economic mobility is also lessened, especially at more prestigious universities (Jaquette, Curs, and Posselt 2016), leading to a continued stratification of access to social and class mobility - a result that higher education is supposed to mitigate at a foundational level. As institutions reach for out-of-state tuition as the preferred method to replace funds lost through state disinvestment and as costs continue to rise with institutions passing those costs onto the consumer (Webber 2017), other exogenous pressures may imperil the already problematic access for certain higher education constituencies such as those in socioeconomic need or underrepresented minorities.

Considering the student as consumer model where net-tuition revenue and student preferences are primary concerns, system-wide decreases to demand have not been fully exerted on the modern system of U.S. higher education. In the coming decade, systemic changes to the 
demand of higher education will likely affect all institutions dependent upon a reliable stream of eligible high school graduates, a resource required by nearly all institutions. First, as state governments disinvest in higher education through curtailed appropriations and, second, as institutions participate in a greater share of the financial aid landscape (The College Board, 2017), students will become more reliant upon institutions to mitigate cost as a barrier to higher education. Third, the Knocking report indicates a potential enrollment crisis for future higher education freshmen classes as the overall volume of high school graduates decreases rapidly over the next decade. Therefore, institutions with excess supply will have a hard time exercising ability to increase revenue streams without a student component.

\section{Challenges to the Future of Higher Education Funding}

This confluence of issues creates a variety of problems, but it also creates opportunities for institutions to strategize, adapt, and respond to their environmental context. The Knocking report indicates a coming dearth of high-school graduates ready to enter higher education. This rapid decline of potential higher education consumers will force institutions to further adjust their resource mix to account for the inevitable revenue decreases associated with a smaller college-ready population. It will also highly influence institutional behavior in the awarding of their own financial resources to students to entice enrollment. Projected enrollment trends from the Knocking report suggested several possibilities. First, as students cannot afford the new price increases necessary to offset both the decrease in demand and continued government disinvestment, institutions will be forced to scale back their operations for fear of pricing themselves out of the market. Second, institutions at a competitive disadvantage will be forced to exit the market. Third, institutions will engage in activities to participate in the capitalist market to secure external funds (Slaughter and Leslie 1997; Slaughter and Rhoades 2004).I 


\section{Potential Institutional Responses to Systemic Higher Education Change}

As institutions continue to engage in a greater share of the financial aid calculus (The College Board, 2017), their share in the influence of student equity of access to earn a higher education also increases. But this reality comes with responsibility. As public institutions continue to privatize their behavior due to government disinvestment, component parts that have been wildly successful and integral to the success of American higher education hegemony, such as academic freedom, shared governance, and government support may be sacrificed in favor of market-driven forces that have historically been buffered by government investment. Second, faculty will become less integral to university administration as content expertise and knowledge become supplanted by market forces or at the very least influenced by their ability to link-up with capitalism. Third, the relationship between attending college and earning a degree may be more similar to a receipt for payment where payment, instead of a measurable demonstration of competency and mastery of a specific discipline or profession earned over time, is the primary means through which higher education is achieved. When educational credentials become purely transactional, the degree holder then suggests economic stature as opposed to competency.

As public institutions continue to confront problematic government disinvestment and downward trends of historically significant student resources, such as projected high school graduates, they will be forced to engage in various forms of academic capitalism to promote growth and solvency. In accordance with the research presented by Jaquette and Curs (2015), it is reasonable to suspect that enrollment dependent institutions that have experienced continued government disinvestment and are fraught with a local economy of stagnation and industrial paradigm shift, will diversify and engage in marketlike activities to produce new revenue streams. Since students present one of the largest and consistent streams of revenue for higher 
education institutions and since students also offer the academic raw materials necessary for the institution to pursue its intellectual goals along with its talented faculty, it is likely that there is a mixture of strategies that volley back and forth between tuition discounting for the best academic talent and enrollment strategies that promote equity of access to higher education that all balances against the financial stability and security of the institution. As institutional aid is a growing form of influence in the financial aid calculus, this dissertation investigates how institutional aid award behavior may change in a resource-dependent higher education institution in to accommodate changes in institutional resource providers.

\section{Research Questions}

Given the conditional assessment of the Appalachian economy, stagnant growth of college enrollments relative to places, and our need for greater understanding of how institutional aid informs organizational decision-making in higher education institutions, this dissertation is guided by the following research questions:

1. In a resource dependent institution, does the institution appear to grant differing institutional aid awards to students based on their residency?

2. In a resource dependent institution, does the institution appear to grant differing institutional aid awards to students with and without demonstrated need?

3. In a resource dependent institution, do institutional aid awards change over time during periods of constrained resources?

In Chapter 2, I present a review of extant financial aid, institutional aid, and resource dependence literature to develop my theoretical framework. In Chapter 3, I propose my methodological strategy and describe my research data. Chapter 4 executes that strategy with a robust display of results and analysis. The dissertation culminates with Chapter 5 where I discuss the results, reflect on my research questions, and provide evidence-based recommendations for higher education administrators, financial aid professionals, and potential avenues for future research. 


\section{Chapter 2: Literature Review}

\section{Overview}

In this section, I explore extant financial aid literature that examines financial and institutional aid within the context of need and non-need-based awards. I begin with a discussion of McPherson and Schapiro's (1998) contribution that examines systemic change to the financial aid system, the genesis of an organized method to calculate student financial aid, and modern methodological approaches used by financial aid administrators to promulgate student financial aid packages. I then move to a discussion of Pfeffer and Salancik's (1978) depiction of resource dependence theory and how it informs an organization's behavior in the endless quest for necessary resources. Through the resource-dependent context, I explore concepts of organizational effectiveness, organizational environment, and organizational constraints to provide for a theoretical background that situates institutional aid as a behavioral mechanism institutions leverage as a means to achieve their goals.

The discussion then moves to the concept and theory of academic capitalism. As public institutions of higher education are dependent upon government resources and since government investment has been on the decline, academic capitalism provides a theoretical backdrop to investigate how higher education institutions attempt to replace lost revenues. Institutions will mobilize their resources and their behaviors to acquire new relationships and links with their environment in an attempt to secure the resources they need. Extant literature suggests that the growing prominence of institutional aid provides evidence for its growing importance in the financial aid mix for a vast array of potential students. As a result, gaps in the scholarly knowledge for how institutional aid is leveraged and dispersed for recent cohorts of students remain an understudied segment of the financial aid literature. 
As financial aid is an important element to a vast array of issues, I then move to a discussion of how financial aid informs student outcomes and how state investment has a direct effect on student ability to afford a higher education as government investment directly affects tuition costs. I conclude the literature review with an in-depth discussion of institutional aid, trends in institutional aid, institutional aid typologies, and the historical attributes of institutional aid recipients. To examine the potential effects of institutional aid and how it may inform institutional behavior, I discuss how student peer groups inform institutional culture and contribute to student success and outcomes. I conclude the final section with a discussion of how latent institutional demands for student constituencies inform the distribution of institutional aid and how changes to the perception of institutional aid and its responses to student attributes may inform the future of institutional aid as a mechanism to concepts of student access. Finally, I provide evidence-based suggestions for the future of higher education strategic planning, financial aid and enrollment management professionals, and possible avenues for future research. Financial Aid - A Brief Overview of Financial Aid History

In the Student Aid Game, McPherson and Schapiro (1998) argue that there has been a persistent and growing gap between the level of services Americans want and their willingness to pay the taxes necessary to support them. As states face mounting pressures from economic challenges and competing budgetary priorities such as healthcare and prisons, state investment in higher education wanes. Furthermore, as institutions compete for fee-paying students, and as parents and families continue to scrutinize higher education costs and its promise of a secure economic future, McPherson and Schapiro (1998) argue that institutional conceptions of financial aid as a "noble charitable opportunity" will continue to evolve (p. 1). 
As a means to enable students to earn a higher education and serve the public good, financial aid has historically attempted to achieve two broad goals: provide equity in individual opportunity to pursue a higher education - also known as access - and to provision students with an array of quality institutions that meets individual talents and needs - also known as choice (McPherson and Schapiro, 1998). However, the authors argue that the shaping of the financial aid system has also come from two vacillating financial aid concepts that do not always serve those broad goals by providing financial aid to the "needy and deserving" (p. 5). As a result, historical allocations of financial aid have fallen within the realm of providing aid to students on the basis of need and/or on the basis of merit.

Although institutions have historically had a stake in providing access on an individual basis, systemic access to higher education was not systematically discussed until the 1950s. McPherson and Schapiro (1998) declare that the post-World War II GI bill and the Korean GI Bill in the mid-1950's served as the impetus for broad realizations that higher education was within reach of many Americans who historically thought it was economically out of reach. The authors further suggested that these two government policies coupled with positive public reaction to them, served as the impetus for the creation of the College Scholarship Service (CSS), an agency of the College Entrance Board - a "long-standing cooperative effort of colleges and high schools to manage admissions policies" (McPherson and Schapiro, 1998, p. 6). The goal of the agency was to work with higher education institutions and families to develop aid packages: "The basic idea was that after being asked to shoulder a reasonable college workload and a tolerable burden of educational debt, the student's remaining need should be financed through grants" (McPherson and Schapiro, 1998, p. 7). As a result, the framework established by the CSS would go on to systematically establish what families could financially 
tolerate and provided a further framework for federal, state, and local governments to establish metrics for their own aid programs.

According to McPherson and Shaprio (1998) founding principles of the CSS dictated that colleges and universities should "award aid only to students with demonstrated need and to the extent of that need" and that packaging be "consistent and equitable" across institutions (p. 7.) The authors argued that this approach to higher education finance encouraged "cooperation among higher education institutions in the determination of financial aid awards" (p. 7). The overarching theme of this practice was twofold. First, it standardized the methodology in which colleges calculated the available resources a student's family could muster to pay for higher education. Second, it laid the foundation for eliminating price differences and cost as a factor in college access and choice for students (McPherson and Schapiro, 1998).

States would soon follow with similar programs. The authors cite the California Master Plan (1960) as an example of state policy leadership to provide higher education that was within financial reach for any student interested in pursuing one. In a means to conquer both issues of access and choice, the California Master Plan devised three tiers of the state higher education system where students with the greatest academic aptitude would be admitted into the prestigious University of California System, those of middle aptitude would be accepted into the State College system, and those in the final category would be given vocational and other educational opportunities that could allow for career training or transfers to other two systems at a later date (McPherson and Schapiro, 1998). Cost as a barrier was controlled through price controls and merit was addressed through the allocation of students to varying degrees of institutional prestige in the three-tiered system (McPherson and Schapiro, 1998). 
Also, out of the CSS and the standardization of calculating family resources came the concept of unmet need. Unmet need is, essentially, the gap between the sum of expected family resources, the financial aid package offered by the institution, and the cost of attendance. The authors argued that as the CSS grew more organized, and as the needs analysis framework grew in prominence, it "proved to be a very powerful instrument in building the case for public support of student aid" (McPherson and Schapiro, 1998, p. 9). State governments began creating their own grant programs that were tied closely to student need. The federal government continued expanded access for need-based grants in 1972 that introduced the Pell grant system as "Basic Educational Opportunity Grants." These grants created a federal methodology for establishing student need and laid the groundwork to establish other need-based programs and, as a consequence, inserted the federal government into the student aid landscape as a major stakeholder and regulator of student aid practices in the United States (McPherson and Schapiro, 1998).

\section{Changes to Financial Aid Perspectives}

Starting in the 1980s, however, the tone of the student aid calculus began to change from an institutional perspective:

Rather than viewing student aid as a kind of charitable operation the college runs on the side, most private colleges and universities - and increasing numbers of public institutions - now regard student as a vital revenue management and enrollment management tool. (McPherson and Schapiro, 1998, p. 16).

Comparing the business model of higher education to the airline industry, the authors claim that the ability of the university to fill its excess capacity with students enhances its ability to generate revenue because an empty airline seat generates no revenue, whereas a deeply 
discounted airline seat, generates at least some revenue. The same is true for seats in higher education. This realization has ushered in three perspectives in financial aid. First, a "need-blind, full-need" approach is best described through institutions with an excess demand of students both willing and capable to pay full-tuition. In other words, these institutions do not need to use student aid as a mechanism to mitigate cost as a barrier and as such, student aid represents a true cost the institution must bear if it chooses to enroll a desired mix of student constituencies and the constituencies it desires requires institutional aid to attend (McPherson and Schapiro, 1998).

The second approach, the "budget stretch" approach, is similar to the "need-blind, fullneed" approach, but differs in that the institution does not have the financial resources necessary to meet the full need of all of its desired applicants. Instead, the institution will allocate the student aid budget that maximizes the probability of achieving student constituencies the institution finds desirable. A third approach, "strategic maximization," occurs in schools that lack the prestige and financial sources of the most selective and wealthy institutions, to deliver an enrollment constituency that maximizes both the goals of selecting the best students possible while maximizing the net-tuition gains possible (McPherson and Schapiro, 1998).

A critical closing point made by the authors is that the trajectory of the financial aid landscape in the U.S. and the manner in which higher education institutions have competed in the last decade. They argue that this shift in financial aid thinking highly informs the change in institutional behavior toward net-revenue generations and the strategic institutional deployment of financial aid resources:

It is important to point out that this growing strategic emphasis did not come about because colleges have lost their moral compass or because college presidents have lost confidence in the professionals of their financial aid offices. Rather, it is the environment 
of college and universities that has changed. Intense competition among colleges and universities for dollars and students has inevitably made student aid a strategic variable in maintaining institutional financial health. (McPherson and Schapiro, 1998, p. 17)

Exploring a theoretical framework that allows us to operationalize institutional behavior that promotes institutional financial health that also controls for institutional priorities and goals, is a key step to building a model that explains institutional behavior and goals constrained by resource dependence. To accomplish this task, I now move to a discussion of how resource dependence tends to inform, if not control, the organizations dependent upon those resources.

\section{Resource Dependence}

Common to all organizations is a persistent and perpetual need for resources. Higher education resources span a variety of elements from the material to philosophical and the political to the financial and often contain a few from all. However, for the purposes of this dissertation, we can think of resources as the tuition, aptitude, and culture generated by students as well as state government appropriations that come to confluence in supporting higher education institutions.

Organizations require resources to survive "[b]ecause organizations are not selfcontained or self-sufficient, the environment must be relied upon to provide support" (Pfeffer and Salancik, 1978, p. 43). Therefore, the ability of the organization to survive is tethered to its ability to respond to the demands of its environment. However, the relationship between the environment and the organization is said to be loosely coupled. According to Pfeffer and Salancik (1978) loose coupling "denote[s] the relationship between elements in a social system, such as those between organizations" (p. 13). Loose coupling exists for two major reasons. First, the institution may be "isolated or buffered" (p. 12) from the event - suggesting that events that 
might otherwise affect the institution do not because of some element that protects the institution or shields it from the effect. Second, the institution simply may not notice the event or the event is minor enough to permit no response by the organization (Pfeffer and Salancik, 1978).

Here, the concept of "loose coupling" is introduced as a "safety feature" between organizations and their constituent parts because "[e]very event confronting an organization does not necessarily affect it” (p. 12-13). Instead, organizations are loosely coupled to their environment. This allows the institution to be somewhat selective in what it will respond to and further allows the organization to prioritize those events and stimuli it thinks are the most important. As a result, the influence of critical resource providers (e.g. state government, students, parents, etc.) are highly informative to institutional behavior: "We would concur that, in general, organizations will tend to be influenced by those who control the resources they require... Uncertainty or instability with respect to an important resource threatens the continued existence of the organization" (Pfeffer and Salancik, 1978, p. 44-47).

To secure resources, organizations engage in specific behavior. Pfeffer and Salancik (1978) suggest that the organizational environment or "ecology" highly informs that behavior. Furthermore, open systems theory (Katz and Kahn 1966) embraces the parsimonious theory that organizations are influenced by the environment in which they operate. The contextual environments can be both internal and external to the organization. Internal forces might include institutional mission and financial strength, expertise and norms, goals, and the balance of power between faculty and administrators within the shared governance structure. External aspects might include economics, politics, and the organization's natural habitat or environment. 


\section{Resource Dependence: The Contextual Perspective}

Pfeffer and Salancik (1978), argued that to truly "understand the behavior of an organization you must understand the context of that behavior" (p. 1). To examine institutional behavior through what Pfeffer and Salancik (1978) term the "contextual perspective" (p. 11) I must cover three concepts. First, organizational effectiveness or "the ability to create acceptable outcomes and actions" (p. 11) is an external measure of the institution's perceived value to its critical constituencies. The authors admit that the ability of the organization to be effective may a sociopolitical one, however, it may be simply stated as the organization's ability to provide something that its customers want or something that makes them relevant or necessary. The authors separate effectiveness from efficiency in that effectiveness is more of an outward measure of how well the organization meets the needs of its stakeholders and efficiency is an internal standard that measures performance. Performance metrics within the organization may or may not be congruent with external assessments and resource-dependence theory might suggest that these incongruencies may lead to unhappy stakeholders (i.e. students) leading to a stressed relationship.

Second, the organizational environment is the broadest collection of events in the world that have any effect on the activities or outcomes of the organization (Pfeffer and Salancik, 1978). But, as we discussed, loose coupling allows organizations to select the stimuli that will receive their attention allowing us to glean insights into organizational priorities. Organizations, in this context, are the totality of the people, norms, culture, rules, and bureaucratic structures that work together to achieve a goal. The authors contend that organizational information is highly suggestive of what the organization finds important because information that is not important is not collected or stored: 
Organizational information systems offer insight to those seeking to analyze and diagnose organizations. Information which is not collected or available is not likely to be used in decision making, and information which is heavily represented in the organization's record keeping is likely to emphatically shape decisions. (Pfeffer and Salancik, 1978, p. 13).

For this reason, institutional data of student-level observations that pertain to student financial aid packages and institutional aid awards will be highly informative as to what the organization feels is important in providing those awards. It may also be an attempt by the organization to learn about the needs of its stakeholders:

How an organization learns about its environment, how it attends to the environment, and how it selects and processes information to give meaning to its environment are all important aspects of how the context of an organization affects its actions, (p. 14) The data will provide insights as to who gets what financial aid awards and will provide a context for understanding the constituencies the organization feels are important for it to accomplish its goals.

Constraints are the third and final concept. Constrained actions are those behaviors "whenever one response to a given situation is more probable than any other response to the situation, regardless of the actor responding" (p. 14). Since people operate within the organizational structure, rules, and norms of the organization, their behavior becomes predictable. Since an organization is highly structured with predictable modes of behavior leaders within the organization will attempt to change their environment:

The social context of an organization is, itself, the outcome of actions of social actors. Since many constraints derive from the actions of others, one important function of 
management is influencing these others as a means of determining one's own

environment. (Pfeffer and Salancik, 1978, p. 18)

Although constraints highly inform behavior, institutional leadership has options. By operating on their environments, leadership has an opportunity to influence the stability and generosity of their environment. This could allow for more abundant resources, greater efficiency in their allocation, and a competitive advantage to use against competing organizations. In operating on the environment, leaders are making assessments of their environmental context and making constrained decisions on how to respond. The constraints also suggest that institutional aid behavior in a resource dependent organization will attempt to achieve a specific goal because the outlays of resources to gain resources demands a rate of return that secures either more resources or specific resources the institution otherwise needs. Constrained resources also indicate that institutions cannot continuously award aid without a return on investment. In other words, institutional aid awards must have payoffs for the institution that coincide with institutional goals.

As a corollary to constraints, it is important to recognize that institutions will adapt to changes in their environment when primary resource providers change (Pfeffer and Salancik, 1978). Resources in the context of a higher education could include student tuition and academic ability, philosophies and ideas such as increased equity of access for underrepresented and lowincome minorities, or government investment and policy support. In the competitive landscape of higher education, institutions compete for these resources by recruiting the best (or most) students and faculty to achieve their goals. 


\section{Academic Capitalism}

In an effort to bring together disparate definitions and connotations with regards to capitalism and its influence on higher education, Slaughter and Leslie (1997) described academic capitalism as: "professorial market or marketlike efforts to secure external moneys" (p. 8). As a conceptualization, the authors advance the notion of academic capitalism as an impetus for organizational changes in behavior stemming from structural and organizational change in the global economy - the organizational global environment. The authors argue that global and structural market changes stemming from the 1970s and 80s, where industrialized countries like the US and the UK lost global market shares to countries in the Pacific rim, encouraged multinational corporations to turn to research universities to gain technological advantages and regain the prospect of future economic dominance (Slaughter and Leslie, 1997). To that end, business and corporate sectors put pressure on states to invest and sponsor research at universities leading to cooperation between federal agencies that fund research (e.g. The National Science Foundation) and universities (Slaughter and Leslie, 1997). This partnership changed the way research in higher education was funded and consequently changed the research funding incentives to center on links to industry as opposed to academic freedom (Slaughter and Leslie, 1997).

\section{Winds of Change - Faculty Work and The Funding of Research:}

In their evaluation of federal policy in Australia, the authors found changes to institutional behavior resulted when the federal government awarded research dollars based upon accountability criteria that aligned with national priorities as opposed to the whims of research proffered by academic freedom. To counter-act the emerging prominence of cheap Asian labor as a competitor to more expensive Australian labor, the Australian government reorganized its 
funding and oversight of Australian higher education to award funds that aligned with national priorities (Slaughter and Leslie, 1997). To achieve this realignment, the Australian federal government replaced the Commonwealth Tertiary Education Commission (CTEC) with the National Board of Employment, Education, and Training and installed a new director, John Dawkins, who fundamentally realigned the way higher education would be funded.

Part of the new Australian system was the consolidation of the bifurcated system of universities geared toward teaching and research and the Colleges of Advanced Education (CAEs) designed to provide teaching for entry level jobs in applied fields (Slaughter and Leslie, 1997). Under the new system, the two institutional types were united into a singular institutional approach. In the process of combining the systems, Dawkins could also greatly influence research priorities by setting the eligibility criteria to receive funding (Slaughter and Leslie, 1997). In an effort to ensure national priorities took precedence in research, future research dollars would be awarded if demonstrable progress or applicable technologies could be created that served the national interests such as job growth, environmental protection, and energy selfsufficiency - goals that the authors suggested spurred the professoriate to develop new ways to fund their research (Slaughter and Leslie, 1997). As a result, disparities in federal funding levels occurred between participating institutions capable of delivering upon the demands of both results and accountability. The gaps in funding levels that occurred between institutions who were capable of successful participation in the new research paradigm and those were not emerged. As a further result, the funding realignment provided incentives for the institutions to engage in greater levels of academic capitalism:

Faculty and institutions began to recruit full-fee-paying overseas students, develop partnerships with industry for research and training, and create products and processes 
suitable for the market. In other words, universities and faculty had to compete - engage in market and marketlike behavior, for critical resources. (Slaughter and Leslie, 1997, p.

The authors described higher education professionals and faculty as "employed simultaneously by the public sector but became increasingly isolated from it. They are academics who act as capitalists from within the public sector; they are state-subsidized entrepreneurs" (Slaughter and Leslie, 1997). As their definition suggests, academic capitalism typically refers to the actions of faculty and how they attempt to link up or engage in behavior and relationships that secures external money. However, the definition also includes "marketlike behaviors" and these refer to "institutional and faculty competition for moneys" (p. 9, my emphasis added) thus indicating the ability of institutions to engage in behavior distinctly different from individual faculty behavior.

The Increasingly Managed Faculty, Tuition Increases, and Government Disinvestment

Building upon the previous language and work by Slaughter and Leslie (1997), Slaughter and Rhoades (2004) assert that the thesis established by Slaughter and Leslie (1997) demonstrated the realignment of funding faculty research and its connectivity to the capitalist market - without a focus on students and the monetization of students directly:

Academic capitalism involved turning away from students, ignoring them despite their tuition monies, which are undesignated and can be shifted for use in noninstructional areas, and turning toward entrepreneurial science, as evidenced by the increased institutional expenditures for research in the 1970s and 1980s. (p. 279)

In the new knowledge economy, "knowledge is a critical raw material to be mined and extracted from any unprotected site, patented, copyrighted, trademarked, or held as a trade secret; then sold 
in the marketplace for profit" (Slaughter and Rhoades, 2004, p. 1). As a result, Slaughter and Rhoades (2004) argue that as faculty become "increasingly managed professionals" we need to "rethink the centrality and dominance of the academic profession" (p. 1).

Slaughter and Rhoades (2004) demonstrate that various aspects of the academy are aligning their approaches and practices to comport with academic capitalism through the creation of internal bureaucracies and capabilities to generate an:

“internal embeddedness of profit-oriented activities as a point of reorganization (and new investment) by higher education institutions to develop their own capacity (and to hire new types of professionals) to market products created by faculty and develop commercializable products outside of (though connected to) conventional academic structures and individual faculty members. (p. 11).

Slaughter and Rhoades (2004) concede that much attention has been focused on the funding paradigm of faculty securing grants, generating patents, and participating with government and industry to secure external monies - the previous notion of academic capitalism as a funding realignment that created a partnership between faculty research and constituencies beyond academia for external monies. However, this method of revenue has also been supplemented and even supplanted by other sources, such as tuition revenue, to which Slaughter and Rhoades (2004) assert:

"The greatest increase in shares of institutional funds has come through raising tuition, which has heightened students' and parents' consumer consciousness about what they expect in terms of their educational experience and in terms of returns on investment in their human capital. These changed expectations reshape student identity from that of learner to that of consumer." (Slaughter and Rhoades, 2004, p. 12) 
Therefore, as academic capitalism operates within universities creating new incentives for capitalist participation, higher education institutions and the new economy forge a new relationship and a demarcation between the public good model of higher education and the new, academic capitalism model of education. Slaughter and Rhoades (2004) define the public good model as one where scientific curiosity and research leads to new knowledge and that this knowledge leads to tangible benefits for society. For the academic capitalism model, the authors suggested that science "is embedded in commercial possibility... These models see little separation between science and commercial activity. Discovery is valued because it leads to high-technology products for a knowledge economy” (Slaughter and Rhoads, 2004, p. 29). The authors do proclaim that the academic capitalism model does not supplant or replace the public good model, but the models do "coexist, intersect, and overlap" (Slaughter and Rhoades, 2004, p. 29).

A common point of intersection at public universities is external funding stemming from government investment. As public universities receive substantial public support, changes to external revenues from government investment or disinvestment creates opportunities for academic capitalism in the new economy to inform institutional decision-making. For example:

Fiscal crises combined with rising tuition have created a climate that emphasizes the importance of new sources of external revenues. Periodic state fiscal crises, marked by budget shortfalls and clawbacks from the higher education sector, give legitimacy to notions of resource shortages. Even though such shortages do not occur regularly or predictably and seldom affect all institutions, they nonetheless reinforce faculty and administrators' beliefs that increases in external resource flows are necessary to sustain the academic enterprise. (Slaughter and Rhoades, 2004, p. 12) 
However, the authors concur with previous research conducted by Slaughter and Leslie (1997) in that state disinvestment was a "gradual, incremental trend...that at the level of colleges and university, shifting resource dependences are more often experienced as periodic episodes of crisis during which institutions go through restructuring processes" (Slaughter and Rhoades, 2004, p. 13). But, Slaughter and Rhoades (2004) go on to declare: [b]ecause universities are seen as a major source of alienable knowledge, they are in the process of establishing new relations with the global economy" (p. 15). As a further result, academic capitalism would suggest that the institution will engage in "[n]ew investment, marketing and consumption behaviors on the part of members of the university community [to] also link them to the new economy. Together these mechanisms and behaviors constitute an academic capitalist knowledge/learning regime (p. 15). Shift to Students as a Source of Revenue - Three Major Themes

As the authors indicated, previous notions of academic capitalism did not focus intently on students as sources of revenue. However, academic capitalism in the new economy "involves institutions turning toward students as targets for the extraction of revenue, including but extending beyond tuition" (Slaughter and Rhoades, 2004, p. 279). The authors point out:

"The increased significance of revenue considerations that comes with academic capitalism leads to a greater concentration of institutional energies and monies on students already privileged and served by higher education, with a lesser focus on those student populations that historically have been underserved. (Slaughter and Rhoades, 2004, p. 284).

Therefore, institutional approaches operating in the new economy where student revenue is critical to institutional survival are likely to share common themes in its quest for students. The authors suggest three major themes. First, institutions engage in marketing to students "in ways 
that serve colleges and universities' economic interests" (p. 279) where "the needs and interests of the enterprise take precedence over the needs of the customer" (p. 286). Examples of this type of behavior include: attracting more students who can afford to pay more, admissions offices pivoting from selection of students to marketing of students, enrolling more international students, manipulating institutional metrics of selectivity to modify their perceived level of prestige, early admissions practices, and on-site admissions. These practices are designed specifically to enhance institutional probability of gaining its desired students: "Colleges and universities are not simply subject to the power of consumer choice; they engage in aggressive marketing to strategically shape those consumer choices" (Slaughter and Rhoades, 2004, p. 292). Institutions are not passive participants in academic capitalism. They are active participants. The second theme is institutions attempting to court a greater share of the wealthy student market. Although academically high achieving students are desirable to most institutions, students of high financial stature are also desirable, especially in light of the new economy:

"However, a market orientation is increasingly entering the equation. In the context of an emphasis on revenue generation, it is not just highly able students that colleges and universities are targeting, it is also moneyed students who can afford to pay full tuition with no financial aid" (Slaughter and Rhoades, 2004, p. 293).

The authors declare that this type of behavior may be exacerbated by government disinvestment and can shape the financial aid apparatus of the institution and the policies it uses to craft its classes. As the managerial capacity of the institution increases, particularly in those areas where financial aid policies are crafted and implemented, long-standing norms of financial aid as a charitable endeavor have been somewhat replaced by bureaucratic machinery that is tethered to upper-level management (Slaughter and Rhoades, 2004; McPherson and Schapiro, 1998). 
The third and final theme is the marketing of consumer capitalism to captive student markets where institutions appeal to consumer needs separate from educational needs (Slaughter and Rhoades, 2004). A symptom of this involves "higher education institutions [featuring] and increasingly [investing] in, services and facilities that are aimed as much or more at attracting applicants than educating them" (Slaughter and Rhoades, 2004, p. 298). Citing data from a 2002 National Association for College Admission Counseling (NACAC) survey, many institutions were investing in amenities to attract more students. Slaughter and Rhoades (2004) suggested that this type of investment indicates the institution is spending more resources to enhance the institution's ability to recruit students and, ultimately, extract greater tuition and fees from students" (p. 299). Similar behavior is observed through the greater connectivity to cable and internet throughout university and collegiate housing, a national trend. Slaughter and Rhoades (2004) suggest that "institutions contract with private-sector services to generate revenue, and institutions pass along increased fees to students to pay for such services, generating another stream of revenue" (p. 299). In conclusion, the authors argue that these behaviors are paramount to understanding previous notions of academic capitalism and academic capitalism in the new economy. The national patterns witnessed through the decreased expenditures on institutional instruction first realized by Slaughter and Leslie (1997) that promoted entrepreneurial science continues today; however, continued institutional disinvestment in instruction is occurring through increased investment in "nonacademic personnel and activities" (Slaughter and Rhoades, 2004, p. 300).

\section{Excesses of Institutional Spending and Student Pushback}

However, the activities described by Slaughter and Rhoades, 2004) do fall victim to excessiveness that even causes students to signal a need for - at least, some - thrift. For example, 
retired President of Missouri State University, Michael Nietzel, offered the following examples: An \$85 million dollar 565-foot lazy river at Louisiana University, the University of North Florida student living quarters complete with pools, themed lounges, and putting greens, the University of Kentucky’s \$200 million dollar student center with “rooftop gardens, fire pits, terraces where the free speech area used to be, and a "worry-free-zone" - a gluten-, peanut-, tree nut- and shellfish-free kitchen" and the valet parking perk at High Point University where the president argued it could serve as a way to "'wow' students and - get this - promote better learning" (Nietzel, 2018, p. 1). The author suggested, however, that a new trend of students unwilling to increase their fees to support institutional investment in new amenities is growing. For example, students at the university of Kansas, Iowa State University, and Cal Polytechnic all rejected proposed increases to student fees for renovations or updates to their student unions whereas students at the University of Texas at San Antonio also vetoed fee increases proposed to update athletic facilities (Nitzel, 2018). The author argues that student reticence to increase fees to pay for institutional investment in better student amenities signals student desire for institutions to "slow down facility binging" (Nietzel, 2018, p. 1).

\section{Resource Dependency and Organizational Behavior - Alternative Revenues}

Concerned with competing state priorities and an overall lessening in the purchasing power of state appropriations, Cheslock and Gianneschi (2008) investigate how higher education institutions attempt to replace government disinvestment with alternative revenue sources. To investigate revenue from institutional donors as a potential replacement to state revenue losses, the authors gathered data from a multitude of sources such as the Voluntary Support to Education (VSE) survey developed by the Council for the Advancement of Education (CAE) from 1994 to 2004, IPEDS data for state appropriations, student enrollment, and Carnegie 
classification along with selectivity indicators from Barron's Profiles of American Colleges (1999), unemployment data from the Bureau of Labor Statistics, personal income per capita from the Bureau of Economic Analysis, and, finally, business, law, and medical school rankings from the U.S. News and World Report's America's Best Graduate Schools. They examine all public four-year undergraduate institutions who, in the year 2000, have a Carnegie Classification of Research/Doctoral, Masters, or Baccalaureate and have valid data (Cheslock and Gianneschi, 2008). Ultimately, the authors found that institutional revenue streams lost to state disinvestment cannot be reliably replaced by monetary donations from donors.

The authors found that state appropriations per student tended to vacillate with the health of the state economy. Analysis by the authors revealed that state appropriations fell by a cumulative 15\% from 1994 to 2004 with private giving increasing by roughly 30\% (Cheslock and Gianneschi, 2008). Their results provided two major findings. First, they found that the level of inequality in private giving is "dramatically higher than that for state appropriations" (Cheslock and Gianneschi, 2008). This finding indicates that two levels of inequality in higher education resources exist. First, there is inequality in the level of state appropriations that institutions receive and, second, that the level of private funding/giving among institutions based on selectivity is even higher than for state appropriations. The authors second major finding suggests that if institutions are expected to replace their funding revenues lost from state appropriations through private funding avenues, the funding inequality gap between highly selective or competitive schools and their lower selective or competitive schools will likely grow. These findings may further complicate student access to highly selective institutions because previous research demonstrates attendance at more selective institutions is tied closely to student aptitude and family background (Cheslock and Gianneschi, 2008). 
Their second main finding is a corollary to the first: Although institutions were able to replace losses of state appropriations in the aggregate, this relationship does not necessarily exist at the institutional level (Cheslock and Gianneschi, 2008). Instead, their results "do not indicate that individual institutions counteract relatively poor state funding with relatively more private gifts" suggesting an "unusual relationship between private donations and government funding exists in higher education" (Cheslock and Gianneschi, 2008, p. 224). To combat this unusual relationship, the authors call for further research into the funding calculus of higher education. One of these concepts involves price elasticity of demand. Price elasticity of demand can be defined as the change in quantity demanded for a good (such as student enrollment) to a change in the price of that good (such as student tuition). If the calculated absolute value of these ratios is greater than one, then price decreases will signal greater demand for the good indicating that the good is relatively elastic. If the absolute value of the elasticity of demand calculation yields a value that is less than one, this indicates that the good is relatively inelastic and that changes to the quantity demanded will not change relative to changes in price.

Cheslock and Gianneschi (2008) argue that since demand for higher education is not perfectly inelastic - where the demand for a good is not critically affected by a change in the good's price - the consistent raising of tuition levels for public institutions will eventually lead to a price threshold where there will be diminishing returns on student enrollment. When this point occurs, institutions will then be forced to engage in higher levels of tuition discounting (such as increasing institutional aid awards) to lower the institutional price and entice student enrollment by lowering the tuition levels back to a point of inelasticity (Cheslock and Gianneschi, 2008). The authors suggest that as this point is not known and that greater research into alternative revenue sources such as research grants and commercial revenues are necessary because 
competition for public dollars will be exacerbated by competing state interests and public reticence to pay higher taxes necessary to support public goods (Cheslock and Gianneschi, 2008).

\section{Resource Dependency and Organizational Behavior - Enrollment Management}

In their seminal (2015) study, Ozan Jaquette and Bradley Curs conducted an empirical examination of 440 institutions with 4,429 institution-year observations to model the effect of declining state appropriations on nonresident freshmen enrollment. The authors used IPEDS institutional data for the analysis period 2002 - 2003 to 2012 - 2013 "for all public non-military, baccalaureate-granting institutions in the U.S. that received state appropriations and enrolled freshman" (p. 545). Drawing on resource dependence theory, the authors created a model to examine the relationship between state appropriations and "institutional willingness to supply seats to nonresident students" (p. 541). As state institutions are often constrained in how much they can increase their tuition and fees from year to year and since these institutions are constrained by their need for resources (e.g. tuition dollars), the authors hypothesized that institutions experiencing state disinvestment would attempt to grow their out-of-state enrollments to maximize their net-tuition revenue per student. Jaquette and Curs (2015) cite evidence from the National Postsecondary Aid Study 2011 - 2012 to demonstrate the net tuition revenue calculation for in-state and out-of-state students. The mean net-tuition revenue for in-state students was $\$ 6,483$ and $\$ 16,979$ for out-of-state students after accounting for a mean of $\$ 877$ in resident and $\$ 2,365$ in institutional aid awards. In their model to estimate the effects of government disinvestment on nonresident freshmen enrollment, Jaquette and Curs (2015) operationalized nonresident freshmen enrollment as the dependent variable and state appropriations (lagged by one year) as the primary independent variable. 
In discussion of which covariates to include in their study, Jaquette and Curs (2015) suggest that since institutions want to diversify their revenue streams per resource dependency theory, college choice, and enrollment management research, institutions increase enrollment from desired student populations by engaging in enrollment management strategies that target particular populations in the search and choice phases of the college choice process. To measure nonresident freshman enrollment, the authors used the Residence and Migration sub-component of the IPEDS Fall Enrollment survey as well as state appropriations from the IPEDS Finance Survey component. Covariates were lagged by one full year for all measures of enrollment demand and institutional supply because both the policy and the effect tend to be based on prior year performance and data. In other words, the effect of increases or decreases in-state appropriations in year one do not manifest until year two. To control for factors that may influence the institution's preference to enroll out-of-state students, the authors included two control measures of total FTE (full-time equivalent) undergraduate enrollment and FTE graduate enrollment. As a result, they could control for institutional enrollment growth, in general, as a possible explanation of increased nonresident enrollment. The authors also argued that since students from states with merit-based scholarships represent a block of students with both attractive student qualities and leverageable financial aid, these students also mitigate institutional preference for nonresident students. To control for that scenario, the authors controlled for individual state expenditures on need-based financial aid and merit-based financial aid as provided by the National Association of State Student Grant and Aid Programs.

The authors include further controls for state population growth, race and ethnicity, state population of 12 to17-year-old students to control for projected college-aged populations and other categories that intersect both race and age. Political controls included two measures. As 
their dataset includes institutions from different states, the first measure is categorical and describes whether each state has a Democratic governor because previous research suggests the relevance of political variables for appropriations to higher education institutions (Jaquette and Curs 2015; Tandberg and Griffith, 2013). The second measure is the percentage of Democrats in each state legislature as these houses are responsible for the promulgation of legislative budgets that control higher education spending. A full list of their variables and the methods used for their construction are found in Appendix 6 of their article.

Results from Jaquette and Curs (2015) demonstrated that for every 1\% decrease in-state appropriations there was a $0.27 \%$ increase in nonresident enrollment at baccalaureate institutions, a .46\% increase in nonresident enrollment at research universities (extensive and non-intensive) and a $.50 \%$ increase at research extensive universities. The authors suggested their research was different from past research by Rizzo and Ehrenberg (2004) because these authors examined ratios of nonresident and resident enrollment, whereas Jaquette and Curs (2015) studied the two variables separately. Furthermore, the analysis time periods were vastly different and do not control for similar periods of government generosity toward higher education appropriations with Rizzo and Ehrenberg (2004) operating during more generous times (1979 to 1998) and Jaquette and Curs (2015) operating during more uncertain or volatile times (2002-03 to 2012-13). Jaquette and Curs (2015) conclude with a discussion of the implications for policy and practice where they urge caution for policymakers concerned with higher education access. Jaquette, Curs and Posselt (2014) demonstrated that as the share of nonresident students increases, the proportional share of low-income students decreases.

Resource Dependency, Institutional Resource Allocation, and Student Outcomes 
Titus (2006) argues that the resource dependency theory advanced by previous scholars Hrebiniak and Joyce (1985), Pfeffer and Salancik (1978) and Scott (1995), "provides a framework to examine the how (sic) an institution's internal allocation of financial resources is influenced by the relative magnitude of the external financial resources” (Titus, 2006, p. 373). Titus (2006) accomplished this task by contextualizing institutional behavior and student outcomes through the Berger-Milem Model of Organizational Behavior in Higher Education and Student Outcomes. The Berger-Milem conceptual model concludes that student entry and organizational characteristics affect student peer group characteristics and that student peer group characteristics inform student culture, behavior, and how they perceive their higher education environment (Berger and Milem, 2000).

According to Titus (2006), the Berger-Milem model gains its value from "organizational behavior theory, peer group effects, and student development theory" to assert that "both institutional and student characteristics influence student outcomes” (Titus, 2006, p. 373.). Implicit in the Berger Milem Model is that student entry characteristics, organizational characteristics, and organizational behavior influence and inform both peer group characteristics and the student experience which also highly informs student outcomes. As a result, institutional behaviors are paramount to understanding not only who the institution selects, but how the institution socializes its students to produce a cultural environment that informs student success. Resource Dependence and Student Outcomes

Pfeffer and Salancik's (1978) resource dependence provided the initial framework for Titus (2006) to extend the Berger Milem Model's depiction of systemic organizational behavior to develop an understanding of "the extent to which college degree completion by SES [socioeconomic status] is influenced by an institution's dependence on market-based revenues 
and internal allocation of expenditures" (Titus, 2006, p. 374). Titus (2006) uses student-level data from the 1996 - 2001 Beginning Post-Secondary Students (BPS) survey, a survey that uses the National Postsecondary Student Aid Study as a "sampling frame" (Titus, 2006, p. 373). Follow-up data was also collected from 1998 and 2001 "to provide such information on studentlevel background characteristics, financial aid, education experiences, persistence, employment, income and career aspirations" (Wine et. al., 2000; Titus, 2006). Institution-level data such as characteristics, enrollment, and academic program offerings were captured along with financial data such as revenue and expenditures for Fall 1995 first-time, full-time, undergraduate, degreeseeking students attending four-year institutions (Titus, 2006). To ensure consistency with the BPS survey, institutions with missing data for finances or enrollment were removed, providing for a total sample of 5,776 students attending 400 four-year institutions (Titus, 2006).

The dependent variable in Titus' (2006) study was binary and defined as "having completed a bachelor's degree program within six years after first enrolling in the same four-year institution" (p. 375). Independent variables include pre-college academic performance measured by SAT score, gender, four racial ethnic groups (African American, Hispanic, Asian, and White as the reference group), and socioeconomic status. Titus (2006) used Ethington's (1990) socioeconomic status measure that combines the sum of "parental income (a total of twelve categories ranging from "less than $\$ 4,000$ ” to “\$40,000 or more") and mother's and father's education (six levels each from "grammar school or less" to "postgraduate degree")" (Ethington, 1990; Titus, 2006). These values ultimately resulted in four quartiles of SES from lowest to highest with the highest SES group serving as the baseline for analysis. Student experiences were measured through college performance (college GPA), declaring a major (whether or not the student declared a major in their freshman year), and living on campus 
(whether or not the student lived on campus in their freshmen year). Student involvement was measured as an amalgamation of various campus activities that can be found in the BPS survey component 96/01 - Titus (2006) warns that the reliability coefficient of .65 for this particular field falls below the acceptability criteria of .70 and should be considered with "caution" ( $p$. 376). Financial variables such as unmet need were calculated as the total cost of attendance minus the student's expected financial aid. Work hours are categorized into four ten-point range categories that began with zero and end with more than twenty hours worked with zero serving as the reference category. Student peer group characteristics such as total percent female (the total percent of students at a single institution that are female), racial and ethnic diversity (see calculation below), and the average SES of full-time freshmen attending the same institution and is calculated in consort with Mitchell Chang's (1999) measure. In this equation, $\mu$ was calculated "by dividing the sum of the four percentages at each institution by four" (Chang 1999, p. 385). The resulting index "measures the variance in the racial/ethnic composition of full-time freshmen Chang's Racial Index Measure:

$$
\sqrt{ }\left((\% \text { Asians }-\mu)^{2}+(\% \text { Latinos }-\mu)^{2}+(\% \text { Blacks }-\mu)^{2}+(\% \text { Whites }-\mu)^{2} / 4\right)
$$

enrollment at the institution" (Titus, 2006, p. 376-77). Other structural demographic measures included indicators for institutional control (such as private or public) and average SAT scores for each institution as a measure of institutional selectivity consistent with Kingston and Smart's (1990) classification where selectivity is broken down into three groups of high selectivity (highest SAT quartile), medium selectivity (second and third quartiles) and low selectivity (lowest quartile) with the medium selectivity category serving as the baseline for analysis (Titus, 2006). Further demographic structural variables included student headcounts categorized into three groups with small institutions having enrollment less than 4,133, medium institutions that 
serve more than 4,133 but less than the large institutions with enrollments that exceed 19,576

(Titus, 2006). The financial institutional context was measured by the "percent of total revenue from state appropriations; percent of total revenue from tuition; percent of total revenue from competitive grants and contracts; and percent of total revenue from endowments" (Titus, 2006, p. 377).

Titus (2006) then explores his research questions through the use of hierarchical generalized linear modeling, ANOVA, and cross tabulations to model the effects of a vector of institutional characteristics and experiences on the probability of a student graduating within six years from a single institution. Using odds ratios, Titus (2006) found that SES six-year completion rates were $46 \%$ of first-time freshmen in the lowest quartile, $51 \%$ in the second quartile, $63 \%$ in the third quartile, and $71 \%$ of those in the highest quartile. Scheffe multiplecomparison tests demonstrated that there was no statistically significant difference between the first and second SES quartiles (Titus 2006). Individual odds ratios also demonstrated that graduation within six years was positively related to college GPA ( odds ratio $=2.152, \mathrm{p}<.011$ ), declaring a major (odds ratio $=1.164, \mathrm{p}<.05)$, living on campus (odds ratio $=2.18, \mathrm{p}<.01$ ), negatively associated with unmet financial need (odds ratio $=0.928, \mathrm{p}<.05$ ), and that African American students and Hispanic students had a lower likelihood of graduating in six years when compared to white students $(.711, \mathrm{p}<.01$ and $.741, \mathrm{p}<.05$, respectively) (Titus, 2006). Socioeconomic status also informs the likelihood of six-year degree completion at a more granular level. For example, students in the lowest quartile were less likely to graduate than those in the highest quartile (odds ratio $=.757, \mathrm{p}<.01$ ); students in the second quartile were also less likely to graduate when compared to the highest quartile (odds ratio $=.782, \mathrm{p}<.01$ ) with the overall odds ratio of socioeconomic status being positively related to the likelihood of six-year 
graduation (odds ratio $=1.082, \mathrm{p}<.05)$ indicating that higher levels of socioeconomic status are associated with a greater probability of graduating with six years.

Other important findings include six-year completion is positively influenced by the racial and ethnic diversity of the freshmen class (odds ratio $=1.087, \mathrm{p}<.01$ ) but " $[\mathrm{t}]$ his finding appears to be inconsistent with the lower chance of college completion for African American and Hispanic students" (Titus, 2006, p. 385). Higher selectivity also increased six-year completion rates (odds ratio $=1.249, \mathrm{p}<.05$ ). Financial context also informed six-year completion rates. Total education and general expenditures (odds ratio $=1.61, \mathrm{p}<.05$ ), tuition and fees as a percent of total revenue (odds ratio $=1.041, \mathrm{p}<.01$ ), total education and general expenditures on instruction per FTE (odds ratio $=1.146, \mathrm{p}<.05$ ). Further findings indicate that although total education and general expenditures per FTE are positively associated with college degree completion within six years, low SES students disproportionately enroll at institutions with relatively lower expenditures per FTE (Titus, 2006). Equally important, null findings for percent of revenue derived from state appropriations, contracts, grants, and endowment income were not predictive of the likelihood of six-year completion (Titus, 2006).

Descriptive statistics revealed further important information pertaining to student SES and how the experiences of low SES students differ vastly from students in a higher SES. For example, low SES students have, on average, not declared a major in their first year, earn a lower first-year college GPA, are less likely to be involved on campus, work more hours than students in the third and fourth SES category, have higher unmet need, tend to work more hours, are more likely to be part of an underrepresented minority group such as Hispanics or African Americans, and are more likely to attend less selective public institutions (Titus, 2006). The author also found that only a small proportion of students in the low SES category attended institutions 
where there were high concentrations of high SES students and when compared to high SES students, low SES students are less likely to attend a private institution.

In total, Titus (2006) concludes five major points. First, the likelihood of completing college is positively influenced by socioeconomic status. Second, after controlling for individual SES characteristics and consistent with previous research, the norms and values of students in higher socioeconomic status positively informs the odds of six-year completion rates. Third, structural demographic measures such as the racial and ethnic diversity of the institution inform completion rates and that since African American and Hispanic students have a lower likelihood of graduating within six-years, these effects have potential "positive spillover effects for whites, but not for underrepresented minorities" (Titus, 2006, p. 393). Titus (2006) suggests that intergenerational wealth transfer among wealthier white families when coupled with the greater likelihood that African American and Hispanics stem from lower-income households, also provides a context for wealthier families to provide for greater human capital investments in their own children when compared to African American and Hispanic students and ultimately manifests in greater educational attainment for high SES students when compared to lower SES minority students (Titus, 2006). Fourth, the author found that "college completion is positively related to such financial aspects of the institutional context as tuition revenue as a percent of total revenue and E\&G [education and general expenditures] expenditures per FTE students" demonstrating that "the source and level of financial resources contribute to an environment that fosters student success (Titus, 2006, p. 393).

\section{State Disinvestment and Tuition Impact}

Webber (2017) analyzed institutional financial data for 497 four-year public institutions from IPEDS from 1987 to 2014 to examine the effect of state investment on student prices to 
attend higher education. In an effort to control for potential bias in their measures, the authors also consult a set of laws and rules constructed by Deming and Walters (2017) to control for tuition freezes and maximum allowable increases to tuition across their sample of 497 institutions. In the overall sample, the net tuition derived per FTE was $\$ 5,216$. By institution the net tuition per FTE was $\$ 6,425$ for Ph. D. institutions, $\$ 4,726$ for master's institutions, and $\$ 8,073$ for bachelor's degree institutions. Using the average net tuition and fee revenue for the dependent variable instead of posted tuition and fees allowed for the control of tuition discounting across institutions (Webber, 2017). In the overall sample, the overall level of state and local appropriations per FTE was $\$ 8,558$. By institution, the state and local appropriations per FTE were \$10,415 for Ph. D. institutions, \$7,518 for master's institutions, and \$4,269 for bachelor's institutions.

According to the two stage model developed by Webber (2017), for every $\$ 1000$ disinvested by state and local funds, the average student paid upwards of $\$ 257(\mathrm{p}<.01$, se=.0291) more in tuition and fees - rates fluctuated somewhat across institutional type, however, all are negative with Ph. D. institutions having the highest coefficient of -.266 ( $\mathrm{p}<.01, \mathrm{se}=.0409$, ), master's institutions at $.262(\mathrm{p}<.01$, se=.0384) and bachelor's institutions at $.183(\mathrm{p}<.05$, $\mathrm{se}=.0746)$. The authors also find temporal changes to the degree in which tuition is increased as a function of state disinvestment. For example, post-2000, the rate was a \$318 dollar increase for each $\$ 1,000$ in revenue losses whereas in the first part of the data, pre-2000, the rate was only $\$ 103$ per $\$ 1,000$ dollars in-state disinvestment.

The author argues that if the relationship between state investment and student price are causal and that the institutional response is to cut non-essential funding first, then continued budgetary pressures inch the institution closer to cut core functions of the university - thus, 
requiring the institution to pass those deeper cuts onto the student (Webber, 2017). For the thirty years the author studies, state and local disinvestment accounts for $16.1 \%$ of the "increase in tuition and fees paid by the average student. But, these figures are exacerbated over time: "Following the early 2000/s recession, $29.8 \%$ of the increase in tuition and fees revenue can be explained by public disinvestment, a figure which rises to $41.2 \%$ post-Great Recession" (Webber, 2017, p. 3). Webber's (2017) finding demonstrates that government disinvestment is accounting for higher proportions of the net-tuition and fees revenues for institutions when institutions raise tuition to offset government disinvestment. This strand of research further suggests that nascent rises in tuition in fees resulting from continued government disinvestment will continue to inform higher proportions of increases to tuition and fees ceterus paribus

\section{Trends in Institutional Aid}

Institutions have become a significant player in the financial aid paradigm through the provisioning of institutional aid - funds the college or university makes available to students through loans, grants, contracts, waivers, etc. that help defray the long and short-term costs of attending their institution. According to the College Board (2017), the institutional aid slice of the financial aid pie, while nothing completely new, has grown substantially, especially since the Great Recession. After the government heavily invested in higher education during and after the Great Recession (ca. 2009) through greater provisioning of grant-based aid, "institutional grant aid has increased rapidly, as both enrollment and federal grant aid have declined" (The College Board, 2017, p. 3). In fact:

[I]nstitutional aid is the only type of grant aid that grew rapidly between 2011-12 and 2016-17. Colleges and universities increased their aid by $32 \%$, from $\$ 44.4$ billion (in 2016 dollars) in $2011-12$ to $\$ 58.7$ billion in $2016-17$. Over these years, federal grant aid 
declined and grant aid from states, employers, and other private sources increased by less than $10 \%$. (p. 12)

This is a continued trend as an earlier report by Baum, Lapovsky, and Ma (2010) demonstrated: "Institutional grants increased from 34\% of total undergraduate grant aid in 1990-91 to $40 \%$ in 2000-01 and were $39 \%$ of the total in 2008-09" (p. 1). It is critical to reiterate that even when controlling for declines to enrollment and the provisioning of federal aid, institutional aid increased. According to the National Center for Education Statistics for 2015-16, public fouryear doctoral degree granting universities provided institutional aid award assistance to $35.7 \%$ of their undergraduate student body with $\$ 5,300$ as the average award amount. Roughly one out of three students received some type of financial aid award that includes all institutional need and merit-based grants, scholarships, tuition waivers, loans, and work-study financed by their institution.

\section{Institutional Aid Recipients}

Aid as a vehicle to propel students into a higher education was growing. Heller (2001) estimated that total expenditures per student increased by 35\% from FY 1990 to FY 1996 (in 2001) dollars, total scholarship expenditures increased by $69 \%$, total federal Pell grants by $33 \%$, and institutional scholarship spending increasing by $98 \%$ for all institutions, $92 \%$ for private non-profits, and 105 for public institutions (Heller, 2001). From 1989 to 1995, Heller (2001) found: "Overall institutional financial aid spending increased $111 \%$ during this period, a rate more than four times that of inflation and more than three times that of the overall increase in institutional expenditures per students" (p. 20). Further findings from Heller (2001) indicated that although the number of non-need-based grants declined from 1989 to 1995, the mean award 
was higher in 1995 indicating that "institutions were making more strategic use of non-needbased awards for enrollment management purposes in 1995 compared to 1989 (p. 20).

Recognizing that institutional aid was a growing slice of the financial aid pie and that need as a basis to award financial aid was waning, Heller (2001) set out to explore institutional aid award changes over time with specific attention to the student socioeconomic and demographic characteristics predictive of receiving aid. Using logistic regression and bivariate analysis and data from the National Postsecondary Student Aid Study, the author examined how the awarding of need-based versus non-need based institutional grant funds changed between 1989-90 and 1995-96. Heller (2001) gathered data from the NPSAS on over 800 institutions of both graduate and undergraduate students for an approximate total of 47,000 for 1989-90 and 41,000 for 1995-96. Measures for Heller's (2001) research contained two distinct measures for institutional aid: need-based and non-need-based aid. Non-need-based grants were "grants that are based solely on the determination of merit or other circumstances not related to financed need" (Heller, 2001, p. 11). Need-based grants were those grant awards that "are based on financial need but may include a non-need-based component” (Heller, 2001, p. 11). Other measures included in the NPSAS to measure socioeconomic status and family financial strength included student dependency status and family income. Only dependent, full-time students, in four-year institutions with a Carnegie classification of research, doctoral, comprehensive, and liberal arts schools are examined as they are the population of interest to Heller's (2001) research. Further exclusions included any student receiving an athletic scholarship. As a share of the total population of students receiving institutional grant aid, 59\% of students in 1989 received institutional aid and 69\% of students in 1995 received institutional aid (Heller, 2001) a $17 \%$ increase. 
Heller (2001) produced initial bivariate results for three student categories: Students receiving any type of grant aid, students receiving need grants, and students receiving non-needbased grants. As a preface to Heller's (2001) findings, it is critical to mention that the overall number of full-time dependent students "decreased by 3\% between 1989 and 1995 from 4,003,992 to 3,892,092" (p. 10). However, despite losses to overall enrollment, the volume of students who received any type of institutional grant aid in 1995 increased by $29 \%$ nationally with just under 243,000 more students receiving any type of institutional grant aid (Heller, 2001). The average grant aid for students receiving the highest aid awards in 1989 (Asian Americans at \$3,589) and the lowest aid awards in 1989 (Hispanic Americans at \$2,320), increased at different rates from 1989 to 1995 . For example, Asian students increased from $\$ 3,589$ to $\$ 5,669$ for a $58 \%$ increase whereas Hispanic students grew from $\$ 2,320$ to $\$ 3,772$ for a $63 \%$ increase - a five percentage point advantage to increase in mean institutional aid awards for Hispanic students when compared to Asian American students. Overall, percent changes in the total dollars awarded for students receiving any type of institutional aid awards increased the most for Asian students (220\%) and the least for African American students (88\%) with Hispanic students at $134 \%$ increase, Caucasian students at a $100 \%$ increase, and all races increased, on average, by $111 \%$.

For students receiving need-based grants, Asians out-performed all other races with an increase of $239 \%$ followed by Hispanic students at $149 \%$, Caucasian students by $100 \%$, all races by $115 \%$, and African Americans receiving the smallest increase of $94 \%$. For the final category of initial bivariate results, students receiving non-need-based grants have similar increases than the other categories with two major differences. First, for non-need-based grants, Asians no longer earned the lion's share as Caucasian students received a 128\% increase, Asians received 
the next highest increase at $112 \%$ follow by all races, on average, at $99 \%$, Hispanics by $68 \%$, and African Americans earning the lowest increase of $66 \%$ and earning the lowest rate of increase across all three institutional grant aid categories. These values do not, however, control for specific changes in enrollment, only the frequency of the aid awards by race and the amounts awarded.

The final category of grants, students receiving non-need-based grants, demonstrated a decrease in the number of grants for Asian Americans by 13\%, Hispanic students by $11 \%$, Caucasian students by $11 \%$, all races on average by $9 \%$, with African American students earning an overall increase of $11 \%$. As an increase in total dollars awarded, Asian Americans increased by $112 \%$, African Americans by $66 \%$, Hispanic Students by $68 \%$, Caucasian students by $128 \%$ and all races, on average, by $99 \%$. These values suggested that although the overall number of grants fell for Asian, Hispanic and Caucasian students, the mean value of the aid awards increased for each student who received a non-need-based award. For African American students, however, the number of students receiving a non-need-based award increased, but the mean average of those awards over time was the lowest for all of the racial categories measured. The highest increase in the mean for non-need-based grant awards was Asian Americans at $144 \%$, Caucasian Students at 127\%, the average for all races at $117 \%$, followed by Hispanics at $89 \%$ and African Americans at 51\%. As a result, although the frequency with which non-needbased grant awards increased for African Americans, the mean value of those awards, relative to awards given to other students, was the lowest racial categorical increase in mean aid awards examined.

Heller (2001) provided a multivariate logistic regression analysis to control for factors that may influence whether or not a student receives an institutional aid award - a dichotomous 
result, students either receive an institutional aid award or they do not. Heller (2001) suggests that although logistic regression is the appropriate modeling technique to investigate the question, the logistic regression assumption that observations in the model are independent would be violated given the "multi-stage nature of the sampling process" used to gather his data (p. 13). To correct for this assumption violation, the "logistic regression models were fit using Huber/White estimators of variance, which allow observations that are not independent" (Huber, 1967; White, 1989, 1982 as cited in Heller 2001, p. 13). Heller (2001) then fit the models by sequential entering of variables in blocks containing both predictor and control variables. Coefficients were presented using the Peterson (1985) delta-p statistic expressing the "the relationship between a unit change in a predictor and the estimated percentage change in the outcome" (p. 13). Coefficients presented as a delta-p allow for intuitive interpretation of results through percentage changes: "For example, a delta-p value of 0.025 indicates that a one unit change in the predictor is related to a 2.5 percentage point change in the likelihood that a student would receive an institutional grant" (Heller, 2001, p. 14).

Heller (2001) found that increases to tuition were slightly predictive of the likelihood of institutional aid with a $\$ 1,000$ increase in tuition resulting in a $6 \%$-point increase in the likelihood of receiving a need-based grant a $.4 \%$-point decrease in the likelihood of receiving a non-need-based grant. Hispanics were the only race to have a statistically significant increase in the likelihood of receiving a need-based grant when compared to whites and African Americans were the only other group to have a greater likelihood than whites to receive a non-need-based grant (Heller, 2001). Other results introduced college GPA as a positive predictor of receiving institutional grant awards that contain both need and non-need-based components. For example, students who increased by one grade level (such as moving from a B to an A) resulting in a 
seven-percentage point increase in the likelihood of receiving a need-based grant and a 19-

percentage point increase in the likelihood of receiving a non-need-based grant (Heller, 2001).

College GPA performance also informed the rate at which institutional aid awards were granted.

A one-point increase in college GPA revealed a seven-percentage point increase in the likelihood of receiving a need-based grant in 1989 and a 12-percentage point increase in 1995 (Heller, 2001). The non-need-based grant relationship, however, revealed a negative relationship. In 1989, a one-point increase in GPA indicated a 19-percentage point increase in the likelihood of receiving a non-need-based grant but decreased 6 percentage points to an increased likelihood of only $13 \%$ in 1995 . This relationship led Heller (2001) to declare: "Institutions had begun to reward merit through their need-based grant programs nearly as much through their programs that did not use financial need as a criterion (p. 18).

In conclusion, Heller (2001) suggested that institutions tended to follow "the federal need analysis rules for determining eligibility for financial aid (p. 21) but "colleges and universities have much more flexibility in the awarding of non-need-based aid... and many use non-needbased aid as an enrollment management and marketing tool to attract certain types of students to their institutions (and to keep them enrolled once they matriculate)" (p. 21 - 22). Also, given Heller's (2001) findings of the impact of college GPA on the likelihood of receiving institutional grants, the author demonstrated "the simple fact that the two categories [need-based versus merit aid] are not mutually exclusive as merit is playing an increasingly important role in the awarding of even need-based aid" (p. 22).

\section{Institutional Aid Recipients - Continued Change to Need and Merit Based Awards}

Doyle (2010) describes institutional demand for students as "latent", where institutions desire a specific type of student and will be responsive to those student characteristics it deems 
most desirable: "[I]nstitutions use institutional aid to encourage students to attend their institutions who might not otherwise come. To award this aid, institutions respond to a variety of characteristics of students, depending on what kind of entering student class they seek" (Doyle 2010, p. 794). Data for Doyle's (2010) research stems from the National Postsecondary Student Aid Study using dependent students from four years of the study 1992-93 (sample size = 13,610), 1995-96 (sample size $=13,690), 1999-2000($ sample size $=12,530)$ and 2003-04 (sample size $=17,260)$. To model institutional aid awards and to control for the censored nature of institutional aid awards - where there institutional aid awards of zero for all of students those who do not receive institutional aid and dollar amounts greater than zero for students who receive an institutional aid award - Doyle (2010) employs a tobit regression model to account for the censored nature of the data.

The dependent variable is the amount of institutional aid a student receives with institutional grants as the sum of all institutional grant aid a student receives minus any athleticbased aid - loan aid and work study aid are not included in the institutional aid summation. Doyle's (2010) measurement of institutional aid as the summation of aid received was designed in this matter so that relationships between independent variables such as student academics and student need could be inferentially persuasive. For example: "I make no distinction in my dependent variable between need-based and merit-based aid. Instead, I posit that any aid that increases as family income goes down can be reasonably inferred to be need-based, while aid that increases as SAT scores go up can be described as merit-based" (Doyle, 2010, p. 794). The two major independent variables of interest are family income and college entrance exam scores. Other control variables include age, gender, race, or ethnicity along with the amounts of federal and state aid awarded to each student, institutional type, and tuition. 
Doyle (2010) suggests that his overall findings indicate greater institutional responsiveness to student academic characteristics over time. Descriptive statistics for public four-year doctoral institutions in 1992-93, demonstrated that the average institutional aid provided to students in the lowest income quintile was $\$ 500$ and $\$ 300$ for those in the highest income quintile with no statistically significant different result between the two (Doyle, 2010). Similar statistically insignificant differences were found for SAT scores in 1992-93 as those with low scores averaged \$260 dollars institutional aid whereas those in the higher bracket averaged \$230. However, these results change dramatically in 2003 as Doyle (2010) suggested institutional aid doubled in relation to inflation and while public doctoral degree institutions "demonstrated signs of a system that had a need-based component (low income students received on average, $\$ 400$ more than their high-income counterparts), they began rewarding higher SAT scores at a much higher level” (p. 798). Evidence from 2003 suggested that the gap between high institutional aid awards and low institutional aid awards increased among those of low performing $($ average $=860)$ and high performing $($ average $=1340)$ SAT scores with those having higher test scores earning higher institutional aid awards on average by $\$ 1,400$ (Doyle, 2010).

Doyle (2010) qualifies his descriptive statistics as non-conclusive evidence that institutions have shifted their aid awards to a merit-based system over time. To make more informed inferences regarding institutional aid awards, the model would need to control for family income and academic quality because students of varying prominence in both categories have different choices on which institution they can or should attend. As tobit results are not directly interpretable as a function of the independent variable influencing the dependent variable, marginal effects are employed as a statistical tool to develop this relationship more intuitively. In the context of a tobit model and since the dependent variable (institutional aid 
award dollars) are discrete values, marginal effects provide for the instantaneous rate of change between institutional aid award dollars and student SAT scores and family income (also discrete values).

According to the results, income and SAT both have statistically significant relationships with institutional aid awards and those relationships remain relatively consistent over time (Doyle, 2010). Further findings indicate that institutional aid awards increase as family income decreases and provided evidence for need as an important component of the institutional aid award (Doyle, 2010). For example, in 1992, marginal effects for family income indicated that for a $\$ 10,000$ decrease in family income, a student would receive a $\$ 130$ increase in institutional aid. For the same year, for every 100-point increase in SAT scores, marginal effects indicate that a student would receive $\$ 246$ in institutional aid. In 2003, however, a \$10,000 increase in family income indicated a $\$ 557$ dollar increase in institutional aid and a 100-point increase in SAT scores predicted an increase in institutional aid awards of \$246 (Doyle, 2010). The author also found that younger students receive more institutional aid dollars and may be a function of these students qualifying for programs that are targeted toward first-year students. Black and Hispanic students received more institutional aid than white students. In the later years of the study, evidence suggested that institutional grant aid became more responsive to tuition.

As Doyle (2010) investigated the awarding of institutional aid behavior over a multitude of institutional types, the author suggested: "At public non-doctoral institutions and at all types of privates, the payoff for academic characteristics has grown dramatically, white the increase in need-based aid has not grown nearly as fast” (p. 808). However, public four-year doctoral institutions provide the exception to this trend. Public four-year doctoral institutions have "been consistently responsive to student need in their provision of institutional aid ... [and] they have 
become more responsive to tuition" (Doyle, 2010, p. 808). As a consequence, public institutions

of higher education bear a greater burden of scrutiny of how their institutional aid is spent:

"Policymakers should gather more information about how public colleges are using their

institutional aid. The (sic) should then decide on the basis of that information if they are satisfied with the way institutional aid is being distributed (Doyle, 2010, p. 808).

\section{Institutional Aid Typologies}

Contributions made by Cheslock, Hughes, Frick Cardelle, and Heller (2018, herein referred to as Cheslock, et. al., 2018) provide greater depth and clarity to our understanding of how institutional aid awards impact individual students on the basis of need and non-needmeeting aid. The authors provide contextual understanding of need-meeting and non-need meeting aid through Table 1 of their article and suggested that need-meeting aid is aid that is awarded and meets financial need whereas non-need meeting is aid that does not meet need and provides aid beyond need (NPSAS 2011/12; Cheslock, 2018). Although the authors concur with the general categorization of need-based (e.g. Woo and Choy, 2011) and non-need-based aid (e.g. Baum and Ma, 2010), they suggest that measuring aid through theses lenses could omit key information (Cheslock et. al., 2018). Intentional need-based aid is aid that is need-meeting and the criteria for awarding it is also need-based. In other words, need is part of the criteria for getting the aid and the aid is also meeting a need component for the student. Secondly, incidental need-meeting aid is a need-meeting award that is non-need based, but it happens to meet need, potentially, by accident. An example of this measurement might be where the top 5\% of ACT takers receive an award, but a student who receives the award also has need - although the aid is strictly merit-based, students of need may incidentally receive the award and have it meet need. For the purposes of this dissertation, the categorizations of need-meeting and non-need meeting 
aid suffice as a measurement of institutional behavior because the application of these categories allows the researcher to ignore the institutional categorization of the aid awards and instead focus on the impact of the aid award for the student. Without information of each aid award that makes up the need-meeting and the non-need meeting aid awards, it is not possible to accurately categorize the institutional aid awards as intentional or incidental aid awards.

In their review of the literature, Cheslock et. al. (2018) suggested that institutions seek to distribute some of their institutional aid awards in a manner that mitigates unmet student need as a detriment to higher education access, persistence, and success. Citing evidence that the growth of institutional aid has paralleled and superseded the scale of large government grant aid programs such as the Pell Grant, institutional grant aid has also moved from a need-based orientation to a merit-based orientation where household income tracks much less closely with institutional aid awards when compared to Pell (Cheslock et. al. 2018).

In constructing their calculated need variable, the authors subtracted federal, state, and other private grants received from the students total cost of attendance. Any other funds that required repayment or exchange of labor for financial aid (e.g. work study) were not immediately subtracted but were considered funds that help cover the unmet need that remains after all initial other grants and scholarships are awarded. They suggested further that institutional strategies in the allocation of institutional aid would center on two possibilities. First, institutions would seek to mitigate the highest levels of unmet need in the student population. As a result, students with the highest levels of unmet need would be, theoretically, the population with the greatest frequency of institutional aid if the institutional goal is to mitigate students with the highest levels of unmet need. The second possibility is where the institution attempts to allocate institutional aid to all students who have need. In this scenario, aid awards would be smaller and 
more uniform where each student with demonstrated need would receive a similar award except for where need levels were below the typical award as these students would receive less. As a result, the authors hypothesized that intentional need-meeting aid would be given to students with the greatest levels of need, because administrators were intentionally attempting to mitigate the students with the highest levels of need.

The targeting of incidental need-meeting aid, however, is much more difficult to ascertain because of the two motivations that influence aid policy. According to Cheslock et. al. (2018) the first motivation is a desire to increase net-tuition revenue and the second is a desire to increase the quality of the student body. The authors frame administrative financial aid and institutional behavior using two economics concepts: price discrimination and customer-input technology. First, price discrimination is organizational behavior that attempts to maximize revenues (i.e. tuition) through price discounting to its most price-sensitive consumers. However, the institution simply cannot know with absolute certainty what a student (or their family) is willing to pay. Instead, they can only make offers they think will produce their desired result. The authors describe a scenario where an institution might provide $\$ 5,000$ in institutional aid to a student whose cost of attendance, net of all financial aid, is $\$ 20,000$, but are only willing to pay $\$ 15,000$ to attend the institution. However, the institution cannot know this perfect price for each student. Therefore, perfect price discrimination does not exist because the institutions do not have concrete information as to the maximum price each student will pay (Cheslock et. al., 2018). The authors suggested that this type of price-discrimination is also more germane to institutions of lower selectivity because institutions that are highly selective often have excess demand along with students willing and able to pay full tuition thus mitigating any need for price discrimination practices (Bowne and Breneman, 1993; Cheslock et. al., 2018). Therefore, the 
authors suggested that for institutions that engage in price discrimination, the question becomes how much of institutional aid is covering student need and is it targeted toward students with higher levels of need (Cheslock et. al., 2018).

Second, customer-input technology informs price because prices stem from two distinct sources. The first is the payment from the student to the institution in the form of tuition and the second is the payment from the institution to the student for their production input in the form of institutional merit aid (Cheslock et. al., 2018). Institutions are not solely interested in net enrollment and net tuition because there are some considerations, like enrolling good students, that also act as vital production input to the university. High quality students improve the learning of their peers, improve the rankings of their institutions, help secure desirable faculty, earn quality industry jobs, and may serve as prospects for future large donations or service to the university. To that end, the authors discuss the unexplored concept of how merit-aid can sometimes also meet need - this is incidental need-meeting aid. Therefore, incidental needmeeting aid is aid that would be directed to students that are vital inputs to higher education production that also fulfills a financial need of the student (Cheslock et. al., 2018).

Using the 2007-08 and 2011-12 National Postsecondary Student Aid Study, the authors collected data in 2012 adjusted dollars for all full-time, dependent, undergraduate students with the exclusion of students who received athletic scholarships because large athletic awards may bias the results. Other excluded students include those receiving Veteran's Administration, Department of Defense, and/or Reserve Officer Training Core grant aid with further exclusion of students who attended multiple institutions due to limited information regarding their cost of attendance. The sample was restricted to all 50 states and the District of Columbia yielding a sample of 30,440 students for the 2007-08 survey and 19,100 students for the 2011-12 survey. 
The authors constructed further measures to include in their regression model such as student pre-institutional need, SAT score in multiples of 100, first-generation status, gender, underrepresented minority status, Asian descent, and distance between campus and home measured in miles. Pre-institutional need is equal to the cost of attendance minus the student's expected total family contribution, state, federal, local, and private grants. Inclusion of these variables allow for the researchers to make inferences into institutional priorities and goals by evaluating demographic and geographic data points.

As their method to investigate the relationship between pre-institutional financial need and their demographic and geographic variables, regression analysis with incidental needmeeting aid and intentional need-meeting as dependent variables is used. Covariates included those mentioned above. The authors recognized that their interpretation would not be straightforward as they were attempting to accomplish two distinct goals. First, they were attempting to understanding the difference in institutional aid awards for students of differing levels of pre-institutional need for students at the same institution. As a result, the authors were concerned that their regression estimates would produce results for inter-institutional, intrainstitutional, or a mixture of the two effects. To correct for this, they estimate models that use "regression models that solely use within-institution variation to estimate results that are desirable (Cheslock et. al., p. 590). Second, they also needed to control for the manner in which the outcome variable (institutional aid) is coded because many observations contain zero. This is due to the two-stage decision-making process regarding the awarding of institutional aid.

Students receive two decisions. Institutions must decide if a student should receive an institutional aid award (decision one) and how much aid they should receive (decision two). The third concern stemmed from the oversampling and weighting techniques used by the NPSAS 
methodology that "stratified and employed oversampling to collect data on subpopulations of interest" (p. 590). The authors declared that if there are variations across the subpopulations and there were oversampling methods used to weight up observations, coefficients that estimate those populations may produce misleading results

Cheslock et. al (2018) are primarily interested in whether or not students with greater levels of pre-institutional need receive more institutional grant aid on average than their within institution counterparts. However, as regression analysis does not necessarily control for interinstitutional variation, the censored nature of institutional aid awards, and the oversampling of subpopulations of interest, they estimated numerous combinations to secure a robust array of results. Cheslock et. al. (2018) found that incidental need-meeting aid was on par with intentional need meeting aid. For 2007-08 the average incidental need meeting aid award for all students was \$1,562 and the average intentional need-meeting award was \$1,823. In 2011-12 these awards were $\$ 1,879$ and $\$ 2,323$ respectively. This relationship held across all institutions except for out-of-state students at public four-year institutions where incidental grants exceeded intentional grants on average (Cheslock et. al. 2018). The authors also found that aid awards for nonresident students increased rapidly at a rate of $51 \%$ points faster than in-state students at public institutions as nonresident awards increased from $\$ 2,017$ to $\$ 3,134$ or $54 \%$ and in-state awards grew from $\$ 1,255$ to $\$ 1,292$ or $3 \%$ (Cheslock et. al. 2018). Further results indicate that intentional need-meeting aid is focused on students with the highest financial need and that incidental need-meeting aid are consistent with expectations that these grants are awarded based on institutional objectives that go beyond access (Cheslock et. al., 2018).

The relationship between SAT scores demonstrated that high achieving students are desirable to the institution for a multitude of reasons. Citing Rothschild and White's model, 
Cheslock et. al. (2018) suggested that the relationship between high test scores and incidental need-meeting aid is intuitive because of the production input the student provides and the institution's willingness to acquire it through institutional merit aid that also meets need. Needbased aid for first-generation and underrepresented minorities suggested that need-based aid programs "combine considerations of financial need with other access-related considerations" (Cheslock, et. al, 597). For incidental need-meeting aid awards, first-generation status and underrepresented minority status were not found to be important indicators of the university "treating diversity as an important input to production when allocating financial aid" (Cheslock et. al., 2018, p. 597). Similar findings were reported for the Asian student indicator. The female indicator was largely insignificant for intentional need-meeting aid but was almost always positive for incidental need-meeting aid indicating female students may have "application materials" (Cheslock, 2018, p. 597) in dimensions amenable to triggering institutional aid.

\section{Theoretical Framework}

\section{Symptoms of Resource Dependence}

Academic capitalism (Slaughter and Leslie, 1997; Slaughter and Rhoades, 2004) in consort with resource dependence theory (Pfeffer and Salancik, 1978) provide the basis for an empirical investigation as to how government disinvestment serves as an impetus for institutional aid award behavior. Resource dependence theory suggests resource-dependent institutions will engage in organizational behavior that aligns with their resource providers. In response to resource dependence and government disinvestment, academic capitalism is viewed as the primary response through which resource-constrained higher education institutions mitigate state disinvestment. As government investment represents an important resource for public institutions dependent upon government support, disruptions to that resource will invoke responses by the 
resource-dependent institution to alleviate those disruptions. Since government disinvestment also tends to increase tuition (Webber, 2017) institutions have the opportunity to use institutional aid as a means to limit cost as a barrier to education for students who are price-sensitive.

Government disinvestment in higher education is captured contextually as an economic reality to the geographic region in which our institution is situated. To secure reasonable anonymity for the institution, government disinvestment in the institution is discussed contextually within the Appalachian region (see Chapter 1). Resource dependence theory advanced by Pfeffer and Salancik (1978) suggested that organizational behavior during periods of disruptions to the flow of institutional resources, such as government disinvestment in higher education, will inform institutional behavior as the institution seeks to allay resource losses and pursue new relationships with new resource providers. As a result, resource dependence suggests that institutional aid is an institutional behavior through which we can learn institutional preferences or indications that the institution is attempting to secure new resource providers or to secure the resources it deems as critical to the institutional mission. In order to provide measurements that are consistent with previous research on institutional aid and to control for potential misnomers or temporal changes to institutional aid award criteria over time, I calculate need-meeting and non-need meeting aid through the calculated impact of the institutional aid; these distinctions are discussed in greater detail in the methods section. As Heller (2001) found broad differences for institutional aid awards to students of differing races and genders, I also provide measurements of student gender and race through a dichotomous gender variable, an underrepresented minority variable, and an indicator for students of Asian descent. Heller (2001) also advanced socioeconomic status by only reviewing data for dependent students socioeconomic status as measured by the students Expected Family Contribution and calculated 
unmet need are also advanced as measures in my multivariate regression models. Consulting Cheslock et. al., (2018) I also employ measures of pre-institutional need, first-generation status, and underrepresented minority status discussed in detail in Chapter 3.

\section{The Importance of Institutional Financial Strength}

The theoretical framework employed by Titus (2006) also suggests that the internal allocation of funding is influenced by the relative magnitude of institutional external financial resources. As a result, institutions that are dependent upon external funds will respond to changes in the environment that affect resource distribution. In other words, Titus (2006) extended the use of the Berger-Milem (2000) model and resource dependence theory of Pfeffer and Salancik (1978) to suggest that systemic organizational characteristics and resource dependence come to influence the institution's peer group characteristics and that peer group characteristics go on to influence student culture, persistence, and outcomes. Therefore, Titus' (2006) framework suggests that institutional selection of students is a purposeful behavior influenced by resource dependence and government disinvestment. Titus (2006) in consort with Doyle (2010) suggests that institutional aid is a mechanism through which the institution can influence socioeconomic and demographic makeup of the student body thus influencing student peer groups which informs student success. Therefore, measurements of student race and socioeconomic status (need) will inform institutional priorities that go beyond merit as a criteria for access.

\section{The Links Between Academic Capitalism and Resource Dependence}

As institutional aid is a direct mechanism through which institutions can ease the costs of student higher education endured by students in light of government investment, investigation of institutional aid recipients help us to understand what customer inputs (Cheslock et. al., 2018) and latent student demands (Doyle, 2010) it values most. Therefore, in response to government 
disinvestment, institutions will engage in "market or marketlike efforts to secure external moneys” (Slaughter and Leslie, 1997, p. 8). More specifically, previous research (Jaquette and Curs, 2015) suggested that institutions will engage in enrollment management strategies (McPherson and Schapiro, 1998) that employ institutional financial aid as a strategy for securing desirable student constituencies (Doyle, 2010) necessary for the institution to conduct its critical business and seek out its goals.

\section{Mapping of Important Variables for Analysis}

As the institution studied in this dissertation is a public research university, previous work by Jaquette and Curs (2015) suggested that these institutions will engage in academic capitalism (Slaughter and Leslie 1997; Slaughter and Rhoades 2004) to offset state disinvestment and explore other avenues to increase institutional revenue streams (Cheslock and Gianneschi, 2008) through increased nonresident enrollment. To operationalize residency, I created a dichotomous variable to differentiate between students who pay out-of-state rates for tuition and fees regardless of physical residency. This measure captures possible instances where institutional aid is awarded to nonresident students in an attempt to monetize nonresident students (Jaquette and Curs, 2015). Furthermore, as public universities increased their enrollment of nonresidents when faced with state appropriation cuts (Jaquette and Curs, 2015), this may suggest that the institution may offer institutional aid to nonresidents in an effort to maximize net tuition under similar circumstances.

Institutional goals, however, may extend beyond monetization and tuition maximization. Therefore, longitudinal assessment of student constituencies within the institution who enroll and receive institutional aid provide insights into the customer input technologies (Cheslock et. al., 2018) that the institution deems important to carrying out its goals and may not be, overtly, 
financial in nature. As customer input technologies via students often includes their academic aptitude to perform well in a higher education setting, I operationalize pre-college academic aptitude through standardized test scores such as the Scholastic Aptitude Test (SAT) and the American College Testing (ACT) exam along with high school GPA. To inform institutional aid awards as a function of student academic quality, I replicated an institutional measure used in the admissions process that concords all standardized test scores to the ACT while incorporating high school GPA into a singular numerical measure. This Student Quality Index Score (SQIS) allows for an apples to apples and longitudinal comparison of student pre-college academic characteristics across the different testing metrics (See Chapter 3).

In conclusion, the various measures advanced by this theoretical framework allow for a rich comprehensive longitudinal analysis of how socioeconomic, demographic, and academic aptitude dimensions come to confluence in understanding institutional aid recipients over time at an institution constrained by a need for resources.

\section{Synthesis of Major Works Reviewed in the Literature Review}

Slaughter and Leslie (1997) - Academic Capitalism and Faculty Work

A key point of Slaughter and Leslie's (1997) contribution to the discussion of academic capitalism was the overall effect of how these various economic and political modalities tended to affect faculty work, the faculty labor force, and faculty behavior while removing the insulation faculty enjoyed from competition in the global marketplace. As the government changed how it incentivized research, it changed the incentives for faculty to engage in research, instead of a focus on research generation regarding topics the researcher found to be intellectually stimulating or for the sake of pure knowledge generation was supplanted by the ability of the knowledge to link up with the economy. As globalization forced companies to innovate and 
provide new products on the global marketplace to be relevant and profitable, the ability of the professoriate to connect with the economy and away from pure knowledge generation for its own sake shifted the intellectual impetus for knowledge generation: "The shift occurred because the corporate quest for new products converged with faculty and institutional searches for increased funding" (Slaughter and Leslie, 1997, p. 7). Although knowledge generation and its potential to link up with the new economy are not mutually exclusive ideas, the new policies provided greater incentives for the knowledge generation that met public and/or private needs. It is these incentives that influence professorial behavior and reinforce the loop between applicable knowledge generation and the gathering of scarce resources (e.g., grant dollars).

\section{Continued Pivots of Institutional Role and Faculty Work in the New Economy}

In linking up with the "new" or "global" economy the authors suggested that a new examination of the relationship between higher education institutions and societal institutions was necessary where we "move beyond thinking of the student as consumer to considering the institution as marketer (Slaughter and Rhoades, 2004, p. 1). The authors also suggested that "knowledge is a critical raw material to be mined and extracted from any unprotected site, patented, copyrighted, trademarked, or held as a trade secret; then sold in the marketplace for profit" (Slaughter and Rhoades, 2004, p. 1). Knowledge, as the authors term it, is not exclusive to professorial research. Critical to their own writing, the authors demonstrate that that knowledge generation has shifted away from a "public good learning regime to an academic capitalist/learning regime" (Slaughter and Rhoades, 2004, p. 8). This shift signals a fundamental change to the incentives as well as the source of the incentives and how the profit motive encouraged institutions to develop internal mechanisms and capacities to "market products created by faculty and develop commercializable products outside of (though connected to) 
conventional academic structures and individual faculty members” (Slaughter and Rhoades, 2004, p. 11).

Therefore, we see a continued shift away from academic capitalism as a lens through which we can only understand changes to faculty behavior to one that allows us to view institutional changes as well. For example, the authors suggested that institutional professionals and bureaucracies who are "initiating academic capitalism, [and] not just as players being 'corporatized' (Slaughter and Rhoades, 2007, p. 12). As a result, academic capitalism has expanded beyond professorial behavior and the re-alignment of research priorities to institutional behavior regarding the stability and future reliability of its resource mix. However, the growing share of the institutional resource mix has typically stemmed from increases to tuition - I repeat the following excerpt from Slaughter and Rhoades (2004) because of its importance: "The greatest increase in shares of institutional funds has come through raising tuition" (p.12) which also hones the student as a consumer's mindset.

As the consciousness of consumerism is realized for both students, parents, and the administration, it is logical to infer that institutional behavior that appeals to the student as a consumer, may be a deliberate act of engaging in academic capitalism. As a result, tuition discounting or the awarding of institutional aid is an attempt by the institution to mitigate consumer concerns. In other words, institutional investment - as evidenced by yearly appropriations of institutional aid and its relative growth over time - offers evidence that institutional aid is an embedded institutional tool to help it compete in the academic marketplace for the raw materials (i.e. students, grant funding, other links to the new economy) it deems necessary to carry out its purpose or mission. As a result, preferences as to who receives this attention and resources offers further evidence of institutional goals and its commitment to 
further embeddedness of the institutional aid apparatus. However, resource dependent institutions do not have infinite resources and, thus, institutions cannot give an unlimited amount of awards; also, institutional resources are not always certain and are subject to disruption.

Slaughter and Rhoades (2004) suggested that resource disruptions - more specifically, government resource disruptions in the form of appropriations to higher education institutions have, historically, been temporary. The authors assert further that government disinvestment is not incremental but episodic. Whereas an overall decrease in government support over the course of ten years may be considered episodic, it may also be incremental. In other words, incremental changes can occur within an episodic change and the degree to which these terms influence one another may be a semantical discussion. For example, a $1 \%$ decrease each year is an incremental decrease over a ten-year episode of disinvestment - each individual year is an incremental change within the ten-year period, or episode. Although the change was incremental over the period of ten years, the period is an overall episode of government disinvestment. Here, an episode may be described as a longer period of smaller time-period increments. In light of their assertion, and the longitudinal disinvestment of Appalachian institutions as asserted in Chapter 1 of this dissertation, I am able to examine Slaughter and Rhoades' (2004) assertion that government resource depletion is episodic and incremental while also providing for contextual observations of institutional behavior (via institutional aid awards) to engage in market and marketlike behaviors to secure new resource providers.

\section{Academic Capitalism and Resource Dependence - The Link}

The academic capitalism literature suggests that institutions will act in accordance with resource dependence to link their behaviors, processes, and products to their environment (or economy) to secure the resources they need to pursue their goals. It also suggests that institutions 
will attempt to develop the capacity to be receptive to opportunities of academic capitalism as well as actively engage in seeking partnerships that limit uncertainty and meet the needs of their resource providers (Slaughter and Leslie, 1997; Slaughter and Rhoades, 2004; Pfeffer and Salancik, 1978). This strand of literature suggests that institutions are active participants in academic capitalism and will seek out resources for their own sake as well as resource partnerships with resource providers.

\section{Other Resource Dead Ends}

In a similar vein, Cheslock and Gianneschi (2008) explored institutional ability to secure donor funds as a replacement to state disinvestment yet found no evidence to reliably suggest that this practice is a suitable replacement. As a result, further investigations into institutional behavior that seek to understand how institutions replace needed resources are warranted. Although universities may attempt to fill the void of state disinvestment with research profiteering and other market-like activities, strategies to increase and secure resources through tuition tend to be the preferred source of revenue growth (Jaquette and Curs, 2015, Cheslock and Gianneschi, 2008; Slaughter and Leslie, 1997). Institutions, however, cannot go back to the same metaphorical well as higher education demand is not perfectly inelastic.

\section{Jaquette and Curs (2015) - Three Strategies for Resource Provider Partnerships}

To that end, Jaquette and Curs (2015) suggested that institutions would seek to increase their out-of-state enrollment in order to replace state investment. Jaquette and Curs (2015) demonstrated that some universities will adapt and move to create greater revenue through ventures in academic capitalism to secure greater nonresident enrollment and increase net-tuition revenue. As institutions strive for predictability, survival, and autonomy, institutions will adapt strategies to accomplish those tasks when the resource provider relationship changes (Pfeffer and 
Salancik, 1978) or declines (Davis and Cobb, 2009). Enrollment management practices are designed to increase stability and predictability of student enrollments and tuition revenues. To frame the resource dependency concept from an organizational standpoint, Jaquette and Curs (2015) suggest three different strategies institutions may engage in to resolve conflicts between the institution and their resource providers: compliance, cooptation, and resource diversification. The compliance strategy involves organizational attention and agreement to new requests or demands from the resource provider in an effort to appease. Cooptation involves inviting external resource providers into the organizational fray for advisory purposes. Diversification occurs when organizations attempt to secure new resource providers because the current resource provider relationship has soured (Pfeffer and Salancik, 1978). Institutional aid provides for an investigation into the organizational strategy to diversify or concentrate its resources in a manner that indicates institutional preferences of student constituencies for reasons numerous reasons that may include the forwarding of societal interests such as increasing equity of access or meritorious endeavors to secure the best and most capable students.

Distinctly different from Jaquette and Curs (2015), this dissertation examines studentlevel observations of socioeconomic, demographic, and financial aid packages that include the full breadth of financial awards given to a student in a year from multiple sources that include the federal government, state government, and institutional aid. I am also able calculate needmeeting and non-need-meeting aid variables for each student, a variable missing from the Jaquette and Curs (2015) study. Also, the timeline that I study allows for student-level observations of institutional data both before and after the recession of 2009-10 with more recent data to include student observations through the Fall of 2016-17 whereas Jaquette and Curs (2015) end their evaluation with data from 2012-13. 
Given the prominence of the growth in institutional aid (The College Board, 2017), it is also quite possible that institutional aid may emerge as an institutional mechanism through which institutions can mitigate the effect of government disinvestment and the ensuing costs that are passed on to the student (Webber, 2017). Doyle (2010) suggests that institutional aid is a means through which we can understand institutional latent demand for student constituencies. Doyle (2010) also suggests that institutional aid is critical to understand from a public policy standpoint. For example, in a direct appeal to policymakers on the issue of institutional aid, Doyle (2010) called for them to "gather more information about how public colleges are using their institutional aid. The (sic) should then decide on the basis of that information if they are satisfied with the way institutional aid is being distributed" (p. 808).

Questions pertaining to how aid is distributed are of paramount importance to both researchers and administrators interested in the fair, equitable, and just dispensation of financial aid dollars. However, institutions also compete for students and this competition may result in disparities of resource allocations. Previous work by Heller (2001) demonstrated the disparities in the awards for need-based and non-need-based aid awards in the context of gender and race from 1989 to 1995 . This dissertation advances Heller's (2001) contribution through detailed investigation of student-level observations for a longer-time period with more recent data and allows for multivariate regression analysis to control for student level awards by race/ethnicity and gender, whereas Heller (2001) investigated the probability of receiving an institutional aid award.

\section{Key Contributions}

This dissertation seizes the opportunity to empirically examine over 52,108 unique observations of institutional aid awards over a period of 11 first-time freshmen cohorts both pre 
and post Great Recession at a major research university. As it is situated within a single institution, it also has great advantage over previous studies of institutional aid (Heller, 2001;

Cheslock et. al. 2018) to examine changes to institutional aid awarding behavior over time. Heller's (2001) contribution utilized nationally representative samples from two separate surveys encompassing only two survey years of 1989-90 and 1995-96. This dissertation offers a substantially increased timeline of 11 cohorts of administrative data that contains not only institutional aid awards, but calculated assessments of individual student financial need, expected family contribution, academic aptitude, first-generation status, Pell recipiency, residency, and underrepresented minority status.

Although Heller (2001) does contribute a wealth of knowledge to understanding institutional aid awards as it pertains to various student and institutional dimensions such as race, gender, institutional type, and mother's educational attainment, it does not specifically engage in first-generation status, student residency as it pertains to fees, pre-college academic characteristics such as high school GPA or standardized test scores (other than SAT), or underrepresented minorities and Asian populations as disaggregated categories in his multivariate or logistic regression analyses. Heller's (2001) research does not, nor was it intended to, delve into institutional resource considerations as a theoretical backdrop undergirding institutional decision-making in the process of awarding institutional aid. Instead, Heller's (2001) contribution was an empirical investigation as to which students receive what aid award, how those aid awards have changed from 1989-90 to 1995-96, and predictive analytics of who is more likely to receive aid awards. Like Heller (2001), this dissertation employs regression analysis to gauge change over time in both the amounts and probabilities of receiving an institutional aid award. However, the data used in this dissertation presents a more contemporary 
and longitudinal approach allowing for greater comparison and analysis of changes to institutional aid awarding behavior over time at a single institution. Although I do lose the ability to gauge institutional aid award change over time across institutional types, I gain greater clarity and specificity in understanding how resource constraints act upon a major research university contextual clues that are missing from the Heller (2001) examination. To that end and dissimilar to Heller (2001), this dissertation offers a theoretical framework to understand how institutional context and resource constraints may also inform the institutional motives in the distribution of institutional aid.

Cheslock et. al. (2018) set out to propose new vocabulary to add greater clarity and specificity to our understanding of institutional aid with the inclusion of incidental and intentional need-meeting aid. To measure intentional and incidental need-meeting aid, the authors Cheslock et. al. (2018) specifically mention the "stratified nature of the NPSAS urvey data" as a limitation to their study. As this dissertation does not rely on survey weights or any other methodologies to quantify a nationally representative sample, potential problems stemming from such challenges are eliminated thus improving the approach taken by Cheslock et. al. (2018). As a single institution study, this dissertation also does not have to contend with within inter-institutional relationships further stressing the implied results of their tobit models as discussed in the Cheslock et. al. (2018) study. Also, like Heller (2001), Cheslock et. al. (2018) utilized NPSAS data, but for more recent years (2007-08 and 2011-12). As such, both studies are grounded heavily in the methodology of the NPSAS. Although similarities in the data are not inherently problematic because the NPSAS provides a source of replicable and stable methodologies and data over time, this dissertation provides a comprehensive evaluation of 
administrative data that is not bound by the strictures of the NPSAS dataset and stands as another body of data to test various hypothesis and findings found in the literature.

Jaquette and Curs (2010) argued that institutions will seek out-of-state students in an effort to offset government disinvestment. However, the outcome they measured, out-of-state enrollments, is wholly different than institutional aid awards. Although their approach does lend evidence to the academic capitalism through the lens of monetizing students, specific institutional behaviors that may deliver out-of-state enrollment require greater discussion. This dissertation forwards their resource dependence conceptual framework (Pfeffer and Salancik, 1978) to institutional aid awards and suggests that institutional aid awards are another behavior through which organizations seek to offset government disinvestment and enroll specific student constituencies. Jaquette and Curs (2015) focused on the enrollment management activities of universities to recruit out-of-state students who pay higher net-tuition than in-state students to offset government disinvestment. In other words, the authors focused on the larger behavior of the institution to enroll out-of-state students in order to garner greater shares of net-tuition per student, but do not necessarily identify institutional mechanisms through which this is achieved.

Current research supported by the Joyce Foundation and conducted by Han, Jaquette, and Salazar (2019) have analyzed off-campus recruiting events (e.g. colleges visiting local high schools) and college admissions websites to gain a greater understanding of how public research universities target specific high school student constituencies. The authors assert: "knowing which student populations are targeted by university recruiting efforts can yield insights about university enrollment priorities" (Han, Jaquette, and Salazar (2019, p. 1). As students are critical inputs to institutional priorities, this dissertation offers institutional aid awards as a potential 
mechanism that the institution can utilize to achieve the goals (e.g. greater net-tuition per student) set forth in Jaquette and Curs (2015). 


\section{Chapter 3: Data and Methods}

This dissertation will comprehensively examine and analyze a student-level dataset of a large, public, research university in Appalachia. Observations are first-time full-time freshmen enrolling in the fall term (including previous summer enrollments) of each academic year from 2005-06 to 2015-16. In total, 52,108 first-time freshmen (FTF) are examined. Data include demographic information such as student gender, state of residency, first-generation status, and racial identity. Financial variables are also examined that include institutional aid, expected family contribution (EFC), federal subsidized and unsubsidized loans, and Pell grants all gleaned from a student's Free Application for Federal Student Aid (FAFSA).

\section{Analysis Period}

This dissertation examines a longitudinal dataset of eleven first-time full-time freshmen cohorts from 2005-06 to 2015-16 at a major research university in Appalachia. The period chosen for analysis was largely determined by the availability of student data. Data for this dissertation stemmed from two major sources within the institution. First, all student data relating to demographics, residency, and student quality stem from the institution's official reporting files established for the purposes of state and federal oversight and follow the specifications set forth by the state reporting body. Second, all student data regarding financial aid stem from the institution's internal financial aid files used for various reporting needs that include local, state, and federal governments, internal constituents, and external stakeholders such as ranking organizations, accrediting bodies, and the board of governors.

As the level of observation used for this dissertation is student-level, the final dataset was de-identified to ensure compliance with applicable federal, state, and local laws as well as Institutional Review Board preferences, policies, and procedures. Racial identity was used to 
create amalgamated race categories as racial categories of students containing less than or equal to approximately 25 students were omitted as individual categories for privacy concerns. Races were combined into the following categories: White, Asian, and underrepresented minorities (URM). As student financial aid data stem from the Free Application for Federal Student Aid and international students do not necessarily complete this application with regularity at the institution, the student population was also limited to U.S. citizens to control for the availability of financial aid data and biased results that exist for omitted nonresident alien students.

\section{Independent Variables}

The framework for this dissertation suggests that institutions may engage in academic capitalism as a means to confront constrained resources brought on through state disinvestment. We can contextualize the understanding of institutional resource provisioning if we understand the impact of an institution's external resources. In other words, if we know the financial factors that are acting on the institution - in this case resource dependency - we can deduce that the institution will strategize to meet its goals and secure the resources it needs (Pfeffer and Salancik, 1978). The immediate challenges to the institution are continued government disinvestment and threats to volume enrollment strategies as indicated by the WICHE report and Chapter 1. Therefore, using the resource-dependence framework of Pfeffer and Salancik (1978), I can operationalize the behavior of the institution through its provisioning of institutional financial aid. Institutional aid allows us to examine the institution's behavior to entice the enrollment of students with various desirable characteristics. To accomplish that task and according to Heller (2001) and Jaquette and Curs (2015) we need to understand student financial need, student academic ability, demographics, and residency status). To operationalize financial need I use various financial categories such as the student's cost of attendance, expected total 
family contribution (EFC), federal grants (e.g. Pell), state grants (both merit and need) and any other grants or scholarships the student receives. Previous work by Cheslock et. al., 2018) suggested that any funding requiring repayment (e.g. loans) or labor in exchange for aid (e.g. federal work study) should not be used in determining student need as they are generally used to fill unmet need after institutional offerings, federal grants, and other scholarships are considered.

Measures of student quality include high school grade point average (GPA), SAT and ACT scores as well as a concordance of SAT scores to ACT to compare student quality over time and across the two different aptitude tests. As the College Board has changed their concordance with the ACT (twice) and overall scoring rubric at least once during the course of the years investigated for this study, scores were converted longitudinally to a 1600-point scale and concorded to an ACT to allow for comparisons between and among the two different testtakers over-time. It is important to note that unless otherwise noted, SAT scores that were concorded to the ACT, were scores stemming from the newest 2018 concordance changes to the SAT. In other words, the scores used for analysis in this dissertation are scores that have been concorded to the new SAT, and, as a result, are slightly higher than the "old" scoring method 80 points on average.

Furthermore, to provide for a mathematical score attributable to student quality over time that can account for changes to both ACT and SAT, the researcher recreated a Student Quality Index Score (SQIS) that combines standardized test scores and high school GPA into a single comparable value and has been used by the institution to award merit-based scholarship dollars. The SQIS serves as a standardized measure of student quality by using the entering characteristics of the 2010 FTFTF cohort as a benchmark. 
Racial categories include American Indian, Asian, Black, Hawaiian, Hispanic, multiracial, nonresident, unknown, and White. Prior to 2009, IPEDS did not disaggregate the racial category Pacific Islander from the Asian population. As the institutional files used to prepare the dataset for this dissertation were constructed to comply with federal race reporting requirements, prior to 2009, students in the Pacific Islander category were considered Asian. However, post 2009, they received their own racial category. Furthermore, the Family Education Rights and Privacy Act of 1974 (FERPA) provides greater privacy to individuals regarding their educational record and rightfully so. As a result, however, reporting the results of students from historically small (e.g. low frequency counts) populations present potential conflicts to student privacy. Racial categories were collapsed into three major categories: white, underrepresented minorities, and Asian students.

Residency is coded as binary, in-state or out-of-state, and in accordance with relevant reciprocity agreements between the organization and other institutions. In other words, if the student is geographically out of state, but belongs to a demographic that has a reciprocity agreement with the institution, those students will likely enjoy deep discounts similar to in-state tuition at their resident institution. Those students along with those students who physically reside within the institution's home state will be considered residents - all others are nonresidents. Categorizing students in this manner allows the researcher to accurately capture out-of-state students that pay out-of-state rates as opposed to a mixture of out-of-state ratepayers and out-of-state students paying considerably less net-tuition through reciprocity agreements. First-generation status is coded yes for students where at least one parent does not have a highest degree attainment of at least a bachelor's degree. 


\section{Dependent Variable}

The main dependent variables examined in this dissertation are institutional amounts awarded to students on the apparent basis of merit and/or need. However, pointed discussion in the higher education financial aid literature suggest that categorization of aid into institutional defined categories of need and merit-aid may obscure the actual impact of the aid for an individual student (Cheslock et. al. 2018). Since there are disparities in the financial circumstances of the student body, controlling for how the institutional aid materially aids the student is critical to calculate. For example, institutional aid that is provided to a student on the basis of merit but helps reduce student need might be considered a need-based award or needmeeting aid. When an individual receives a merit-based award and that amount is in excess of student need, the aid may be considered aid that is in addition to need or non-need meeting aid.

Using non-need meeting aid and need-meeting aid calculations allow for the researcher to control for possible misnomers in the institutional labeling of a specific type of aid and, instead, allows the researcher to mathematically identify the effect of the aid as opposed to semantics of the aid type. It is also important to convey that the data regarding institutional aid is not actual dollars awarded to a student but are monetary discounts the student receives as a condition of enrollment. In other words, the student does not actually receive any cash, only a monetary award that serves as a discount to the student in exchange for their enrollment. Athletic scholarships are not included in the construction of the merit-based aid variable. As the needbased institutional aid variable is constructed by the institution and objective criteria required to meet the threshold for the institutional need aid are not readily available, constructing needmeeting and non-need meeting aid adds considerable leverage to contextualizing the impact of institutional aid awards. 
As institutions are constrained by their need for resources, my theoretical framework suggests that it is possible for need-meeting and non-need meeting aid to be driven towards students of a pedigree the institution prefers. Need-meeting aid is likely to be targeted toward students with demonstrated pre-institutional need and non-need meeting aid will likely be driven toward students with attractive academic credentials. As an institutional strategy, targeting institutional aid towards students with need may induce their enrollment where the institution is attempting to entice enrollment of a student who may not attend otherwise without institutional aid. Institutional strategies that grant institutional aid that is non-need-meeting may provide insights into institutional goals and desires to entice student constituencies of greater academic prowess to fulfill institutional needs beyond net-tuition maximization. Establishing evidence between institutional aid and student type are of primary interest to this dissertation. Through regression analysis, a goal of this dissertation is to understand how institutional aid is distributed as a function of the student's financial need while also controlling for academic quality such as high school GPA and standardized test score performance through the SQIS score and how the awarding changes over time as a function of the institutions financial environment.

To adequately calculate need-meeting aid or non-need-meeting aid, I must first demonstrate how individual student need is calculated. Need will be equal to the difference of the total cost of attendance for the student based upon their residency and the summation of their expected total family contribution (EFC) and any federal or state grants (see Measure 1). The resulting difference is the amount of money the student must secure, through other sources of financial aid such as work study, federal, state, or private loans etc.

Expected family contribution is a value calculated by the institution and is largely codified by law (for more see reference list for The EFC Formula, 2018-2019. (n.d.)). Grants the 
student receives may be from numerous sources. For this dissertation, the main source of grants stem from the federal government Pell program or the state government through its merit based and need-based grant programs. Institutional aid that meets need is calculated using a logical sequence of measurements that include the student's calculated need and the amount of grant dollars they receive. On the one hand, need-meeting aid, is calculated as the sum of all grants a student received if the sum of those grants is equal to or less than their need (see Measure 2A). On the other hand, need-meeting aid is calculated as the student's need if the sum of their grants is greater than the student's need (see Measure 2B). If either of the conditions for Measures 2A or $2 \mathrm{~B}$ are met, the institutional aid awarded is need-meeting aid. Institutional aid that is nonneed-meeting aid is calculated in a similar fashion. Non-need-meeting aid is equal to zero if the sum of the student's total grant awards from all sources are less than or equal to their need (see Measure 3A). Similarly, non-need meeting aid is equal to the difference of the sum of all grants the student received from all sources and their need if the sum of all their grant funding from all sources is greater than their need (see Measure 3B). Values that are less than zero are coded to reflect zero as their value.

Measure 1: Need $=\left(\right.$ Cost of Attendance $-\sum$ (Expected Family Contribution $+\sum$ (Federal Grants + State Grants + Other Grants))

Measure 2A: Need-Meeting Aid $=\sum$ Grants IF $\sum$ Grants $<=$ Need

Measure 2B: Need-Meeting Aid = Need IF $\sum$ Grants $>$ Need

Measure 3A: Non-Need-Meeting Aid = IF $\sum$ Grants $<=$ Need then Non-Need Meeting Aid $=0$

Measure 3B: Non-Need-Meeting Aid $=\left(\sum\right.$ Grants - Need $)$ IF $\left(\sum\right.$ Grants $>$ Need $)$ 
Together, measures one through 3B will be used in conjunction with other socioeconomic, demographic, and student academic variables to estimate their relationships with institutional aid awards per student and will be discussed in the following methodology section

\section{Methodology Introduction}

Using SAS enterprise guide, I was able to connect directly to university databases. To ensure the data is of the highest quality, and more importantly, accurate, files used for this dissertation are files compiled for use in official federal and state reporting for the institution at study. The files used to compile and aggregate the data examined here, are those files used by the institution to populate any and all federal reporting requirements such as IPEDS as well as external ranking organizations such as U.S. News and World Report, The Princeton Review, and the S\&P500. Furthermore, these institutional files are also used for university governance and administrative decision-making highlighting the importance of their use for official reporting purposes as well as overall university stewardship.

Statistical methods for this dissertation will focus on regression analysis and summary statistics. Multivariate regression analysis via ordinary least squares and tobit transformations will be used in conjunction with summary statistics to tease out relationships between my dependent variable (institutional aid) and control variables relating to student demographics, socioeconomic status, and academic quality. Unique to my approach is the use of a rolling window regression (Zivot and Wang, 2006) that pools three years of data into the regression model to provide for robust estimations

\section{Model Specification}

As resource dependency influences the behavior of enrollment dependent institutions to pursue greater participation in academic capitalism through the monetization of students 
(Jaquette and Curs (2015), the resource dependency of these institutions is also likely to be exacerbated by state disinvestment. As state disinvestment pushes institutions to privatize, and since privatization increases tuition (Webber, 2017), students may also become more selective in the institutions to which they enroll thus forcing institutions to be more strategic in their enrollment management operations and the provisioning of their institutional aid - a reality that is further compounded through a decrease to college-eligible high school students as evidenced by the WICHE report. As a result, institutional disbursement of funds through institutional aid also known as the organization's behavior - may be funneled to select populations the institution finds attractive in order to maximize the net tuition calculus or serve other institutional goals such as ensuring equity of access. To examine the relationship between the student's offering of institutional as a function of demographic, socioeconomic, and academic aptitude, I offer Equation 1.

\section{$\underline{\text { Equation 1: }}$}

$$
Y_{i}=f\left(\alpha_{i}, \beta A_{i}, \gamma D_{i}, \delta R_{i}, £ N_{i}, \varepsilon_{i}\right)
$$

The dependent variable $Y$ is equal to the total dollar amount of the institutional aid award. $A$ is a measure that quantifies pre-college academic characteristics such as high school GPA and standardized test scores as measured by the Student Quality Index Score (SQIS). The variable $D$ is a vector of demographic variables such as the student's race, gender, and first-generation status. The $R$ variable represents student residency and is based off the institutional agreement that is used to determine the students cost of attendance. The $N$ variable is a vector of student financial characteristics such as need and socioeconomic status. The $\varepsilon_{1}$ variable represents the error term of the specified model whereas $\alpha_{i}, \beta_{1}, \gamma_{1}, \delta_{1}, £_{1}$ represent the coefficients to be 
estimated by the regression model. This equation will highly inform Research Questions 1, 2, and 3.

To examine need meeting aid awards, I replace the independent variable $\mathrm{Y}_{1}$ with needmeeting aid. All control variables remain the same. Longitudinal examination of the coefficients produced for student academic quality, gender, race, and residency status will be used to investigate potential changes in the institutional behavior to the awarding of need-meeting aid and will inform Research Questions 1, 2, and 3.

\section{Methodological Strategy}

A longitudinal analysis of the coefficients for awarded institutional aid will be the primary means through which we can understand and evaluate any systematic changes to institutional aid. For example, comparing the coefficients over time, such as their effect size and their statistical significance, will offer some evidence as to the awarding behavior of institutional aid over time and will inform the discussion and conclusions for research question one. Longitudinal examination of regression coefficients after controlling for a student's pre-college need will be informative for research question two. Changes to coefficients over time that control for the student's need will provide evidence for changing priorities in the institutional provisioning of its for students of financial need and will offer a sensitivity check to institutional aid awards over time that control for student need. Coefficient effect size and statistical significance for the institutional aid awards for nonresident students along with summary statistics of aid awards will also provide evidence for exploring research questions 1, 2, and 3.

Tobit regression will be employed to account for the censored nature of the student data. The data is censored because the students receive two "answers" with respect to the institutional aid question. The first question is: Do they receive an aid award? The second question is: How 
much is the aid award? As students who receive an institutional aid award always have a value that is non-zero whereas non-recipients have a zero or null value and are considered censored values because we can observe the other exogenous variables (Amemiya, 1984). Since students cannot receive a negative aid award, the data is censored and the linearity assumption of ordinary least squares regression (Berry, 1993) is violated which could lead to inaccurate estimates (Amemiya, 1984). To correct for the censored nature of the data, Tobit regressions are employed. In addition to estimating individual coefficients, I also intend to pool the first three years of data $(2005,2006$, and 2007) into a single regression and continuing this measurement for subsequent years in the dataset. I will refer to this as a rolling window regression where three years in sequence are pooled together. For example, as the first sequence starts with the first three years in the dataset $(2005,2006$, and 2007), the second window will drop the first year (2005) and start with the second year $(2006,2007,2008)$. This sequence will repeat until the final window is created $(2013,2014,2015)$. The pooled nature of the rolling window regressions allows for the researcher to combine similarly situated students over longer time periods to control for variability in institutional behaviors in the doling out of institutional aid. Stimson (1985) suggested: "Pooling data gathered across both units and time points can be an extraordinarily robust research design, allowing the study of causal dynamics across multiple cases, where the potential cause may even appear at different times in different cases" (p. 916). Furthermore, by increasing the sample size in the rolling window regressions, I increase the statistical power of the tests - as well as decrease the standard errors - and further increase the likelihood of finding relationships between the explanatory variables and the independent variable. 


\section{Study Limitations}

Although institutional aid packages awarded to enrolled students have explanatory power and leverage in explaining institutional behavior, potential limitations to the dataset include issues of data availability. For example, I am only able to measure the financial and academic profiles of students who enrolled at the institution instead of all students who applied, admitted, and/or enrolled. Although it would be beneficial to evaluate students who received aid or did not receive aid and their requisite decision to enroll or not to enroll as well as the institutional aid awards offered to these students based upon observable characteristics, it is important to consider that what I lose in scope of institutional aid awards, I gain in the richness and longitudinal nature of the multi-cohort dataset of student-level observations. Students may also receive institutional financial aid awards for extra-curricular activities, volunteering, civic engagement or other activities that are not captured by the data. Students may also receive financial considerations for being a legacy student (e.g. a relative or other special alumni) or students who enter with recommendations by donors or from the university's foundation.

Pre-college characteristics, student demographics, and financial aid variables examined in this dissertation are constructed using rigorous and replicable methods. However, there are variables of interest omitted due to limitations of available data from institutional databases. Other variables such as locus of control, student expectations, student goals, student integration, and student wellness are not considered as covariates - chiefly due to a lack of availability of the data for the years examined. Further research into the applications of student financial aid, student success, and student outcomes should attempt to gather information regarding student expectations and agency. 
High school GPA is a value reported by the student on their application and bolstered by high school transcripts that demonstrated the relative success the student experienced in high school. In this dissertation, high school GPAs are capped at a 4.0. However, not all high schools are created equal and not all high schools use a 4.0 scale. Thus, some high schools are more rigorous than others introducing some ambiguity to the high school GPA measure. As a result, it is difficult to control for grade inflation that may exist between different high school institutions. It is also difficult to control for variations in high school rigor. For example, various programs such as the College Board's Advanced Placement (AP) or ubiquitous dual enrollment programs where students enroll in college-courses in lieu of high school coursework - often scale grades differently to account for their difficulty and time commitment. As a result, student GPAs may earn a GPA in excess of a 4.0. Therefore, it is possible for a student who received an 4.0 in regular high-school coursework to be considered equivalent to a student who received above a 4.0 for dual-enrollment and or advanced placement courses. Although the students are both in high school and have received an "A" average, the resulting GPA does not control for individualized coursework rigor.

In the construction of various variables, the researcher had to make decisions regarding categorization of various student attributes. For example, first-generation student status was decided using information from the student's financial aid file. Data from the financial aid file is preferred by the institution for determining first generation status because there is an assumption that financial aid data is most likely completed by parents on behalf of the student. The financial aid application asks the parent to define their highest grade of education achieved. The institution defines first-generation status as neither parent having earned a bachelor's degree. Fields with no response are indicated as "unknown", whereas fields indicating anything other than education 
equal to or higher than a bachelor's degree is considered "Yes" for first-generation students. In other words, null responses equate to an unknown first-generation status unless one of the parents has earned a bachelor's degree. In other words, without evidence to the affirmative of first-generation status - where both fields of the parent are not null and each indicates a parent higher education less than a bachelor's degree, the student is not considered a first-generation student thus introducing some risk of committing a Type I error in applying the first generation status. Type I errors result when the rejection criteria necessary to reject the null hypothesis- the $p$ value in a regression, for example - is so demanding, that the researcher does not reject the null hypothesis where in fact she should.

Also, in cases of divorce where one parent achieved a bachelor's degree and the other did not, there is no way to know, according to the data, with which parent the student lives. Although a parent may have achieved a bachelor's degree, if the student does not live with that parent, the beneficial socialization that would otherwise occur, does not. The same is essentially true for students of a deceased parent or parents if the death occurred before the socialization can occur. The current dataset does allow for observations of institutional aid packaging from 2005 to 2015 allowing for tremendous robustness in controlling for the Great Recession of 2009-10. Having approximately four years pre-recession and another six to seven years post-recession provides for temporal, economic, as well as historical context in evaluating the data. 


\section{Chapter 4: Results}

To establish a better understanding of the data, this section first discusses trends of overall enrollment by residency, student quality, and race. As the timeline of observation for this dissertation covers FTFTF cohorts from 2005 to 2015, a better understanding of the overall trends in the growth of enrollment provide greater context for understanding the institution's enrollment landscape (see Figure 4.1). Overall enrollment for the institution has experienced volatile ebbs and flows to its stream of FTFTF. For example, from 2005 to 2009, the institution netted a $1 \%$ increase to its overall enrollment with gains of 5\% from 2005 to 2006 and $8.4 \%$ from 2007 to 2008 , but a large loss from 2008 to 2009 of $10.3 \%$ - leading up to the Great Recession. From 2009 to 2010, however, the tides turned and a large influx of approximately 430 students bolstered overall enrollment gains by $9.6 \%$ over the previous year. Enrollment again to levels lower than 2005 to 2009 as the overall net growth was .8\% averaging just .1\% in average annual growth.

Figure 4.2 demonstrates the patterns of overall enrollment by residency. The middle of Figure 4.2 would indicate a fair and even split between the in-state and out-of-state students. In other words, if the trendlines were tightly clustered around the middle of the graph, the trends would indicate that in-state and out-of-state students share a similar and equitable share of the overall enrollment at the institution. In 2005 and 2006, in-state and out-of-state students shared a relatively similar proportion of the overall FTFTF student body. However, these values begin to diverge quickly in 2007 to 2008, contract slightly in 2008 and continuing a path of separation from 2009 to 2012, contracting again from 2012 to 2013 and reaches a new equilibrium in 2013 that holds relatively steady through 2015. Throughout this analysis period, the share of in-state students decreased from $49.6 \%$ in 2005 to $46.4 \%$ an overall decrease in share of $3.2 \%$. Out-of- 
state students went from a proportional share of $50.4 \%$ in 2005 to $53.6 \%$ in 2015 for an overall increase $2.9 \%$. Overall, in-state students averaged $46.7 \%$ and out-of-state students averaged $53.3 \%$ of the overall institutional student body.

The proportion of in-state and out-of-state students were not the only systematic changes that occurred at the institution during the time of study. Tuition and fees were also adjusted to accommodate the changing needs of the institution. I combined both tuition and fees into a singular value (see Figure 17 3) to plot changes in institutional charges for in-state and out-ofstate students. In-state and out-of-state students shared similar increases to their overall fee and tuition structure from 2005-06 to 2008-9, however, the fee structures changed to favor out of-ofstate-students from 2009 to the end of my study. In fact, from 2005-06 to 2015-16, in-state students saw an average growth of $5.8 \%$ average annual increases to their tuition and fees whereas out-of-state students experienced a 5.0\% average annual increase. As the institution is a public land-grant institution funded by state taxpayer dollars, it is also important to mention that in-state students pay substantially less in tuition and fees when compared to out-of-state students. For example, in 2005 in-state students paid a total of $\$ 4,476$ and out-of-state students paid $\$ 12,874$. In 2015, in-state students paid \$7,992 (91.9\% increase from 2005) and in-state students paid $\$ 22,488$ (74.7\% increase from 2005$)$.

\section{Student Pre-College Academics}

This section will examine the pre-college academic characteristics of the institutions entering FTFTF classes. Table 4.1 contains summary statistics for all FTFTF from 2005-06 and 2015-16 and are presented in a tabular format so that comparisons can be easily made between the first year of the dataset and the last. For in-state students, the average high school GPA has increased slightly from 3.51 in 2005 to 3.60 in 2015 (see Table 4.1 and Figure 4.7). Out-of-state 
students in 2005 had an average high school GPA of 3.14 whereas they had a 3.34 average in 2015. Both in-state and out-of-state students share an upward trend of measures for academic quality from 2005 to 2015 (see Table 4.1 and Figure 4.10). In-state students experienced mode increases to their average SQIS from 105.3 to 108.3 whereas out-of-state students demonstrated a much larger increase of six points from 93.8 to 99.5 (see Table 4.1). As all standardized test scores are concorded according to specifications from the College Board which includes all older SAT scores converted to the newest SAT concordance (as of July 2019), and are then concorded to ACT (see Table 4.1 and Figures 21 and 22). The test scores provided and examined are a robust longitudinal measure of student aptitude. As the SQIS score incorporates both high school GPA and standardized testing into its calculation, any appreciable change to the score may be attributed to an overall increase in student aptitude and/or academic quality. The trend for SQIS (see Figure 24) indicates in-state students have historically trended around the 102 to 105 mark. Out-of-state students have been steadily gaining ground from their ten-year average low point of below 94 in 2006 to scores at or above 100 from 2013 to 2015. Overall, students with a SQIS of 113 or higher were in Quartile 4 of the SQIS (the highest performing quartile), higher than 100 but less than 113 were in Quartile 3, higher than 87 but less than 100 comprised Quartile 2 and all other test scores - including missing test scores - were combined into the lowest performing quartile, Quartile 1.

As the SQIS is calculated as a longitudinal measure that combines high school GPA and overall standardized test scores of the 2010 cohort as a benchmark, the SQIS can be used as a proxy for measuring the overall academic makeup of entering FTFTF each year. quartile were 
Figure 4.1: Institutional Enrollment by Year and Residency

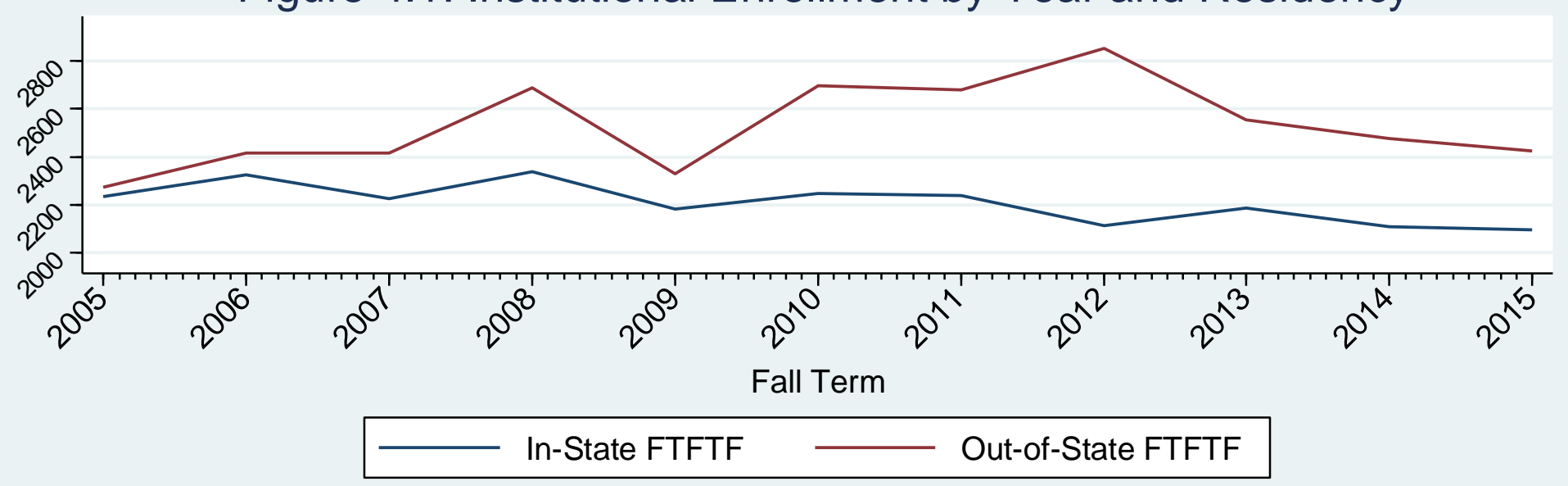

Figure 4.2: Proportional Total Enrollment by Year and Residency

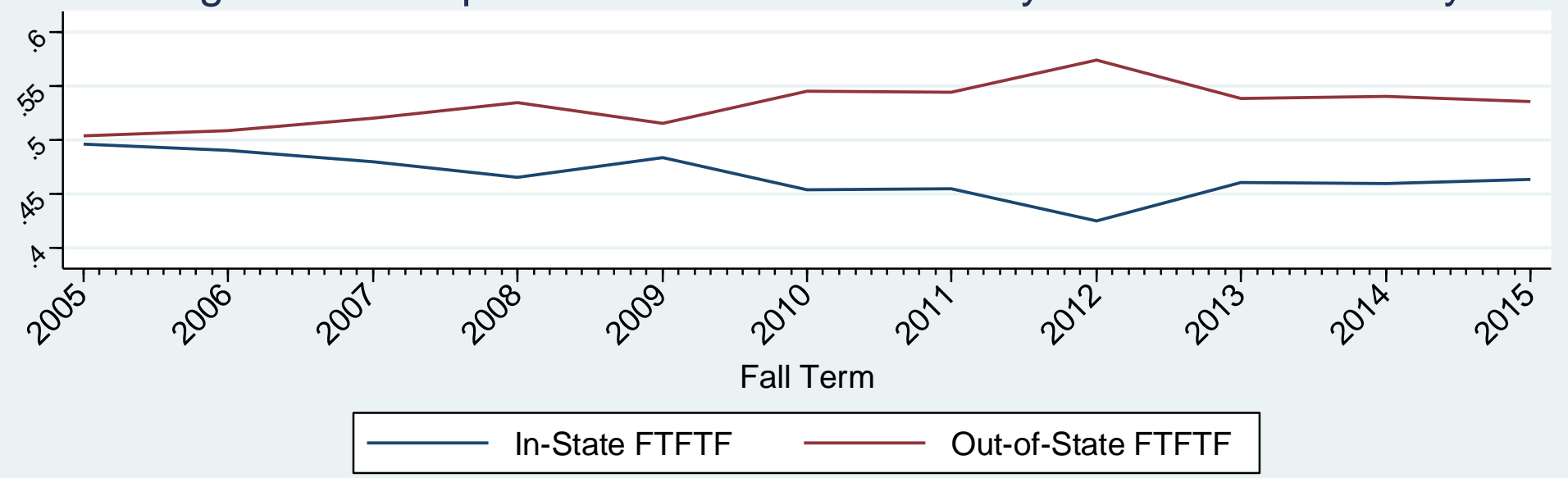


Table 4.1: Comparison Table of Summary Statistics for 2005-06 and 2015-06 FTFTF by Residency

2005-06 - In-State Students

\begin{tabular}{lrrrrr}
\multicolumn{1}{c}{ Variable } & \multicolumn{1}{c}{$\begin{array}{l}\text { Std. } \\
\text { Obs }\end{array}$} & \multicolumn{1}{c}{ Mean } & \multicolumn{1}{c}{ Dev. } & \multicolumn{1}{c}{ Max } \\
\hline High School GPA & 2003 & 3.51 & 0.46 & 1.71 & 4.00 \\
Sat Combined Scores & 308 & 1129.68 & 146.02 & 790.00 & 1540.00 \\
Concorded ACT & 1987 & 23.68 & 3.90 & 15.00 & 35.00 \\
SQIS & 1987 & 105.31 & 17.42 & 55.00 & 146.00 \\
EFC & 2003 & 15.89 & 19.65 & 0.00 & 100.00 \\
ACT Composite Score & 1679 & 23.47 & 3.82 & 15.00 & 35.00 \\
Need Meeting IA & 2003 & 11.45 & 166.73 & 0.00 & 5000.00 \\
Non-Need-Meeting IA & 2003 & 1189.29 & 1400.97 & 0.00 & 12800.00 \\
Aggregate IA & 2003 & 1200.74 & 1406.78 & 0.00 & 12800.00
\end{tabular}

2005-06 Out-of-State Students

\begin{tabular}{lrrrrr}
\multicolumn{1}{c}{ Variable } & Obs & \multicolumn{1}{c}{ Mean } & \multicolumn{1}{c}{$\begin{array}{l}\text { Dev. } \\
\text { Dev }\end{array}$} & \multicolumn{1}{c}{ Max } \\
\hline High School GPA & 1713 & 3.14 & 0.49 & 2.00 & 4.00 \\
Sat Combined Scores & 1455 & 1037.72 & 122.00 & 710.00 & 1600.00 \\
Concorded ACT & 1713 & 22.25 & 3.47 & 14.00 & 36.00 \\
SQIS & 1713 & 93.81 & 16.13 & 50.00 & 149.00 \\
EFC & 1713 & 17.66 & 18.05 & 0.00 & 100.00 \\
ACT Composite Score & 258 & 22.49 & 3.43 & 16.00 & 33.00 \\
Need Meeting IA & 1713 & 741.85 & 1665.85 & 0.00 & 8842.00 \\
Non-Need-Meeting IA & 1713 & 1263.17 & 3027.99 & 0.00 & 27556.00 \\
Aggregate IA & 1713 & 2005.02 & 3371.99 & 0.00 & 27556.00
\end{tabular}

* IA = Institutional Aid

* Student groups are limited to those in the annual tobit

regressions.

* Missing student SQIS scores were combined with students in the first quartile.
2015-16 - In-State Students

\begin{tabular}{lrrrrr|rr}
\multicolumn{1}{c}{ Variable } & \multicolumn{1}{c}{$\begin{array}{c}\text { Std. } \\
\text { Obs }\end{array}$} & \multicolumn{1}{c}{ Mean } & \multicolumn{1}{c}{ Dev. } & \multicolumn{1}{c}{ Min } & \multicolumn{1}{c}{ Max } & $\begin{array}{c}\Delta \text { in } \\
\text { Mean }\end{array}$ & $\begin{array}{c}\text { \% } \Delta \text { in } \\
\text { Mean }\end{array}$ \\
\hline High School GPA & 2061 & 3.60 & 0.44 & 1.98 & 4.00 & 0.09 & $2.51 \%$ \\
Sat Combined Scores & 143 & 1119.72 & 154.37 & 750.00 & 1520.00 & -9.95 & $-0.89 \%$ \\
Concorded ACT & 2057 & 24.15 & 3.86 & 13.00 & 35.00 & 0.47 & $1.96 \%$ \\
SQIS & 2054 & 108.27 & 16.89 & 48.00 & 146.00 & 2.97 & $2.74 \%$ \\
EFC & 2065 & 20.36 & 28.03 & 0.00 & 207.14 & 4.47 & $21.96 \%$ \\
ACT Composite Score & 1914 & 24.12 & 3.83 & 13.00 & 35.00 & 0.65 & $2.70 \%$ \\
Need Meeting IA & 2065 & 73.64 & 752.20 & 0.00 & 14500.00 & 62.19 & $84.45 \%$ \\
Non-Need-Meeting IA & 2065 & 2190.54 & 2165.09 & 0.00 & 28000.00 & 1001.25 & $45.71 \%$ \\
Aggregate IA & 2065 & 2264.18 & 2262.94 & 0.00 & 28000.00 & 1063.44 & $46.97 \%$
\end{tabular}

2015-16 Out-of-State Students

\begin{tabular}{lrrrrr|rr}
\multicolumn{1}{c}{ Variable } & Obs & \multicolumn{1}{c}{ Mean } & \multicolumn{1}{c}{$\begin{array}{l}\text { Std. } \\
\text { Dev. }\end{array}$} & \multicolumn{1}{c}{ Min } & \multicolumn{1}{c}{ Max } & $\begin{array}{c}\Delta \text { in } \\
\text { Mean }\end{array}$ & $\begin{array}{c}\% \text { in } \\
\text { Mean }\end{array}$ \\
\hline High School GPA & 2101 & 3.34 & 0.47 & 2.11 & 4.00 & 0.20 & $6.48 \%$ \\
Sat Combined Scores & 1365 & 1038.92 & 132.52 & 720.00 & 1480.00 & 1.20 & $0.12 \%$ \\
Concorded ACT & 2098 & 22.82 & 3.89 & 14.00 & 34.00 & 0.57 & $2.49 \%$ \\
SQIS & 2098 & 99.45 & 17.42 & 53.00 & 143.00 & 5.63 & $5.67 \%$ \\
EFC & 2101 & 24.41 & 28.74 & 0.00 & 207.61 & 6.76 & $27.67 \%$ \\
ACT Composite Score & 733 & 23.90 & 3.90 & 15.00 & 34.00 & 1.41 & $5.90 \%$ \\
Need Meeting IA & 2101 & 2504.97 & 4754.80 & 0.00 & 16250.00 & 1763.12 & $70.38 \%$ \\
Non-Need-Meeting IA & 2101 & 4362.61 & 6859.83 & 0.00 & 34000.00 & 3099.44 & $71.05 \%$ \\
Aggregate IA & 2101 & 6867.59 & 8312.52 & 0.00 & 36000.00 & 4862.56 & $70.80 \%$
\end{tabular}


those students with an EFC of $\$ 26,674$; both values for both years exceed the total cost of attendance to attend the institution for a full year as an in-state students. Out-of-state students had a median EFC of $\$ 12,774$ in 2005 and a median EFC of $\$ 16,148$ in 2015. Students in the highest quartile for 2005 had an EFC of $\$ 24,870$ and $\$ 34,196$ in 2015. For out-of-state students,

but less than 100 were Quartile 2, and all other students with a reported SQIS score of below 100 were considered to be in Quartile 1 (the lowest performing quartile).

\section{Student Finances}

Student Total Expected Family Contribution (EFC) is a primary indicator of a student's family financial resources and greatly informs the overall financial aid package offered to the student by the school for each student (see Table 4.1 and Figure 4.6). As EFC accounts for the cost of attendance in its calculation and since out-of-state students pay a higher cost of attendance at a public state university, it is natural to see out-of-state EFCs be somewhat higher than in-state EFCS all else equal. In 2005, the mean EFC was $\$ 15,891$ and \$20,361 in 2015 for in-state students - a $28.1 \%$ increase. The median EFC (not pictured) for 2005 was $\$ 9,639$ and was $\$ 11,332$ in 2015 for out-of-state students. Students in the highest quartile of EFC were those the median values for EFC fell short of their total cost of attendance. Therefore, without further aid for out-of-state students in the median EFC, those out-of-state students with an EFC equal to or greater than $\$ 20,350$ whereas out of state student's in highest students will have unmet need and may ultimately serve as an impediment to enrollment, a need to take on more federal or state loan debt, secure funds from other sources such as private corporations or lenders or become a candidate for institutional aid. Financial need for students was highly correlated with student residency for fees. Recalling that student need was calculated as the cost of attendance minus the sum of the student's total expected family contribution (EFC), federal Pell grants, state grants or 

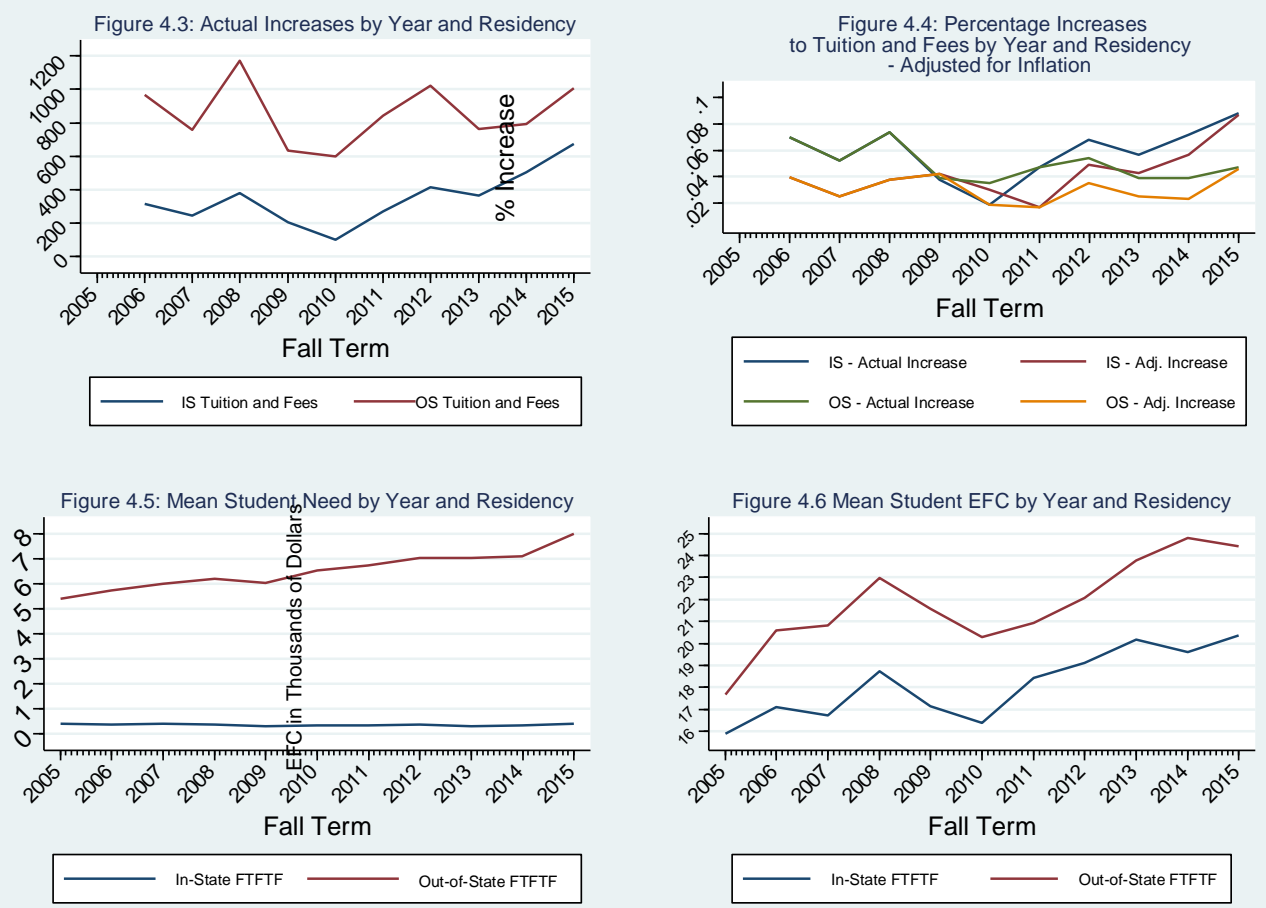

Figure 4.7: High School GPA of FTFTF by Residency

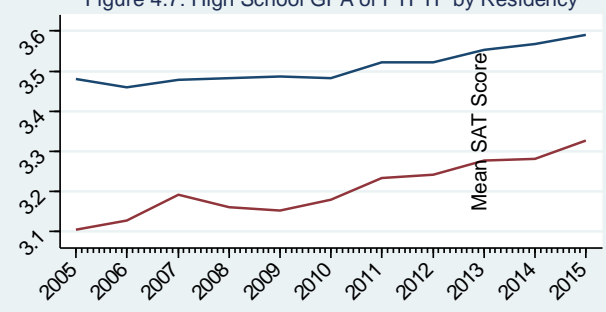

Fall Term

In-State FTFTF -Out-of-State FTFTF



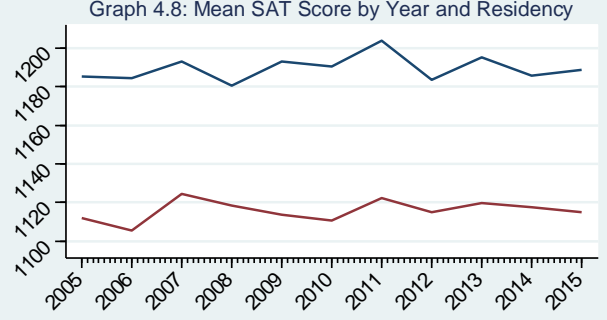

Fall Term

In-State FTFTF — Out-of-State FTFTF

Figure 4.10: Mean Student Quality Index Score (SQIS) by Year and Residency





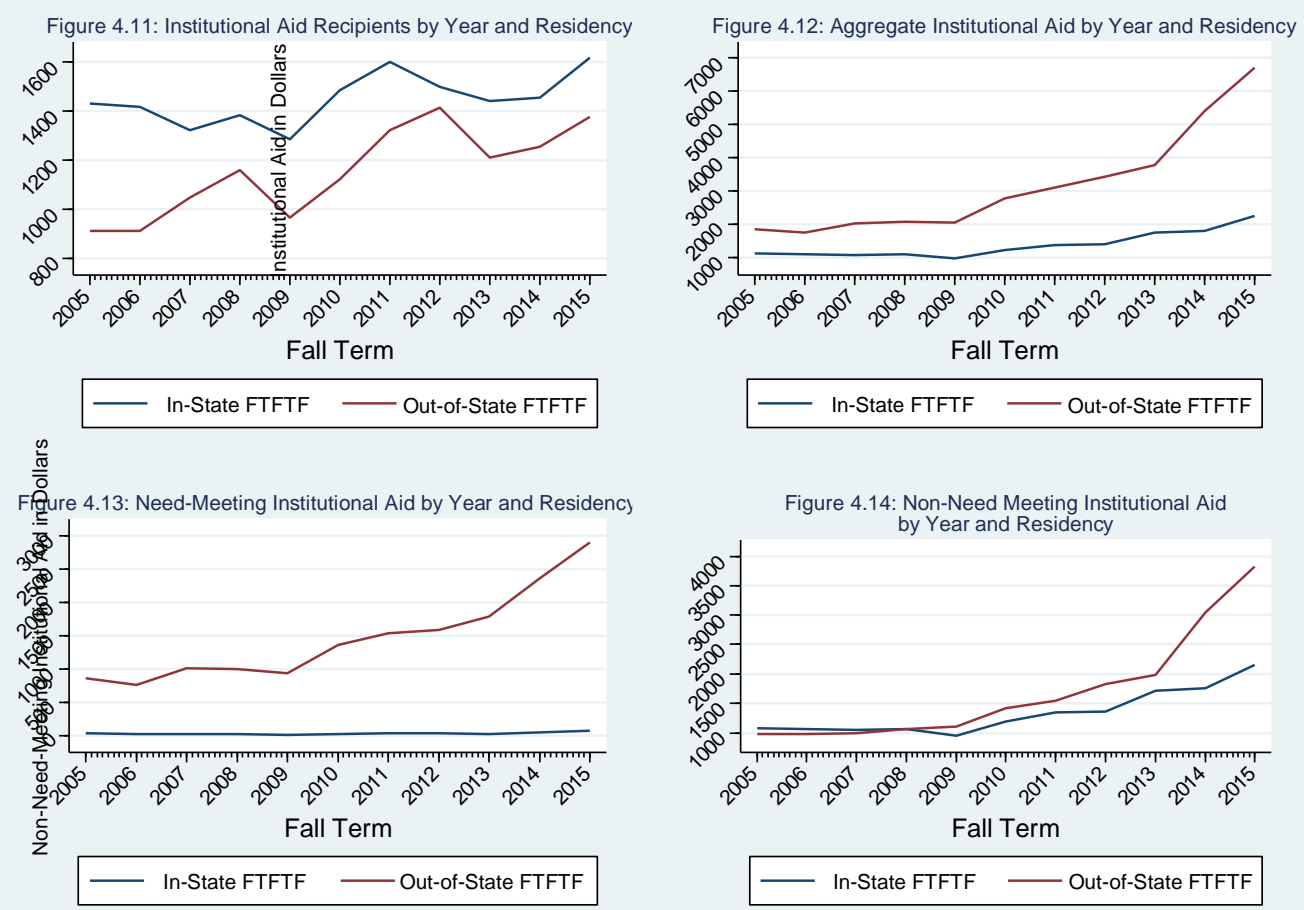

aid, and any other remaining grants or scholarships, student need provides a broad indication of a student's average cost that must be met in order to attend college. Furthermore, the need calculation is what also helps to translate the underlying purpose (need-meeting or non-nonneed-meeting) of institutional aid that will be discussed later.

Table 4.2 Proportion and Mean Need of Students With Demonstrated Need by Residency

\begin{tabular}{|cccc|cc|}
\hline \multirow{2}{*}{ Year } & \multicolumn{2}{c|}{ Proportion of Students With Need > } & \multicolumn{2}{c|}{ Mean Need of Students With Need >0 } \\
\cline { 2 - 6 } & IS & OS & Total & Mean Need IS & Mean Need OS \\
\hline $\mathbf{2 0 0 5}$ & $8.44 \%$ & $58.84 \%$ & $27.13 \%$ & 1001.36 & 6354.32 \\
$\mathbf{2 0 0 6}$ & $8.52 \%$ & $56.37 \%$ & $26.01 \%$ & 1117.49 & 7060.11 \\
$\mathbf{2 0 0 7}$ & $6.92 \%$ & $56.06 \%$ & $26.47 \%$ & 1300.42 & 6980.03 \\
$\mathbf{2 0 0 8}$ & $5.42 \%$ & $51.06 \%$ & $24.94 \%$ & 1860.55 & 7932.83 \\
$\mathbf{2 0 0 9}$ & $2.09 \%$ & $50.65 \%$ & $24.54 \%$ & 2830.70 & 8650.69 \\
$\mathbf{2 0 1 0}$ & $2.88 \%$ & $55.50 \%$ & $28.78 \%$ & 2739.72 & 9050.33 \\
$\mathbf{2 0 1 1}$ & $5.35 \%$ & $58.30 \%$ & $29.88 \%$ & 2271.51 & 9090.00 \\
$\mathbf{2 0 1 2}$ & $6.24 \%$ & $58.44 \%$ & $31.76 \%$ & 2727.63 & 9087.12 \\
$\mathbf{2 0 1 3}$ & $6.40 \%$ & $64.17 \%$ & $32.23 \%$ & 2553.96 & 9760.64 \\
$\mathbf{2 0 1 4}$ & $6.40 \%$ & $58.99 \%$ & $30.16 \%$ & 2870.02 & 10181.38 \\
$\mathbf{2 0 1 5}$ & $6.68 \%$ & $60.45 \%$ & $30.48 \%$ & 3736.87 & 11455.77 \\
\hline
\end{tabular}

*As proportions of each group. 
Student need is plotted in thousands of dollars (see Figure 4.5). The student need trend for in-state students is relatively flat and indicates that the student need (in thousands of dollars) trends between zero and $\$ 1,000$ for the course of the study. In 2005, the average need for in-state students was \$303 and was \$410 in 2015 - a 35.3\% increase. Out-of-state students had a mean need of $\$ 5,397$ in 2005 and a mean need of $\$ 7,968$ in 2015 - a $47.6 \%$ increase. Table 4.2 provides data and analysis regarding the average proportion of need found within the in-state population as well as the out-of-state populations as well as the percentage of the overall FTFTF classes that have financial need in excess of $\$ 0$ dollars. On average, $5.94 \%$ of in-state students have a financial need that is in excess of $\$ 0$, whereas and average of $57.17 \%$ of students in the out-of-state cohort have financial need in excess of $\$ 0$. The mean need of in-state students with a need greater than $\$ 0$ dollars is $\$ 2,819$ and $\$ 8,610$ four out-of-state students.

\section{Institutional Aid Awards - Aggregate}

Institutional aid values for cohort changes between 2005 and 2015 will be discussed in this section (see Table 4.3) and will also be converted to real 2015 dollars using the consumer price index. In 2005 , the institution awarded a total of $\$ 8,111,088$ dollars to a total of 2,345 students for an average in-state award of $\$ 2,128$, and average out-of-state award of $\$ 5,546$, and an overall average award of $\$ 3,459$. Ten years later, the institution increased its overall spending on institutional aid in the aggregate to $\$ 25,416,318$ (a $213.4 \%$ increase from 2005) with an instate average award of $\$ 3,523$ (a $65.5 \%$ increase from 2005), an average out-of-state award of $\$ 14,334$ (a $158.5 \%$ increase from 2005) and an overall average total award of $\$ 8,495$ (a $145.6 \%$ increase from 2005). The total number of awards in 2015 increased from 2,345 to 2,992 for a $27.6 \%$ increase in overall awards with in-state awards increasing by $12.8 \%$ from 1,432 to 1,616 and out-of-state awards increasing by $50.7 \%$ from 913 to 1,376. In the aggregate, in-state aid 
spending increased by $86.8 \%$ from $\$ 3.04$ million to $\$ 5.69$ million, out-of-state spending increased by $289.5 \%$ from $\$ 5.06$ million to $\$ 19.7$, and overall spending by $213.4 \%$ from $\$ 8.1$ million to $\$ 25.4$ million.

Table 4.3: Frequency Distribution of Institutional Awards by Institutional Aid Typology

\begin{tabular}{|c|c|c|c|c|c|c|}
\hline \multicolumn{7}{|c|}{ Aggregate Institutional Aid Awards } \\
\hline & Total & Total IS & Total OS & AVG IS & AVG OS & AVG TOTAL \\
\hline & Awards & Awards & Awards & AWARD & AWARD & AWARD \\
\hline 2005 & 2345 & 1432 & 913 & 2128 & 5546 & 3459 \\
\hline 2015 & 2992 & 1616 & 1376 & 3523 & 14334 & 8495 \\
\hline$\Delta$ & $27.6 \%$ & $12.8 \%$ & $50.7 \%$ & $65.5 \%$ & $158.5 \%$ & $145.6 \%$ \\
\hline \multicolumn{7}{|c|}{ Need-Meeting Institutional Aid Awards } \\
\hline & Total & Total IS & Total OS & AVG IS & AVG OS & AVG TOTAL \\
\hline & Awards & Awards & Awards & AWARD & AWARD & AWARD \\
\hline 2005 & 624 & 89 & 535 & 1203 & 4454 & 3990 \\
\hline 2015 & 839 & 66 & 773 & 3072 & 10993 & 10370 \\
\hline$\Delta$ & $34.5 \%$ & $-25.8 \%$ & $44.5 \%$ & $155.4 \%$ & $146.8 \%$ & $159.9 \%$ \\
\hline \multicolumn{7}{|c|}{ Non-Need-Meeting Institutional Aid Awards } \\
\hline & Total & Total IS & Total OS & AVG IS & AVG OS & AVG TOTAL \\
\hline & Awards & Awards & Awards & AWARD & AWARD & AWARD \\
\hline 2005 & 1882 & 1387 & 495 & 2120 & 5416 & 2987 \\
\hline 2015 & 2571 & 1574 & 997 & 3488 & 11260 & 6502 \\
\hline$\Delta$ & $36.6 \%$ & $13.5 \%$ & $101.4 \%$ & $64.5 \%$ & $107.9 \%$ & $117.7 \%$ \\
\hline
\end{tabular}

The total number of need-meeting institutional aid grants increased by $34.5 \%$ from 624 in 2005 to 839 in 2015 (see table 4.3). In-state grants did not see growth from 2005 to 2015 as the total number of need-meeting in-state grants went from 89 total awards to 66 for a $25.8 \%$ decrease but the total value of in-state grants did increase by $89.4 \%$ from $\$ 107,048$ to $\$ 202,758$. Out-of-state need-meeting aid increased in both frequency and overall investment as the frequency increased by $44.5 \%$ from 535 to 773 and investment increased from $\$ 2.38$ million to $\$ 8.5$ million for a $256.6 \%$ increase. The institutional also increased its overall investment in need-meeting institutional aid from $\$ 2.49$ million to $\$ 8.7$ million for a $249.4 \%$ overall increase 
with both the average aid awards increasing for in-state students from \$1,203 to \$3,072 (155.4\% increase) and out-of-state students from $\$ 4,454$, to $\$ 10,993$ (146.8\% increase).

Non-need-meeting aid also experienced growth across all award totals (see Table 4.3). The total number of non-need-meeting aid awards increased from 1,882 to 2,571 for a $36.6 \%$ increase with the average total aid award also increasing from $\$ 2,987$ to $\$ 6502$ (an increase of $117.7 \%$ ). The average in-state award increased from $\$ 2,120$ to $\$ 3,488$ (an increase of $64.5 \%$ ) and the average out-of-state non-need-meeting award increased by $107.9 \%$ from $\$ 5,416$ to $\$ 11,260$. Total in-state and out-of-state non-need-meeting aid awards increased in frequency by $13.5 \%$ and $101.4 \%$, up from 1,387 to 1574 and 495 to 995 respectively. Out-of-state students received a $318.8 \%$ increase to their overall aid pool as students in 2005 received \$2.7 million in 2005 and $\$ 11.2$ million in 2005. In-state students also experienced growth to their overall non-needmeeting aid pool as the total institutional aid invested for non-need-meeting in-state student aid increased by $86.7 \%$ from $\$ 2.9$ million to $\$ 5.5$ million.

\section{Results and IPEDS Benchmarks}

To add greater validity to the data examined here, I have prepared Table 3 to demonstrate similarities and differences found between the data I have collected for this dissertation and values that were reported to the Integrated Post-Secondary Data System (IPEDS) by the institution as required by Federal law. As Table 4.4 indicates, the average aid awards for students who are US citizens are smaller than the average aid award of students included in the IPEDS cohort (i.e. all first-time freshmen degree/certificate seeking undergraduates.) However, it is important to recognize that the population of students I have examined in this dissertation includes only first-time full-time freshmen and US citizens. Data submitted to IPEDS would include both non-full-time students and non-citizens as well as certificate seeking students. As a 
result and as indicated by Table 4.4, the total number of grants and the average grant examined in this dissertation are less than those reported to IPEDS for all years represented in the table. Furthermore, the percentage of all first-time freshmen receiving an institutional grant award is lower for the dissertation population indicating that non-citizens and non-full-time students make up at least another one to two percent of the institutional grant-aid population.

Although the total amounts awarded for first-time full-time freshmen in this dissertation are higher than those reported to IPEDS, potential reasons may include a front-loading of the financial aid package in the fall semester that covers the rest of the student's academic year, which may also include spring, and summer aid. However, it is also critical to point out that maximum Pell values are correct for each year, especially when considering the possibility of supplemental Pell grants that range between $\$ 100$ and $\$ 4,000$ for eligible students adding further veracity to the dissertation's data and results.

It may also be possible that the financial aid office prepares separate queries for institutional aid calculations that do not capture institutional aid in the fashion demonstrated in this dissertation. This could be an opportunity for the university to examine their institutional aid querying and reporting practices to ensure proper calculation of institutional aid awards are being captured and reported to the federal government in a manner that demonstrates the full reach of institutional aid awards. As a further result, it may also provide additional opportunities to highlight institutional willingness to aid financially conscious students and parents who may require institutional aid as a condition of enrollment as the values examined here surpass the values self-reported by the institution. 
Table 4.4: Benchmarking of Integrated Post-Secondary Education Data System Values and Dissertation Findings

\begin{tabular}{|c|c|c|c|c|c|c|c|c|c|c|c|c|}
\hline \multirow[b]{3}{*}{ Year } & \multicolumn{12}{|c|}{ Comparison of IPEDS Values and Research Findings } \\
\hline & \multicolumn{4}{|c|}{ IPEDS } & \multicolumn{8}{|c|}{ Dissertation } \\
\hline & $\begin{array}{c}\text { Average } \\
\text { Grant }\end{array}$ & $\begin{array}{c}\text { Total } \\
\text { Awards } \\
\text { to FTF }\end{array}$ & $\begin{array}{l}\text { Count } \\
\text { of } \\
\text { Grants } \\
\text { to FTF }\end{array}$ & $\begin{array}{c}\% \text { of } \\
\text { Grants } \\
\text { Given to } \\
\text { FTF }\end{array}$ & $\begin{array}{c}\text { Average } \\
\text { Grant }\end{array}$ & $\Delta$ & $\begin{array}{l}\text { Total } \\
\text { Awards to } \\
\text { FTF }\end{array}$ & $\Delta$ & $\begin{array}{c}\text { Count } \\
\text { of } \\
\text { Grants } \\
\text { to FTF }\end{array}$ & $\Delta$ & $\begin{array}{c}\% \text { of } \\
\text { Grants } \\
\text { Given to } \\
\text { FTFTF }\end{array}$ & $\Delta$ \\
\hline 2011 & 3376 & 10239661 & 3033 & $61 \%$ & 3883 & 507 & 11349960 & 1110299 & 2923 & -110 & $59 \%$ & $-2 \%$ \\
\hline 2012 & 3820 & 11646577 & 3049 & $60 \%$ & 4360 & 540 & 12688223 & 1041646 & 2910 & -139 & $59 \%$ & $-1 \%$ \\
\hline 2013 & 4338 & 12098872 & 2789 & $57 \%$ & 5086 & 748 & 13484986 & 1386114 & 2651 & -138 & $56 \%$ & $-1 \%$ \\
\hline 2014 & 4948 & 14226507 & 2875 & $59 \%$ & 6335 & 1387 & 17180994 & 2954487 & 2712 & -163 & $59 \%$ & $0 \%$ \\
\hline 2015 & 4843 & 15142993 & 3127 & $66 \%$ & 7000 & 2157 & 20942831 & 5799838 & 2992 & -135 & $66 \%$ & $0 \%$ \\
\hline Total & 4265 & 12670922 & 2974.6 & $61 \%$ & 5332.8 & 1067.8 & 15129398.8 & 2458476.8 & 2837.6 & -137 & $60 \%$ & $-1 \%$ \\
\hline
\end{tabular}




\section{Multivariate Analysis}

Two major types of results are presented in this section. The first are marginal effects for the probability of a student receiving an institutional aid award (see Table 4.5). The second are the marginal effects (or average) institutional aid award for students who received an institutional aid award while all other explanatory values are held at their means (see Table 4.6). The regression results will be discussed in the aggregate (Tables 4.7 and 4.8) and then as needmeeting aid awards (Tables 4.9 and 4.10) and then non-need meeting aid awards (Tables 4.11 and 4.12) for both the dollar amounts and the probabilities marginal effects results. All full regression tables with the transformed coefficients (i.e. marginal effects) and standard errors are located at the end of this section (Appendix Tables $1-15$ ). Ordinary Least Squares Regressions and the Tobit Regressions are included in the appendix of this dissertation with untransformed coefficients. The first two tables (Tables 4.5 and 4.6) provided in this section offer quick references to the change over time in the amount of in both the probability of receiving an institutional aid award as well as the average institutional aid award a student received, along with controls, in the earliest years of the pooled data (2005-07) to the final years in the dataset (2013-15). The data is presented in three-year pooled segments to increase the robustness of my estimates by decreasing the size of my standard errors. The table values for the categorical variables first generation, SQIS Quartiles two through four, Pell Recipients, and Gender, are presented relative to their respective reference categories. For example, the values for SQIS quartiles two through four are presented relative to the SQIS Quartile 1 references group; firstgeneration is compared to non-first-generation students; non-Pell recipients are the reference group for Pell Recipients; residents are the reference category for nonresidents; non 
underrepresented minorities are the reference group for underrepresented minorities; Males are the reference category for females.

In the aggregate, the probability of receiving an institutional aid award was $104.4 \%$ percentage points higher for students in the highest quartile of the SQIS (Quartile 4) in 2005 when compared to the lowest SQIS (Quartile1) in 2005. The probability increased to $132 \%$ percentage points higher for Quartile 4 students to receive an institutional aid award in the aggregate when compared to Quartile 1 students in 2015 - a result that is highly significant for each year of the regression $(\mathrm{p}<.001)$. The values for Quartiles 3 and Quartile 2 also, on average, have a greater probability of receiving an institutional aid award in the aggregate by $82 \%$ and $102 \%$ when compared to Quartile 1 students.

Student need is a highly significant predictor of receiving an institutional aid award for seven of the pooled years in the study, but the overall effect is highly dependent on the level of need the student has. For example, as the coefficient is positive and highly significant (for all pooled regressions), it suggests that the probability of receiving an institutional aid award increases by $1 \%$ point for every one thousand dollars of need relative to an individual with no need. Figures representing the longitudinal change in student need for aggregate, need-meeting and non-need-meeting aid can be found in Figures 4.16, 4.20, 4.24, 4.28, 4.32, and 4.36.

Institutional aid awards in the aggregate are also conditional on the student's residency. Figures representing the longitudinal change in the coefficients for nonresident students can be found in figures $4.17,4.21,4.25,4.29,4.33$, and 4.37 . The probability of receiving an institutional aid for nonresident students was $30.5 \%$ in 2005 when compared to nonresident students. In 2015, the probability of nonresidents receiving an institutional aid award increased again when compared to in-state students by $55.8 \%$ points. Initially, under-represented minority 
students had a higher probability of receiving an institutional aid award when compared to nonunderrepresented minority students by $4.4 \%$ points, however, this trend reversed in 2015 as these students were $4.1 \%$ points less likely than non-underrepresented minorities to receive an Table 4.5: Longitudinal Comparison of Pooled Regression Results - (ME) Probabilities

\begin{tabular}{|c|c|c|c|c|c|c|c|c|c|}
\hline \multicolumn{10}{|c|}{ Pooled Regression Results - Marginal Effects, Probability of Receiving an Aid Award } \\
\hline & \multicolumn{2}{|c|}{ Aggregate } & \multicolumn{4}{|c|}{ Need-Meeting } & \multicolumn{2}{|c|}{ Non-Need-Meeting } & \\
\hline & 2005-07 & 2013-15 & $\Delta$ & 2005-07 & 2013-15 & $\Delta$ & 2005-07 & 2013-15 & $\Delta$ \\
\hline First Generation & -0.01 & 0.00 & $0.90 \%$ & $0.00 \%$ & $0.00 \%$ & $0.00 \%$ & $-1.00 \%$ & $0.00 \%$ & $1.00 \%$ \\
\hline SQIS Quartile 2 & 0.434 & 0.601 & $16.70 \%$ & $0.00 \%$ & $0.80 \%$ & $0.80 \%$ & $35.00 \%$ & $58.00 \%$ & $23.00 \%$ \\
\hline SQIS Quartile 3 & 0.82 & 1.022 & $20.20 \%$ & $0.00 \%$ & $1.30 \%$ & $1.30 \%$ & $68.00 \%$ & $98.00 \%$ & $30.00 \%$ \\
\hline SQIS Quartile 4 & 1.044 & 1.323 & $27.90 \%$ & $0.00 \%$ & $1.40 \%$ & $1.40 \%$ & $90.00 \%$ & $131.00 \%$ & $41.00 \%$ \\
\hline Student EFC & -0.001 & 0 & $0.10 \%$ & $0.00 \%$ & $-0.10 \%$ & $-0.10 \%$ & $-0.10 \%$ & $0.00 \%$ & $0.10 \%$ \\
\hline Student Need & 0.002 & 0.007 & $0.50 \%$ & $0.00 \%$ & $0.00 \%$ & $0.00 \%$ & $-10.00 \%$ & $-6.00 \%$ & $4.00 \%$ \\
\hline Pell Recipients & -0.02 & -0.01 & $1.50 \%$ & $0.00 \%$ & $-0.40 \%$ & $-0.40 \%$ & $-2.50 \%$ & $-1.00 \%$ & $1.50 \%$ \\
\hline Female & 0.016 & -0.024 & $-4.00 \%$ & $0.00 \%$ & $0.00 \%$ & $0.00 \%$ & $1.00 \%$ & $-2.00 \%$ & $-3.00 \%$ \\
\hline Nonresidents & 0.305 & 0.558 & $25.30 \%$ & $0.00 \%$ & $1.40 \%$ & $1.40 \%$ & $27.00 \%$ & $62.00 \%$ & $35.00 \%$ \\
\hline Asian & -0.066 & -0.087 & $-2.10 \%$ & $0.00 \%$ & $-0.10 \%$ & $-0.10 \%$ & $-4.00 \%$ & $-7.00 \%$ & $-3.00 \%$ \\
\hline URM & 0.044 & -0.041 & $-8.50 \%$ & $0.00 \%$ & $0.00 \%$ & $0.00 \%$ & $8.00 \%$ & $-4.00 \%$ & $-12.00 \%$ \\
\hline
\end{tabular}

Table 4.6: Longitudinal Comparison of Pooled Regression Results - Marginal Effects

\begin{tabular}{|c|c|c|c|c|c|c|c|c|c|}
\hline \multicolumn{10}{|c|}{ Pooled Regression Results - Marginal Effects on Average Award Size } \\
\hline & \multicolumn{2}{|c|}{ Aggregate } & \multicolumn{4}{|c|}{ Need-Meeting } & \multicolumn{2}{|c|}{ Non-Need-Meeting } & \multirow[b]{2}{*}{$\Delta$} \\
\hline & 2005-06 & 2015-16 & $\Delta$ & 2005-06 & 2015-16 & $\Delta$ & 2005-06 & 2015-16 & \\
\hline First Generation & -13.12 & 21.41 & 34.52 & 3.92 & -2.53 & -6.45 & -13.14 & 5.53 & 18.67 \\
\hline SQIS Quartile 2 & 1216.97 & 3293.33 & 2076.36 & 178.33 & 602.59 & 424.26 & 816.77 & 2247.36 & 1430.59 \\
\hline SQIS Quartile 3 & 2301.23 & 5598.81 & 3297.58 & 297.15 & 961.90 & 664.75 & 1593.84 & 3059.47 & 1465.63 \\
\hline SQIS Quartile 4 & 2930.21 & 7243.8 & 4313.59 & 328.72 & 1033.53 & 704.81 & 2091.64 & 4191.21 & 2099.57 \\
\hline Student EFC & -3.17 & -1.21 & 1.96 & -33.20 & -49.51 & -16.31 & -2.18 & -0.29 & 1.89 \\
\hline Student Need & 5.939 & 40.69 & 34.75 & -10.79 & 11.85 & 22.64 & -221.86 & -221.65 & 0.21 \\
\hline Pell Recipients & -60.26 & -31.80 & 28.46 & -106.86 & -303.11 & -196.25 & -59.47 & -25.62 & 33.85 \\
\hline Female & 45.92 & -132.97 & -178.89 & 6.74 & -27.36 & -34.10 & 23.74 & -86.04 & -109.78 \\
\hline Nonresidents & 856.5 & 3056.76 & 2200.26 & 477.72 & 1021.64 & 543.92 & 635.34 & 2391.03 & 1755.69 \\
\hline Asian & -184.51 & -474.58 & -290.07 & -47.16 & -88.87 & -41.71 & -92.76 & -269.01 & -176.25 \\
\hline URM & 122.58 & -223.84 & -346.42 & -14.15 & -33.52 & -19.37 & 179.61 & -141.32 & -320.93 \\
\hline
\end{tabular}


institutional aid award. Pell recipiency was negatively correlated with receiving an institutional aid award as Pell recipients were $2 \%$ points less likely than non-Pell recipients to earn an institutional aid award in 2005 but decreased to only $1 \%$ points less likely than non-Pell recipients to receive an institutional aid award in 2015.

Marginal effects help demonstrate the dollar values associated with aggregate institutional aid awards. For example, for students in Quartile 4 of the SQIS score, they received an average institutional aid award of $\$ 2,920$ more than Quartile 1 students in 2005. In 2015, students in Quartile 4 students earned, on average, $\$ 7,243.8$ dollars more than students in Quartile 1. Figures for the longitudinal change in the coefficients for students in SQIS Quartile 4 are found in Figures 4.15, 4.19, 4.23, 4.27, 4.31 and 4.35. The values for Quartiles 3 and Quartile 2 are also, on average, $\$ 2,930$ and $\$ 1,217$ higher than students in Quartile 1 respectively in 2005. For every one thousand dollar increase in student need, these students received an additional $\$ 5.93$ more than students with no need and $\$ 40.69$ more in institutional aid in 2015 than students with no need. Nonresident students received an average aid award of $\$ 856$ more than resident students in 2005 . Nonresidents in 2015 earned, on average $\$ 3,056.76$ more than nonresidents $\$ 1,580$ - almost doubling their average 2005 institutional aid award when compared to residents. Underrepresented minority students enjoyed a larger award, on average, when compared to non-underrepresented minorities students in 2005 , earning an average of $\$ 122.58$ more than non-underrepresented minorities. However, the sign on this relationship flipped in 2009-11 and continued on a negative trend culminating with underrepresented minorities receiving, on average, $-\$ 233.84(\mathrm{p}<.01)$ less in institutional aid awards when compared to nonunderrepresented minorities in 2013-15. Overall, the graphical trend of underrepresented 
minority coefficients for the aggregate, need-meeting and non-need-meeting institutional aid awards can be found in Figures 4.18, 4.22, 4.26, 4.30, 4.34 and 4.38.

The regressions for need-meeting institutional aid awards provide measurable probability results for select variables in the regression model. The SQIS quartiles provide significant results for all SQIS quartiles and pooled years when compared to the SQIS Quartile 1 baseline. Student EFC is predictive of receiving a need-meeting institutional aid awards, however, the probabilities for earning institutional aid awards are not highly influenced by any of the regression variables. All regressors for pooled years 2005-07 to 2007-08 (except for student need) are not shown as significant predictors of increased or decreased probability for receiving a need-meeting institutional aid award, on average. Student need is a significant predictor ( $\mathrm{p}<.001$ for models 2005-07 (p <.01), 2006-08 (p <.01), 2007-09 (p < .05), 2008-10 (p<.01), and 2009-11 (p < .01 ). Student need is also a significant predictor for 2008-10 at the .01 level. In total, only three independent variables were shown to have a $>1 \%$ percentage point effect on the marginal probability of receiving an institutional aid award when compared to their baselines: Quartile 4 $(\beta=.014, p<.001)$ students when compared to Quartile 1 students ; Nonresidents $(\beta=.014$, $\mathrm{p}<.001)$ when compared to resident students; and SQIS Quartile $3(\beta=.013, \mathrm{p}<.001)$ students when compared to SQIS Quartile 1 students.

Marginal effects for the average need-meeting dollar amounts are highly predicted by the four different SQIS Quartiles. All quartiles demonstrated positive coefficients when compared to the SQIS baseline 1 and all are significant at the .001 level. Longitudinal growth for all of the coefficients and for all of the quartiles are observed. In 2005, students in SQIS Quartile 4 received, on average, $\$ 328.72$ more than Quartile 1 students and $\$ 1,033.53$ more than Quartile 1 students in 2015. Expected total family contribution is negatively correlated and statistically 
significant at the .001 level for all years of the pooled regression. In 2005, as student EFC increased by one thousand dollars, students earned $\$ 33.20$ dollars less than students with no EFC and increased to $\$ 49.51$ less than students with no EFC in 2013-15. Student need is also predictive; however, it is negatively associated with need-meeting aid dollars when compared to students of no need until the 2012-14 and 2013-15 pooled regressions where the sign flips and need becomes a positive indicator of need-meeting aid. For every one thousand dollar increase in student need, the average need-meeting aid award decreased by $\$ 10.79(\mathrm{p}<.001)$ in 2005 when compared to students of no need. In the pooled regression for 2012-14, the coefficient (although nonsignificant) was $\$ 5.03$ dollars in need-meeting aid for every one thousand dollars of student need compared to students of no need, the coefficient more than doubles for the following years pooled regression (2013-15) to $\$ 11.85$ and is statistically significant at the .001 level. Nonresidents also received more need-meeting aid, on average, when compared to the resident baseline. In 2005-07, nonresidents received, on average, $\$ 477.72$ more than the baseline residents increased to $\$ 1,021$ more than residents in 2013-15. Non-residency was also highly statistically significant for all pooled years of need-meeting aid at .001 level. Underrepresented minorities do not appear to be earning differently, on average, than non-underrepresented minorities except for pooled years 2007-09 $(\beta=-\$ 28.66, p<.01), 2008-10(\beta=-\$ 29.53, p<$ $.01)$, and 2009-11 ( $\beta=-\$ 49.95, \mathrm{p}<.001)$ where they earn less than their non-underrepresented peers.

Marginal effects on the probability of receiving a non-need-meeting institutional aid are positive and highly significant for SQIS Quartiles 2, 3, and 4 when compared to the Quartile 1 baseline for all years of pooled regressions. Students in Quartile 4 where $90 \%$ more likely that students in Quartile one to receive a non-need-meeting institutional aid award in 2005-07 and 
were $131 \%$ more likely than students in Quartile 1 to receive a non-need meeting institutional aid award in 2013-15. Student EFC were only predictive for two of the window regressions - with identical coefficients and statistical significance - non-need-meeting institutional aid awards in 2005-07 and 2006-08 ( $\beta=-.001, \mathrm{p}<.0)$. In other words, as EFC increased by one thousand dollars, the probability of receiving an institutional aid award decreased by one tenth of a percentage point when compared to students with no EFC. Student need was highly predictive, significant $(\mathrm{p}<.001)$ and negative for each year of the pooled regressions. In the $2005-07$ pooled year, for every one thousand dollar increase in student need, there was a $\% 10$ decreased probability of a student earning a non-need-meeting institutional aid award when compared to students of no need. This probability, however, decreased to a $-6 \%$ for every one thousand dollar increase to student need in 2013-15 when compared to students of no need.

The nonresident independent variable also displayed high levels of increased probability for earning a non-need-meeting institutional aid award as coefficients for each year of the pooled regressions were statistically significant at the .001 level. Nonresidents in 2005-07 had a 27\% increased probability of earning a non-need-meeting institutional aid award when compared to resident students. This probability increased to $62 \%$ more likely for nonresidents than residents to earn a non-need-meeting institutional aid award in 2013-15.

Underrepresented minorities were slightly more likely than non-underrepresented minorities to receive an institutional aid award in 2005-07 $(\beta=.08, \mathrm{p}<.01), 2006-08(\beta=.06, \mathrm{p}$ $<.05)$, and 2013-05 $(\beta=-.04, \mathrm{p}<.01)$. Therefore, in the early years of the pooled regressions, underrepresented minorities were $6 \%$ more likely than non-underrepresented minorities to receive a non-need-meeting institutional aid award in 2006-08. The probability decreased by $2 \%$ points in the pooled years of 2006-08 where underrepresented minorities were only $6 \%$ more 
likely than non-underrepresented minorities to earn a non-need-meeting institutional aid award. The sign, and resulting probability, flips in the last year of the regression (2013-15) suggesting that underrepresented minorities were $4 \%$ less likely than non-underrepresented minorities to receive a non-need-meting institutional aid award.

Student academic quality, as measured by the SQIS quartiles, were highly predictive of the marginal effects on the average non-need-meeting institutional aid awards. The marginal effects for the average non-need-meeting institution aid award increased for each year in the pooled regressions for SQIS Quartiles 2, 3, and 4 when compared to the baseline SQIS Quartile 1 students. Furthermore, each SQIS quartile was statistically significant at the .001 level. Marginal effects on the average non-need-meeting institutional aid award demonstrated that students in SQIS Quartile 4 received \$2,091.64 more than students in SQIS Quartile 1 in 2005-07. Student EFC was predictive for the first two pooled regression windows $2005-07(\beta=-2.182, p<.001)$ and 2006-08 $(\beta=-1.18, p<.001)$. As a result, for every one thousand dollar increase in expected total family contribution resulted in $-\$ 1.18$ dollars in non-need-meeting institutional aid awards when compared to those with no EFC in 2006-06 and $-\$ 2.18$ dollars per every one thousand dollar increase in expected total family contribution when compared to students with no EFC in 2006-08.

Nonresident students also saw increased growth in the marginal effects of the average non-need-meeting institutional aid award across all of the pooled regression years. In 2005-07 nonresident students earned, on average, $\$ 635.34$ more than nonresident students and was statistically significant at the .001 level. In the 2013-15 regression window, nonresidents earned $\$ 2,391.03$ more than residents students and was also statistically significant at the .001 level. 
Underrepresented minority students showed early positive coefficients for non-needmeeting institutional aid. In 2005-07 underrepresented minorities received \$179.61 more in nonneed-meeting institutional aid than non-underrepresented minorities $(\beta=179.61, \mathrm{p}<.001)$. However, this advantage decreased in the following pooled regression window (2006-08) where they decreased to $\$ 130.87(\beta=-130.87, p<.01)$ when compared to non-underrepresented minorities. Although the coefficients for the first two windows are positive and significant, the 2007-09 window is not significant, but remained positive, followed by the 2008-10 window that remains significant $(\beta=78.81, p<.05)$ but drops in overall statistical significance from the first two windows as well as its overall coefficient. The 2009-10 and 2010-12 windows remain positive but are not statistically significant. In the following two windows, 2011-13 and 2012-14, the sign flips from positive to negative but does not reach statistical significance. The underrepresented minority variable does turn negative and statistically significant $(\beta=-141.32 \mathrm{p}$ $<.05)$ for the last pooled regression window. 
Table 4.7: Tobit Pooled Aggregate Aid Regression Results - Marginal Effects on the Probability of Receiving an Aid Award

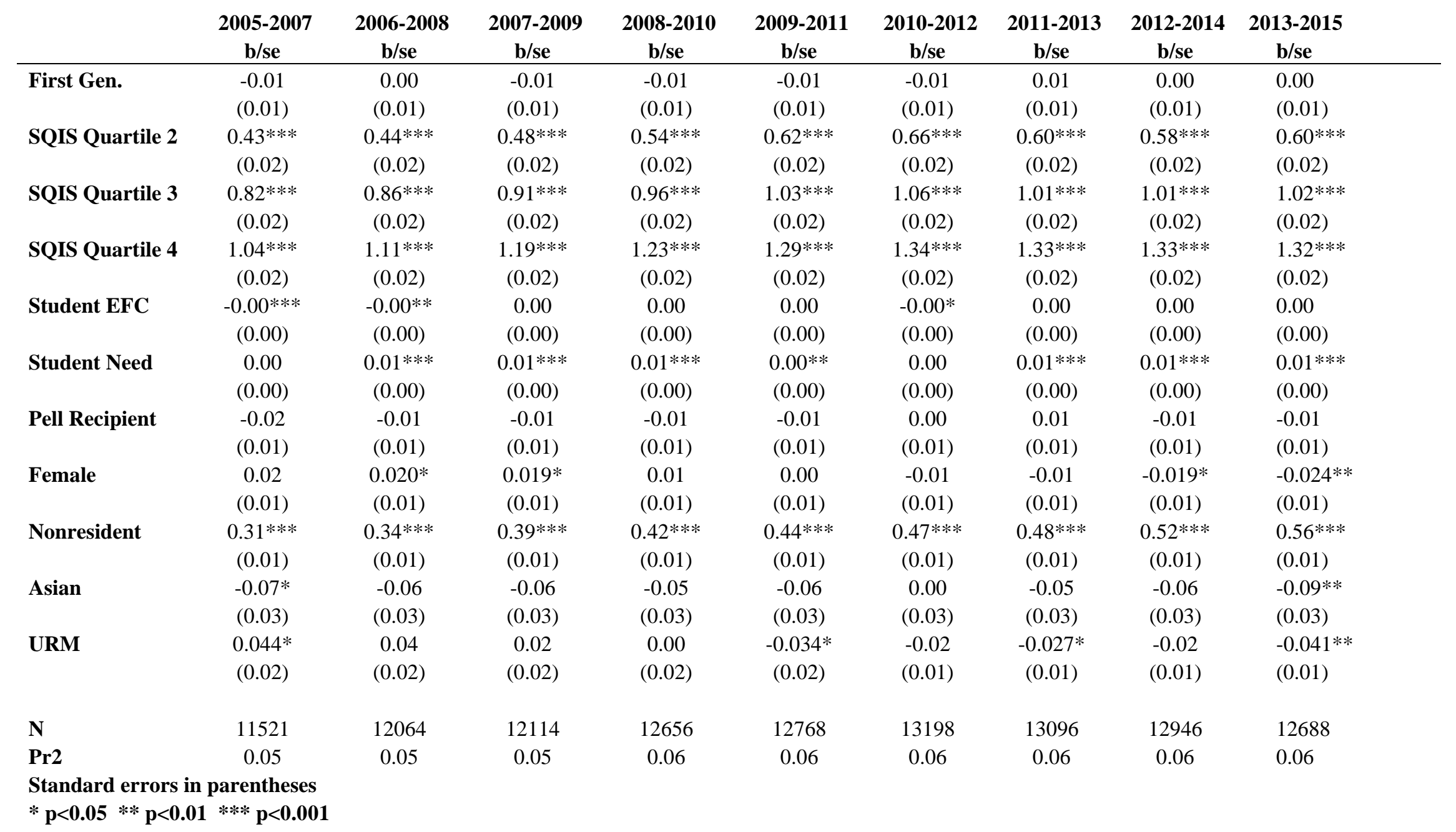


Table 4.8: Tobit Pooled Aggregate Results - Marginal Effects on the Average Institutional Aid Award

\begin{tabular}{|c|c|c|c|c|c|c|c|c|c|}
\hline & $\begin{array}{c}2005-2007 \\
\text { b/se }\end{array}$ & $\begin{array}{c}2006-2008 \\
\text { b/se }\end{array}$ & $\begin{array}{c}2007-2009 \\
\text { b/se }\end{array}$ & $\begin{array}{c}2008-2010 \\
\text { b/se }\end{array}$ & $\begin{array}{c}2009-2011 \\
\text { b/se }\end{array}$ & $\begin{array}{c}2010-2012 \\
\text { b/se }\end{array}$ & $\begin{array}{c}\text { 2011-2013 } \\
\text { b/se }\end{array}$ & $\begin{array}{c}\text { 2012-2014 } \\
\text { b/se }\end{array}$ & $\begin{array}{c}2013-2015 \\
\text { b/se }\end{array}$ \\
\hline First Gen. & $\begin{array}{l}-13.12 \\
(28.55)\end{array}$ & $\begin{array}{l}-4.27 \\
(28.07)\end{array}$ & $\begin{array}{l}-13.26 \\
(28.12)\end{array}$ & $\begin{array}{l}-28.73 \\
(30.20)\end{array}$ & $\begin{array}{l}-39.81 \\
(32.59)\end{array}$ & $\begin{array}{l}-32.25 \\
(35.95)\end{array}$ & $\begin{array}{c}28.24 \\
(39.96)\end{array}$ & $\begin{array}{c}8.90 \\
(46.77)\end{array}$ & $\begin{array}{c}21.41 \\
(56.01)\end{array}$ \\
\hline SQIS Quartile 2 & $\begin{array}{c}1216.97 * * * \\
(41.17)\end{array}$ & $\begin{array}{c}1226.76^{* * *} \\
(41.35)\end{array}$ & $\begin{array}{c}1317.95^{* * *} \\
(42.42)\end{array}$ & $\begin{array}{c}1621.38^{* * *} \\
(44.94)\end{array}$ & $\begin{array}{c}1986.77 * * * \\
(49.12)\end{array}$ & $\begin{array}{c}2372.20 * * * \\
(54.04)\end{array}$ & $\begin{array}{c}2384.57 * * * \\
(59.53)\end{array}$ & $\begin{array}{c}2656.15^{* * * *} \\
(68.65)\end{array}$ & $\begin{array}{c}3293.33 * * * \\
(82.18)\end{array}$ \\
\hline SQIS Quartile 3 & $\begin{array}{c}2301.23 * * * \\
(39.27)\end{array}$ & $\begin{array}{c}2395.4 * * * \\
(38.98)\end{array}$ & $\begin{array}{c}2515.53 * * * \\
(39.77)\end{array}$ & $\begin{array}{c}2879.04 * * * \\
\quad(42.41)\end{array}$ & $\begin{array}{c}3313.74 * * * \\
(46.64)\end{array}$ & $\begin{array}{c}3837.01 * * * \\
(51.68)\end{array}$ & $\begin{array}{c}4023.67 * * * \\
(56.64)\end{array}$ & $\begin{array}{c}4632.92 * * * \\
(64.77)\end{array}$ & $\begin{array}{c}5598.81 * * * \\
(76.82)\end{array}$ \\
\hline SQIS Quartile 4 & $\begin{array}{c}2930.21 * * * \\
(40.63)\end{array}$ & $\begin{array}{c}3088.18 * * * \\
\quad(40.34)\end{array}$ & $\begin{array}{c}3279.18 * * * \\
(40.93)\end{array}$ & $\begin{array}{c}3678.77 * * * \\
\quad(43.61)\end{array}$ & $\begin{array}{c}4160.51^{* * * *} \\
(47.61)\end{array}$ & $\begin{array}{c}4828.32 * * * \\
(52.76)\end{array}$ & $\begin{array}{c}5271.31 * * * \\
(57.68)\end{array}$ & $\begin{array}{c}6094.37 * * * \\
(65.97)\end{array}$ & $\begin{array}{c}7243.80^{* * *} \\
(77.98)\end{array}$ \\
\hline Student EFC & $\begin{array}{c}-3.17 * * * \\
(0.68)\end{array}$ & $\begin{array}{c}-1.79 * * \\
(0.63)\end{array}$ & $\begin{array}{l}-0.64 \\
(0.63)\end{array}$ & $\begin{array}{l}-0.52 \\
(0.67)\end{array}$ & $\begin{array}{l}-1.13 \\
(0.72)\end{array}$ & $\begin{array}{c}-1.60 * \\
(0.78)\end{array}$ & $\begin{array}{l}-1.47 \\
(0.81)\end{array}$ & $\begin{array}{l}-0.24 \\
(0.83)\end{array}$ & $\begin{array}{l}-1.21 \\
(0.91)\end{array}$ \\
\hline Student Need & $\begin{array}{c}5.94 \\
(5.30)\end{array}$ & $\begin{array}{c}21.78 * * * \\
(4.72)\end{array}$ & $\begin{array}{c}25.39 * * * \\
(4.42)\end{array}$ & $\begin{array}{c}19.67 * * * \\
(4.45)\end{array}$ & $\begin{array}{c}11.94 * * \\
(4.58)\end{array}$ & $\begin{array}{c}8.99 \\
(4.68)\end{array}$ & $\begin{array}{c}18.25 * * * \\
(4.81)\end{array}$ & $\begin{array}{c}38.42 * * * \\
(5.23)\end{array}$ & $\begin{array}{c}40.69 * * * \\
(5.87)\end{array}$ \\
\hline Pell Recipient & $\begin{array}{l}-60.26 \\
(34.99)\end{array}$ & $\begin{array}{l}-39.92 \\
(34.38)\end{array}$ & $\begin{array}{l}-30.38 \\
(33.78)\end{array}$ & $\begin{array}{l}-41.86 \\
(35.16)\end{array}$ & $\begin{array}{l}-29.29 \\
(37.18)\end{array}$ & $\begin{array}{c}-5.66 \\
(40.70)\end{array}$ & $\begin{array}{c}56.61 \\
(44.64)\end{array}$ & $\begin{array}{l}-39.85 \\
(50.87)\end{array}$ & $\begin{array}{l}-31.80 \\
(59.27)\end{array}$ \\
\hline Female & $\begin{array}{l}45.92 \\
(24.17)\end{array}$ & $\begin{array}{l}54.87 * \\
(23.71)\end{array}$ & $\begin{array}{l}52.27 * \\
(23.48)\end{array}$ & $\begin{array}{c}36.44 \\
(24.96)\end{array}$ & $\begin{array}{l}-10.04 \\
(26.64)\end{array}$ & $\begin{array}{l}-32.01 \\
(29.03)\end{array}$ & $\begin{array}{l}-39.75 \\
(31.68)\end{array}$ & $\begin{array}{l}-85.16^{*} \\
(36.58)\end{array}$ & $\begin{array}{c}-132.97 * * \\
(43.09)\end{array}$ \\
\hline Nonresident & $\begin{array}{c}856.50 * * * \\
(32.65)\end{array}$ & $\begin{array}{c}939.28 * * * \\
(31.85)\end{array}$ & $\begin{array}{c}1079.06 * * * \\
(32.04)\end{array}$ & $\begin{array}{c}1245.00^{* * * *} \\
(34.90)\end{array}$ & $\begin{array}{c}1429.75^{* * * *} \\
(38.24)\end{array}$ & $\begin{array}{c}1699.79 * * * \\
(41.88)\end{array}$ & $\begin{array}{c}1921.99 * * * \\
(45.40)\end{array}$ & $\begin{array}{c}2378.45^{* * * *} \\
(52.53)\end{array}$ & $\begin{array}{c}3056.76^{* * * *} \\
(62.79)\end{array}$ \\
\hline Asian & $\begin{array}{c}-184.51 * \\
(93.13)\end{array}$ & $\begin{array}{l}-157.52 \\
(90.95)\end{array}$ & $\begin{array}{l}-152.41 \\
(92.19)\end{array}$ & $\begin{array}{l}-153.59 \\
(102.50)\end{array}$ & $\begin{array}{l}-201.94 \\
(107.34)\end{array}$ & $\begin{array}{c}-13.93 \\
(115.06)\end{array}$ & $\begin{array}{l}-180.44 \\
(128.12)\end{array}$ & $\begin{array}{l}-282.48 \\
(146.52)\end{array}$ & $\begin{array}{c}-474.58^{* *} \\
(179.05)\end{array}$ \\
\hline URM & $\begin{array}{l}122.58^{*} \\
(52.07)\end{array}$ & $\begin{array}{c}96.52 \\
(50.25)\end{array}$ & $\begin{array}{c}40.79 \\
(48.36)\end{array}$ & $\begin{array}{c}12.17 \\
(48.59)\end{array}$ & $\begin{array}{c}-109.62^{*} \\
(49.88)\end{array}$ & $\begin{array}{l}-65.66 \\
(50.66)\end{array}$ & $\begin{array}{c}-106.63^{*} \\
(53.67)\end{array}$ & $\begin{array}{c}-108 \\
(60.33)\end{array}$ & $\begin{array}{c}-223.84 * * \\
(70.73)\end{array}$ \\
\hline $\mathbf{N}$ & 11521 & 12064 & 12114 & 12656 & 12768 & 13198 & 13096 & 12946 & 12688 \\
\hline Pr2 & 0.05 & 0.05 & 0.05 & 0.06 & 0.06 & 0.06 & 0.06 & 0.06 & 0.06 \\
\hline
\end{tabular}


Table 4.9: Tobit Pooled Need-Meeting Aid Regression Results - Marginal Effects on the Probability of Receiving an Aid Award

\begin{tabular}{|c|c|c|c|c|c|c|c|c|c|}
\hline & $\begin{array}{c}2005-2007 \\
\text { b/se }\end{array}$ & $\begin{array}{c}2006-2008 \\
\text { b/se }\end{array}$ & $\begin{array}{c}2007-2009 \\
\text { b/se }\end{array}$ & $\begin{array}{c}\text { 2008-2010 } \\
\text { b/se }\end{array}$ & $\begin{array}{c}2009-2011 \\
\text { b/se }\end{array}$ & $\begin{array}{c}2010-2012 \\
\text { b/se }\end{array}$ & $\begin{array}{c}2011-2013 \\
\text { b/se }\end{array}$ & $\begin{array}{c}2012-2014 \\
\text { b/se }\end{array}$ & $\begin{array}{c}2013-2015 \\
\text { b/se }\end{array}$ \\
\hline First Gen. & $\begin{array}{c}0.00 \\
(0.00)\end{array}$ & $\begin{array}{c}0.00 \\
(0.00)\end{array}$ & $\begin{array}{c}0.00 \\
(0.00)\end{array}$ & $\begin{array}{c}0.00 \\
(0.00)\end{array}$ & $\begin{array}{c}0.00 \\
(0.00)\end{array}$ & $\begin{array}{c}0.00 \\
(0.00)\end{array}$ & $\begin{array}{c}0.00 \\
(0.00)\end{array}$ & $\begin{array}{c}0.00 \\
(0.00)\end{array}$ & $\begin{array}{c}0.00 \\
(0.00)\end{array}$ \\
\hline SQIS Quartile 2 & $\begin{array}{c}0.00 \\
(0.00)\end{array}$ & $\begin{array}{c}0.00 \\
(0.00)\end{array}$ & $\begin{array}{c}0.00 \\
(0.00)\end{array}$ & $\begin{array}{c}0.00 \\
(0.00)\end{array}$ & $\begin{array}{c}0.002 * * \\
(0.00)\end{array}$ & $\begin{array}{c}0.004 * * \\
(0.00)\end{array}$ & $\begin{array}{c}0.003^{* *} \\
(0.00)\end{array}$ & $\begin{array}{c}0.004 * * \\
(0.00)\end{array}$ & $\begin{array}{c}0.008 * * * \\
(0.00)\end{array}$ \\
\hline SQIS Quartile 3 & $\begin{array}{c}0.00 \\
(0.00)\end{array}$ & $\begin{array}{c}0.00 \\
(0.00)\end{array}$ & $\begin{array}{c}0.00 \\
(0.00)\end{array}$ & $\begin{array}{c}0.00 \\
(0.00)\end{array}$ & $\begin{array}{c}0.003^{* * *} \\
(0.00)\end{array}$ & $\begin{array}{c}0.006^{* * *} \\
(0.00)\end{array}$ & $\begin{array}{c}0.006^{* *} \\
(0.00)\end{array}$ & $\begin{array}{c}0.007 * * \\
(0.00)\end{array}$ & $\begin{array}{c}0.013 * * * \\
(0.00)\end{array}$ \\
\hline SQIS Quartile 4 & $\begin{array}{c}0.00 \\
(0.00)\end{array}$ & $\begin{array}{c}0.00 \\
(0.00)\end{array}$ & $\begin{array}{c}0.00 \\
(0.00)\end{array}$ & $\begin{array}{c}0.00 \\
(0.00)\end{array}$ & $\begin{array}{c}0.003 * * \\
(0.00)\end{array}$ & $\begin{array}{c}0.007 * * \\
(0.00)\end{array}$ & $\begin{array}{c}0.006 * * \\
(0.00)\end{array}$ & $\begin{array}{c}0.008^{* *} \\
(0.00)\end{array}$ & $\begin{array}{c}0.014 * * * \\
(0.00)\end{array}$ \\
\hline Student EFC & $\begin{array}{c}0.00 \\
(0.00)\end{array}$ & $\begin{array}{c}0.00 \\
(0.00)\end{array}$ & $\begin{array}{c}0.00 \\
(0.00)\end{array}$ & $\begin{array}{c}0.00 \\
(0.00)\end{array}$ & $\begin{array}{c}-0.000 * * \\
(0.00)\end{array}$ & $\begin{array}{c}-0.000 * * * \\
(0.00)\end{array}$ & $\begin{array}{c}-0.000 * * * * \\
(0.00)\end{array}$ & $\begin{array}{c}-0.000 * * * \\
(0.00)\end{array}$ & $\begin{array}{c}-0.001 * * * \\
(0.00)\end{array}$ \\
\hline Student Need & $\begin{array}{c}-0.000^{*} \\
(0.00)\end{array}$ & $\begin{array}{c}-0.000 * * \\
(0.00)\end{array}$ & $\begin{array}{c}-0.000^{*} \\
(0.00)\end{array}$ & $\begin{array}{c}-0.000 * * \\
(0.00)\end{array}$ & $\begin{array}{c}-0.000^{*} \\
(0.00)\end{array}$ & $\begin{array}{c}0.00 \\
(0.00)\end{array}$ & $\begin{array}{c}0.00 \\
(0.00)\end{array}$ & $\begin{array}{c}0.00 \\
(0.00)\end{array}$ & $\begin{array}{c}0.00 \\
(0.00)\end{array}$ \\
\hline Pell Recipient & $\begin{array}{c}0.00 \\
(0.00)\end{array}$ & $\begin{array}{c}0.00 \\
(0.00)\end{array}$ & $\begin{array}{c}0.00 \\
(0.00)\end{array}$ & $\begin{array}{c}0.00 \\
(0.00)\end{array}$ & $\begin{array}{c}-0.001 * * \\
(0.00)\end{array}$ & $\begin{array}{c}-0.002 * * * \\
(0.00)\end{array}$ & $\begin{array}{c}-0.002 * * * \\
(0.00)\end{array}$ & $\begin{array}{c}-0.003 * * * \\
(0.00)\end{array}$ & $\begin{array}{c}-0.004 * * * \\
(0.00)\end{array}$ \\
\hline Female & $\begin{array}{c}0.00 \\
(0.00)\end{array}$ & $\begin{array}{c}0.00 \\
(0.00)\end{array}$ & $\begin{array}{c}0.00 \\
(0.00)\end{array}$ & $\begin{array}{c}0.00 \\
(0.00)\end{array}$ & $\begin{array}{c}0.00 \\
(0.00)\end{array}$ & $\begin{array}{c}0.00 \\
(0.00)\end{array}$ & $\begin{array}{c}0.00 \\
(0.00)\end{array}$ & $\begin{array}{c}0.00 \\
(0.00)\end{array}$ & $\begin{array}{c}0.00 \\
(0.00)\end{array}$ \\
\hline Nonresident & $\begin{array}{c}0.00 \\
(0.00)\end{array}$ & $\begin{array}{c}0.00 \\
(0.00)\end{array}$ & $\begin{array}{c}0.00 \\
(0.00)\end{array}$ & $\begin{array}{c}0.00 \\
(0.00)\end{array}$ & $\begin{array}{c}0.004^{* * *} \\
(0.00)\end{array}$ & $\begin{array}{c}0.008 * * * \\
(0.00)\end{array}$ & $\begin{array}{c}0.007 * * * \\
(0.00)\end{array}$ & $\begin{array}{c}0.009^{* * *} \\
(0.00)\end{array}$ & $\begin{array}{c}0.014 * * * \\
(0.00)\end{array}$ \\
\hline Asian & $\begin{array}{c}0.00 \\
(0.00)\end{array}$ & $\begin{array}{c}0.00 \\
(0.00)\end{array}$ & $\begin{array}{c}0.00 \\
(0.00)\end{array}$ & $\begin{array}{c}0.00 \\
(0.00)\end{array}$ & $\begin{array}{c}0.00 \\
(0.00)\end{array}$ & $\begin{array}{c}0.00 \\
(0.00)\end{array}$ & $\begin{array}{c}0.00 \\
(0.00)\end{array}$ & $\begin{array}{c}0.00 \\
(0.00)\end{array}$ & $\begin{array}{c}0.00 \\
(0.00)\end{array}$ \\
\hline URM & $\begin{array}{c}0.00 \\
(0.00)\end{array}$ & $\begin{array}{c}0.00 \\
(0.00)\end{array}$ & $\begin{array}{c}0.00 \\
(0.00)\end{array}$ & $\begin{array}{c}0.00 \\
(0.00)\end{array}$ & $\begin{array}{c}-0.000 * \\
(0.00)\end{array}$ & $\begin{array}{c}0.00 \\
(0.00)\end{array}$ & $\begin{array}{c}0.00 \\
(0.00)\end{array}$ & $\begin{array}{c}0.00 \\
(0.00)\end{array}$ & $\begin{array}{c}0.00 \\
(0.00)\end{array}$ \\
\hline $\mathbf{N}$ & 11521 & 12064 & 12114 & 12656 & 12768 & 13198 & 13096 & 12946 & 12688 \\
\hline PR2 & 0.15 & 0.16 & 0.16 & 0.16 & 0.16 & 0.15 & 0.15 & 0.15 & 0.15 \\
\hline
\end{tabular}

Standard errors in parentheses

$* \mathbf{p}<0.05 * * \mathbf{p}<0.01 * * * \mathbf{p}<0.001$ 
Table 4.10: Tobit Pooled Need-Meeting Aid Regression Results- Marginal Effects on the Average Institutional Aid Award

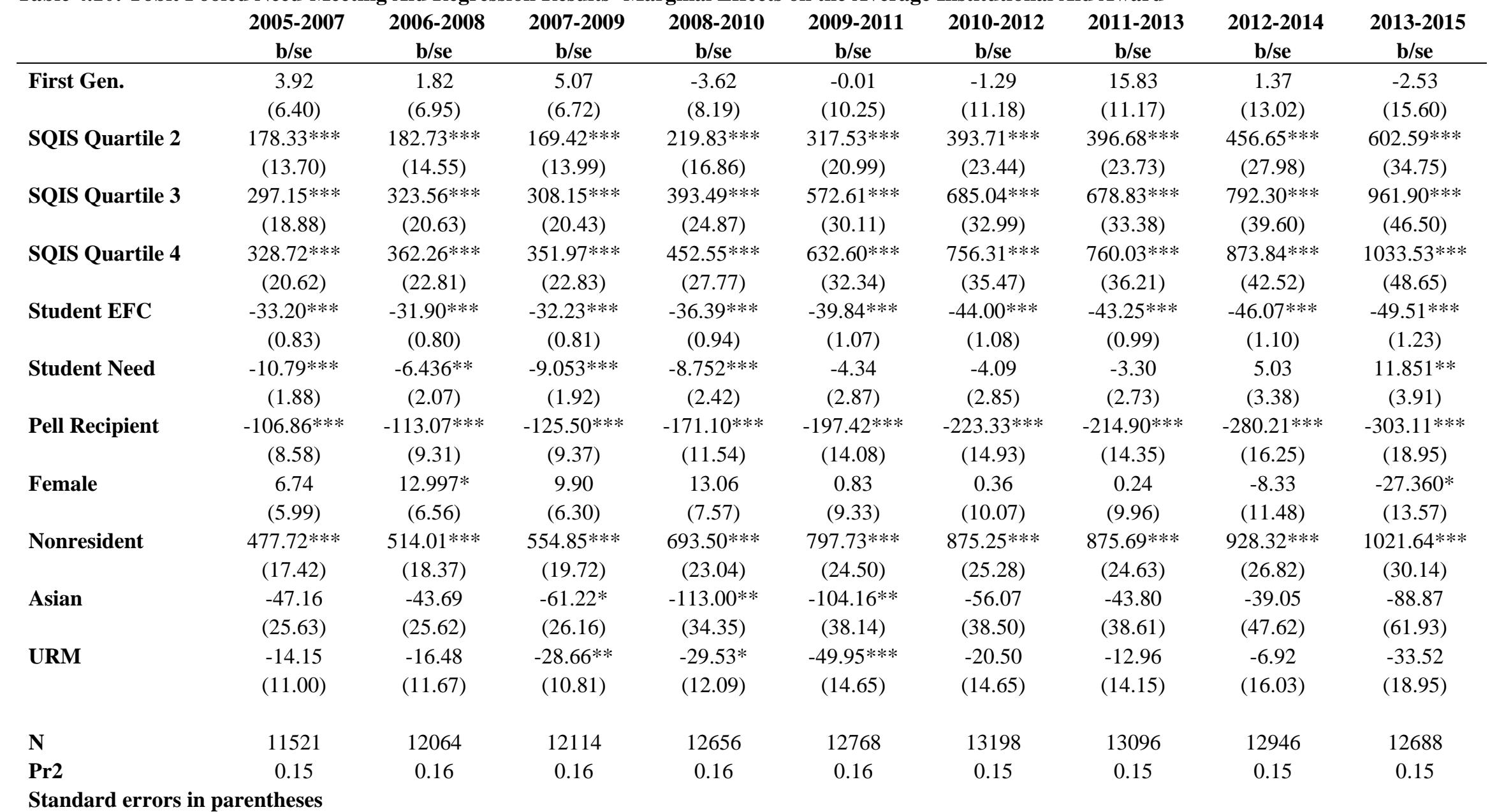

$* \mathrm{p}<0.05 * * \mathrm{p}<0.01 * * * \mathrm{p}<0.001$ 
Table 4.11: Tobit Pooled Non-Need-Meeting Aid Regression Results - Marginal Effects on the Probability of Receiving an Aid Award

\begin{tabular}{|c|c|c|c|c|c|c|c|c|c|}
\hline & $\begin{array}{c}2005-2007 \\
\text { b/se }\end{array}$ & $\begin{array}{c}2006-2008 \\
\text { b/se }\end{array}$ & $\begin{array}{c}2007-2009 \\
\text { b/se }\end{array}$ & $\begin{array}{c}2008-2010 \\
\mathrm{~b} / \mathrm{se}\end{array}$ & $\begin{array}{c}2009-2011 \\
\text { b/se }\end{array}$ & $\begin{array}{c}2010-2012 \\
\mathrm{~b} / \mathrm{se}\end{array}$ & $\begin{array}{c}\text { 2011-2013 } \\
\text { b/se }\end{array}$ & $\begin{array}{c}\text { 2012-2014 } \\
\mathrm{b} / \mathrm{se}\end{array}$ & $\begin{array}{c}\text { 2013-2015 } \\
\text { b/se }\end{array}$ \\
\hline First Gen. & $\begin{array}{l}-0.01 \\
(0.01)\end{array}$ & $\begin{array}{c}0.00 \\
(0.01)\end{array}$ & $\begin{array}{c}0.00 \\
(0.01)\end{array}$ & $\begin{array}{c}0.00 \\
(0.01)\end{array}$ & $\begin{array}{l}-0.02 \\
(0.01)\end{array}$ & $\begin{array}{l}-0.02 \\
(0.01)\end{array}$ & $\begin{array}{l}-0.01 \\
(0.01)\end{array}$ & $\begin{array}{c}0.00 \\
(0.01)\end{array}$ & $\begin{array}{l}0.00 \\
(0.01)\end{array}$ \\
\hline SQIS Quartile 2 & $\begin{array}{c}0.35^{* * * *} \\
(0.02)\end{array}$ & $\begin{array}{c}0.37 * * * \\
(0.02)\end{array}$ & $\begin{array}{c}0.40 * * * \\
(0.02)\end{array}$ & $\begin{array}{c}0.48^{* * * *} \\
(0.02)\end{array}$ & $\begin{array}{c}0.54 * * * \\
(0.02)\end{array}$ & $\begin{array}{c}0.61 * * * \\
(0.02)\end{array}$ & $\begin{array}{c}0.55^{* * * *} \\
(0.02)\end{array}$ & $\begin{array}{c}0.55^{* * * *} \\
(0.02)\end{array}$ & $\begin{array}{l}0.58 * * * \\
(0.02)\end{array}$ \\
\hline SQIS Quartile 3 & $\begin{array}{c}0.68 * * * * \\
(0.01)\end{array}$ & $\begin{array}{c}0.72 * * * \\
(0.01)\end{array}$ & $\begin{array}{c}0.75 * * * \\
(0.02)\end{array}$ & $\begin{array}{c}0.80 * * * \\
(0.01)\end{array}$ & $\begin{array}{c}0.86^{* * * *} \\
(0.02)\end{array}$ & $\begin{array}{c}0.92^{* * * *} \\
(0.02)\end{array}$ & $\begin{array}{c}0.88 * * * \\
(0.02)\end{array}$ & $\begin{array}{c}0.92^{* * * *} \\
(0.02)\end{array}$ & $\begin{array}{l}0.98 * * * \\
(0.02)\end{array}$ \\
\hline SQIS Quartile 4 & $\begin{array}{c}0.90^{* * * *} \\
(0.02)\end{array}$ & $\begin{array}{c}0.95^{* * * *} \\
(0.02)\end{array}$ & $\begin{array}{c}1.00 * * * \\
(0.02)\end{array}$ & $\begin{array}{c}1.04 * * * \\
(0.02)\end{array}$ & $\begin{array}{c}1.10^{* * * *} \\
(0.02)\end{array}$ & $\begin{array}{c}1.19^{* * * *} \\
(0.02)\end{array}$ & $\begin{array}{c}1.20^{* * * *} \\
(0.02)\end{array}$ & $\begin{array}{c}1.27^{* * * *} \\
(0.02)\end{array}$ & $\begin{array}{l}1.31 * * * \\
(0.02)\end{array}$ \\
\hline Student EFC & $\begin{array}{c}-0.001 * * * \\
(0.00)\end{array}$ & $\begin{array}{c}-0.001^{*} \\
(0.00)\end{array}$ & $\begin{array}{c}0.00 \\
(0.00)\end{array}$ & $\begin{array}{c}0.00 \\
(0.00)\end{array}$ & $\begin{array}{c}0.00 \\
(0.00)\end{array}$ & $\begin{array}{c}0.00 \\
(0.00)\end{array}$ & $\begin{array}{c}0.00 \\
(0.00)\end{array}$ & $\begin{array}{c}0.00 \\
(0.00)\end{array}$ & $\begin{array}{l}0.00 \\
(0.00)\end{array}$ \\
\hline Student Need & $\begin{array}{c}-0.10^{* * *} \\
(0.00)\end{array}$ & $\begin{array}{c}-0.09 * * * \\
(0.00)\end{array}$ & $\begin{array}{c}-0.08 * * * \\
(0.00)\end{array}$ & $\begin{array}{c}-0.08 * * * \\
(0.00)\end{array}$ & $\begin{array}{c}-0.08 * * * \\
(0.00)\end{array}$ & $\begin{array}{c}-0.08^{* * *} \\
(0.00)\end{array}$ & $\begin{array}{c}-0.08 * * * \\
(0.00)\end{array}$ & $\begin{array}{c}-0.06 * * * \\
(0.00)\end{array}$ & $\begin{array}{l}-0.06 * * * \\
(0.00)\end{array}$ \\
\hline Pell Recipient & $\begin{array}{c}-0.025^{*} \\
(0.01)\end{array}$ & $\begin{array}{l}-0.02 \\
(0.01)\end{array}$ & $\begin{array}{l}-0.02 \\
(0.01)\end{array}$ & $\begin{array}{l}-0.02 \\
(0.01)\end{array}$ & $\begin{array}{l}-0.02 \\
(0.01)\end{array}$ & $\begin{array}{c}0.00 \\
(0.01)\end{array}$ & $\begin{array}{c}0.02 \\
(0.01)\end{array}$ & $\begin{array}{c}0.00 \\
(0.01)\end{array}$ & $\begin{array}{l}-0.01 \\
(0.01)\end{array}$ \\
\hline Female & $\begin{array}{c}0.01 \\
(0.01)\end{array}$ & $\begin{array}{c}0.01 \\
(0.01)\end{array}$ & $\begin{array}{c}0.01 \\
(0.01)\end{array}$ & $\begin{array}{c}0.01 \\
(0.01)\end{array}$ & $\begin{array}{c}0.00 \\
(0.01)\end{array}$ & $\begin{array}{l}-0.01 \\
(0.01)\end{array}$ & $\begin{array}{l}-0.01 \\
(0.01)\end{array}$ & $\begin{array}{c}-0.02^{* *} \\
(0.01)\end{array}$ & $\begin{array}{l}-0.02 * * \\
(0.01)\end{array}$ \\
\hline Nonresident & $\begin{array}{c}0.27 * * * \\
(0.01)\end{array}$ & $\begin{array}{c}0.30^{* * * *} \\
(0.01)\end{array}$ & $\begin{array}{c}0.34 * * * \\
(0.01)\end{array}$ & $\begin{array}{c}0.36 * * * \\
(0.01)\end{array}$ & $\begin{array}{c}0.40 * * * \\
(0.01)\end{array}$ & $\begin{array}{c}0.45^{* * * *} \\
(0.01)\end{array}$ & $\begin{array}{c}0.47 * * * \\
(0.01)\end{array}$ & $\begin{array}{c}0.55^{* * * *} \\
(0.01)\end{array}$ & $\begin{array}{l}0.62 * * * \\
(0.01)\end{array}$ \\
\hline Asian & $\begin{array}{l}-0.04 \\
(0.03)\end{array}$ & $\begin{array}{l}-0.03 \\
(0.03)\end{array}$ & $\begin{array}{l}-0.03 \\
(0.03)\end{array}$ & $\begin{array}{l}-0.01 \\
(0.03)\end{array}$ & $\begin{array}{l}-0.01 \\
(0.03)\end{array}$ & $\begin{array}{c}0.05 \\
(0.03)\end{array}$ & $\begin{array}{c}0.00 \\
(0.03)\end{array}$ & $\begin{array}{l}-0.04 \\
(0.03)\end{array}$ & $\begin{array}{l}-0.07^{*} \\
(0.03)\end{array}$ \\
\hline URM & $\begin{array}{c}0.08^{* * * *} \\
(0.02)\end{array}$ & $\begin{array}{c}0.06 * * \\
(0.02)\end{array}$ & $\begin{array}{c}0.03 \\
(0.02)\end{array}$ & $\begin{array}{l}0.03^{*} \\
(0.02)\end{array}$ & $\begin{array}{c}0.02 \\
(0.02)\end{array}$ & $\begin{array}{c}0.02 \\
(0.01)\end{array}$ & $\begin{array}{l}-0.01 \\
(0.01)\end{array}$ & $\begin{array}{c}-0.02 \\
(0.01)\end{array}$ & $\begin{array}{l}-0.04 * \\
(0.01)\end{array}$ \\
\hline $\mathbf{N}$ & 11521 & 12064 & 12114 & 12656 & 12768 & 13198 & 13096 & 12946 & 12688 \\
\hline Pr2 & 0.06 & 0.06 & 0.07 & 0.07 & 0.07 & 0.07 & 0.07 & 0.07 & 0.07 \\
\hline
\end{tabular}


Table 4.12: Tobit Pooled Non-Need-Meeting Regression Results - Marginal Effects on the Average Institutional Aid Award

\begin{tabular}{|c|c|c|c|c|c|c|c|c|c|}
\hline & $\begin{array}{c}\text { 2005-2007 } \\
\text { b/se }\end{array}$ & $\begin{array}{c}\text { 2006-2008 } \\
\text { b/se }\end{array}$ & $\begin{array}{c}2007-2009 \\
\text { b/se }\end{array}$ & $\begin{array}{c}\text { 2008-2010 } \\
\text { b/se }\end{array}$ & $\begin{array}{c}\text { 2009-2011 } \\
\text { b/se }\end{array}$ & $\begin{array}{c}\text { 2010-2012 } \\
\text { b/se }\end{array}$ & $\begin{array}{c}2011-2013 \\
\text { b/se }\end{array}$ & $\begin{array}{c}2012-2014 \\
\text { b/se }\end{array}$ & $\begin{array}{c}\text { 2013-2015 } \\
\text { b/se }\end{array}$ \\
\hline First Gen. & $\begin{array}{l}-13.14 \\
(23.83)\end{array}$ & $\begin{array}{c}9.52 \\
(23.03)\end{array}$ & $\begin{array}{c}-2.22 \\
(22.66)\end{array}$ & $\begin{array}{c}-5.29 \\
(23.47)\end{array}$ & $\begin{array}{l}-41.45 \\
(24.76)\end{array}$ & $\begin{array}{l}-48.91 \\
(26.76)\end{array}$ & $\begin{array}{l}-20.71 \\
(30.68)\end{array}$ & $\begin{array}{l}-13.17 \\
(36.06)\end{array}$ & $\begin{array}{c}5.53 \\
(43.33)\end{array}$ \\
\hline SQIS Quartile 2 & $\begin{array}{c}816.77 * * * \\
(36.00)\end{array}$ & $\begin{array}{c}844.87 * * * * \\
(36.16)\end{array}$ & $\begin{array}{c}919.52^{* * * *} \\
(37.61)\end{array}$ & $\begin{array}{c}1163.95 * * * \\
(39.14)\end{array}$ & $\begin{array}{c}1366.57 * * * \\
(41.54)\end{array}$ & $\begin{array}{c}1619.18^{* * * *} \\
(45.19)\end{array}$ & $\begin{array}{c}1584.77^{* * * *} \\
(50.98)\end{array}$ & $\begin{array}{c}1817.93^{* * *} * \\
(59.55)\end{array}$ & $\begin{array}{c}2247.36 * * * \\
(70.83)\end{array}$ \\
\hline SQIS Quartile 3 & $\begin{array}{c}1593.84 * * * \\
(33.48)\end{array}$ & $\begin{array}{c}1662.61 * * * \\
(33.12)\end{array}$ & $\begin{array}{c}1732.56 * * * \\
(34.16)\end{array}$ & $\begin{array}{c}1958.45 * * * \\
(35.72)\end{array}$ & $\begin{array}{c}2153.44 * * * \\
(38.31)\end{array}$ & $\begin{array}{c}2449.24 * * * \\
\quad(41.82)\end{array}$ & $\begin{array}{c}2570.74 * * * \\
\quad(46.75)\end{array}$ & $\begin{array}{c}3059.47 * * * \\
(53.65)\end{array}$ & $\begin{array}{c}3766.49 * * * \\
(63.20)\end{array}$ \\
\hline SQIS Quartile 4 & $\begin{array}{c}2091.64 * * * \\
(34.17)\end{array}$ & $\begin{array}{c}2199.32 * * * \\
(33.72)\end{array}$ & $\begin{array}{c}2306.67 * * * \\
(34.45)\end{array}$ & $\begin{array}{c}2547.64 * * * \\
(35.81)\end{array}$ & $\begin{array}{c}2776.11 * * * \\
(38.07)\end{array}$ & $\begin{array}{c}3177.93 * * * \\
(41.17)\end{array}$ & $\begin{array}{c}3499.35^{* * * *} \\
(45.75)\end{array}$ & $\begin{array}{c}4191.21^{* * *} \\
(52.24)\end{array}$ & $\begin{array}{c}5076.64 * * * \\
(61.54)\end{array}$ \\
\hline Student EFC & $\begin{array}{c}-2.18 * * * \\
(0.53)\end{array}$ & $\begin{array}{l}-1.19^{*} \\
(0.48)\end{array}$ & $\begin{array}{l}-0.31 \\
(0.47)\end{array}$ & $\begin{array}{l}-0.17 \\
(0.47)\end{array}$ & $\begin{array}{l}-0.65 \\
(0.50)\end{array}$ & $\begin{array}{l}-0.83 \\
(0.53)\end{array}$ & $\begin{array}{l}-0.72 \\
(0.57)\end{array}$ & $\begin{array}{c}0.34 \\
(0.59)\end{array}$ & $\begin{array}{l}-0.29 \\
(0.66)\end{array}$ \\
\hline Student Need & $\begin{array}{c}-221.86 * * * \\
(6.05)\end{array}$ & $\begin{array}{c}-200.51 * * * \\
(5.34)\end{array}$ & $\begin{array}{c}-187.12 * * * \\
(4.84)\end{array}$ & $\begin{array}{c}-187.25^{* * *} \\
(4.43)\end{array}$ & $\begin{array}{c}-200.27 * * * \\
(4.28)\end{array}$ & $\begin{array}{c}-210.29 * * * \\
(4.15)\end{array}$ & $\begin{array}{c}-218.00 * * * * \\
(4.38)\end{array}$ & $\begin{array}{c}-208.59 * * * \\
(4.55)\end{array}$ & $\begin{array}{c}-221.65^{* * * *} \\
(4.96)\end{array}$ \\
\hline Pell Recipient & $\begin{array}{c}-59.470 * \\
(29.80)\end{array}$ & $\begin{array}{l}-42.27 \\
(28.87)\end{array}$ & $\begin{array}{l}-38.65 \\
(27.69)\end{array}$ & $\begin{array}{l}-47.87 \\
(27.52)\end{array}$ & $\begin{array}{l}-40.75 \\
(28.09)\end{array}$ & $\begin{array}{c}-2.98 \\
(30.06)\end{array}$ & $\begin{array}{c}54.16 \\
(34.11)\end{array}$ & $\begin{array}{c}11.82 \\
(39.11)\end{array}$ & $\begin{array}{l}-25.62 \\
(45.63)\end{array}$ \\
\hline Female & $\begin{array}{c}23.74 \\
(19.81)\end{array}$ & $\begin{array}{c}24.93 \\
(19.09)\end{array}$ & $\begin{array}{c}29.25 \\
(18.50)\end{array}$ & $\begin{array}{c}16.55 \\
(18.87)\end{array}$ & $\begin{array}{c}-7.35 \\
(19.63)\end{array}$ & $\begin{array}{l}-33.10 \\
(20.91)\end{array}$ & $\begin{array}{l}-34.06 \\
(23.47)\end{array}$ & $\begin{array}{c}-75.13 * * \\
(27.33)\end{array}$ & $\begin{array}{c}-86.04 * * \\
(32.44)\end{array}$ \\
\hline Nonresident & $\begin{array}{c}635.34 * * * \\
(25.25)\end{array}$ & $\begin{array}{c}700.94 * * * \\
(24.16)\end{array}$ & $\begin{array}{c}783.56 * * * \\
(23.72)\end{array}$ & $\begin{array}{c}890.70 * * * \\
(24.76)\end{array}$ & $\begin{array}{c}1004.94 * * * \\
(26.41)\end{array}$ & $\begin{array}{c}1195.73 * * * * \\
(28.35)\end{array}$ & $\begin{array}{c}1379.12 * * * \\
(31.62)\end{array}$ & $\begin{array}{c}1808.73 * * * \\
(37.28)\end{array}$ & $\begin{array}{c}2391.03 * * * \\
(45.32)\end{array}$ \\
\hline Asian & $\begin{array}{l}-92.76 \\
(76.23)\end{array}$ & $\begin{array}{l}-77.23 \\
(73.91)\end{array}$ & $\begin{array}{l}-61.17 \\
(73.25)\end{array}$ & $\begin{array}{l}-11.98 \\
(78.85)\end{array}$ & $\begin{array}{l}-14.14 \\
(81.16)\end{array}$ & $\begin{array}{l}139.74 \\
(84.33)\end{array}$ & $\begin{array}{l}-7.58 \\
(96.45)\end{array}$ & $\begin{array}{l}-121.05 \\
(109.13)\end{array}$ & $\begin{array}{c}-269.01 * \\
(134.39)\end{array}$ \\
\hline URM & $\begin{array}{c}179.61 * * * \\
(46.17)\end{array}$ & $\begin{array}{c}130.87 * * \\
(43.93)\end{array}$ & $\begin{array}{c}73.07 \\
(41.84)\end{array}$ & $\begin{array}{l}78.81 * \\
(40.07)\end{array}$ & $\begin{array}{c}52.57 \\
(39.63)\end{array}$ & $\begin{array}{l}41.14 \\
(39.49)\end{array}$ & $\begin{array}{l}-14.90 \\
(42.98)\end{array}$ & $\begin{array}{l}-77.13 \\
(48.65)\end{array}$ & $\begin{array}{c}-141.32 * \\
(56.88)\end{array}$ \\
\hline $\mathbf{N}$ & 11521 & 12064 & 12114 & 12656 & 12768 & 13198 & 13096 & 12946 & 12688 \\
\hline $\begin{array}{l}\text { Pr2 } \\
\text { Standard errors in } \\
\text { parentheses } \\
* \text { p }<0.05 * * \mathbf{p}<0.01\end{array}$ & 0.06 & 0.06 & 0.06 & 0.07 & 0.07 & 0.07 & 0.07 & 0.07 & 0.07 \\
\hline
\end{tabular}


Figure 4.15

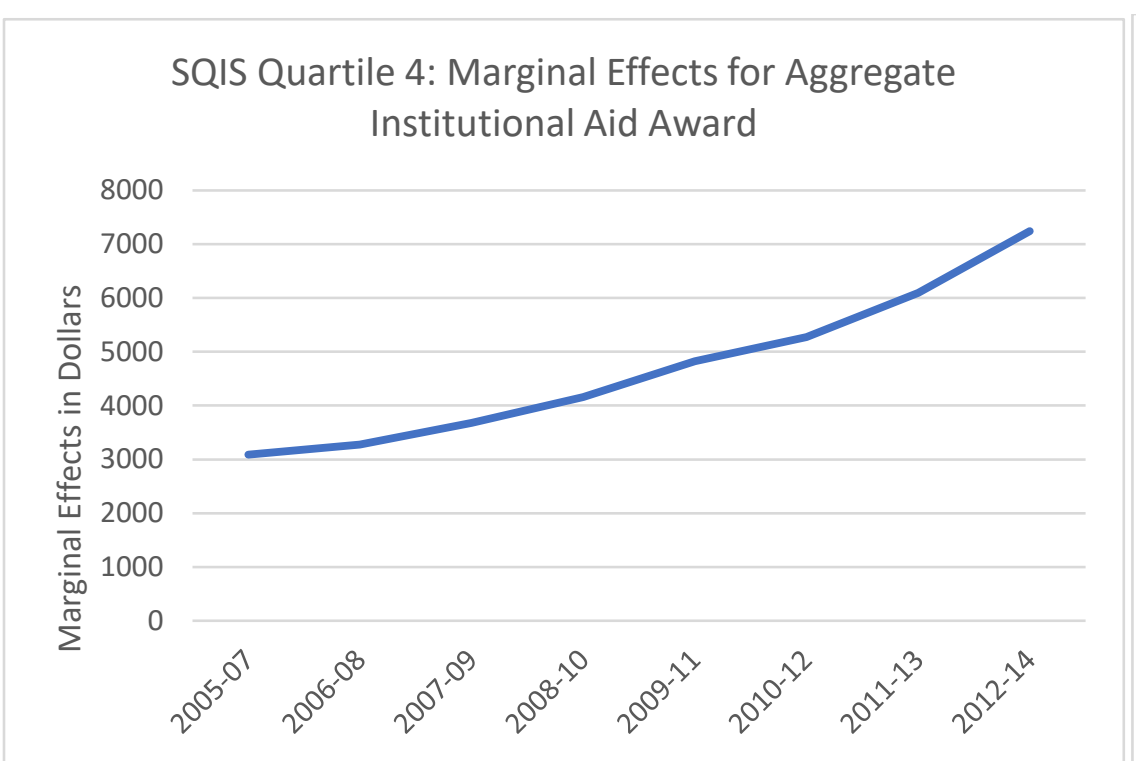

Figure 4.16

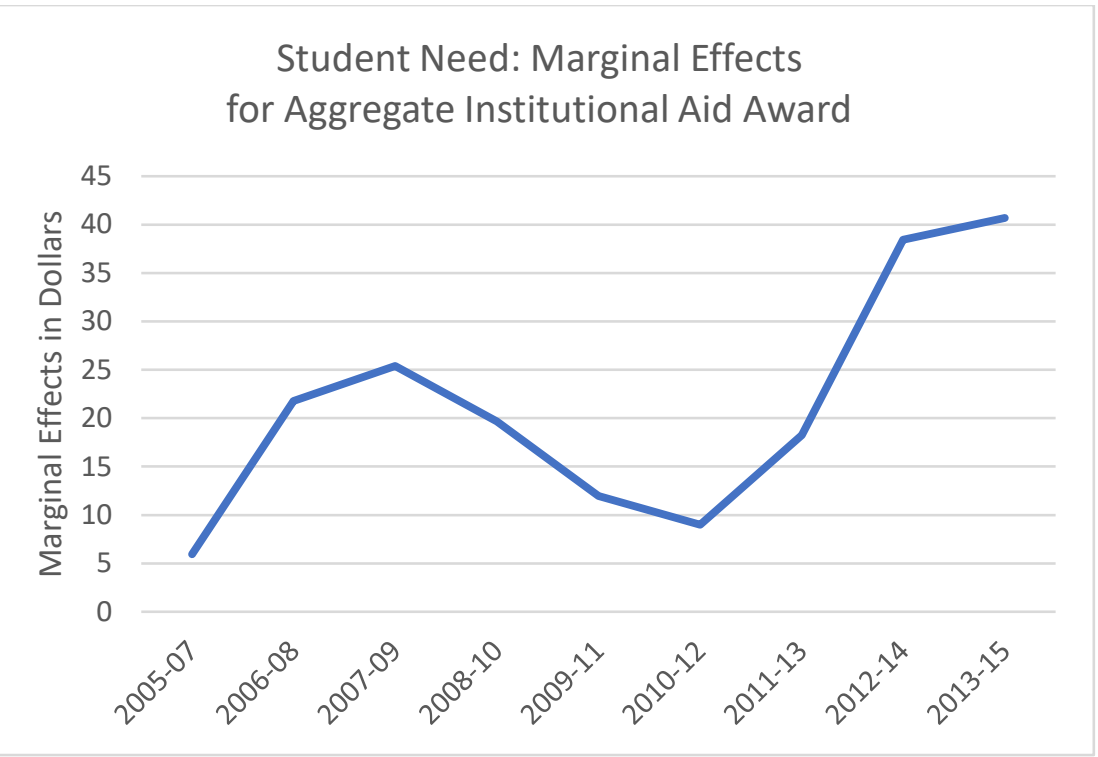

Figure 4.17:

Figure 4.18:

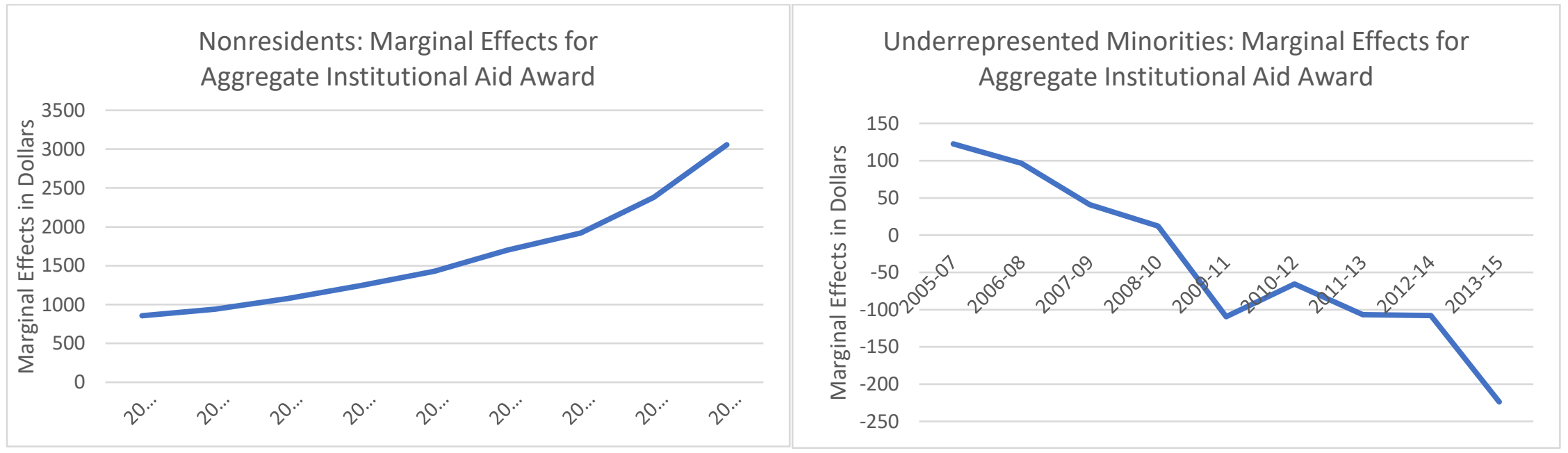


Figure 4.19:

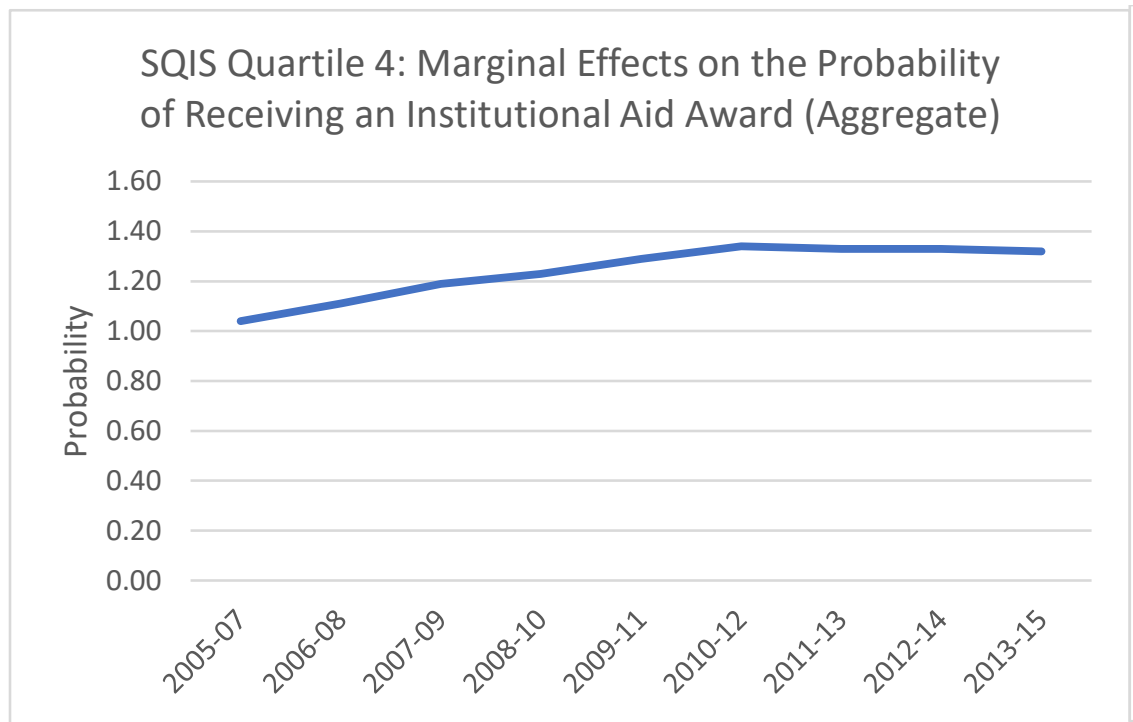

Figure 4.20:

Student Need: Marginal Effects on the Probability of Receiving an Institutional Aid Award (Aggregate)

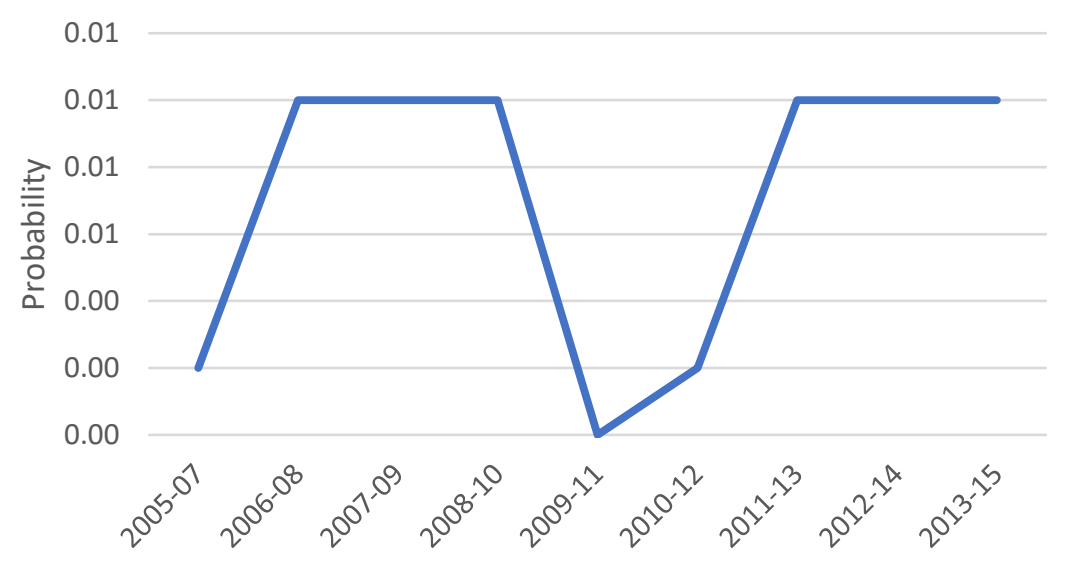

Figure 4.21:

Figure 4.22:

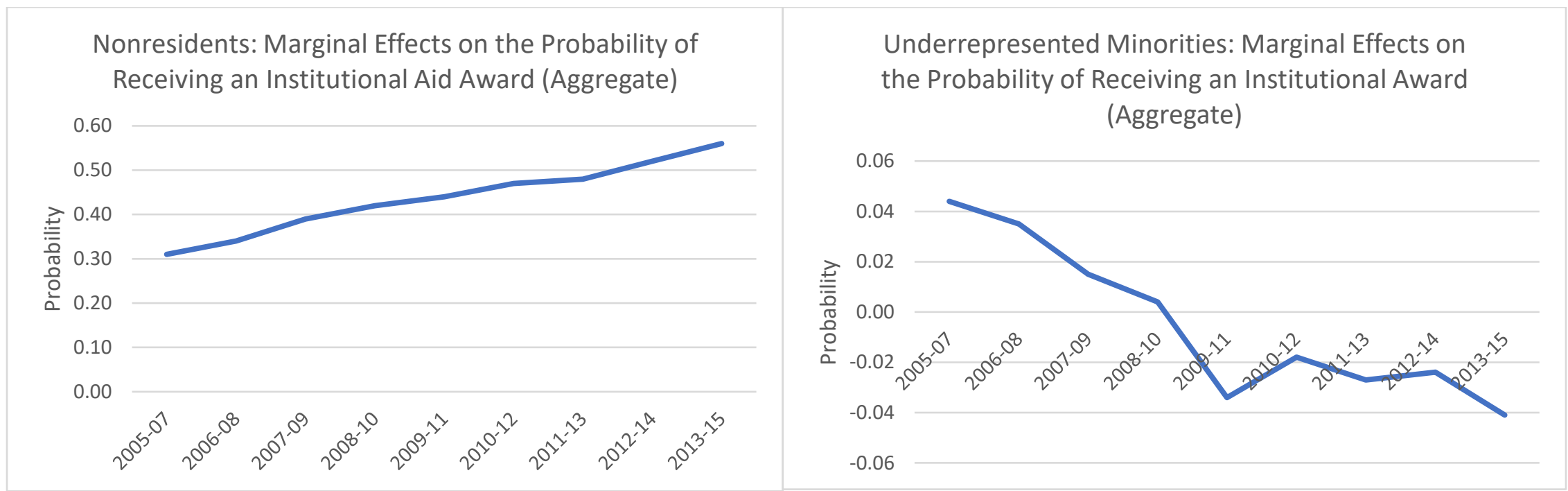


Figure 4.23:

SQIS Quartile 4: Marginal Effects of Need-Meeting Institutional Aid Awardsfor SQIS Quartile 4 Students

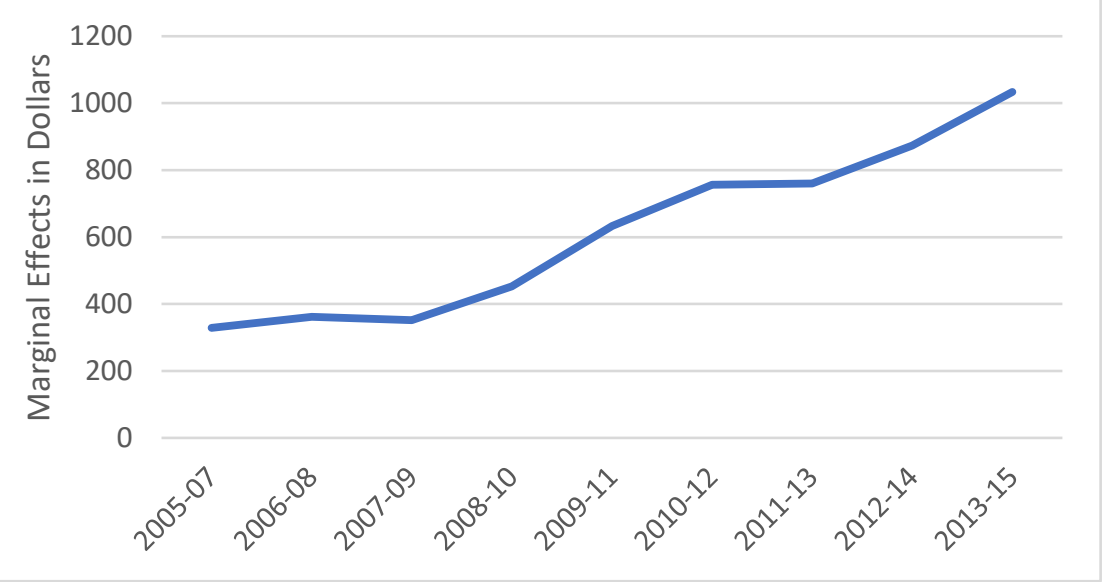

Figure 4.24:

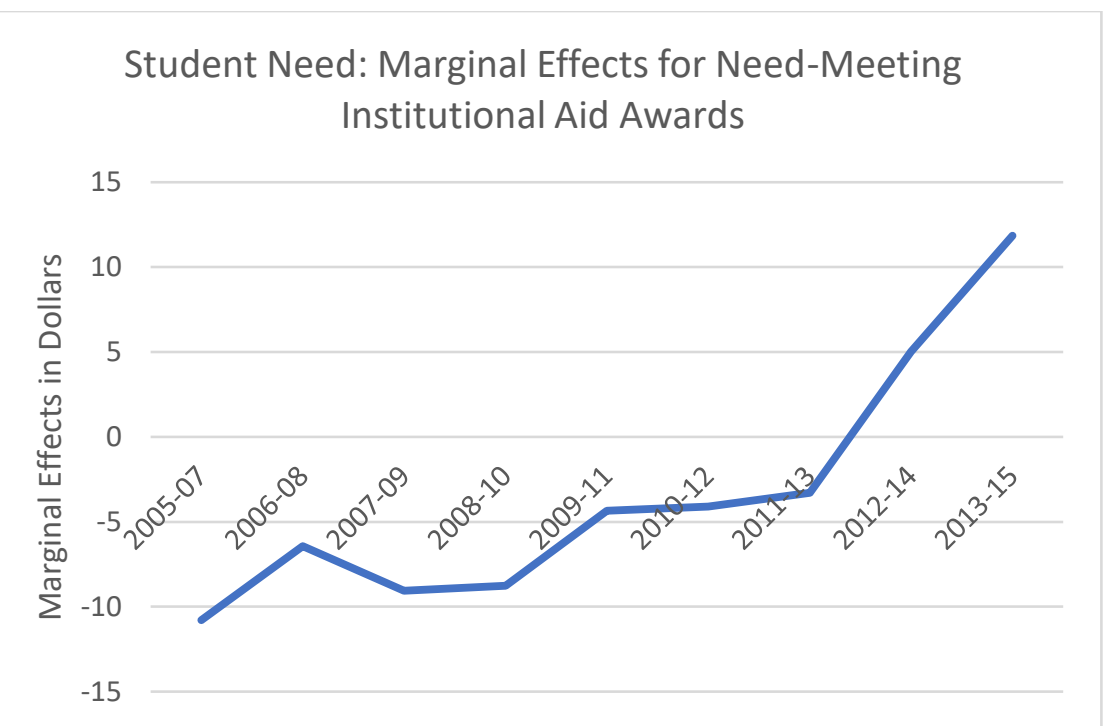

Figure 4.26:

Figure 4.25

Underrepresented Minorities: Marginal Effects for Need-Meeting Instittuional Aid Awards Instituional Aid Awards

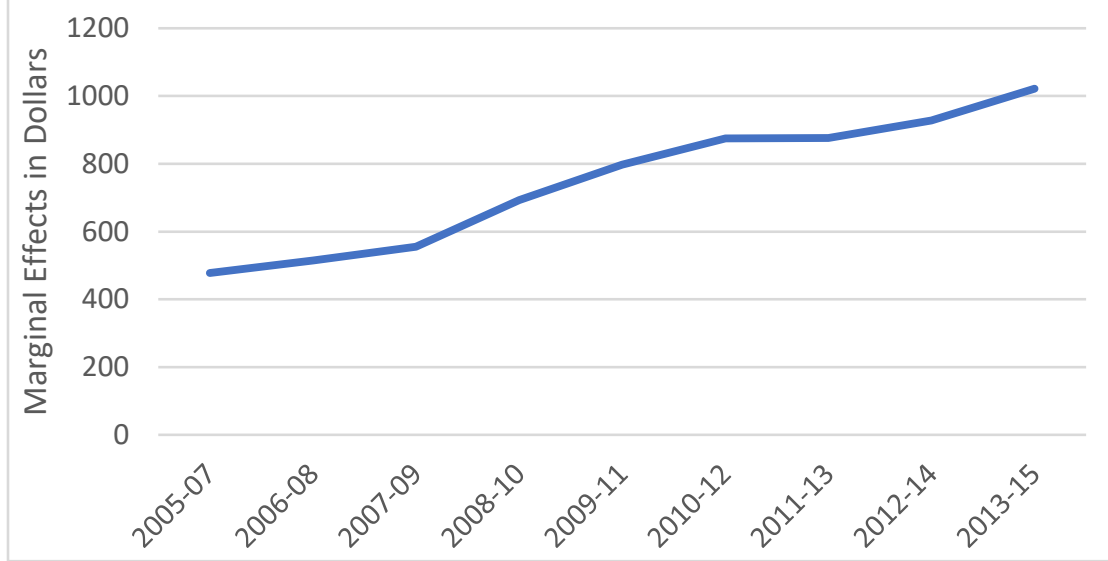


Figure 4.27:

SQIS Quartile 4: Marginal Effects for Need-Meeting Institutional Aid Awards

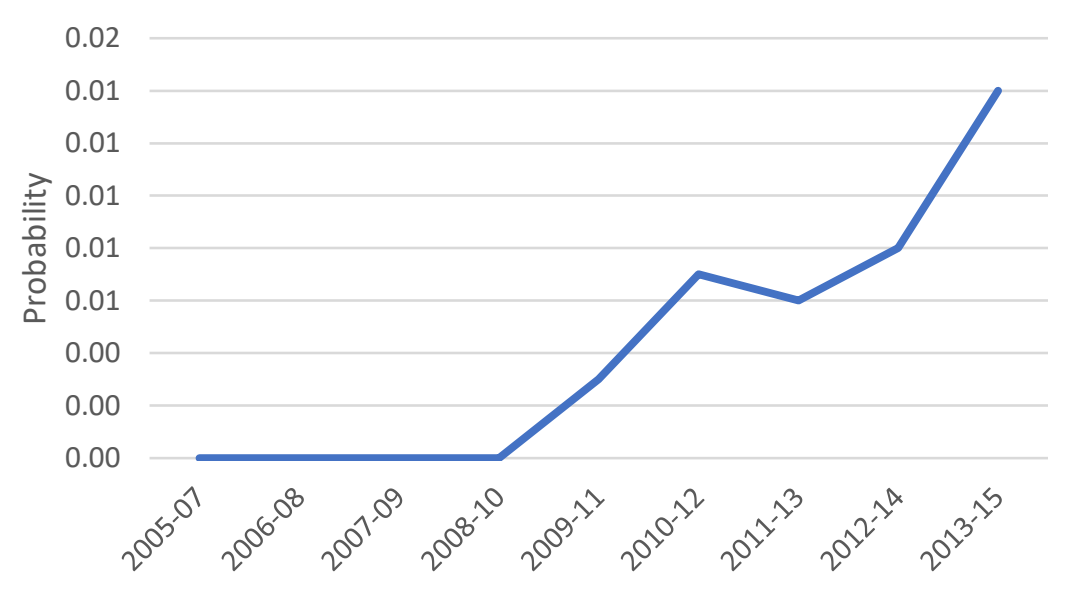

Figure 4.29:

Nonresidents: Marginal Effects for Need-Meeting Institutional Aid Awards

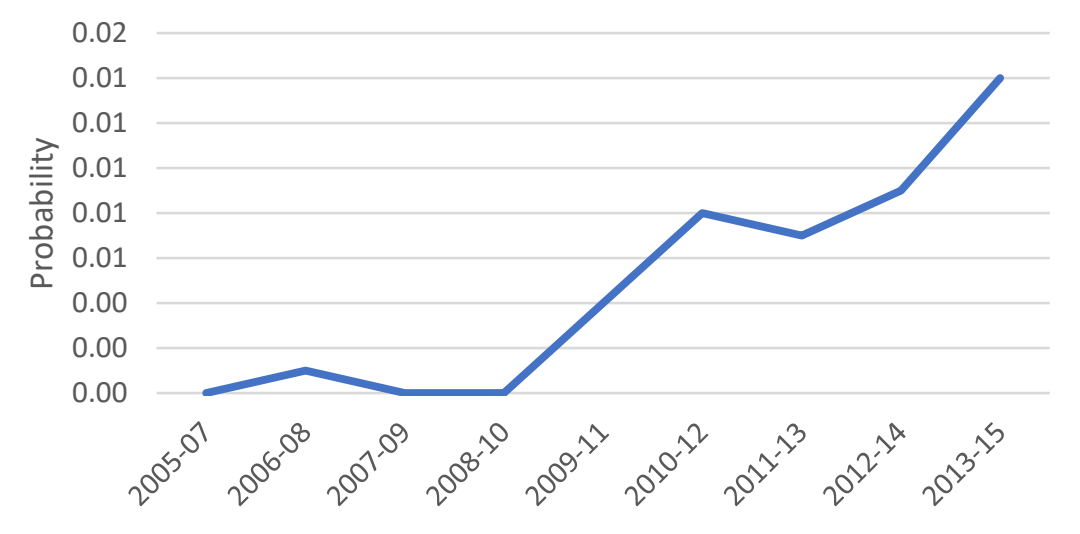

Figure 4.28:

Student Need: Marginal Effects for Need Meeting Institutional Aid Awards

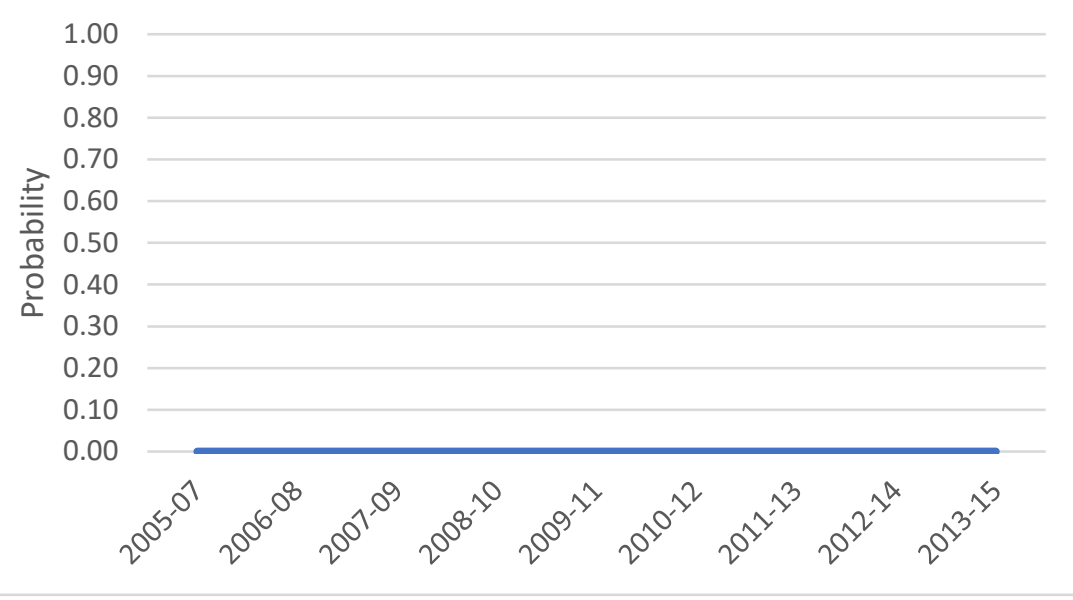

Figure 4.30:

Underrepresented Minorities: Marginal Effects for Need Meeting Institutional Aid Awards

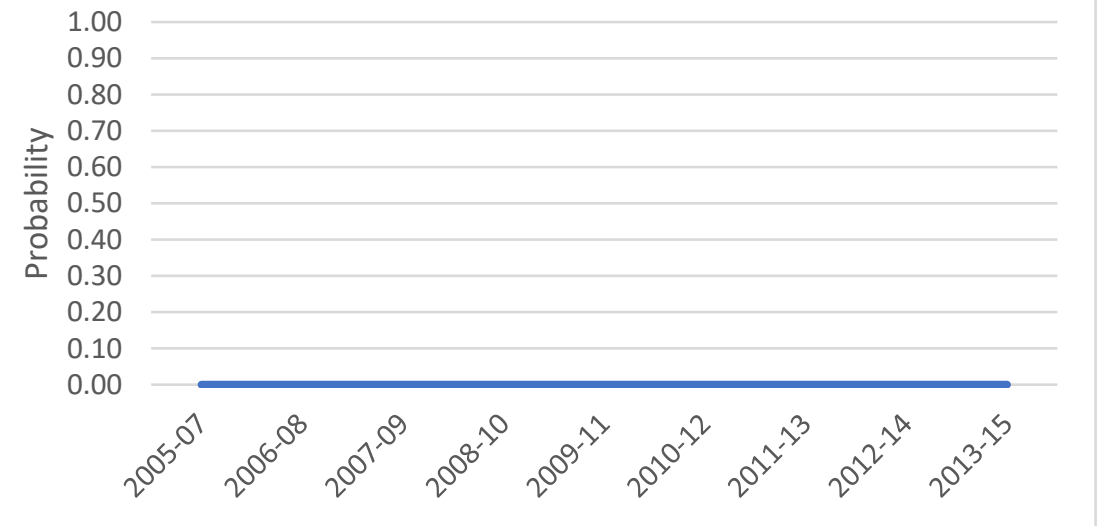


Figure 4.31:

SQIS Quartile 4: Marginal Effects for Non-Need-Meeting Institutional Aid Awards



Figure 4.33:

Nonresidents: Marginal Effects for Non-Need-Meeting Institutional Aid Awards

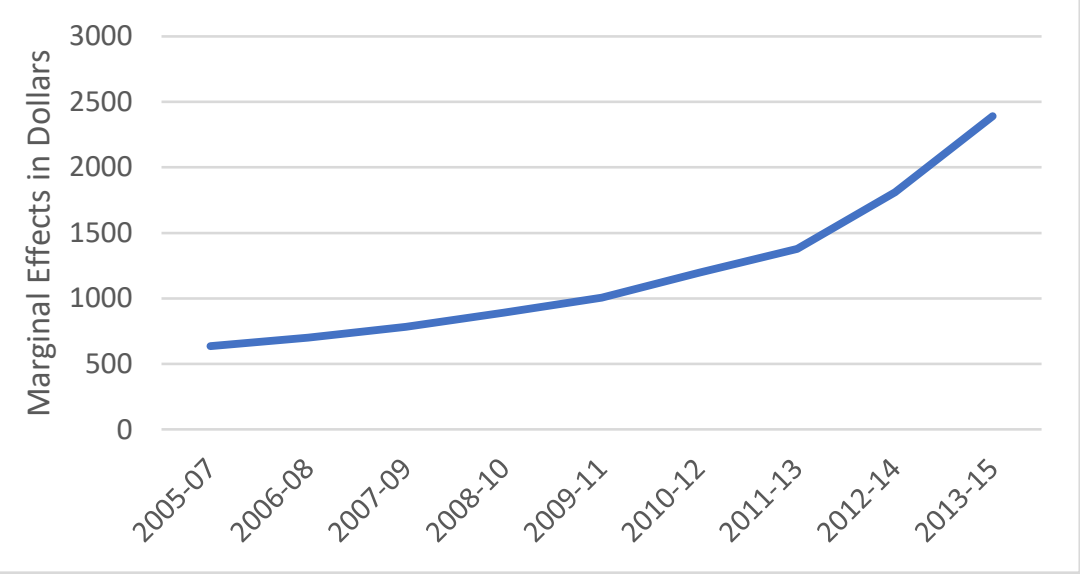

Figure 4.32:

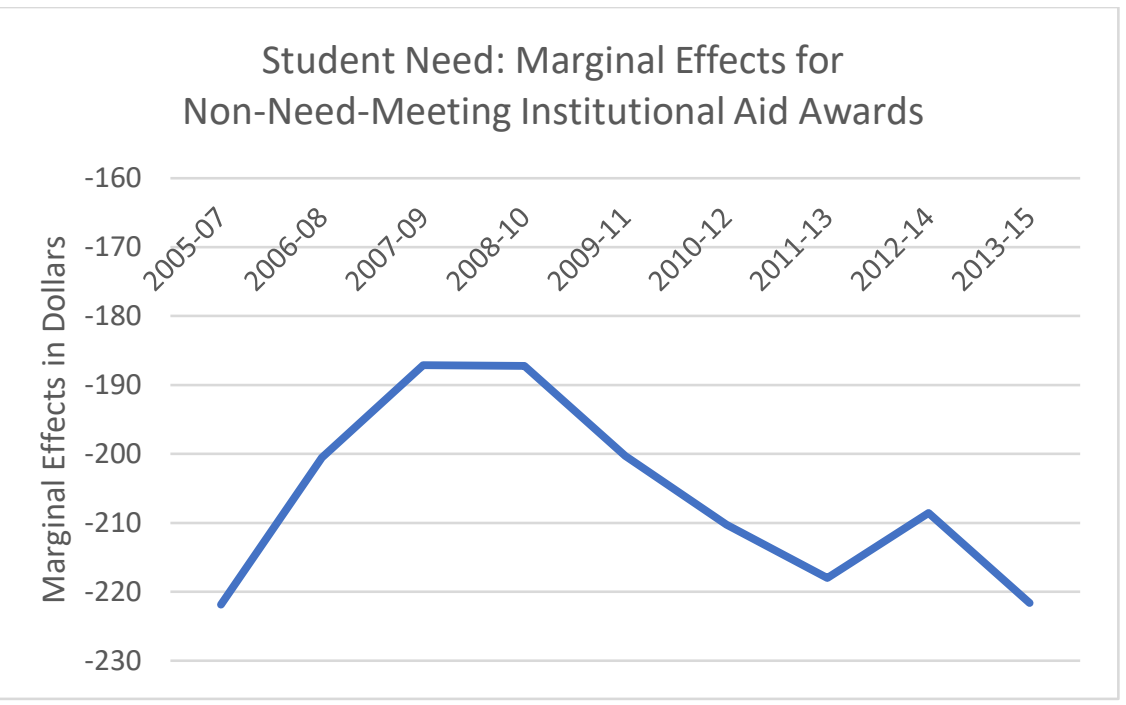

Figure 4.34:

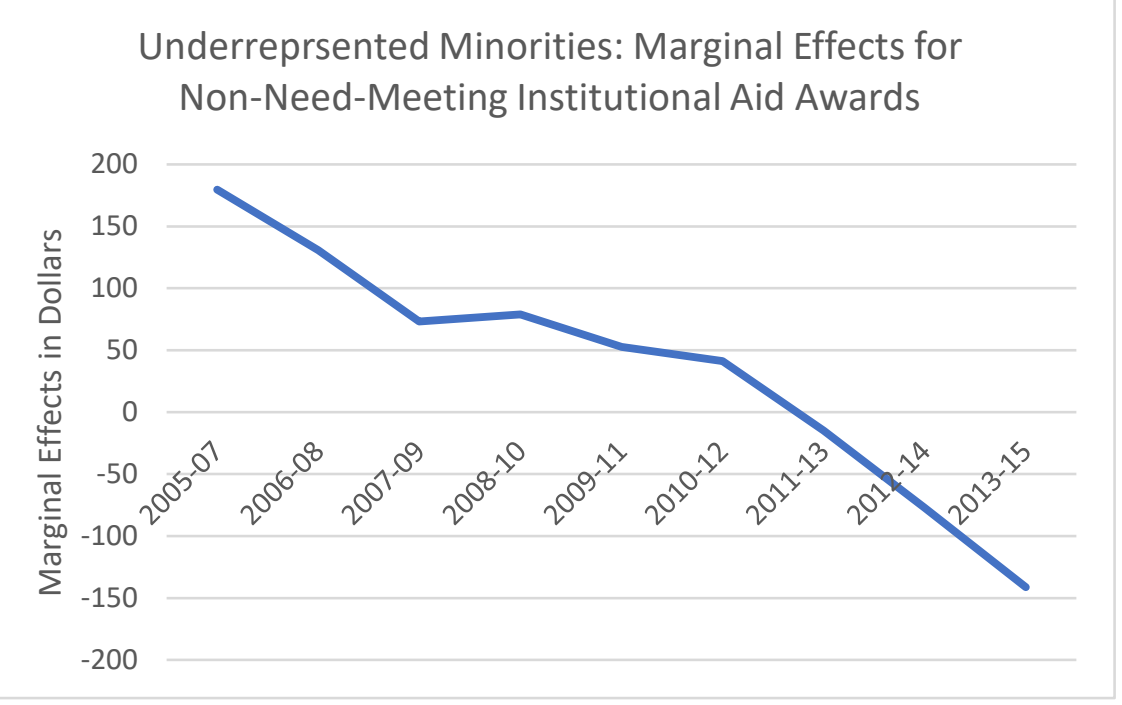


Figure 4.35:

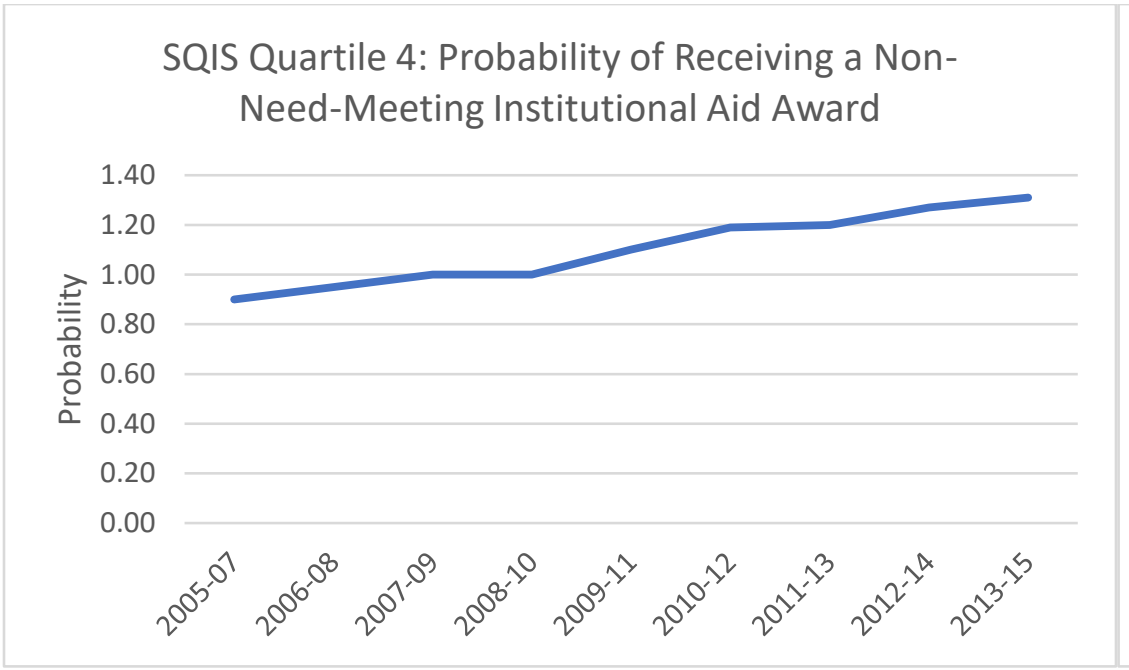

Figure 4.36:

Student Need: Probability of Receiving a Non-NeedMeeting Institutional Aid Award

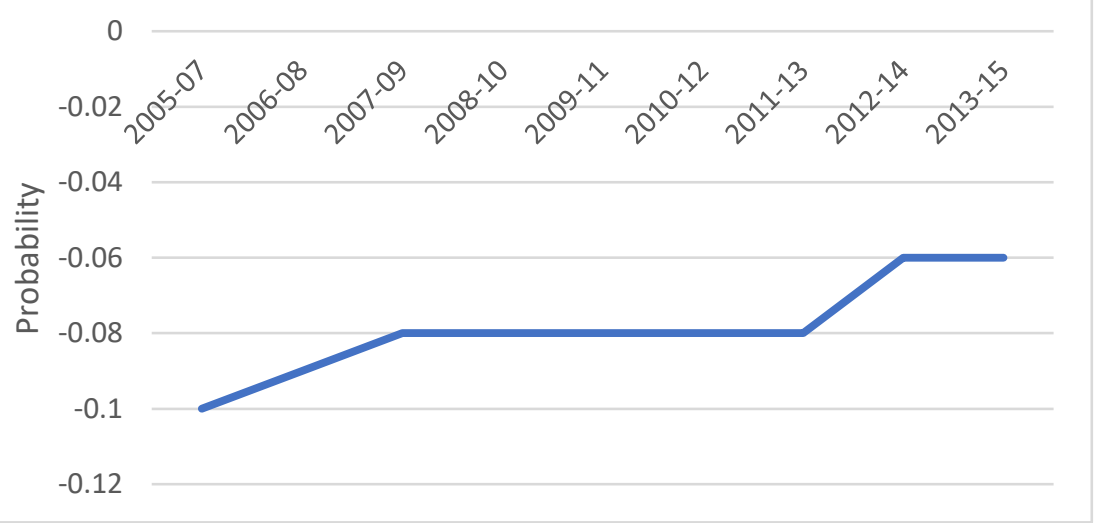

Figure 4.38:

Figure 4.37:

Underrepresented Minorities: Probability of

Nonresidents: Probability of Receiving a Non-NeedMeeting Institutional Aid Award

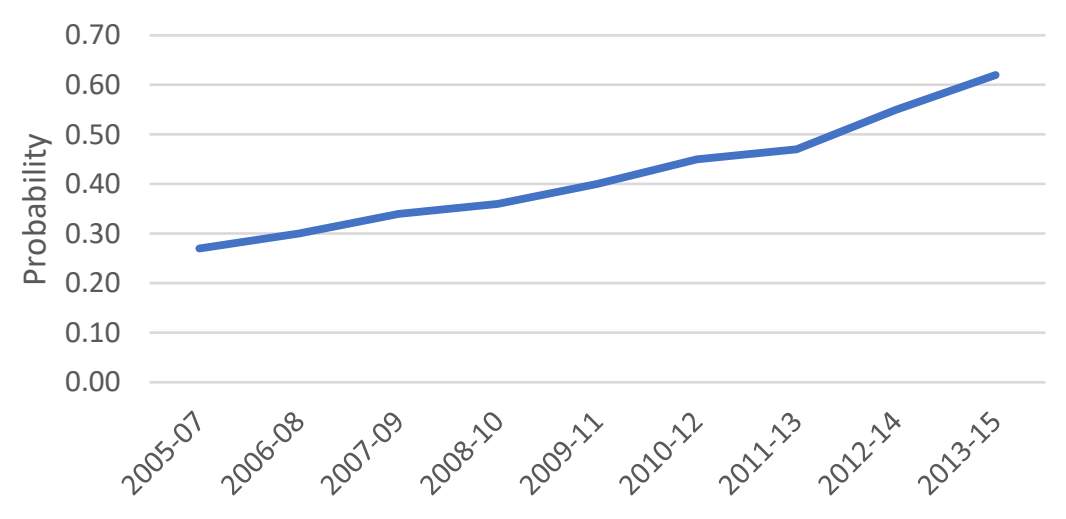

Receiving a Non-Need-Meeting Institutional Aid

Award

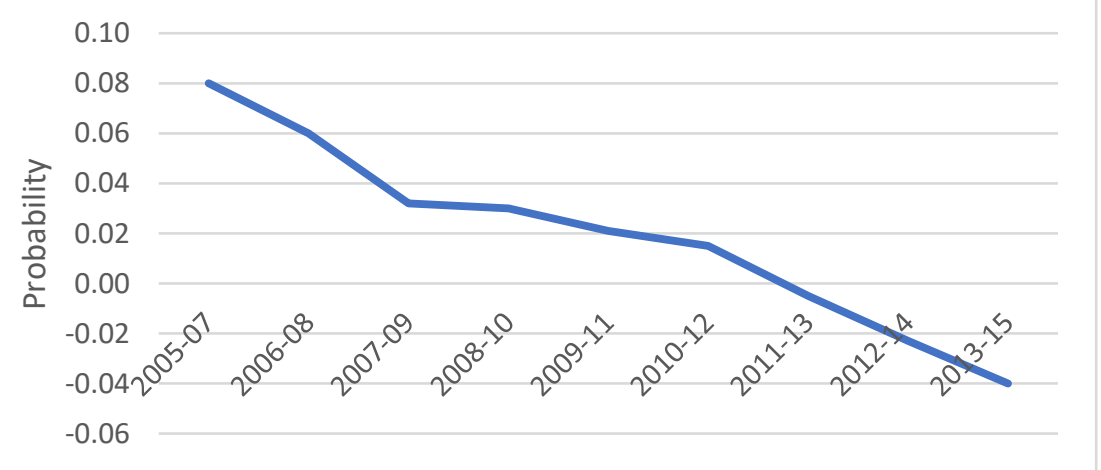




\section{Chapter 5: Conclusion and Discussion}

The results demonstrated many interesting themes of change at the institution. First, enrollment has been relatively stagnant, and in some cases, particularly in-state enrollment, has seen consistent decline during the time period studied. Out-of-state enrollment, while volatile, has steadily out-paced in-state enrollment. Particularly interesting are the proportional changes in institutional enrollment of in-state and out-of-state students where, closer to 2005, the proportions were much closer together resulting in a near even split of in-state versus out-of-state students. The proportion of out-of-state students grew from 2005 to 2008, contracted slightly in 2008 to 2009 , but grew steadily in the following years to reach a new equilibrium in 2005 that places out of state enrollment by residency for fees roughly seven percentage points higher than in-state students overall. As a net result, the institution is enrolling more out-of-state students than it is in-state students, and this trend is continuing.

Since the institution has also proportionally increased in-state student fees at a greater rate than out-of-state fees when controlling for inflation, it appears as though the institution is attempting to incentivize, or at the very least, discount out-of-state enrollment. The decline in out-of-state enrollment from 2012 to 2013 (in 2015 dollars) and virtually no increase from 2013 to 2014, demonstrate institutional willingness to derive greater net tuition revenue from out-ofstate students even if they have to discount tuition. Out-of-state students also see a decrease to their tuition and fees increases by roughly one half of a percentage point from 2009 to 2010 , followed by two years of increased tuition and fee growth, a year of decline, a flat change, and a moderate increase in 2014-15.

A second major theme demonstrated by the data was the increased probability of earning institutional aid awards for students in the highest quartile of academic achievement (as 
measured by SQIS Quartile 4), when compared to those in the lowest quartile of academic achievement (as measured by SQIS Quartile 1). In the aggregate, all three SQIS quartiles provided statistically significant and positive results for both the amount of institutional aid a student would receive on average as well as an increased probability to receive an institutional aid award when compared to the Quartile 1 baseline. As the probability of receiving an institutional aid award for students in Quartile 4, when compared to Quartile 1 students, increases each year of the pooled regressions and the dollar amounts awarded likewise increase, this relationship provides evidence that the institution is awarding institutional aid awards with academic merit as a key consideration. In fact, the average academic award for Quartile 4 students when compared to Quartile 1 students, more than doubles from $\$ 2,930.21$ in 2005 to $\$ 7,243.80$ in 2015. Similar gains are seem for Quartiles 2 and three when compared to Quartile 1 students over time for average institutional aid awards in the aggregate.

SQIS quartiles 2, 3, and 4 also provide some of the few statistically significant independent variables (pooled regression years 2009-11 through 2013-15) with measurable impact on the amount of need-meeting institutional aid a student receives as well and suggests that the institution is providing aid that meets a student's need but is, statistically, highly conditional on a student's academic merit. This may also be what (Cheslock et. al., 2018) consider to be incidental need-meeting aid; especially since need is a statistically significant independent variable from 2005-07 to 2009-11 (and is insignificant thereafter) in the probability of receiving a need-meeting aid award, however overall impact on the probability of receiving a need-meeting aid award is negligible (as indicated by 0.000 coefficients). In other words, the probability of receiving an award may be distributed on the basis of merit without student financial need as a primary condition, yet it still meets a student's financial need. 
For non-need-meeting institutional aid, SQIS Quartiles 2, 3, and 4 are statistically significant at the .001 level for every year of the pooled regression model and demonstrate that merit is a key consideration in the doling out of non-need-meeting aid or aid that goes beyond a student's financial need. The amount of aid, on average, that a student in Quartile 4 of the SQIS received in 2005-07 was \$2,091.64 and \$5,076 in 2013-15 when compared to Quartile 1 students. A similar trend of increases to SQIS Quartiles 2 and 3 are observed when those Quartiles are compared to Quartile 1 students throughout the pooled regression years.

The nonresident indicator - recall that nonresident students are those students who pay nonresident fees as opposed to mere geographical residency - saw the odds of their earning an institutional aid award increase by $28 \%$ points from 2005 to 2015 . This lends evidence to institutional calibration and targeting in the awarding of institutional aid to out-of-state students when compared to in-state students. Nonresidents also receive greater shares of institutional aid awards in the aggregate as well. In 2005, nonresidents received $\$ 856.50$ dollars more in aggregate institutional aid awards and $\$ 3,056.76$ in 2013-15 when compared to resident students - a \%256.9 increase from 2005-07 to 2013-15. Couple that finding with the trend with imbalanced changes to tuition and fees for in-state and out-of-state students may provide evidence of an institutional approach to leverage net-tuition by sharply increasing the rate of increase for in-state student tuition and fees - which are already relatively low when compared to out-of-state students residents - and only marginally increasing, or in some cases decreasing, out-of-state student tuition and fees while also providing discounts to out-of-state students in the form of institutional aid awards. Granted, the increases or decreases are to the prior year's tuition price, it does demonstrate institutional willingness to change its sticker price to differing student constituencies to affect student consumer habits to capitalize on potential discounts. 
However, in-state students have a greater overall share of the SQIS Quartile 4 student population for 2005-06. In 2005-06, 694 in-state students represented an overall share of 77.98\% of the total Quartile 4 students, $60.76 \%$ of Quartile 3 students, $43.83 \%$ of Quartile 2 students, and $35.36 \%$ of Quartile 1 students. Over the next decade, the proportions change. In 2015-06, instate students represented 63.94\% (a 14.04\% point decrease) of the overall Quartile 4 student population, $54.80 \%$ (a $5.96 \%$ point decrease) of the Quartile 3 population, $39.35 \%$ (a $4.48 \%$ point decrease) of the Quartile 2 population, and 32.10\% (a 3.26\% point decrease) of the Quartile 1 population. The data suggests that although in-state students represent a greater share of the overall student quality as measured by SQIS quartiles, they still receive a smaller amount of institutional aid in the aggregate when compared to nonresidents. Need as an independent variable may help partially explain this relationship because need is positively correlated with institutional aid awards in the aggregate and since the nonresident student has more need, on average, they are more likely to receive an institutional aid award when compared to residents because resident need is lower relative to out-of-state students (see Chapter 4, Table 2).

Resource dependence theory would suggest that this enrollment management behavior is also indicative of institutional attempts to align itself with its new resource providers. As the institution becomes more dependent upon out-of-state enrollment - a theme that the trend in enrollments suggests - the institution will also become more responsive to its new resource providers (Pfeffer and Salancik, 1978). Therefore, discounts to potential increases in tuition and fees provide greater incentives for current out-of-state students to re-enroll the following semester or term - at least for students where cost is a consideration - as well as to entice new enrollments the following year where a potential discount to the new out-of-state students are perceived. 
Although the institution has been enrolling greater proportions of out-of-state students, those students have also increased in overall academic quality when measured by the SQIS. In 2005-06, the average in-state SQIS score was 105.31 and out-of-state was 93.81. In 2015-16 the average in-state SQIS was 108.27 (a 2.8\% increase from 2005-06) and the average out-of-state SQIS was 99.45 (a $6.0 \%$ increase from 2005-06). Much of this change is likely attributable to increasing GPAs as the average high school GPA for in-state students was a 3.51 whereas it was 3.14 for out-of-state students. These values increased to 3.60 for in-state students (a $2.8 \%$ increase from 2005-06) and 3.34 for out-of-state students (a 6.4\% increase from 2005-06). Standardized test scores as measured by a concorded ACT for in-state student averaged 23.68 for in-state students and 22.25 for out-of-state students. These values increased to 24.15 (a $2 \%$ increase from 2005-06) for in-state students in 2015-16 and 22.82 (a 2.26\% increase from 200506) for out-of-state students in 2015-16.

An important take-away regarding academics as a driver of institutional aid as it concerns in-state and out-of-state students is that nonresidents enjoy a much higher probability for receiving an institutional aid award and they also enjoy a much higher institutional aid award on average as demonstrated by the regression tables. However, it is also critical to consider that, on average, in-state students out-perform out-of-state students in average SQIS score, average high school GPA, and average concorded ACT score for both 2005-06 and 2015-06.

The evidence suggests that nonresidents became a favored constituency over time. In 2005-06, nonresident students were $104 \%$ more likely than residents to earn an institutional aid award. The probability of nonresidents to earn an institutional aid award steadily increased from 2005-06 to 2015-16 to a new high of $132 \%$ more likely than residents to earn an institutional aid award. Not only does the probability of earning an institutional aid award increase over time for 
nonresidents, but the actual value of the institutional aid award also increases over time. The pooled nature of the data also allows for controlling for outliers and other noise that may provide for unreliable estimates, thus providing robust coefficients for comparison. The smooth transition of the data from year to year and the overall dearth of sporadic changes to institutional practice demonstrates the deliberate and steady nature of the change in institutional preference for out-ofstate students.

A third theme is that a student's need, while statistically significant and having a positive and statistically significant impact on the probability of a student receiving an institutional aid award in the aggregate, does not have a dramatic impact on whether or not a student receives an institutional aid award as the coefficient for need only reaches 1\% increases for 2006-8, 2007-09, 2008-10, 2011-12, 2013-14, and 2015-16. Given the large disparities between the need of instate and out-of-state students as demonstrated in Chapter 4, Table 2, I would have anticipated a greater effect for a student's financial need on the probability of a student receiving an award. Perhaps this result is highly conditional on residency as opposed to aggregate awards. In other words, although the model suggests that student need is a significant predictor (i.e. not happening by chance), the impact of that relationship is very low. Granted, a one unit increase in need $(\$ 1,000)$ is cumulative suggesting that higher levels of need may result in an institutional aid award. However, the average in-state need is very low when compared to in-state student need (see Chapter 4, Table 2). This relationship may also suggest that institutional priorities for assigning institutional aid was not particularly driven by a student's financial need and instead by the need that is generated primarily due to the difference in tuition and fees for resident and nonresident students. 
A fourth theme is the rate in which the overall cost of attendance is highly mitigated for out-of-state students when compared to in-state students. When comparing the median and mean discount rates for in-state and out-of-state students the rate of increase in the discount rate for instate students lags far behind out-of-state students (see Figure 5.1). Evaluating the discount rate Figure 5.1

Aggregate Institutional Aid Discount Rate by Year and Residency

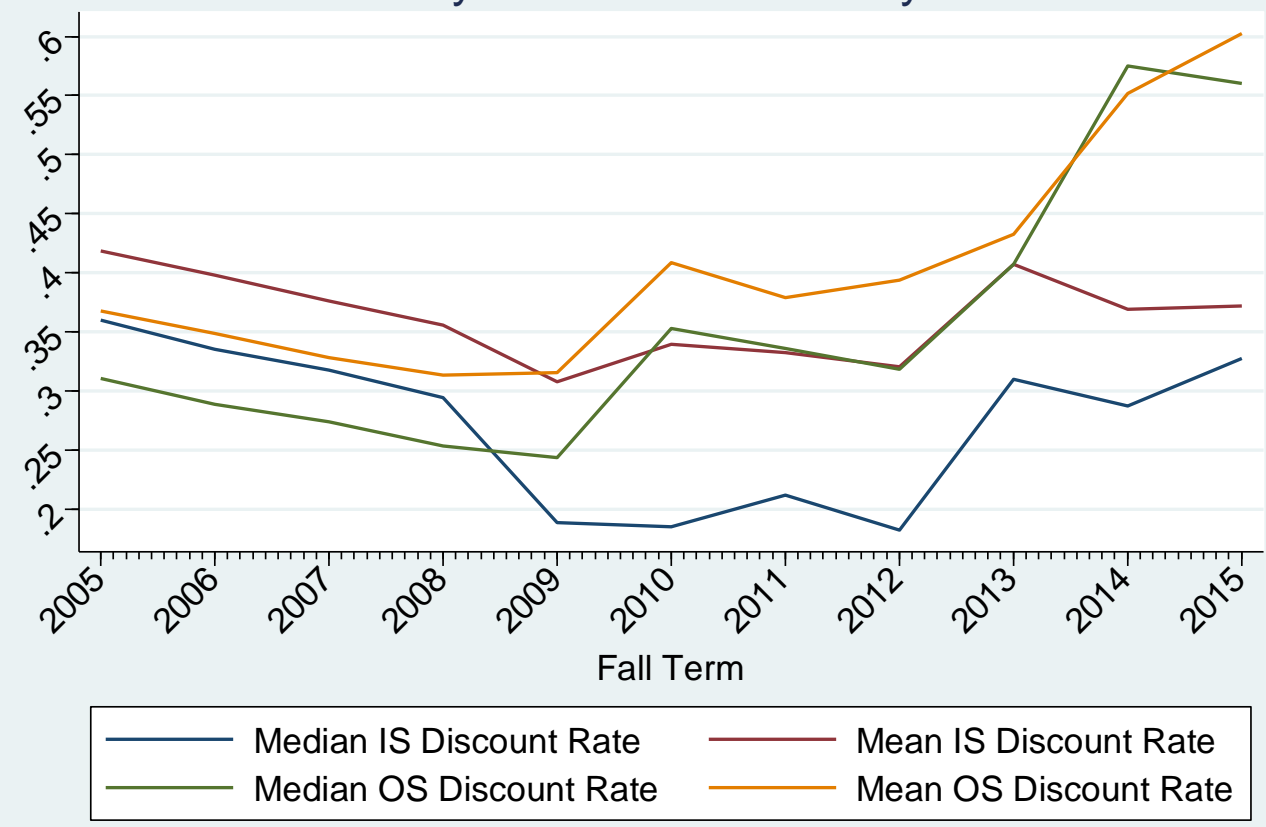

of in-state students at the start of the evaluation period (2005) indicates that the in-state discount rate was higher than out-of-state students. In 2009, however, the mean rates intersect and the mean rate at which out-of-state students receive a discount outpaces in-state students. The instate and out-of-state rates do not intersect again after 2009 and remain separated by roughly 5\% points until 2013, where the mean out-of-state discount rates rises above $60 \%$ and the in-state mean discount rate drops below $40 \%$. The median rates for in-state and out-of-state students indicate that out-of-state students from 2005 to 2009 had a lower rate of discount when 
compared to in-state students where, again, intersect from 2008 to 2009 and the median out-ofstate discount rate outpaces the in-state discount rate resulting in a roughly $55 \%$ median discount rate for out-of-state students in 2015 to a less than $35 \%$ median discount rate for in-state students.

If I evaluate the lower differences in differences in the discount rates - the median discount rate - a $60 \%$ discount to an out-of-state student in 2015 would equal a $\$ 12,859$ discount on a cost of attendance of $\$ 21,432$ where the out-of-state student ends up paying $\$ 8,572$. For instate students, a $35 \%$ discount on an in-state cost of attendance of $\$ 7,632$ would equal a total discount of $\$ 4,579$ where the in-state student would end up paying $\$ 3,053$. Therefore, the difference between in-state and out-of-state students is that, in the aggregate, out-of-state institutional aid award recipients pay $\$ 4,579$ more than in-state students. The average award, in the aggregate for out-of-state students in 2015 was $\$ 10,058$ and \$1,148 for in-state students in 2015. Finally, in the net tuition calculation where the median discount rate is considered, out-ofstate students pay approximately $\$ 5,520$ more that in-state students. As a ratio, out-of-state students pay approximately, $\$ 2.81$ dollars per every in-state student dollar and suggests that while the outlays of institutional for students is higher, the overall net-tuition received by the institution is approximately 2.8 times higher than in-state students.

\section{Implications for Future Research}

Results and the Current Literature

Heller's (2001) research found that institutional aid increased by 111\% from 1989 to 1995. The results from this dissertation found that, in the aggregate, institutional aid increased by 213.4\% from 2005 to 2015 with the average institutional aid award, in the aggregate, increasing by $145.6 \%$. Heller (2001) had also found that the quantity of non-need-based grants decreased, 
but the overall mean of the awards had increased, signaling the greater possibility of its strategic use by institutions for enrollment management purposes. The current results suggested similar findings in that in-state students did receive a decreased amount of need-meeting aid awards in 2015 when compared to 2005, however, the average aid award did increase for in-state students by $155.4 \%$. Out-of-state need-meeting aid awards did increase in the aggregate in both the number of awards by $44.5 \%$ and the average aid award by $146.8 \%$. Consistent with Heller's (2001) assertion, these increase to out-of-state student award values both in frequency and amount may signal institutional aid need-meeting aid awards as having strategic use.

However, Heller (2001) did find that Asian students had outpaced all other racial demographics when receiving a need-based award. Asian students in the current study suffer from a low population that does not allow for adequate and reliable statistical inferences to be made. Asian students did drop by $5.1 \%$ in the number of non-need-meeting aid awards received between 2005 and 2015 with the losses stemming entirely from the in-state constituency, whereas the out-of-state constituency rose by $133.3 \%$ from 3 awards to 7 . Also, the total value of in-state non-need-meeting aid awards increased by $95.2 \%$ in 2015 , out-of-state awards increased by $388.1 \%$, and total non-need-meeting institutional aid increased by $134.3 \%$. All of these values were surpassed by the URM cohort as they increased by $116.2 \%, 826.6 \%$, and $393.0 \%$ respectively. Also, Asian students did not outpace URM students in the aggregate rate for increase in aid awards for the frequency of in-state or out-of-state awards but did outpace URM students for the average in-state award increase rate (104.8\% to $23.1 \%)$, the average out-of-state increase rate ( $143.8 \%$ to $128.7 \%)$, and the average total award (137.1\% to $119.7 \%)$.

Heller (2001) had found that the overall number of non-need based awards were falling across the racial categories. This dissertation has found that non-need-meeting aid grew across 
all cohorts both in the average size of the aid award pool out for in-state and out-of-state students, but in the actual growth rate of non-need-meeting pool of money invested by the institution. Frequency, however, did decline for Asian students from 2005 to 2015 as a smaller amount of total awards were doled out, but that was only limited to in-state students suggesting that while the overall amount of non-need-meeting funds increased and the number of in-state awards for the same decreased, the institution likely engaged in strategic use of those funds for out-of-state Asian students.

Doyle (2012) found that over time student need was a good early predictor of institutional aid amounts as needier students received approximately $\$ 400$ more than their high-income counterparts, but also found that the institution shifted away from need to merit as they awarded higher SAT performers as time progressed. Results compiled here demonstrated that need was also a significant negative predictor of institutional aid in the early years of the pooled regressions and only became positively significant in the final year of the pooled regression however, the impact of student need never exceeded $1 \%$ for each $\$ 1,000$ demonstrated in student need when measured against students with no need. Furthermore, the highest level of student academic aptitude as measured by the SQIS quartile four also demonstrated the increased impact of high academic aptitude from 2005 to 2015 as the probability of receiving an aid award for Quartile 4 increased from 104\% (2005-06) to 132\% (2015-16) when compared to Quartile 1. Doyle (2012) also suggested that institutions may use institutional aid as an impetus for students to attend their institution who might not otherwise come and that to achieve that end institutions will respond to a myriad of student characteristics.

Cheslock et. al. (2018) suggested that institutional aid awards centered on two possibilities. First, the institution would attempt to mitigate the highest levels of need with 
institutional aid or, second, would allocate institutional aid to all students who have need without necessarily focusing on the highest levels of need. In the data examined here, this does not appear to be the case as need while a strong predictor of the probability of receiving an award, its actual impact on the institutional aid received is marginal and is highly conditional on the amount of financial need a student has. Cheslock et. al. (2018) did find that institutional aid awards increased quickly for nonresident students as out-of-state awards increased by $54 \%$ from $\$ 2017$ to $\$ 3134$ whereas in-state awards increased only 3\% from $\$ 1,255$ to $\$ 1,292$. This dissertation confirms those findings but with much wider growth intervals. For the institution at study, the aggregate institutional aid awards for out-of-state students increased by $289.5 \%$ (over five times of that found in Cheslock et. al., 2018) and in-state student institutional aid award increased by $65.5 \%$ - an almost 22-fold increase compared to Cheslock et. al., (2018).

The authors also found that students with high SAT scores were considered important to the institution for many reasons. One reason included the production input the students provide and the desire of the institution to acquire it through the use of institutional aid. Results from this dissertation demonstrated an increased importance of the highest performing students in both standardized test scores - including SAT and ACT test-takers - and high school GPA, suggesting institutional aid is tethered to academic aptitude as measured by the SQIS. Nonresidency was also a significant predictor of the probability of receiving an aid award in the aggregate was the students residency status, where nonresidents were $132 \%$ more likely than nonresidents to get an institutional aid award in 2015-16 a 25\% point increase from 2005-06. The average award also increased from $\$ 856.50$ in $2005-06$ to $\$ 3,056.76$ in $2015-16$. Nonresident students were also $1.4 \%$ (up from $0 \%$ in 2005-06) more likely than resident students to receive a 
need-meeting aid award in 2015-16, and 62\% (up from 27\% in 2005-06) more likely than residents to receive a non-need-meeting institutional aid award in 2015-16.

Nonresident status also informs need-meeting aid as it is one of the few variables in the need-meeting regressions to demonstrate a statistically significant result $(\beta=.039, \mathrm{p}<.001)$ with a probability that is greater than $1 \%$. These results however, are only applicable to the second half of the sample years non-residency only becomes significant as predictor in the probability of receiving a need-meeting aid award from 2009-11 to 2013-15. In fact, student need is the only significant variable in predicting the probability of receiving a need-meeting aid award from 2008-10 and earlier. Nearly all other variables in the need-meeting regressions produced statistically insignificant results or results below a $1 \%$ increase in probability.

Nonresident status was also a positive and highly significant variable for non-needmeeting aid whereas the underrepresented minorities produces alarming results for non-needmeeting aid. URM students in 2005-07 were 8\% more likely than non URM students to receive a non-need-meeting aid award. However, this relationship flips in 2013-15 as URM students were then $4 \%$ less likely than non URM students to receive a non-need-meeting aid award. These results suggest that URM students were previously targeted with institutional aid awards that go beyond need, however, no longer receive these aid awards with any statistically significant result, but instead, receive \$223.84 less in institutional aid (in the aggregate) than their nonunderrepresented peers.

Jaquette and Curs (2015) suggested that institutions will respond to government disinvestment through nonresident enrollment as a means to increase their net-tuition per student and offset the costs of lost government investment. As the institution at study in this dissertation experienced state disinvestment intermittently and an economic recession that occurred near the 
middle of the period studied, calculation and re-calculation of the institution's solvency and resource dependence (Pfeffer and Salancik, 1978) on certain student constituencies were evaluated and re-evaluated over time. Changes to institutional enrollment strategies are witnessed when evaluating both the proportional change to in-state and out-of-state enrollments in general as well as the institutional preferences for institutional aid award recipients over time. Although nonresident students have always been a component of balanced enrollment portfolio at the institution, the institution's dependence on out-of-state enrollment has been exacerbated in recent years.

As resource dependency suggests, as the institution becomes more dependent on the outof-state student enrollment and the concomitant increase in net-tuition gained from recruiting out-of-state students, the institution also saw greater benefit to align with out-of-state interests to lower the cost of attendance through the increase in institutional aid awards for nonresident students. The institution also increased at a lower rate (when accounting for inflation) out-ofstate increases for tuition and fees over time. Although a smaller increase may lead to a larger increasing in real dollars spent for out-of-state students because the cost of attendance for out-ofstate students is already substantially higher than in-state students, the decision to increase those rates at lower rates than in-state students suggests a change in institutional strategy that aligns with the start of the great recession. By increasing in-state rates at a higher overall rate while strategically increasing out-of-state rates at a lower rate, the institution still provided a relatively low cost option to its in-state residents, but a more attractive rate, potentially, to its out-of-state residents when compared to their other options. As the institution also increased its institutional aid offerings to nonresident students while also increasing its spending on in-state institutional aid offerings, the institution was hedging in-state investment through out-of-state tuition 
maximization. In other words, although out-of-state students received more aid in the aggregate and experienced more growth, out-of-state students were still paying, on average, 2.8 times more than in-state students when accounting for institutional aid.

The link that this dissertation establishes is the preferential awarding of institutional aid funds to out-of-state students using criteria that is not objectively based upon the students academic aptitude as measured by the SQIS score, first-generation status, student need, student EFC, gender, or Asian status. Although SQIS is an important indicator of a student's probability of receiving an aid award where students in the highest quartile are $3.1 \%$ more likely than those in the bottom performing quartile, the finding is overshadowed by the significance $(\mathrm{p}<.001)$ and the impact $(\beta=\$ 1,580)$ of nonresident students when compared to resident students.

A final and surprising conclusion relates to unexpected growth in the proportion of underrepresented minority students. Research by Jaquette, Curs, and Posselt (2016) demonstrated that the growth in the proportion of nonresident students also resulted in the decline in the proportion of low-income students as well as the proportion of underrepresented minorities. Findings from this dissertation demonstrate that the proportion of underrepresented minorities increased as the proportion of nonresidents grew over time. For example, in 2005-06, the overall proportion underrepresented minorities were $6.59 \%$ of the FTFTF population increasing to $12.61 \%$ in $2015-16$ (a $6.02 \%$ increase). URM students constituted $8.34 \%$ of the instate student population (up from 4.52\% in 2005-06). In 2015, URM students constituted 16.30\% of the out-of-state student population up from $8.63 \%$ in $2005-06$.

In 2015, 28.68\% of all FTFTF were Pell recipients (up from 19.79\% in 2005-06). In-state Pell recipients increased to $34.70 \%$ in $2015-16$ (up from $23.48 \%$ in $2005-06$. Out-of-state Pell recipients also increased by $7.32 \%$ points in 2015 to $23.47 \%$ (up from $16.15 \%$ in $2005-06$ ). 
Students at the intersection of being a URM student as well as a Pell Recipient also saw growth over the analysis period. Overall, students who were a URM student and a Pell Recipient increased from an overall rate of $39.06 \%$ in $2005-06$ to $48.95 \%$ in $2015-06$. In-state URM students who were also Pell recipients increased from $41.58 \%$ in $2005-06$ to $56.00 \%$ in $2015-06$. Finally, out-of-state students increased to $45.82 \%$ in 2015-06 (up from $37.76 \%$ ). These results suggest that while the out-of-state enrollment for institution did indeed grow, the resulting proportional decrease in low-income students as well as underrepresented minorities found by Jaquette, Curs, and Posselt (2016) was not supported by the results found in this dissertation.

\section{Implications for Practice}

Through the lens of resource dependence, readers of this dissertation should understand that institutional aid as a mechanism to align with resource providers must be considered in light of all institutional goals. While net-tuition maximization is a worthwhile strategy, especially for enrollment dependent organizations, the goal of institutional aid should also consider student dimensions such as student need, student aptitude, institutional mission, higher education access, and the purpose of creating an educated citizenry. As the institution studied here is a public, research, land-grant university, consideration of those realities should have some appreciable influence on instructional decision-making. The purpose of land-grant institutions has, historically, been to provide the working classes with an opportunity to become educated in the liberal arts and gain a practical education to apply in their everyday lives. But, when the primary paradigm through which these institutions is disrupted (e.g. government disinvestment) the institutions are required to look elsewhere in order to fill those gaps and continue their goalseeking behavior - which may also cause it to drift away from those primary mission-oriented goals. 
The implications for the practice of higher education administration are numerous. First, this research helps demonstrate the power of resource dependence and how it can inform institutional decision-making. Second, it also demonstrates how institutional decision-making may have an effect on the type of student and the ensuing student culture you create based upon your enrollment practices (Titus, 2006). Students are the raw materials through which faculty and other institutional personnel mix, share, and coalesce to produce culture, knowledge, and important technological breakthroughs and contributions. Third, it demonstrates the institutional resource distribution of who gets what, when, and how (Laswell, 1936) thereby value signaling its core constituencies. Fourth, the implications of resource allocation may challenge the various elements of an institution's mission and force leadership to evaluate the current trajectory of their institutional aid policy. This implication may have course-correcting effects for financial aid offices, institutional strategic and visionary leaders, as well as citizens and their elected officials in a conversation of what is the most appropriate allocation of resources ultimately created through taxpayer institutions.

Fifth, the research here demonstrates that so long as public higher education institutions continue to remain vulnerable to resource dependence and are continually divorced and distanced from public support and taxpayer disinvestment, the erosion of the public land-grant institution will likely continue. This is not to say that public higher education institutions will no longer exist or that the funding of higher education will become out-of-reach and unattainable for the working class; only that so long as financial resources inform both the inputs, throughputs, and outputs of higher education, the continued incorporation of academic capitalism and the appeasement of students as consumers will likely continue to inform institutional decisionmaking for enrollment dependent institutions. 
It, however, is not all doom and gloom. The ability of institutions to help individuals they deem desirable constituencies has never been more promising. The status of institutions as a primary player in the financial aid game has never been more important. Deciding who will provide institutional resources - faculty research and the ensuing external monies it has the potential to produce- may continue the tug-of-war game of who is the primary resource provider at higher education institutions: Faculty or students? Going forward, the higher education resource provider must be renewable, dependable, and hard-coded into the political, cultural, and economic fabric that binds various societal institutions together. Equity of access into the system that credentials our best and brightest may be an excellent start to encouraging the political support necessary to restore the public higher education to a road to recovery.

The largest problem is the inability of institutions to find creative solutions to decaying public financial support without consistently passing those problems off onto the student as the consumer or the faculty member as a managed professional. As the control of faculty research increases and its suitability or feasibility is constantly tied to its ability to link up with the capitalist market, the spirit of academic freedom will be undermined along with the relative value of knowledge generation for the sake of knowledge generation. Only knowledge deemed necessary by profit-seeking organizations will be pursued, relegating creativity to economic practicality and expediency. Going back to the well of increasing tuition to offset public disinvestment is also problematic. As Cheslock and Gianneschi (2008) described, the demand for higher education is not perfectly inelastic - at some point, the price of higher education will reach a point where there will be diminishing returns on enrollment, thus slowing the desired reality of a highly educated citizenry. 
The second perspective dovetails with the first: Promoting equitable access to higher education that accounts for both abilities to pay and aptitude for success that doesn't leave entire segments of society without assistance. For example, across all of the pooled regression models examined in this dissertation, URM students received the least support from the institution across the aggregate, need-meeting, and non-need-meeting institutional aid typologies. For all three institutional aid typologies, URM students decreased in probability from 2005 to 2015 of receiving an aid award in the aggregate from $4.4 \%$ to $-4.1 \%$ and non-need-meeting aid from $8 \%$ to $-4.0 \%$. If net-tuition maximization and bigger and better enrollments are necessary for institutional survival, portions of the proceeds received from, say, out-of-state enrollment should be used to offset the obvious disparities in institutional aid allocations to URM students. Without a consorted effort to address the real disparity between URM and non URM students while controlling for many other pre-college academic and financial characteristics is hardly defensible.

Implications for Strategic Planning

As a land-grant university, orientation of the institution's efforts to serve its supporting state and region should be a guiding principle. Given the declines of general population to the state that supports the institution and when coupled with a decline in-state resources previously enjoyed by the university, the institution is faced with a puzzle. How does it retain its status as a land-grant institution while at the same time pursuing new revenue streams to offset both in-state population losses and declines in-state appropriations while also pursuing greater autonomy from its resource providers, and greater academic hegemony in the higher education landscape? If the land-grant mission is to mean anything at all, institutional leadership must reaffirm and embrace 
that mission while also embracing the realities of higher education in the new economy. These concepts do not have to be mutually exclusive.

As a result, movement to the national and global scale are inevitable symptoms of the institution's dwindling base of resource providers. As the institution moves beyond its historical support base and into regions beyond its base, resource dependence predicts that the institution will have to align its goals and processes with its new resource providers (Pfeffer and Salancik, 1978). Therefore, resource dependence theory is highly informative to the future of the organization as it establishes new connections and relationships with its changing base of resource providers. Specifically, the evidence presented in this dissertation examines what happens to institutional aid awards when an institution is faced with declining primary markets and disinvestment by state government. As a result, the institution must entice out-of-state enrollment to support itself. But at what cost to its primary constituencies?

Symptoms of resource dependency and how it may affect in-state students may appear in the form of decreased access to in-state students due to cost. However, as the evidence from this dissertation shows, student need for in-state students is highly mitigated and much lower when compared to out-of-state students. When this case is true, the question of access to the populations that ought to be served by a land-grant institution (i.e. in-state students) are less problematic. The problem of access may crop up for in-state students when institutional aid is funneled to out of state to students and out-of-state students begin crowding out in-state students - especially when net-tuition maximation is the primary impetus for that specific behavior. As a direct result, state residents will then be subsidizing out-of-state students so that the institution can maximize its tuition revenue at the expense of the taxpayer it was meant to serve. To that end, leadership within the financial aid office should also have the bureaucratic support of the 
president and oversight bodies to ensure the land-grant mission is met while also ensuring institutional priorities regarding tuition strategies are met. Those strategies however, must be congruent with primary resource providers, both demographic and geographic. Institutional aid must be tightly controlled and steered by the overarching principles of the organization and the constituencies it is meant to serve.

To guard against this possibility, institutional officials tasked with enrollment management and strategic vision should be cognizant of the relative need of in-state students compared to out-of-state students and how institutional aid may be used as a tool to mitigate instate student need. For example, in 2005, the mean in-state student need for students with a need greater than zero was $\$ 1,001.36$ or $15.8 \%$ of the need of nonresident students $(\$ 6,354.32)$. This percentage increased to $\$ 3,736$ or $32.6 \%$ of $2015-16$ nonresident need $(\$ 11,455.77)$. This increased percentage signifies that relative to out-of-state students, student need for in-state students is increasing all the while out-of-state students were also gaining greater shares of institutional aid during the same time period. As in-state student need increases relative to outof-state student need, the impact of student aid for out-of-state students may cause a crowding out of in-state students in favor of out-of-state students. In other words, the cost for in-state enrollees may gradually reach parity with out-of-state enrollees - especially when institutional aid is continuously funneled toward nonresident students - thus nullifying the cost benefits for in-state enrollment from a student perspective which may also come into conflict with the institution's primary mission.

\section{Implications for Financial Aid Professionals}


Many of the explanatory variables used to estimate the probability of a student receiving a need-meeting aid award were not highly informative or predictive. Instead, much of the statistical significance and impact on the probability of receiving a need-meeting institutional aid award stemmed from variables that represented the student's residency and academic prowess thus favoring nonresidents and high achieving students. This suggests that much of the institutional aid distributed by the institution are distributed without need as a primary consideration. Current research suggests that when institutions go out-of-state for enrollment purposes, students of low-socioeconomic status and underrepresented minorities tend to diminish (Jaquette, Curs, and Posselt, 2016).

However, data from this dissertation provided evidence for an overall increase to the various constituencies considered to be at risk of diminishment in light of increased out-of-state enrollment such as low income students, underrepresented minorities, and the intersection of underrepresented minorities and low-income students. As a financial aid professional, it may be beneficial to evaluate the impact of the institutional aid your institution provides to the student. Then, it could be further beneficial to understand the short and long-term impact of that aid. Understanding how the institutional aid impacts student need may highly inform short and longterm student behavior Gross, Hossler, and Ziskin (2015) suggest that institutions conduct an "equity analysis" (pg. 244) to identify which students received need and merit-based aid to find potential linkages between that aid and persistence to degree. Does the aid meet a student's need or does it go beyond need? Actual impacts should be measured against programmatic goals to identify shortcomings and strengths. If a primary goal of the institution is to mitigate need as a potential barrier to institutional access, yet all of the institutional financial aid awards are being provided to students goes beyond their need, the institution may want to re-evaluate the criteria 
used to dole out its aid. This is not to say that institutions should not award merit-based aid. Instead, it is suggesting that the impact of the aid offered to students may have a greater impact if properly aligned with your institutional goals.

\section{Implications for Enrollment Management, Marketing, and Recruiting Professionals}

It may also be possible that institutional aid criteria are not strictly controlled by the institution's financial aid office. Instead, these policies are set forth by university or college administrators (e.g. enrollment management) in an effort to secure an ideal enrollment of students. Financial aid administrators need to understand that institutional aid is an institutional mechanism that can be used to fulfill institutional goals whether it be enrollment goals such as a specific class makeup that contains a good mix of underrepresented minorities, international students, men, women, and/or nontraditional students, etc. Institutional aid can also be used to maximize the net-tuition calculus and create greater revenue streams for the institution to reinvest in other aid programs, new equipment or amenities to entice higher quality students and faculty, and/or recruitment strategies. Aid can also be used to mitigate cost as a barrier to students that would also increase enrollment, but not necessarily maximize tuition.

Institutional aid may also provide other tangible benefits that increase the overall marketability of the institution. These could include metrics such as retention and persistence to degree that are closely monitored by ranking organizations in addition to state and federal oversight organizations. For example, institutional financial assistance has demonstrated positive effects on freshmen to sophomore retention (Olbrech, Romano, and Teigan, 2016). Institutions could then advertise that the generosity of their institutional aid awards promotes both a financial incentive to enroll as well as a perceived increased chance of success. 
Marketing agents and recruiters must also be highly aware of the projected changes coming to the demographics of projected high school graduates over the next decade. In 2031-32 there will be approximately 252,100 fewer white students than in 2012-13 generating a marked shift away from white dominance in higher education as white students will go from comprising $58 \%$ of all public school graduates to $51 \%$ of high school graduates (WICHE, 2019). Increases to the non-white high school graduate constituency will jump from $42 \%$ to $49 \%$ of public high school graduates that includes an increase of 165,300 non-white students from 2012-13 to 203132 (WICHE, 2019).

\section{Future Research}

The research presented here scratches the surface of institutional aid as a variable of interest to higher education professionals, scholars, administrators, citizens, and political leaders. Continued research on the effects of how institutional aid influences student outcomes such as retention, persistence to degree completion, timely degree attainment, student debt loads upon graduation or departure, and the relative benefits of maximizing net-tuition versus encouraging other higher education goals such as increased equity of access to higher education.

Future research should also continue to consider the importance of student need in the institutional aid calculus; especially since socioeconomic status is predictive of the resources of the institution in which the student attends (Titus, 2006). As mentioned in the limitations section of this dissertation, I was only able to evaluate the impact of institutional aid for students who enrolled at the institution. Research that started with all of the admissions data for an institution that also identified full institutional aid packages would then be able to provide analyses of both how institutional aid influences student agency on college choice as well as institutionally preferred students that, perhaps, enrolled elsewhere. Upon gaining that information, the 
researcher could also conduct queries with the National Student Clearinghouse to obtain information on a student's declined admission to shed light on institutional competitiveness in the college selection process.

Furthermore, by understanding how institutional aid influences student agency in the college choice phase, researchers may also begin to probe the impact of student cost and debt as a variable of interest in the college going process, specifically, how that is conditioned based upon student discounts. Record level observations for several institutions worth of students with similar characteristics (e.g. land-grant, size, cost of attendance, resource constraints, etc.) might provide valuable information to both researchers and administrators. The sharing of the data among participating institutions would help close information asymmetries that occur amongst institutions that could, theoretically, help stabilize higher education prices among competing institutions would as they would share their discounting practices openly.

However, institutions have attempted to collaborate on their charitable actions among similarly situated and commonly recruited student pools - those of high aptitude and those of low income status - only to face anti-trust investigation brought on by the United States Justice Department in 1989 (see Depalma, 1992). As a result, institutional sharing of practices that includes the use of Federal Financial Aid and institutional funds could be construed as price fixing when institutions agree upon mutually acceptable terms. Therefore, future collaboration between institutions on their institutional aid practices remains unlikely in the shadow of potential price-fixing charges via the Sherman Anti-Trust Act.

The future availability of institutional aid data will greatly inform future research on the topic. Dynamic data from single-institution studies, multi-institutional studies, and longitudinal national studies will all be useful in triangulating the greater effects, purposes, and the overall 
reach of institutional aid data. For example, data that is currently collected by IPEDS aggregates institutional aid awards and does not provide opportunities for nuanced statistical analysis via regression. Record level data that is shared amongst institutions can help researchers identify not only potential disparities in the overall awarding of institutional aid but it can also help inform the discussion of how institutional aid influences long-term student outcomes such as persistence to graduation. Greater data sharing amongst institutions, especially public universities, may be necessary to ensure the proper stewardship of institutional funds as well as continued assurance that the institution is meeting the guiding principles of their mission as a civic institution.

Instead, researchers may continue to find extended use of the National Postsecondary Student Aid Study (NPAS) as it continues to expand its extensive data capabilities. For example, new NPSAS data initiatives include formulations of state-representative data that will allow researchers to drill down to the state level and create comparisons based on a 2-year cycle instead of the current 4-year cycle to allow for state and regional comparisons. With the increased frequency at which the data is sampled and the ability to compare representative state financial aid samples, researchers will gain greater leverage in understanding regional financial aid dynamics as well as a greater ability to monitor those changes over shorter time intervals thanks to the 2-year cycle report as opposed to 4-year reporting.

Another fecund source of data includes the 2013 follow-up to the National Center for Education Statistics' (NCES) 2009 High School Longitudinal Survey (HSLS 2009) to further investigate the ripple effects of institutional aid as high school students continue on through the post-secondary education pipeline. As it is a follow up the 2009 survey - where students were high school Freshmen in 2009 - the survey asks several questions of interests including: "whether they [a student] had applied for financial aid, and, if not, why they had not" allowing 
for greater understanding of the potential non-academic barriers to higher education access specifically as it relates to financial aid. In addition, the survey asks the student to "provide the total cost of their first year of enrollment before financial aid, how much they were borrowing, how much they received in scholarships and grants, and the types of financial aid they were offered by their institution" (Ingels, Pratt, Herget, et. al., 2009).

\section{Conclusion}

This dissertation has examined institutional aid awards in the context of a resourcedependent institution experiencing population loss and disinvestment from its host state government. I examined three major questions and all three questions are asked within the context of a resource dependent institution. First, I sought to examine the conditions under which institutional aid was awarded. Second, I wanted to know if institutional aid awards were offered differently to students based upon residency. Third, I wanted to know if aid was distributed to students with and without demonstrated need and whether or not those aid awards have changed over time.

Residency was a consistent and statistically significant predictor of institutional aid awards as nonresidents outpaced residents in both the average amount of the institutional aid award received in the aggregate as well as an increased probability of receiving an institutional aid award in the aggregate over time. Nonresidents also increased in the average amount of institutional aid awarded to them in the aggregate for each year examined in the pooled regressions - an amount that increased over time as well. Nonresidents also grew as a proportion of the FTFTF from $50.40 \%$ in $2005-06$ to $57.44 \%$ in $2015-16$.

High academic ability was also consistently and progressively awarded when compared to those in the lowest quartile of academic ability over the years in this study. Quartile 4 students 
were highly predictive for the amount of institutional aid a student would receive on average across all three dimensions of institutional aid: aggregate, need-meeting, and non-need-meeting. The results suggest that the institution was awarding higher amounts of institutional aid awards to students who were nonresidents and to students who were of high academic ability, but not necessarily students with both high academic ability and non-residency status

Student need was also a statistically significant predictor for seven of the years examined in the pooled regressions, however, the impact of student aid on the aggregate institutional aid award was relatively small. The highest coefficient for need indicated a $\$ 40.69$ increase in aggregate institutional aid for every one thousand dollars in student need. Therefore, although need is a significant predictor, it appears that the institution does not necessarily award institutional aid with need as a primary criterion.

In summary, academic capitalism may be a symptom of resource dependence. Findings from this dissertation provide evidence for enrollment management practices that prioritize nonresident enrollment brought on by decreases to state appropriations and declining host state enrollment. Regression analysis also provides evidence for the increased preferences for students high in academic ability as measured by the student quality index score 


\section{$\underline{\text { References }}$}

Amemiya, T. (1984). Tobit models: A survey. Journal of econometrics, 24(1-2), 3-61.

Baum, S., Lapovsky, L., \& Ma, J. (2010). Tuition Discounting: Institutional Aid Patterns at Public and Private Colleges and Universities, 2000-01 to 2008-09. Retrieved from WwW.collegeboard.com.

Baum, S., \& Ma, J. (2010). Tuition Discounting: Institutional Aid Patterns at Public and Private Colleges and Universities. Retrieved from www.collegeboard.com/trends

Baum, S. \& Payea, K. (2014). Trends in student aid 2014. College Board Advocacy \& Policy Center. Retrieved from https://trends.collegeboard.org/student-aid

Berger, J. B., and Milem, J. F. (2000). Organizational behavior in higher education and student outcomes. In: Smart, J. C. (ed.), Higher Education: Handbook ofTheory and Research (Vol. XV), Agathon Press, New York, pp. 268-338.

Berry, W. D. (1993). Understanding regression assumptions(Vol. 92). Sage Publications.

Bowen, E., Christiadi, Deskins, J., \& Lego, B. (2018, January). An Overview of the Coal Economy in Appalachia. Retrieved November 20, 2018, from https://www.arc.gov/assets/research_reports/CIE1OverviewofCoalEconomyinAppalachia $\underline{\text { pdf }}$

Chang, M. J. (1999). Does racial diversity matter?: The educational impact of a racially diverse undergraduate population. Journal of College Student Development 40(4): 377-395.

Cheslock, J. J., \& Gianneschi, M. (2008). Replacing state appropriations with alternative revenue sources: The case of voluntary support. The Journal of Higher Education, 79(2), 208229.

Cheslock, J. J., Hughes, R. P., Cardelle, R. F., \& Heller, D. E. (2018). Filling the Gap: The Use 
of Intentional and Incidental Need-Meeting Financial Aid. The Review of Higher Education, 41(4), 577-605.

College Board Advocacy \& Policy Center. (2017). Trends in Student Aid 2017, 1-36. Retrieved from http://trends.collegeboard.org/sites/default/files/student-aid-2013-fullreport.pdf\%5Cnpapers2://publication/uuid/74B810D6-8F4C-4D9E-860C-

\section{E5FE702152FD}

Davis, G. F .. \& Cobb, J. A. (2009). Resource dependence theory: Past and future. Research in the Sociology of Organizations. 28, 21-42.

Deming, D., \& Walters, C. (2017). The impacts of price and spending subsidies on US postsecondary attainment. NBER Working Paper, 23736.

Depalma, A. (1992, September 3). M.I.T. Ruled Guilty in Antitrust Case. The New York Times. Retrieved from https://www.nytimes.com/1992/09/03/us/mit-ruled-guilty-in-antitrust$\underline{\text { case.html }}$

Doyle, W. R. (2010) Changes in Institutional Aid, 1992-2003: The Evolving Role of Merit Aid. https://doi.org/10.1007/s11162-010-9177-0

Ethington, C. A. (1990). A psychological model of student persistence. Research in Higher Education 31(3): 279-293.

Federal Student Aid Website (2018). www.studentaid.gov

Fontenot, Semega, \& Kollar, M. A. (2018). Income and poverty in the United States: 2017. Current Population Reports.

Geiger, R. L. (2014). The history of American higher education: Learning and culture from the founding to World War II (Vol. 80). Princeton University Press.

Geiger, R. L. (2004). Knowledge and money: Research universities and the paradox of the 
marketplace. Stanford University Press.

Gram, D. (2012, May 17). Vermont becomes 1st state to ban gas 'fracking. The Bennington Banner. Retrieved January 6, 2019, from https://www.benningtonbanner.com/stories/vermont-becomes-1st-state-to-ban-gaslsquofracking, 157632

Han, C., Jaquette, O., \& Salazar, K. (2019). Recruiting the Out-of-State University: Off-Campus Recruiting by Public Research Universities.

Heller, D. E., \& Nelson Laird, T. F. (1999). Institutional need-based and non-need grants: Trends and differences among college and university sectors. Journal of Student Financial Aid, 29(3), 1.

Heller, D. E. (2001). Race, Gender, and Institutional Financial Aid Awards. Journal of Student Financial Aid (Vol. 31). Retrieved from https://publications.nasfaa.org/cgi/viewcontent.cgi?referer=https://scholar.google.com/\& $\underline{\text { httpsredir }=1 \& \text { article }=1185 \& \text { context }=\text { jsfa }}$

Hoxby, C., \& Avery, C. (2013). The missing" one-offs": The hidden supply of high-achieving, low-income students. Brookings papers on economic activity, 2013(1), 1-65.

Hrebeniak, L. G., and Joyce, W. E. (1985). Organizational adaptation: Strategic choice and economic determinism. Administrative Science Quarterly 30(3): 336-349.

Ingels, S. J., Pratt, D. J., Herget, D. R., Bryan, M., Burns, L., Ottem, F. R., ... Christopher, E. M. (2009). High school longitudinal study of 2009 (HSLS:09) 2013 update and high school Transcript data file documentation. 2009(June), 154. Retrieved from https://nces.ed.gov/pubs2015/2015036.pdf

Jaquette, O., \& Curs, B. R. (2015). Creating the out-of-state university: Do public universities i ncrease nonresident freshman enrollment in response to declining state appropriations? Research in Higher Education, 56(6), 535-565. 
Jaquette, O., Curs, B. R., \& Posselt, J. R. (2016). Tuition rich, mission poor: Nonresident enrollment growth and the socioeconomic and racial composition of public research universities. The Journal of Higher Education, 87(5), 635-673.

Katz, D., \& Kahn, R. L. (1978). The social psychology of organizations New York: Wiley. Kaplan, T. (2014, December 17). Citing Health Risks, Cuomo Bans Fracking in New York State. The New York Times. Retrieved January 6, 2018, from https://www.nytimes.com/2014/12/18/nyregion/cuomo-to-ban-fracking-in-new-york$\underline{\text { state-citing-health-risks.html }}$

Kim, D. (2004). The effect of financial aid on students' college choice: Differences by racial groups. Research in Higher Education, 45(1), 43-70.

Mackellar, E. (2017). State Budget Update. National Conference of State Legislatures, 1-18. Retrieved November 20, 2018, from http://www.ncsl.org/Portals/1/Documents/fiscal/StateBudgetUpdateSpring2017_31383.pdf

McPherson, M. S., \& Schapiro, M. O. (1999). The student aid game: Meeting need and rewarding talent in American higher education (Vol. 31). Princeton University Press.

Mitchell, M., Leachman, M., \& Masterson, K. (2017). A lost decade in higher education funding state cuts have driven up tuition and reduced quality.

Parsons, T. (1956). Suggestions for a sociological approach to the theory of organizations, part I. Administrative Science Quarterly, 1(1), 63-85.

National Center for Education Statistics. (2015-16). Table 3. Percentage of Undergraduates receiving selected types of financial aid from federal, state, or institutional sources, by control and level of institution, attendance pattern, dependence status, and income level: 
2015-16. Retrieved January $14^{\text {th }}, 2019$, from

https://nces.ed.gov/Datalab/TablesLibrary/TableDetails/11910?keyword=2018466\&rst=tr

ue

National Center for Education Statistics. (2015-16). Table 4. Average amounts of selected types of financial aid from federal, state, or institutional sources received among undergraduates receiving that type of aid, by control and level of institution, attendance pattern, dependency status, and income level: 2015-16. Retrieved January 14th, 2019, from https://nces.ed.gov/Datalab/TablesLibrary/TableDetails/11912?rst=true

Nietzel, M. T. (2018, November 5). Students Begin To Tap The Brakes On The Campus Amenities Arms Race. Forbes. Retrieved July 11, 2019, from https://www.forbes.com/sites/michaeltnietzel/2018/11/05/students-begin-to-tap-thebrakes-on-the-campus-amenities-arms-race/\#432607671bcc

Olbrecht, A. M., Romano, C., \& Teigen, J. (2016). How money helps keep students in college: The relationship between family finances, merit-based aid, and retention in higher education. Journal of Student Financial Aid, 46(1), 2.

Perrins, G., \& Nilsen, D. (2010). Math calculations to better utilize CPI data. Rep. Bureau of Labor Statistics, nd Web.

Pfeffer, J., \& Salancik, G. R. (1978/2003). The External Control of Organizations - A resource Dependence Perspective. Stanford, CA: Stanford University Press

Pless (2012). Natural Gas Development and Hydraulic Fracturing: A Policymaker's Guide. National Conference of State Legislatures.

Pollard, K., \& Jacobsen, L. (2019, May). The Appalachian Region: A Data Overview from the 
2013-2017 American Community Survey. Retrieved from https://www.arc.gov/research/researchreportdetails.asp?REPORT_ID=159

Quinn, K. (2017, January 12). National Conference of State Legislatures. Retrieved November 2018

Radwin, D., Wine, J., Siegel, P., and Bryan, M. (2013). 2011-12 National Postsecondary Student Aid Study (NPSAS:12): Student Financial Aid Estimates for 2011-12 (NCES 2013-165). Institute of Education Sciences, U.S. Department of Education. Washington, DC: National Center for Education Statistics. Retrieved [date] from http://nces.ed.gov/pubsearch.

Scott, W. R. (1995). Institutions and Organizations, Sage, Thousand Oaks, CA. Swail, 20, 2018, from http://www.ncsl.org/research/fiscal-policy/happy-8th-birthday-economicrecovery.aspx

Rizzo, M. J., \& Ehrenberg, R. G. (2004). Resident and nonresident tuition and enrollment at flagship state universities. In C. M. Hoxby (Ed.), The economics of where to go, when to go, and how to pay for it. Chicago: University of Chicago Press.

Scott, W. R. (1995). Institutions and Organizations, Sage, Thousand Oaks, CA.

Seltzer, R. (2018, January 22). State support for higher ed grows 1.6 percent in 2018. Retrieved January 1, 2019, from https://www.insidehighered.com/news/2018/01/22/state-supporthigher-ed-grows-16-percent-2018

Singell Jnr, L. D., \& Stone, J. A. (2002). The good, the poor and the wealthy: Who responds most to college financial aid? Bulletin of Economic Research, 54(4), 393-407.

Slaughter, S., \& Leslie, L. L. (1997). Academic Capitalism: Politics, Policies, and the Entrepreneurial University. Baltimore Johns Hopkins University Press. 
Slaughter, S., \& Rhoades, G. (2004). Academic Capitalism and the New Economy. Academic Capitalism and the New Economy. https://doi.org/10.1007/s13398-014-0173-7.2

Stimson, J. A. (1985). Regression in space and time: A statistical essay. American Journal of Political Science, 914-947.

The EFC Formula, 2018-2019. (n.d.). Retrieved November 20, 2018, from https://ifap.ed.gov/efcformulaguide/attachments/071017EFCFormulaGuide1819.pdf

Titus, M. A. (2006). Understanding college degree completion of students with low socioeconomic status: The influence of the institutional financial context. Research in Higher Education, 47(4), 371-398.

Webber, D. A. (2017). State divestment and tuition at public institutions. Economics of Education Review, 60, 1-4. https://doi.org/10.1016/j.econedurev.2017.07.007

Western Interstate Commission for Higher Education (WICHE). Knocking at the College Door (2018 ed., Publication)

Woo, J., \& Choy, S. (2011). Merit Aid for Undergraduates: Trends From 1995-96 to 2007-08. Retrieved from http://nces.ed.gov/pubsearch/pubsinfo.asp?pubid=2012160.

Wood, P. (2017, March 27). Maryland General Assembly approves fracking ban. The Baltimore Sun. Retrieved January 6, 2019, from https://www.baltimoresun.com/news/maryland/politics/bs-md-fracking-ban-passes20170327-story.html

United States Department of Labor: Bureau of Labor Statistics: 53-7033 Loading Machine Operators, Underground Mining. (2018, March 30). Retrieved May 30, 2019, from https://www.bls.gov/oes/2017/may/oes537033.htm

United States Department of Labor: Bureau of Labor Statistics (2016). Consumer Price Index. 
United States Census Bureau: Small Area and Income Poverty Estimates (SAIPE). (n.d.).

Retrieved May 30, 2019, from

https://www.census.gov/datatools/demo/saipe/\#/?map_geoSelector=aa_c

U.S Energy Information Administration - EIA - Independent Statistics and Analysis. (2019,

November 2). Retrieved May 30, 2019, from https://www.eia.gov/coal/annual/

West Virginia Center on Budget and Policy. (2019). Retrieved May 30, 2019, from

https://wvcbp.nationbuilder.com/

Zivot, E., \& Wang, J. (2006). Modeling Financial Time Series with S-PLUS®. 
Appendix Table 1: OLS Pooled Regression Table for Aggregate Inst. Aid

\begin{tabular}{|c|c|c|c|c|c|c|c|c|}
\hline & 2005-07 & 2006-09 & 2007-10 & 2008-11 & 2009-12 & 2010-13 & 2011-14 & 2012-15 \\
\hline \multirow[t]{2}{*}{ First Gen. } & -70.69 & -6.298 & -0.394 & -17.13 & -60.31 & -28.44 & 69.93 & 91.06 \\
\hline & (47.79) & $(47.42)$ & (48.66) & (52.67) & (56.63) & (61.75) & (68.13) & (79.47) \\
\hline \multirow[t]{2}{*}{ SQIS Quartile 2} & $962.0^{* * *}$ & $931.4 * * *$ & $925.1 * * *$ & $1076.7 * * *$ & $1221.7 * * *$ & $1387.3 * * *$ & $1390.3^{* * *}$ & $1650.8^{* * *}$ \\
\hline & $(57.86)$ & $(57.54)$ & $(58.91)$ & $(62.98)$ & $(67.47)$ & (72.92) & (80.03) & (93.41) \\
\hline \multirow[t]{2}{*}{ SQIS Quartile 3} & $2340.2^{* * *}$ & $2392.5^{* * *}$ & $2380.4 * * *$ & $2711.4^{* * *}$ & $3098.5^{* * *}$ & $3548.2^{* * *}$ & $3621.9^{* * *}$ & $4273.5^{* * *}$ \\
\hline & $(58.85)$ & (58.09) & (59.46) & (63.76) & $(68.56)$ & (74.02) & (80.39) & (92.77) \\
\hline \multirow[t]{2}{*}{ SQIS Quartile 4} & $3707.2^{* * *}$ & $3908.4^{* * *}$ & $4078.5^{* * *}$ & $4543.2 * * *$ & $5052.1 * * *$ & $5823.2 * * *$ & $6431.8^{* * * *}$ & $7476.0^{* * * *}$ \\
\hline & (61.69) & (61.05) & $(62.24)$ & $(66.80)$ & (71.00) & (76.43) & (82.34) & (94.47) \\
\hline \multirow[t]{2}{*}{ Student EFC } & $-5.910 * * *$ & $-4.331 * * *$ & $-2.572 *$ & $-2.615^{*}$ & $-3.411 *$ & $-4.633 * *$ & $-4.342 * *$ & $-3.052 *$ \\
\hline & $(1.20)$ & (1.12) & (1.15) & (1.24) & (1.34) & $(1.42)$ & (1.46) & $(1.52)$ \\
\hline \multirow[t]{2}{*}{ Student Need } & -10.07 & 12.3 & 13.42 & 2.348 & -11.22 & $-20.12 *$ & -10.85 & 11.83 \\
\hline & $(8.78)$ & $(8.02)$ & (7.77) & (7.90) & (8.09) & $(8.14)$ & $(8.32)$ & $(9.10)$ \\
\hline \multirow[t]{2}{*}{ Pell Recipient } & 51.06 & 61.18 & 96.76 & 84.97 & $165.0^{*}$ & $208.7^{* *}$ & $335.0^{* * * *}$ & $245.4 * *$ \\
\hline & (58.49) & $(57.91)$ & $(58.47)$ & $(62.01)$ & (65.71) & (70.91) & (76.59) & (87.32) \\
\hline \multirow[t]{2}{*}{ Female } & 16.37 & 26.3 & 4.835 & -15.58 & -83.29 & -70.96 & -97.68 & $-137.4^{*}$ \\
\hline & (41.12) & (40.83) & (41.67) & $(44.86)$ & (47.73) & (51.25) & $(55.20)$ & (63.63) \\
\hline \multirow[t]{2}{*}{ Nonresident } & $1872.8^{* * *}$ & $1953.7 * * *$ & $2151.2 * * *$ & $2562.0 * * *$ & $3048.8^{* * *}$ & $3638.2 * * *$ & $3978.0^{* * * *}$ & $4816.1 * * *$ \\
\hline & $(54.50)$ & (53.77) & (55.74) & (61.60) & $(67.01)$ & (71.87) & (76.69) & (88.31) \\
\hline \multirow[t]{2}{*}{ Asian } & $-349.9^{*}$ & -266.5 & $-328.4 *$ & -349.8 & $-462.8^{*}$ & -69.93 & -357.4 & $-599.9^{*}$ \\
\hline & (157.00) & (154.10) & $(163.80)$ & (182.60) & (191.60) & (203.30) & (225.10) & $(259.40)$ \\
\hline \multirow[t]{2}{*}{ URM } & 83.87 & 82.75 & -14.84 & -74.28 & $-261.7 * *$ & $-238.8 * *$ & $-284.3 * * *$ & $-312.1 * *$ \\
\hline & (81.98) & (79.76) & (78.02) & (79.17) & (80.13) & (81.88) & (86.31) & (97.41) \\
\hline \multirow[t]{2}{*}{ Constant } & $-853.9 * * *$ & $-1015.8 * * *$ & $-1175.9 * * *$ & $-1376.6^{* * *}$ & $-1571.2 * * *$ & $-1896.6^{* * *}$ & $-2061.1 * * *$ & $-2546.1 * * *$ \\
\hline & $(62.62)$ & $(62.47)$ & (64.48) & (69.72) & (75.18) & $(80.82)$ & (87.28) & (100.20) \\
\hline $\mathbf{N}$ & 11521 & 12064 & 12114 & 12656 & 12768 & 13198 & 13096 & 12946 \\
\hline r2 & 0.289 & 0.31 & 0.325 & 0.339 & 0.37 & 0.401 & 0.42 & 0.445 \\
\hline
\end{tabular}

Standard errors in parentheses

$* \mathbf{p}<0.05 * * \mathbf{p}<0.01 * * * \mathbf{p}<0.001 "$ 
Appendix Table 2: OLS Pooled Regression Table for Need-Meeting Inst. Aid

\begin{tabular}{|c|c|c|c|c|c|c|c|c|c|}
\hline & 2005-07 & 2006-09 & 2007-10 & 2008-11 & 2009-12 & 2010-13 & 2011-14 & 2012-15 & 2013-15 \\
\hline \multirow[t]{2}{*}{ First Gen. } & 19.61 & 18.94 & 32.67 & 14.50 & 32.20 & 68.22 & $133.2 * * *$ & $121.6^{* *}$ & 92.69 \\
\hline & $(22.40)$ & $(23.62)$ & $(25.20)$ & $(28.92)$ & $(32.61)$ & $(36.50)$ & (39.76) & $(46.31)$ & $(53.30)$ \\
\hline \multirow[t]{2}{*}{ SQIS Quartile 2} & $412.2 * * *$ & $409.3 * * *$ & $440.9 * * *$ & $488.5^{* * *}$ & $576.2 * * *$ & $697.1 * * *$ & $787.0 * * *$ & $917.6 * * *$ & $1217.7 * * *$ \\
\hline & (27.13) & $(28.66)$ & $(30.51)$ & $(34.58)$ & $(38.85)$ & $(43.10)$ & $(46.70)$ & (54.43) & $(63.52)$ \\
\hline \multirow[t]{2}{*}{ SQIS Quartile 3} & $831.6^{* * *}$ & $868.2^{* * *}$ & $932.6^{* * *}$ & $1101.3^{* * *}$ & $1353.5^{* * *}$ & $1610.2 * * *$ & $1684.1 * * *$ & $1982.9 * * *$ & $2337.3^{* * *}$ \\
\hline & $(27.59)$ & $(28.93)$ & $(30.79)$ & $(35.01)$ & (39.48) & (43.74) & $(46.92)$ & $(54.06)$ & $(61.66)$ \\
\hline \multirow[t]{2}{*}{ SQIS Quartile 4} & $905.0 * * *$ & $949.4 * * *$ & $1002.8^{* * *}$ & $1166.8 * * *$ & $1414.1 * * *$ & $1714.4 * * *$ & $1864.3 * * *$ & $2114.4 * * *$ & $2456.0 * * *$ \\
\hline & $(28.92)$ & $(30.41)$ & $(32.23)$ & (36.68) & (40.88) & (45.17) & (48.06) & $(55.05)$ & (62.03) \\
\hline \multirow[t]{2}{*}{ Student EFC } & $-4.121 * * *$ & $-3.647 * * *$ & $-3.476 * * *$ & $-3.981 * * *$ & $-4.558 * * *$ & $-6.038 * * *$ & $-5.694 * * *$ & $-5.798 * * *$ & $-5.960 * * *$ \\
\hline & $(0.562)$ & $(0.558)$ & $(0.593)$ & $(0.679)$ & $(0.772)$ & $(0.842)$ & $(0.852)$ & $(0.885)$ & $(0.930)$ \\
\hline \multirow[t]{2}{*}{ Student Need } & $197.8 * * *$ & $203.3^{* * *}$ & $199.9 * * *$ & $207.6 * * *$ & $226.1 * * *$ & $242.2 * * *$ & $261.4 * * *$ & $307.7 * * *$ & $351.9 * * *$ \\
\hline & (4.117) & (3.993) & $(4.025)$ & $(4.338)$ & (4.657) & $(4.813)$ & $(4.853)$ & (5.304) & $(5.724)$ \\
\hline \multirow[t]{2}{*}{ Pell Recipient } & $-81.76^{* *}$ & $-72.25^{*}$ & -42.10 & -49.07 & -24.39 & -59.58 & -34.08 & $-159.2 * *$ & $-175.6^{* *}$ \\
\hline & $(27.42)$ & $(28.85)$ & $(30.28)$ & $(34.05)$ & (37.84) & $(41.91)$ & $(44.70)$ & $(50.88)$ & $(57.18)$ \\
\hline \multirow[t]{2}{*}{ Female } & 19.39 & 18.16 & 11.73 & -6.516 & -31.52 & 7.679 & 26.91 & 22.36 & -54.02 \\
\hline & (19.28) & (20.34) & $(21.58)$ & (24.63) & (27.48) & $(30.29)$ & $(32.21)$ & $(37.07)$ & $(42.01)$ \\
\hline \multirow[t]{2}{*}{ Nonresident } & $351.3 * * *$ & $339.4 * * *$ & $366.1 * * *$ & $425.0 * * *$ & $517.6^{* * * *}$ & $610.3 * * *$ & $621.0 * * *$ & $598.9 * * *$ & $682.1 * * *$ \\
\hline & $(25.55)$ & (26.79) & $(28.87)$ & $(33.82)$ & (38.58) & $(42.47)$ & (44.75) & (51.46) & $(58.68)$ \\
\hline \multirow[t]{2}{*}{ Asian } & $-190.9 * *$ & -121.5 & -162.9 & $-321.5 * *$ & $-454.7 * * *$ & $-333.9 * *$ & $-350.9 * *$ & $-339.8^{*}$ & $-536.0 * *$ \\
\hline & (73.61) & (76.77) & $(84.81)$ & $(100.2)$ & (110.3) & $(120.1)$ & (131.4) & $(151.2)$ & $(178.6)$ \\
\hline \multirow[t]{2}{*}{ URM } & $-221.5^{* * *}$ & $-161.1 * * *$ & $-181.9 * * *$ & $-245.9 * * *$ & $-411.2 * * *$ & $-372.3 * * *$ & $-328.6^{* * * *}$ & $-262.1 * * *$ & $-388.3 * * *$ \\
\hline & $(38.43)$ & (39.73) & $(40.40)$ & $(43.47)$ & (46.14) & $(48.39)$ & $(50.37)$ & $(56.76)$ & $(64.16)$ \\
\hline \multirow[t]{2}{*}{ Constant } & $-536.4 * * *$ & $-572.5^{* * *}$ & $-626.7 * * *$ & $-700.0^{* * * *}$ & $-850.9 * * *$ & $-1044.6^{* * *}$ & $-1179.7 * * *$ & $-1345.6^{* * *}$ & $-1587.0 * * *$ \\
\hline & (29.35) & $(31.12)$ & (33.39) & $(38.28)$ & (43.29) & (47.76) & $(50.93)$ & (58.38) & $(66.98)$ \\
\hline $\mathbf{N}$ & 11521 & 12064 & 12114 & 12656 & 12768 & 13198 & 13096 & 12946 & 12688 \\
\hline r2 & 0.352 & 0.354 & 0.355 & 0.348 & 0.377 & 0.395 & 0.414 & 0.427 & 0.454 \\
\hline
\end{tabular}


Appendix Table 3: OLS Pooled Regression Table for Non Need-Meeting Aid Inst. Aid

\begin{tabular}{|c|c|c|c|c|c|c|c|c|c|}
\hline & 2005-07 & 2006-09 & 2007-10 & 2008-11 & 2009-12 & 2010-13 & 2011-14 & 2012-15 & 2013-15 \\
\hline First Gen. & $\begin{array}{l}-90.30^{*} \\
(42.85)\end{array}$ & $\begin{array}{l}-25.24 \\
(41.57)\end{array}$ & $\begin{array}{l}-33.06 \\
(42.26)\end{array}$ & $\begin{array}{l}-31.63 \\
(44.81)\end{array}$ & $\begin{array}{l}-92.51 \\
(47.92)\end{array}$ & $\begin{array}{l}-96.65 \\
(51.82)\end{array}$ & $\begin{array}{l}-63.29 \\
(57.38)\end{array}$ & $\begin{array}{l}-30.52 \\
(65.29)\end{array}$ & $\begin{array}{l}-35.08 \\
(76.46)\end{array}$ \\
\hline SQIS Quartile 2 & $\begin{array}{c}549.8 * * * \\
(51.88)\end{array}$ & $\begin{array}{c}522.1 * * * \\
(50.44)\end{array}$ & $\begin{array}{c}484.2 * * * \\
(51.15)\end{array}$ & $\begin{array}{c}588.2 * * * \\
(53.58)\end{array}$ & $\begin{array}{c}645.5 * * * \\
(57.08)\end{array}$ & $\begin{array}{c}690.2 * * * \\
(61.18)\end{array}$ & $\begin{array}{c}603.3 * * * \\
(67.41)\end{array}$ & $\begin{array}{c}733.2 * * * \\
(76.75)\end{array}$ & $\begin{array}{c}1080.6^{* * * *} \\
(91.12)\end{array}$ \\
\hline SQIS Quartile 3 & $\begin{array}{c}1508.6 * * * \\
(52.76)\end{array}$ & $\begin{array}{c}1524.3 * * * \\
(50.92)\end{array}$ & $\begin{array}{c}1447.8 * * * \\
(51.63)\end{array}$ & $\begin{array}{c}1610.1 * * * \\
(54.25)\end{array}$ & $\begin{array}{c}1745.0 * * * \\
(58.01)\end{array}$ & $\begin{array}{c}1938.1 * * * \\
(62.11)\end{array}$ & $\begin{array}{c}1937.9 * * * \\
(67.72)\end{array}$ & $\begin{array}{c}2290.6 * * * \\
(76.22)\end{array}$ & $\begin{array}{c}2911.4^{* * * *} \\
(88.45)\end{array}$ \\
\hline SQIS Quartile 4 & $\begin{array}{c}2802.2 * * * \\
(55.30)\end{array}$ & $\begin{array}{c}2958.9 * * * \\
(53.52)\end{array}$ & $\begin{array}{c}3075.7 * * * \\
(54.05)\end{array}$ & $\begin{array}{c}3376.4 * * * \\
(56.83)\end{array}$ & $\begin{array}{c}3637.9 * * * \\
(60.08)\end{array}$ & $\begin{array}{c}4108.8 * * * \\
(64.13)\end{array}$ & $\begin{array}{c}4567.5 * * * \\
(69.36)\end{array}$ & $\begin{array}{c}5361.6 * * * \\
(77.62)\end{array}$ & $\begin{array}{c}6224.8^{* * * *} \\
(88.97)\end{array}$ \\
\hline Student Need & $\begin{array}{c}-207.8 * * * \\
(7.87)\end{array}$ & $\begin{array}{c}-191.0 * * * \\
(7.03)\end{array}$ & $\begin{array}{c}-186.5 * * * \\
(6.75)\end{array}$ & $\begin{array}{c}-205.3 * * * \\
(6.72)\end{array}$ & $\begin{array}{c}-237.3 * * * \\
(6.84)\end{array}$ & $\begin{array}{c}-262.3 * * * \\
(6.83)\end{array}$ & $\begin{array}{c}-272.3 * * * \\
(7.01)\end{array}$ & $\begin{array}{c}-295.9 * * * \\
(7.48)\end{array}$ & $\begin{array}{c}-335.5 * * * \\
(8.21)\end{array}$ \\
\hline Pell Recipient & $\begin{array}{l}132.8^{*} \\
(52.43)\end{array}$ & $\begin{array}{l}133.4 * * \\
(50.77)\end{array}$ & $\begin{array}{l}138.9 * * \\
(50.77)\end{array}$ & $\begin{array}{l}134.0^{*} \\
(52.76)\end{array}$ & $\begin{array}{c}189.4 * * * \\
(55.60)\end{array}$ & $\begin{array}{c}268.3 * * * \\
(59.50)\end{array}$ & $\begin{array}{c}369.1 * * * \\
(64.51)\end{array}$ & $\begin{array}{c}404.6 * * * \\
(71.75)\end{array}$ & $\begin{array}{c}399.9 * * * \\
(82.02)\end{array}$ \\
\hline Female & $\begin{array}{l}-3.022 \\
(36.87)\end{array}$ & $\begin{array}{c}8.144 \\
(35.79)\end{array}$ & $\begin{array}{l}-6.892 \\
(36.18)\end{array}$ & $\begin{array}{l}-9.06 \\
(38.17)\end{array}$ & $\begin{array}{l}-51.77 \\
(40.38)\end{array}$ & $\begin{array}{l}-78.64 \\
(43.01)\end{array}$ & $\begin{array}{c}-124.6^{* * *} \\
(46.49)\end{array}$ & $\begin{array}{c}-159.7^{* *} \\
(52.27)\end{array}$ & $\begin{array}{c}-143.4^{*} \\
(60.26)\end{array}$ \\
\hline URM & $\begin{array}{c}305.3 * * * \\
(73.49)\end{array}$ & $\begin{array}{c}243.9^{* * * *} \\
(69.92)\end{array}$ & $\begin{array}{l}167.1^{*} \\
(67.74)\end{array}$ & $\begin{array}{l}171.6^{*} \\
(67.36)\end{array}$ & $\begin{array}{l}149.5^{*} \\
(67.80)\end{array}$ & $\begin{array}{l}133.5 \\
(68.70)\end{array}$ & $\begin{array}{c}44.23 \\
(72.70)\end{array}$ & $\begin{array}{l}-50.01 \\
(80.03)\end{array}$ & $\begin{array}{l}-69.22 \\
(92.03)\end{array}$ \\
\hline Constant & $\begin{array}{c}-317.4 * * * \\
(56.14)\end{array}$ & $\begin{array}{c}-443.3 * * * \\
(54.76)\end{array}$ & $\begin{array}{c}-549.2 * * * \\
(55.99)\end{array}$ & $\begin{array}{c}-676.6^{* * *} \\
(59.32)\end{array}$ & $\begin{array}{c}-720.3 * * * \\
(63.61)\end{array}$ & $\begin{array}{c}-852.1 * * * \\
(67.81)\end{array}$ & $\begin{array}{c}-881.4^{* * *} \\
(73.51)\end{array}$ & $\begin{array}{c}-1200.4^{* * *} * \\
(82.32)\end{array}$ & $\begin{array}{c}-1507.1^{* * *} \\
(96.07)\end{array}$ \\
\hline $\mathbf{N}$ & 11521 & 12064 & 12114 & 12656 & 12768 & 13198 & 13096 & 12946 & 12688 \\
\hline $\mathbf{r} 2$ & 0.257 & 0.281 & 0.299 & 0.315 & 0.337 & 0.369 & 0.389 & 0.424 & 0.44 \\
\hline
\end{tabular}

Standard errors in parentheses

$* \mathbf{p}<0.05 * * \mathbf{p}<0.01 * * * \mathbf{p}<0.001$ 
Appendix Table 4: Annual Tobit Regression Table for Aggregate Inst. Aid

\begin{tabular}{|c|c|c|c|c|c|c|c|c|c|c|c|}
\hline & 2005 & 2006 & 2007 & 2008 & 2009 & 2010 & 2011 & 2012 & 2013 & 2014 & 2015 \\
\hline First Gen. & $\begin{array}{c}38.54 \\
(137.70)\end{array}$ & $\begin{array}{c}-91.59 \\
(143.70)\end{array}$ & $\begin{array}{c}-33.99 \\
(135.20)\end{array}$ & $\begin{array}{c}114.4 \\
(136.90)\end{array}$ & $\begin{array}{c}-199 \\
(157.10)\end{array}$ & $\begin{array}{c}-129.1 \\
(165.40)\end{array}$ & $\begin{array}{c}26.83 \\
(151.20)\end{array}$ & $\begin{array}{c}-135.6 \\
(178.20)\end{array}$ & $\begin{array}{c}413.0^{*} \\
(204.30)\end{array}$ & $\begin{array}{c}-143.7 \\
(225.50)\end{array}$ & $\begin{array}{c}101.6 \\
(248.20)\end{array}$ \\
\hline SQIS Quartile 2 & $\begin{array}{c}3541.9 * * * \\
(202.70)\end{array}$ & $\begin{array}{c}3369.3 * * * \\
(211.30)\end{array}$ & $\begin{array}{c}3464.3 * * * \\
(221.90)\end{array}$ & $\begin{array}{c}3793.5 * * * \\
(217.50)\end{array}$ & $\begin{array}{c}4411.3 * * * \\
(253.20)\end{array}$ & $\begin{array}{c}6109.3 * * * \\
(281.00)\end{array}$ & $\begin{array}{c}6004.4 * * * \\
(260.80)\end{array}$ & $\begin{array}{c}6734.4 * * * \\
(290.80)\end{array}$ & $\begin{array}{c}5399.2 * * * \\
(318.30)\end{array}$ & $\begin{array}{c}7955.3 * * * \\
(354.70)\end{array}$ & $\begin{array}{c}10447.0^{* * * *} \\
(391.00)\end{array}$ \\
\hline SQIS Quartile 3 & $\begin{array}{c}6256.0 * * * \\
(204.90)\end{array}$ & $\begin{array}{c}6595.0^{* * * *} \\
(213.70)\end{array}$ & $\begin{array}{c}6673.2 * * * \\
(225.00)\end{array}$ & $\begin{array}{c}7386.8^{* * * *} \\
(219.60)\end{array}$ & $\begin{array}{c}8192.4 * * * \\
(260.70)\end{array}$ & $\begin{array}{c}9876.3 * * * \\
(289.00)\end{array}$ & $\begin{array}{c}9641.0 * * * \\
(264.30)\end{array}$ & $\begin{array}{c}10967.2 * * * \\
(298.30)\end{array}$ & $\begin{array}{c}10407.8^{* * *} \\
(319.50)\end{array}$ & $\begin{array}{c}13622.8 * * * \\
(350.10)\end{array}$ & $\begin{array}{c}15882.3 * * * \\
(384.90)\end{array}$ \\
\hline SQIS Quartile 4 & $\begin{array}{c}7748.4 * * * \\
(213.40)\end{array}$ & $\begin{array}{c}8305.5^{* * * *} \\
(222.80)\end{array}$ & $\begin{array}{c}8796.4 * * * \\
(233.10)\end{array}$ & $\begin{array}{c}9533.2 * * * \\
(230.10)\end{array}$ & $\begin{array}{c}10656.8 * * * \\
(270.90)\end{array}$ & $\begin{array}{c}12320.7 * * * \\
(298.00)\end{array}$ & $\begin{array}{c}11922.7 * * * \\
(270.20)\end{array}$ & $\begin{array}{c}14177.4 * * * \\
(305.90)\end{array}$ & $\begin{array}{c}14604.9^{* * *} \\
(326.30)\end{array}$ & $\begin{array}{c}17446.1 * * * \\
(356.50)\end{array}$ & $\begin{array}{c}19727.3 * * * \\
(387.60)\end{array}$ \\
\hline Student EFC & $\begin{array}{c}-8.735^{*} \\
(3.50)\end{array}$ & $\begin{array}{c}-11.84 * * * \\
(3.25)\end{array}$ & $\begin{array}{l}-5.501 \\
(3.24)\end{array}$ & $\begin{array}{l}1.131 \\
(2.89)\end{array}$ & $\begin{array}{l}-3.108 \\
(3.48)\end{array}$ & $\begin{array}{l}-3.506 \\
(3.81)\end{array}$ & $\begin{array}{l}-4.564 \\
(3.23)\end{array}$ & $\begin{array}{c}-7.906^{*} \\
(3.68)\end{array}$ & $\begin{array}{l}-1.269 \\
(3.87)\end{array}$ & $\begin{array}{l}1.772 \\
(3.42)\end{array}$ & $\begin{array}{c}-12.81 * * * \\
(3.87)\end{array}$ \\
\hline Student Need & $\begin{array}{l}-26.95 \\
(27.61)\end{array}$ & $\begin{array}{l}-29.69 \\
(26.69)\end{array}$ & $\begin{array}{c}89.73 * * * \\
(23.66)\end{array}$ & $\begin{array}{c}97.59 * * * \\
(20.98)\end{array}$ & $\begin{array}{c}33.24 \\
(23.49)\end{array}$ & $\begin{array}{c}28.11 \\
(23.56)\end{array}$ & $\begin{array}{c}13.93 \\
(20.12)\end{array}$ & $\begin{array}{c}5.536 \\
(21.34)\end{array}$ & $\begin{array}{c}105.3 * * * \\
(22.76)\end{array}$ & $\begin{array}{c}141.7 * * * \\
(24.02)\end{array}$ & $\begin{array}{l}-13.64 \\
(24.52)\end{array}$ \\
\hline Pell Recipient & $\begin{array}{c}-45.18 \\
(168.40)\end{array}$ & $\begin{array}{l}-362.1^{*} \\
(176.50)\end{array}$ & $\begin{array}{c}-80.13 \\
(166.50)\end{array}$ & $\begin{array}{c}134 \\
(167.30)\end{array}$ & $\begin{array}{c}-320.5 \\
(181.70)\end{array}$ & $\begin{array}{c}-266 \\
(187.90)\end{array}$ & $\begin{array}{c}278.7 \\
(171.90)\end{array}$ & $\begin{array}{c}29.39 \\
(201.20)\end{array}$ & $\begin{array}{c}215.6 \\
(222.70)\end{array}$ & $\begin{array}{c}-438.3 \\
(237.90)\end{array}$ & $\begin{array}{c}68.22 \\
(257.20)\end{array}$ \\
\hline Female & $\begin{array}{c}169.2 \\
(115.90)\end{array}$ & $\begin{array}{c}214 \\
(122.00)\end{array}$ & $\begin{array}{c}19.59 \\
(115.00)\end{array}$ & $\begin{array}{c}270.1^{*} \\
(114.70)\end{array}$ & $\begin{array}{c}180.2 \\
(128.30)\end{array}$ & $\begin{array}{c}-118.6 \\
(136.20)\end{array}$ & $\begin{array}{c}-106.6 \\
(122.70)\end{array}$ & $\begin{array}{c}-91.04 \\
(140.60)\end{array}$ & $\begin{array}{c}-112.7 \\
(159.20)\end{array}$ & $\begin{array}{c}-449.6^{*} \\
(175.10)\end{array}$ & $\begin{array}{c}-500.3^{* *} \\
(187.10)\end{array}$ \\
\hline Nonresident & $\begin{array}{c}2304.2 * * * \\
(155.50)\end{array}$ & $\begin{array}{c}2391.4 * * * \\
(162.30)\end{array}$ & $\begin{array}{c}2614.3^{* * * *} \\
(153.80)\end{array}$ & $\begin{array}{c}3168.7 * * * \\
(152.30)\end{array}$ & $\begin{array}{c}3844.2 * * * \\
(179.90)\end{array}$ & $\begin{array}{c}4085.6 * * * \\
(193.10)\end{array}$ & $\begin{array}{c}4240.9 * * * \\
(171.00)\end{array}$ & $\begin{array}{c}5365.6 * * * \\
(195.00)\end{array}$ & $\begin{array}{c}5485.9 * * * \\
(220.00)\end{array}$ & $\begin{array}{c}7712.7 * * * \\
(242.10)\end{array}$ & $\begin{array}{c}9532.8 * * * \\
(264.70)\end{array}$ \\
\hline Asian & $\begin{array}{c}-443 \\
(483.70)\end{array}$ & $\begin{array}{c}-730.2 \\
(465.60)\end{array}$ & $\begin{array}{c}-368 \\
(418.00)\end{array}$ & $\begin{array}{c}-192.7 \\
(466.30)\end{array}$ & $\begin{array}{c}-730.8 \\
(528.90)\end{array}$ & $\begin{array}{c}-393.9 \\
(564.80)\end{array}$ & $\begin{array}{c}-677 \\
(474.40)\end{array}$ & $\begin{array}{c}855 \\
(550.00)\end{array}$ & $\begin{array}{l}-1670.0^{*} \\
(704.60)\end{array}$ & $\begin{array}{c}-1427.6^{*} \\
(658.40)\end{array}$ & $\begin{array}{c}-3.457 \\
(825.20)\end{array}$ \\
\hline URM & $\begin{array}{c}562.0 * \\
(250.60)\end{array}$ & $\begin{array}{l}768.6 * * \\
(276.00)\end{array}$ & $\begin{array}{c}-141.5 \\
(236.90)\end{array}$ & $\begin{array}{c}333.5 \\
(236.90)\end{array}$ & $\begin{array}{c}224.1 \\
(263.60)\end{array}$ & $\begin{array}{c}-397.7 \\
(243.40)\end{array}$ & $\begin{array}{l}-727.3^{* *} \\
(224.20)\end{array}$ & $\begin{array}{c}367.3 \\
(232.40)\end{array}$ & $\begin{array}{l}-544.4^{*} \\
(259.10)\end{array}$ & $\begin{array}{l}-664.5^{*} \\
(292.20)\end{array}$ & $\begin{array}{c}-471 \\
(304.40)\end{array}$ \\
\hline Constant & $\begin{array}{c}-5195.7 * * * \\
(223.30)\end{array}$ & $\begin{array}{c}-5454.2 * * * \\
(232.20)\end{array}$ & $\begin{array}{c}-6118.4 * * * \\
(248.60)\end{array}$ & $\begin{array}{c}-7239.0 * * * \\
(248.80)\end{array}$ & $\begin{array}{c}-8051.6 * * * \\
(290.90)\end{array}$ & $\begin{array}{c}-8920.4^{* * * *} \\
(320.20)\end{array}$ & $\begin{array}{c}-8409.5 * * * \\
(286.40)\end{array}$ & $\begin{array}{c}-10031.8^{* * * *} \\
(323.00)\end{array}$ & $\begin{array}{c}-10257.8^{* * * *} \\
(355.00)\end{array}$ & $\begin{array}{c}-12571.5 * * * \\
(382.10)\end{array}$ & $\begin{array}{c}-13810.6^{* * * *} \\
(420.10)\end{array}$ \\
\hline Sigma & $\begin{array}{c}3073.1 * * * \\
(49.63)\end{array}$ & $\begin{array}{c}3278.4 * * * \\
(52.87)\end{array}$ & $\begin{array}{c}3055.7 * * * \\
(49.14)\end{array}$ & $\begin{array}{c}3160.6^{* * * *} \\
(48.47)\end{array}$ & $\begin{array}{c}3368.5 * * * \\
(54.02)\end{array}$ & $\begin{array}{c}3822.4 * * * \\
(57.47)\end{array}$ & $\begin{array}{c}3536.1 * * * \\
(49.69)\end{array}$ & $\begin{array}{c}4062.2^{* * *} \\
(57.33)\end{array}$ & $\begin{array}{c}4499.7 * * * \\
(66.20)\end{array}$ & $\begin{array}{c}4976.4^{* * *} \\
(72.16)\end{array}$ & $\begin{array}{c}5422.8 * * * \\
(74.33)\end{array}$ \\
\hline $\mathbf{N}$ & 3716 & 3944 & 3861 & 4259 & 3994 & 4403 & 4371 & 4424 & 4301 & 4221 & 4166 \\
\hline r2 & 0.043 & 0.046 & 0.051 & 0.055 & 0.0581 & 0.056 & 0.056 & 0.058 & 0.059 & 0.063 & 0.06 \\
\hline
\end{tabular}

Standard errors in parentheses

$* \mathbf{p}<0.05 * * \mathbf{p}<0.01 * * * \mathbf{p}<0.001$ 
Appendix Table 5: Annual Tobit Regression Table for Need-Meeting Inst. Aid

\begin{tabular}{|c|c|c|c|c|c|c|c|c|c|c|c|}
\hline & 2005 & 2006 & 2007 & 2008 & 2009 & 2010 & 2011 & 2012 & 2013 & 2014 & 2015 \\
\hline First Gen. & $\begin{array}{l}123.0 \\
(210.5)\end{array}$ & $\begin{array}{l}-84.60 \\
(240.1)\end{array}$ & $\begin{array}{c}226.0 \\
(247.0)\end{array}$ & $\begin{array}{c}39.46 \\
(252.6)\end{array}$ & $\begin{array}{c}110.5 \\
(293.2)\end{array}$ & $\begin{array}{l}-212.2 \\
(337.6)\end{array}$ & $\begin{array}{c}204.2 \\
(261.9)\end{array}$ & $\begin{array}{l}-87.86 \\
(295.4)\end{array}$ & $\begin{array}{l}671.2 * \\
(333.5)\end{array}$ & $\begin{array}{l}-312.3 \\
(358.5)\end{array}$ & $\begin{array}{l}-280.2 \\
(397.5)\end{array}$ \\
\hline SQIS Quartile 2 & $\begin{array}{c}3849.7 * * * \\
(315.6)\end{array}$ & $\begin{array}{c}3616.4 * * * \\
(363.9)\end{array}$ & $\begin{array}{c}3554.6^{* * *} \\
(382.0)\end{array}$ & $\begin{array}{c}3991.5^{* * *} \\
(362.0)\end{array}$ & $\begin{array}{c}3937.8^{* * * *} \\
(404.8)\end{array}$ & $\begin{array}{c}5791.3 * * * \\
(506.2)\end{array}$ & $\begin{array}{c}5906.5^{* * *} \\
(428.8)\end{array}$ & $\begin{array}{c}6208.4^{* * * *} \\
(442.8)\end{array}$ & $\begin{array}{c}6072.4 * * * \\
(495.7)\end{array}$ & $\begin{array}{c}7910.3 * * * \\
(550.6)\end{array}$ & $\begin{array}{c}10614.6^{* * * *} \\
(622.9)\end{array}$ \\
\hline SQIS Quartile 3 & $\begin{array}{c}5751.8^{* * * *} \\
(333.3)\end{array}$ & $\begin{array}{c}6431.5 * * * \\
(388.3)\end{array}$ & $\begin{array}{c}6439.1 * * * \\
(396.3)\end{array}$ & $\begin{array}{c}6891.0 * * * \\
(382.0)\end{array}$ & $\begin{array}{c}7722.7 * * * \\
(441.0)\end{array}$ & $\begin{array}{c}10143.8^{* * * *} \\
(540.9)\end{array}$ & $\begin{array}{c}10210.2 * * * \\
(446.5)\end{array}$ & $\begin{array}{c}10730.9 * * * \\
(470.1)\end{array}$ & $\begin{array}{c}10214.8^{* * *} \\
(515.1)\end{array}$ & $\begin{array}{c}13683.1 * * * \\
(549.9)\end{array}$ & $\begin{array}{c}15047.2^{* * * *} \\
(626.0)\end{array}$ \\
\hline SQIS Quartile 4 & $\begin{array}{c}6357.1 * * * * \\
(363.0)\end{array}$ & $\begin{array}{c}7206.2 * * * \\
(416.6)\end{array}$ & $\begin{array}{c}7102.8^{* * * *} \\
(428.1)\end{array}$ & $\begin{array}{c}7983.2 * * * \\
(426.3)\end{array}$ & $\begin{array}{c}9117.7 * * * * \\
(495.1)\end{array}$ & $\begin{array}{c}11446.5 * * * \\
(588.4)\end{array}$ & $\begin{array}{c}11027.0 * * * \\
(470.3)\end{array}$ & $\begin{array}{c}12155.6 * * * \\
(503.7)\end{array}$ & $\begin{array}{c}11782.1 * * * \\
(545.6)\end{array}$ & $\begin{array}{c}14466.1 * * * \\
(578.7)\end{array}$ & $\begin{array}{c}15691.5^{* * * * *} \\
(642.5)\end{array}$ \\
\hline Student EFC & $\begin{array}{c}-931.2 * * * \\
(87.12)\end{array}$ & $\begin{array}{c}-788.0^{* * * *} \\
(85.77)\end{array}$ & $\begin{array}{c}-718.4 * * * \\
(79.88)\end{array}$ & $\begin{array}{c}-933.8 * * * \\
(98.68)\end{array}$ & $\begin{array}{c}-824.8 * * * \\
(89.94)\end{array}$ & $\begin{array}{c}-805.2 * * * \\
(90.84)\end{array}$ & $\begin{array}{c}-725.4^{* * *} \\
(65.28)\end{array}$ & $\begin{array}{c}-787.2 * * * \\
(72.80)\end{array}$ & $\begin{array}{c}-733.0^{* * *} \\
(75.97)\end{array}$ & $\begin{array}{c}-750.0 * * * \\
(76.33)\end{array}$ & $\begin{array}{c}-761.4^{* * * *} \\
(74.66)\end{array}$ \\
\hline Student Need & $\begin{array}{c}-523.7 * * * \\
(99.18)\end{array}$ & $\begin{array}{c}-370.3^{* * *} \\
(100.7)\end{array}$ & $\begin{array}{l}-195.9^{*} \\
(94.55)\end{array}$ & $\begin{array}{c}-430.3 * * * \\
(111.2)\end{array}$ & $\begin{array}{c}-332.9^{* *} \\
(107.8)\end{array}$ & $\begin{array}{l}-121.2 \\
(111.4)\end{array}$ & $\begin{array}{c}-214.3^{* *} \\
(79.65)\end{array}$ & $\begin{array}{c}-231.3^{* *} \\
(85.19)\end{array}$ & $\begin{array}{l}-55.12 \\
(90.19)\end{array}$ & $\begin{array}{l}179.3 * \\
(89.46)\end{array}$ & $\begin{array}{c}29.73 \\
(89.12)\end{array}$ \\
\hline Pell Recipient & $\begin{array}{c}-2743.2 * * * \\
(361.0)\end{array}$ & $\begin{array}{c}-2570.5^{* * *} \\
(391.1)\end{array}$ & $\begin{array}{c}-2398.8^{* * * *} \\
(410.6)\end{array}$ & $\begin{array}{c}-3240.7 * * * \\
(456.7)\end{array}$ & $\begin{array}{c}-3855.4 * * * \\
(521.8)\end{array}$ & $\begin{array}{c}-4628.8^{* * *} \\
(568.3)\end{array}$ & $\begin{array}{c}-2799.5^{* * *} \\
(434.1)\end{array}$ & $\begin{array}{c}-3830.6^{* * *} \\
(475.7)\end{array}$ & $\begin{array}{c}-3901.0 * * * \\
(505.4)\end{array}$ & $\begin{array}{c}-5072.2^{* * *} \\
(540.5)\end{array}$ & $\begin{array}{c}-3972.3 * * * \\
(583.0)\end{array}$ \\
\hline Female & $\begin{array}{l}-20.33 \\
(195.1)\end{array}$ & $\begin{array}{l}585.4 * * \\
(226.1)\end{array}$ & $\begin{array}{c}5.294 \\
(232.8)\end{array}$ & $\begin{array}{c}340.5 \\
(236.5)\end{array}$ & $\begin{array}{l}361.1 \\
(271.6)\end{array}$ & $\begin{array}{c}181.1 \\
(307.6)\end{array}$ & $\begin{array}{l}-232.4 \\
(236.6)\end{array}$ & $\begin{array}{c}29.76 \\
(263.3)\end{array}$ & $\begin{array}{c}270.5 \\
(298.6)\end{array}$ & $\begin{array}{l}-585.2 \\
(309.1)\end{array}$ & $\begin{array}{l}-744.5^{*} \\
(336.8)\end{array}$ \\
\hline Nonresident & $\begin{array}{c}11285.9^{* * * *} \\
(896.6)\end{array}$ & $\begin{array}{c}11387.5^{* * * *} \\
(989.6)\end{array}$ & $\begin{array}{c}10952.0^{* * * *} \\
(982.9)\end{array}$ & $\begin{array}{c}15186.2 * * * \\
(1296.6)\end{array}$ & $\begin{array}{c}16340.4 * * * \\
(1337.7)\end{array}$ & $\begin{array}{c}16122.7 * * * \\
(1376.2)\end{array}$ & $\begin{array}{c}13962.6 * * * \\
(995.4)\end{array}$ & $\begin{array}{c}15357.6 * * * \\
(1129.9)\end{array}$ & $\begin{array}{c}15287.1 * * * \\
(1276.9)\end{array}$ & $\begin{array}{c}14416.8 * * * \\
(1253.5)\end{array}$ & $\begin{array}{c}16320.8 * * * \\
(1323.6)\end{array}$ \\
\hline Asian & $\begin{array}{l}-2131.0 \\
(1375.7)\end{array}$ & $\begin{array}{l}-726.0 \\
(843.1)\end{array}$ & $\begin{array}{l}-999.7 \\
(890.5)\end{array}$ & $\begin{array}{l}-975.1 \\
(983.9)\end{array}$ & $\begin{array}{l}-2514.2^{*} \\
(1233.0)\end{array}$ & $\begin{array}{c}-3751.8^{*} \\
(1482.7)\end{array}$ & $\begin{array}{l}-945.4 \\
(839.2)\end{array}$ & $\begin{array}{c}316.6 \\
(967.7)\end{array}$ & $\begin{array}{l}-1938.3 \\
(1406.1)\end{array}$ & $\begin{array}{c}-415.7 \\
(1318.3)\end{array}$ & $\begin{array}{l}-1234.9 \\
(1591.6)\end{array}$ \\
\hline URM & $\begin{array}{c}360.6 \\
(337.6)\end{array}$ & $\begin{array}{l}-131.0 \\
(430.4)\end{array}$ & $\begin{array}{c}-1338.7 * * \\
(436.3)\end{array}$ & $\begin{array}{c}209.2 \\
(385.1)\end{array}$ & $\begin{array}{c}-910.3^{*} \\
(448.4)\end{array}$ & $\begin{array}{c}-1117.3^{*} \\
(466.5)\end{array}$ & $\begin{array}{c}-934.0^{* * *} \\
(359.2)\end{array}$ & $\begin{array}{c}399.4 \\
(360.7)\end{array}$ & $\begin{array}{l}-280.9 \\
(415.8)\end{array}$ & $\begin{array}{l}-758.2 \\
(439.5)\end{array}$ & $\begin{array}{l}-666.8 \\
(463.6)\end{array}$ \\
\hline Constant & $\begin{array}{c}-5361.7 * * * \\
(555.5)\end{array}$ & $\begin{array}{c}-7615.5^{* * * *} \\
(636.9)\end{array}$ & $\begin{array}{c}-7899.2^{* * * *} \\
(666.4)\end{array}$ & $\begin{array}{c}-8549.0^{* * * *} \\
(727.5)\end{array}$ & $\begin{array}{c}-11568.4 * * * \\
(908.1)\end{array}$ & $\begin{array}{c}-14164.2^{* * * *} \\
(975.8)\end{array}$ & $\begin{array}{c}-11300.2^{* * *} \\
(701.4)\end{array}$ & $\begin{array}{c}-11860.9 * * * \\
(762.0)\end{array}$ & $\begin{array}{c}-13144.3^{* * * *} \\
(827.1)\end{array}$ & $\begin{array}{c}-14418.3^{* * * *} \\
(887.3)\end{array}$ & $\begin{array}{c}-16129.0 * * * \\
(972.3)\end{array}$ \\
\hline Sigma & $\begin{array}{c}2738.6^{* * * *} \\
(105.6)\end{array}$ & $\begin{array}{c}3109.7 * * * \\
(126.5)\end{array}$ & $\begin{array}{c}3346.8^{* * *} \\
(126.1)\end{array}$ & $\begin{array}{c}3412.4 * * * \\
(123.6)\end{array}$ & $\begin{array}{c}3587.1^{* * *} \\
(141.3)\end{array}$ & $\begin{array}{c}4723.3 * * * \\
(164.1)\end{array}$ & $\begin{array}{c}3933.2^{* * * *} \\
(121.3)\end{array}$ & $\begin{array}{c}4477.8 * * * \\
(137.4)\end{array}$ & $\begin{array}{c}4846.4^{* * *} \\
(151.6)\end{array}$ & $\begin{array}{c}5146.1 * * * \\
(154.8)\end{array}$ & $\begin{array}{c}5891.0 * * * \\
(173.9)\end{array}$ \\
\hline $\mathbf{N}$ & 3716 & 3944 & 3861 & 4259 & 3994 & 4403 & 4371 & 4424 & 4301 & 4221 & 4166 \\
\hline $\operatorname{Pr} 2$ & 0.16 & 0.16 & 0.15 & 0.17 & 0.17 & 0.15 & 0.16 & 0.15 & 0.15 & 0.16 & 0.14 \\
\hline
\end{tabular}

Standard errors in parentheses

$* \mathbf{p}<0.05 * * \mathbf{p}<0.01 * * * \mathbf{p}<0.001$ 
Appendix Table 6: Annual Tobit Regression Table for Non-Need-Meeting Inst. Aid

\begin{tabular}{|c|c|c|c|c|c|c|c|c|c|c|c|}
\hline & 2005 & 2006 & 2007 & 2008 & 2009 & 2010 & 2011 & 2012 & 2013 & 2014 & 2015 \\
\hline First Gen. & $\begin{array}{c}6.044 \\
(146.4)\end{array}$ & $\begin{array}{l}-102.2 \\
(150.3)\end{array}$ & $\begin{array}{l}-26.08 \\
(134.1)\end{array}$ & $\begin{array}{c}248.3 \\
(141.3)\end{array}$ & $\begin{array}{l}-265.1 \\
(169.1)\end{array}$ & $\begin{array}{l}-48.15 \\
(162.0)\end{array}$ & $\begin{array}{l}-127.3 \\
(153.6)\end{array}$ & $\begin{array}{l}-313.3 \\
(180.7)\end{array}$ & $\begin{array}{c}327.2 \\
(208.6)\end{array}$ & $\begin{array}{l}-113.5 \\
(208.1)\end{array}$ & $\begin{array}{c}74.82 \\
(229.9)\end{array}$ \\
\hline SQIS Quartile 2 & $\begin{array}{c}3008.0^{* * * *} \\
(224.6)\end{array}$ & $\begin{array}{c}2924.9 * * * \\
(228.7)\end{array}$ & $\begin{array}{c}2701.7 * * * \\
(231.9)\end{array}$ & $\begin{array}{c}3611.1 * * * \\
(256.9)\end{array}$ & $\begin{array}{c}4242.9^{* * *} \\
(312.0)\end{array}$ & $\begin{array}{c}5621.7^{* * * *} \\
(313.3)\end{array}$ & $\begin{array}{c}5354.2^{* * * *} \\
(296.2)\end{array}$ & $\begin{array}{c}6405.8 * * * \\
(357.8)\end{array}$ & $\begin{array}{c}4217.8^{* * * *} \\
(358.0)\end{array}$ & $\begin{array}{c}6945.5^{* * *} \\
(384.3)\end{array}$ & $\begin{array}{c}8952.5 * * * \\
(423.9)\end{array}$ \\
\hline SQIS Quartile 3 & $\begin{array}{c}5522.2 * * * \\
(221.8)\end{array}$ & $\begin{array}{c}5805.1 * * * \\
(225.4)\end{array}$ & $\begin{array}{c}5430.3^{* * * *} \\
(230.6)\end{array}$ & $\begin{array}{c}6761.4 * * * \\
(253.8)\end{array}$ & $\begin{array}{c}7578.3^{* * * *} \\
(313.7)\end{array}$ & $\begin{array}{c}8482.2 * * * \\
(316.7)\end{array}$ & $\begin{array}{c}8160.0 * * * \\
(295.7)\end{array}$ & $\begin{array}{c}9635.9 * * * \\
(360.0)\end{array}$ & $\begin{array}{c}8571.8^{* * * *} \\
(350.2)\end{array}$ & $\begin{array}{c}11310.3^{* * * *} \\
(377.8)\end{array}$ & $\begin{array}{c}13294.9 * * * \\
(414.8)\end{array}$ \\
\hline SQIS Quartile 4 & $\begin{array}{c}7002.3 * * * \\
(227.7)\end{array}$ & $\begin{array}{c}7468.1 * * * \\
(232.5)\end{array}$ & $\begin{array}{c}7497.0^{* * * *} \\
(235.3)\end{array}$ & $\begin{array}{c}8801.8 * * * \\
(260.8)\end{array}$ & $\begin{array}{c}9967.8^{* * *} \\
(319.8)\end{array}$ & $\begin{array}{c}10900.2^{* * * *} \\
(321.9)\end{array}$ & $\begin{array}{c}10421.8 * * * \\
(298.6)\end{array}$ & $\begin{array}{c}12798.3^{* * * *} \\
(364.0)\end{array}$ & $\begin{array}{c}12675.5^{* * * *} \\
(353.7)\end{array}$ & $\begin{array}{c}15127.6^{* * * *} \\
(379.6)\end{array}$ & $\begin{array}{c}17064.5 * * * \\
(414.8)\end{array}$ \\
\hline Student EFC & $\begin{array}{l}-7.388^{*} \\
(3.471)\end{array}$ & $\begin{array}{c}-10.95^{* * *} \\
(3.177)\end{array}$ & $\begin{array}{l}-4.015 \\
(3.025)\end{array}$ & $\begin{array}{c}1.595 \\
(2.756)\end{array}$ & $\begin{array}{l}-2.950 \\
(3.396)\end{array}$ & $\begin{array}{l}-1.846 \\
(3.415)\end{array}$ & $\begin{array}{l}-3.666 \\
(3.003)\end{array}$ & $\begin{array}{l}-5.694 \\
(3.376)\end{array}$ & $\begin{array}{c}0.00293 \\
(3.609)\end{array}$ & $\begin{array}{c}3.406 \\
(2.950)\end{array}$ & $\begin{array}{c}-9.709 * * \\
(3.337)\end{array}$ \\
\hline Student Need & $\begin{array}{c}-886.0 * * * \\
(46.20)\end{array}$ & $\begin{array}{c}-837.9 * * * \\
(46.43)\end{array}$ & $\begin{array}{c}-645.4 * * * \\
(34.01)\end{array}$ & $\begin{array}{c}-696.0 * * * \\
(33.81)\end{array}$ & $\begin{array}{c}-778.0 * * * \\
(39.80)\end{array}$ & $\begin{array}{c}-751.1 * * * \\
(30.55)\end{array}$ & $\begin{array}{c}-775.9 * * * \\
(27.82)\end{array}$ & $\begin{array}{c}-754.5 * * * \\
(27.58)\end{array}$ & $\begin{array}{c}-721.2 * * * \\
(30.09)\end{array}$ & $\begin{array}{c}-645.9 * * * \\
(24.94)\end{array}$ & $\begin{array}{c}-730.3 * * * \\
(24.71)\end{array}$ \\
\hline Pell Recipient & $\begin{array}{l}-50.29 \\
(183.3)\end{array}$ & $\begin{array}{l}-464.2^{*} \\
(188.6)\end{array}$ & $\begin{array}{l}-63.28 \\
(168.1)\end{array}$ & $\begin{array}{c}66.29 \\
(177.8)\end{array}$ & $\begin{array}{l}-459.6^{*} \\
(195.5)\end{array}$ & $\begin{array}{l}-279.9 \\
(183.2)\end{array}$ & $\begin{array}{c}170.8 \\
(173.3)\end{array}$ & $\begin{array}{c}146.5 \\
(201.8)\end{array}$ & $\begin{array}{c}298.7 \\
(227.5)\end{array}$ & $\begin{array}{l}-263.7 \\
(220.0)\end{array}$ & $\begin{array}{l}-197.9 \\
(235.2)\end{array}$ \\
\hline Female & $\begin{array}{c}209.1 \\
(121.0)\end{array}$ & $\begin{array}{c}113.8 \\
(124.9)\end{array}$ & $\begin{array}{l}-57.40 \\
(112.4)\end{array}$ & $\begin{array}{c}218.6 \\
(115.6)\end{array}$ & $\begin{array}{c}175.3 \\
(133.3)\end{array}$ & $\begin{array}{l}-182.5 \\
(129.8)\end{array}$ & $\begin{array}{l}-32.55 \\
(120.9)\end{array}$ & $\begin{array}{l}-203.9 \\
(136.9)\end{array}$ & $\begin{array}{l}-121.0 \\
(156.7)\end{array}$ & $\begin{array}{l}-376.8^{*} \\
(158.1)\end{array}$ & $\begin{array}{l}-361.7^{*} \\
(168.6)\end{array}$ \\
\hline Nonresident & $\begin{array}{c}2152.0^{* * * *} \\
(154.6)\end{array}$ & $\begin{array}{c}2198.0^{* * * *} \\
(158.5)\end{array}$ & $\begin{array}{c}2373.7 * * * \\
(143.2)\end{array}$ & $\begin{array}{c}3005.9 * * * \\
(145.9)\end{array}$ & $\begin{array}{c}3600.0^{* * * *} \\
(177.2)\end{array}$ & $\begin{array}{c}3871.6^{* * * *} \\
(174.2)\end{array}$ & $\begin{array}{c}3974.0^{* * * *} \\
(159.4)\end{array}$ & $\begin{array}{c}5103.3 * * * \\
(180.4)\end{array}$ & $\begin{array}{c}5267.3 * * * \\
(206.2)\end{array}$ & $\begin{array}{c}7575.7 * * * \\
(211.4)\end{array}$ & $\begin{array}{c}9098.7 * * * \\
(232.0)\end{array}$ \\
\hline Asian & $\begin{array}{l}-293.1 \\
(489.4)\end{array}$ & $\begin{array}{l}-548.5 \\
(485.3)\end{array}$ & $\begin{array}{l}-165.0 \\
(407.7)\end{array}$ & $\begin{array}{l}-84.62 \\
(476.4)\end{array}$ & $\begin{array}{l}-417.6 \\
(560.5)\end{array}$ & $\begin{array}{c}368.0 \\
(548.8)\end{array}$ & $\begin{array}{l}-196.0 \\
(484.1)\end{array}$ & $\begin{array}{c}1205.8^{*} \\
(534.3)\end{array}$ & $\begin{array}{l}-1222.6 \\
(705.7)\end{array}$ & $\begin{array}{c}-1202.5^{*} \\
(585.1)\end{array}$ & $\begin{array}{c}229.0 \\
(747.1)\end{array}$ \\
\hline URM & $\begin{array}{l}571.4^{*} \\
(287.2)\end{array}$ & $\begin{array}{c}1290.0^{* * * *} \\
(304.7)\end{array}$ & $\begin{array}{c}223.3 \\
(247.6)\end{array}$ & $\begin{array}{l}111.0 \\
(266.1)\end{array}$ & $\begin{array}{c}582.6 \\
(304.3)\end{array}$ & $\begin{array}{c}116.4 \\
(246.1)\end{array}$ & $\begin{array}{l}-144.6 \\
(237.9)\end{array}$ & $\begin{array}{c}334.6 \\
(248.1)\end{array}$ & $\begin{array}{l}-405.4 \\
(272.2)\end{array}$ & $\begin{array}{l}-594.4^{*} \\
(284.8)\end{array}$ & $\begin{array}{l}-289.8 \\
(292.2)\end{array}$ \\
\hline Constant & $\begin{array}{c}-4564.2 * * * * \\
(236.6)\end{array}$ & $\begin{array}{c}-4691.4 * * * \\
(239.9)\end{array}$ & $\begin{array}{c}-4920.1^{* * * *} \\
(249.1)\end{array}$ & $\begin{array}{c}-6581.3 * * * \\
(276.5)\end{array}$ & $\begin{array}{c}-7415.6 * * * \\
(338.3)\end{array}$ & $\begin{array}{c}-7699.8 * * * \\
(339.8)\end{array}$ & $\begin{array}{c}-7116.2 * * * \\
(311.1)\end{array}$ & $\begin{array}{c}-8843.2^{* * * *} \\
(378.8)\end{array}$ & $\begin{array}{c}-8498.9 * * * * \\
(378.8)\end{array}$ & $\begin{array}{c}-10580.9 \text { *** } \\
(396.9)\end{array}$ & $\begin{array}{c}-11530.6^{* * * *} \\
(435.4)\end{array}$ \\
\hline Sigma & $\begin{array}{c}3005.9^{* * *} \\
(51.76)\end{array}$ & $\begin{array}{c}3157.3 * * * \\
(54.12)\end{array}$ & $\begin{array}{c}2817.7 * * * \\
(48.70)\end{array}$ & $\begin{array}{c}2963.5^{* * * *} \\
(49.22)\end{array}$ & $\begin{array}{c}3226.4 * * * \\
(56.17)\end{array}$ & $\begin{array}{c}3372.3^{* * *} \\
(54.83)\end{array}$ & $\begin{array}{c}3236.7 * * * \\
(49.22)\end{array}$ & $\begin{array}{c}3666.3 * * * \\
(55.72)\end{array}$ & $\begin{array}{c}4132.1 \text { *** } \\
(66.26)\end{array}$ & $\begin{array}{c}4271.1 * * * \\
(65.54)\end{array}$ & $\begin{array}{c}4669.4 * * * \\
(67.03)\end{array}$ \\
\hline $\mathbf{N}$ & 3716 & 3944 & 3861 & 4259 & 3994 & 4403 & 4371 & 4424 & 4301 & 4221 & 4166 \\
\hline r2 & 0.05 & 0.06 & 0.06 & 0.07 & 0.07 & 0.07 & 0.07 & 0.07 & 0.07 & 0.07 & 0.07 \\
\hline
\end{tabular}

Standard errors in parentheses

$* \mathbf{p}<0.05 * * \mathbf{p}<0.01 * * * \mathbf{p}<0.001$ 
Appendix Table 7: Pooled Tobit Regression Table for Aggregate Inst. Aid

\begin{tabular}{|c|c|c|c|c|c|c|c|c|c|}
\hline & 2005-07 & 2006-09 & 2007-10 & 2008-11 & 2009-12 & 2010-13 & 2011-14 & 2012-15 & 2013-15 \\
\hline First Gen. & $\begin{array}{c}-36.94 \\
(80.39)\end{array}$ & $\begin{array}{l}-12.22 \\
(80.33)\end{array}$ & $\begin{array}{c}-39.00 \\
(82.66)\end{array}$ & $\begin{array}{l}-85.06 \\
(89.42)\end{array}$ & $\begin{array}{l}-112.4 \\
(92.00)\end{array}$ & $\begin{array}{c}-86.01 \\
(95.87)\end{array}$ & $\begin{array}{r}73.00 \\
(103.3)\end{array}$ & $\begin{array}{r}22.79 \\
(119.8)\end{array}$ & $\begin{array}{c}51.96 \\
(135.9)\end{array}$ \\
\hline SQIS Quartile 2 & $\begin{array}{c}3427.1 * * * \\
(121.8)\end{array}$ & $\begin{array}{c}3510.9 * * * \\
(124.7)\end{array}$ & $\begin{array}{c}3874.6^{* * * *} \\
(133.1)\end{array}$ & $\begin{array}{c}4800.5^{* * * *} \\
(145.2)\end{array}$ & $\begin{array}{c}5608.6 * * * \\
(154.4)\end{array}$ & $\begin{array}{c}6325.8 * * * \\
(161.5)\end{array}$ & $\begin{array}{c}6163.5^{* * * *} \\
(168.3)\end{array}$ & $\begin{array}{c}6805.4 * * * \\
(190.0)\end{array}$ & $\begin{array}{c}7994.1 * * * \\
(213.8)\end{array}$ \\
\hline SQIS Quartile 3 & $\begin{array}{c}6480.4 * * * \\
(123.3)\end{array}$ & $\begin{array}{c}6855.4 * * * \\
(126.0)\end{array}$ & $\begin{array}{c}7395.4^{* * * *} \\
(135.4)\end{array}$ & $\begin{array}{c}8524.2 * * * \\
(148.6)\end{array}$ & $\begin{array}{c}9354.5^{* * * *} \\
(158.0)\end{array}$ & $\begin{array}{c}10232.0^{* * * *} \\
(165.1)\end{array}$ & $\begin{array}{c}10400.1 * * * \\
(171.0)\end{array}$ & $\begin{array}{c}11870.1 \text { *** } \\
(191.5)\end{array}$ & $\begin{array}{c}13590.3^{* * * *} \\
(212.3)\end{array}$ \\
\hline SQIS Quartile 4 & $\begin{array}{c}8251.7 * * * * \\
(128.1)\end{array}$ & $\begin{array}{c}8838.1 * * * \\
(131.3)\end{array}$ & $\begin{array}{c}9640.5 * * * \\
(141.0)\end{array}$ & $\begin{array}{c}10892.0 * * * \\
(154.4)\end{array}$ & $\begin{array}{c}11744.9 * * * \\
(162.7)\end{array}$ & $\begin{array}{c}12875.5^{* * * *} \\
(169.5)\end{array}$ & $\begin{array}{c}13625.0^{*} * * * \\
(175.0)\end{array}$ & $\begin{array}{c}15614.5^{* * * *} \\
(195.6)\end{array}$ & $\begin{array}{c}17583.4 * * * \\
(215.4)\end{array}$ \\
\hline Student EFC & $\begin{array}{c}-8.921 * * * \\
(1.917)\end{array}$ & $\begin{array}{c}-5.110^{* *} \\
(1.798)\end{array}$ & $\begin{array}{l}-1.883 \\
(1.838)\end{array}$ & $\begin{array}{l}-1.535 \\
(1.971)\end{array}$ & $\begin{array}{l}-3.200 \\
(2.039)\end{array}$ & $\begin{array}{l}-4.269^{*} \\
(2.070)\end{array}$ & $\begin{array}{l}-3.800 \\
(2.092)\end{array}$ & $\begin{array}{l}-0.625 \\
(2.138)\end{array}$ & $\begin{array}{l}-2.926 \\
(2.220)\end{array}$ \\
\hline Student Need & $\begin{array}{c}16.72 \\
(14.92)\end{array}$ & $\begin{array}{c}62.33 * * * \\
(13.53)\end{array}$ & $\begin{array}{c}74.67 * * * \\
(13.02)\end{array}$ & $\begin{array}{c}58.25 * * * \\
(13.18)\end{array}$ & $\begin{array}{c}33.70 * * \\
(12.93)\end{array}$ & $\begin{array}{c}23.98 \\
(12.50)\end{array}$ & $\begin{array}{c}47.17 * * * \\
(12.46)\end{array}$ & $\begin{array}{c}98.43 * * * \\
(13.44)\end{array}$ & $\begin{array}{c}98.76^{* * * *} \\
(14.27)\end{array}$ \\
\hline Pell Recipient & $\begin{array}{l}-169.7 \\
(98.55)\end{array}$ & $\begin{array}{l}-114.2 \\
(98.41)\end{array}$ & $\begin{array}{l}-89.33 \\
(99.33)\end{array}$ & $\begin{array}{l}-123.9 \\
(104.1)\end{array}$ & $\begin{array}{l}-82.68 \\
(105.0)\end{array}$ & $\begin{array}{l}-15.10 \\
(108.5)\end{array}$ & $\begin{array}{l}146.3 \\
(115.4)\end{array}$ & $\begin{array}{l}-102.1 \\
(130.3)\end{array}$ & $\begin{array}{l}-77.18 \\
(143.9)\end{array}$ \\
\hline Female & $\begin{array}{c}129.3 \\
(68.09)\end{array}$ & $\begin{array}{l}157.0^{*} \\
(67.89)\end{array}$ & $\begin{array}{l}153.7^{*} \\
(69.06)\end{array}$ & $\begin{array}{c}107.9 \\
(73.90)\end{array}$ & $\begin{array}{l}-28.33 \\
(75.21)\end{array}$ & $\begin{array}{l}-85.37 \\
(77.42)\end{array}$ & $\begin{array}{l}-102.7 \\
(81.88)\end{array}$ & $\begin{array}{l}-218.2^{*} \\
(93.73)\end{array}$ & $\begin{array}{c}-322.8^{* *} \\
(104.6)\end{array}$ \\
\hline Nonresident & $\begin{array}{c}2412.0 * * * \\
(90.86)\end{array}$ & $\begin{array}{c}2688.2 * * * \\
(90.16)\end{array}$ & $\begin{array}{c}3172.3 * * * \\
(93.28)\end{array}$ & $\begin{array}{c}3686.5^{* * *} \\
(101.9)\end{array}$ & $\begin{array}{c}4036.1 * * * \\
(105.4)\end{array}$ & $\begin{array}{c}4532.8^{* * * *} \\
(108.1)\end{array}$ & $\begin{array}{c}4967.8 * * * \\
(113.4)\end{array}$ & $\begin{array}{c}6093.9 * * * \\
(129.5)\end{array}$ & $\begin{array}{c}7419.9 * * * \\
(145.6)\end{array}$ \\
\hline Asian & $\begin{array}{c}-519.6^{*} \\
(262.3)\end{array}$ & $\begin{array}{l}-450.8 \\
(260.3)\end{array}$ & $\begin{array}{l}-448.1 \\
(271.0)\end{array}$ & $\begin{array}{l}-454.7 \\
(303.5)\end{array}$ & $\begin{array}{l}-570.1 \\
(303.0)\end{array}$ & $\begin{array}{l}-37.13 \\
(306.8)\end{array}$ & $\begin{array}{l}-466.4 \\
(331.1)\end{array}$ & $\begin{array}{l}-723.7 \\
(375.4)\end{array}$ & $\begin{array}{c}-1152.0 * * \\
(434.5)\end{array}$ \\
\hline URM & $\begin{array}{l}345.2^{*} \\
(146.7)\end{array}$ & $\begin{array}{c}276.2 \\
(143.8)\end{array}$ & $\begin{array}{c}119.9 \\
(142.2)\end{array}$ & $\begin{array}{c}36.03 \\
(143.9)\end{array}$ & $\begin{array}{l}-309.4^{*} \\
(140.8)\end{array}$ & $\begin{array}{l}-175.1 \\
(135.1)\end{array}$ & $\begin{array}{l}-275.6^{*} \\
(138.7)\end{array}$ & $\begin{array}{l}-276.7 \\
(154.5)\end{array}$ & $\begin{array}{c}-543.3 * * \\
(171.6)\end{array}$ \\
\hline Constant & $\begin{array}{c}-5543.3 * * * \\
(134.8)\end{array}$ & $\begin{array}{c}-6220.5^{* * *} \\
(139.7)\end{array}$ & $\begin{array}{c}-7122.3 * * * \\
(151.5)\end{array}$ & $\begin{array}{c}-8133.5^{* * * *} \\
(166.3)\end{array}$ & $\begin{array}{c}-8560.4 * * * \\
(174.0)\end{array}$ & $\begin{array}{c}-9217.4 * * * \\
(180.2)\end{array}$ & $\begin{array}{c}-9612.3 * * * \\
(186.7)\end{array}$ & $\begin{array}{c}-11167.6 * * * \\
(209.3)\end{array}$ & $\begin{array}{c}-12534.1 * * * \\
(232.5)\end{array}$ \\
\hline Sigma & $\begin{array}{c}3149.6^{* * * *} \\
(29.33)\end{array}$ & $\begin{array}{c}3182.0^{* * * *} \\
(29.11)\end{array}$ & $\begin{array}{c}3209.2 * * * \\
(29.29)\end{array}$ & $\begin{array}{c}3501.2 * * * \\
(31.23)\end{array}$ & $\begin{array}{c}3621.7 * * * \\
(31.32)\end{array}$ & $\begin{array}{c}3842.9^{* * *} \\
(31.90)\end{array}$ & $\begin{array}{c}4078.0^{* * * *} \\
(33.63)\end{array}$ & $\begin{array}{c}4640.1 * * * \\
(38.64)\end{array}$ & $\begin{array}{c}5185.7 * * * \\
(42.75)\end{array}$ \\
\hline $\mathbf{N}$ & 11521 & 12064 & 12114 & 12656 & 12768 & 13198 & 13096 & 12946 & 12688 \\
\hline r2 & 0.05 & 0.05 & 0.05 & 0.06 & 0.06 & 0.06 & 0.06 & 0.06 & 0.06 \\
\hline
\end{tabular}

Standard errors in parentheses

$* \mathbf{p}<0.05 * * \mathbf{p}<0.01 * * * \mathbf{p}<0.001$ 
Appendix Table 8: Pooled Tobit Regression Table for Need-Meeting Aid Inst. Aid

\begin{tabular}{|c|c|c|c|c|c|c|c|c|c|}
\hline & 2005-07 & 2006-09 & 2007-10 & 2008-11 & 2009-12 & 2010-13 & 2011-14 & 2012-15 & 2013-15 \\
\hline First Gen. & $\begin{array}{c}83.05 \\
(135.5)\end{array}$ & $\begin{array}{c}37.54 \\
(143.6)\end{array}$ & $\begin{array}{c}114.7 \\
(151.8)\end{array}$ & $\begin{array}{l}-77.41 \\
(175.3)\end{array}$ & $\begin{array}{l}-0.0809 \\
(173.8)\end{array}$ & $\begin{array}{l}-19.74 \\
(170.8)\end{array}$ & $\begin{array}{c}244.4 \\
(171.9)\end{array}$ & $\begin{array}{c}20.52 \\
(194.3)\end{array}$ & $\begin{array}{l}-34.69 \\
(214.4)\end{array}$ \\
\hline SQIS Quartile 2 & $\begin{array}{c}3776.7 * * * \\
(206.6)\end{array}$ & $\begin{array}{c}3777.1 * * * \\
(215.2)\end{array}$ & $\begin{array}{c}3831.5 * * * \\
(221.7)\end{array}$ & $\begin{array}{c}4704.5 * * * \\
(252.7)\end{array}$ & $\begin{array}{c}5380.9 * * * \\
(265.3)\end{array}$ & $\begin{array}{c}6014.7 * * * \\
(265.4)\end{array}$ & $\begin{array}{c}6122.8 * * * \\
(264.1)\end{array}$ & $\begin{array}{c}6819.2 * * * \\
(293.9)\end{array}$ & $\begin{array}{c}8279.3 * * * \\
(329.7)\end{array}$ \\
\hline SQIS Quartile 3 & $\begin{array}{c}6293.0^{* * * *} \\
(217.6)\end{array}$ & $\begin{array}{c}6688.2^{* * * *} \\
(226.7)\end{array}$ & $\begin{array}{c}6968.9 * * * \\
(234.4)\end{array}$ & $\begin{array}{c}8420.6^{* * * *} \\
(270.2)\end{array}$ & $\begin{array}{c}9703.4 * * * \\
(281.8)\end{array}$ & $\begin{array}{c}10465.4^{* * * *} \\
(280.3)\end{array}$ & $\begin{array}{c}10478.0 * * * * \\
(276.8)\end{array}$ & $\begin{array}{c}11831.6^{* * * *} \\
(304.1)\end{array}$ & $\begin{array}{c}13215.9^{* * * *} \\
(334.5)\end{array}$ \\
\hline SQIS Quartile 4 & $\begin{array}{c}6961.6^{* * * *} \\
(235.2)\end{array}$ & $\begin{array}{c}7488.2 * * * \\
(246.8)\end{array}$ & $\begin{array}{c}7960.0 * * * \\
(258.5)\end{array}$ & $\begin{array}{c}9684.6 * * * \\
(298.8)\end{array}$ & $\begin{array}{c}10720.0 * * * \\
(303.5)\end{array}$ & $\begin{array}{c}11554.2^{* * * *} \\
(299.5)\end{array}$ & $\begin{array}{c}11731.2 * * * \\
(294.0)\end{array}$ & $\begin{array}{c}13049.1 * * * \\
(322.6)\end{array}$ & $\begin{array}{c}14200.0 * * * \\
(349.3)\end{array}$ \\
\hline Student EFC & $\begin{array}{c}-703.1 * * * \\
(41.82)\end{array}$ & $\begin{array}{c}-659.3 * * * \\
(41.11)\end{array}$ & $\begin{array}{c}-729.0 * * * \\
(45.04)\end{array}$ & $\begin{array}{c}-778.8 * * * \\
(50.07)\end{array}$ & $\begin{array}{c}-675.1^{* * * *} \\
(41.42)\end{array}$ & $\begin{array}{c}-672.1^{* * * *} \\
(37.67)\end{array}$ & $\begin{array}{c}-667.6^{* * *} \\
(36.69)\end{array}$ & $\begin{array}{c}-687.9 * * * \\
(40.11)\end{array}$ & $\begin{array}{c}-680.2 * * * \\
(40.08)\end{array}$ \\
\hline Student Need & $\begin{array}{c}-228.6 * * * \\
(49.38)\end{array}$ & $\begin{array}{c}-133.0^{* * *} \\
(48.78)\end{array}$ & $\begin{array}{c}-204.7 * * * \\
(52.76)\end{array}$ & $\begin{array}{c}-187.3 * * \\
(60.22)\end{array}$ & $\begin{array}{l}-73.46 \\
(51.33)\end{array}$ & $\begin{array}{l}-62.50 \\
(45.63)\end{array}$ & $\begin{array}{l}-50.93 \\
(43.97)\end{array}$ & $\begin{array}{c}75.18 \\
(47.73)\end{array}$ & $\begin{array}{c}162.8 * * * \\
(47.89)\end{array}$ \\
\hline Pell Recipient & $\begin{array}{c}-2263.2 * * * \\
(214.3)\end{array}$ & $\begin{array}{c}-2337.2 * * * \\
(225.3)\end{array}$ & $\begin{array}{c}-2838.3 * * * \\
(251.4)\end{array}$ & $\begin{array}{c}-3661.5 * * * \\
(291.5)\end{array}$ & $\begin{array}{c}-3345.4 * * * \\
(281.6)\end{array}$ & $\begin{array}{c}-3411.8^{* * *} \\
(270.7)\end{array}$ & $\begin{array}{c}-3317.0 * * * \\
(264.7)\end{array}$ & $\begin{array}{c}-4184.3 * * * \\
(291.1)\end{array}$ & $\begin{array}{c}-4164.5 * * * \\
(310.8)\end{array}$ \\
\hline Female & $\begin{array}{c}142.6 \\
(126.5)\end{array}$ & $\begin{array}{l}268.7^{*} \\
(134.6)\end{array}$ & $\begin{array}{c}223.8 \\
(141.9)\end{array}$ & $\begin{array}{c}279.6 \\
(161.6)\end{array}$ & $\begin{array}{c}14.11 \\
(158.1)\end{array}$ & $\begin{array}{c}5.501 \\
(153.8)\end{array}$ & $\begin{array}{c}3.659 \\
(153.7)\end{array}$ & $\begin{array}{l}-124.4 \\
(171.5)\end{array}$ & $\begin{array}{l}-375.9^{*} \\
(185.7)\end{array}$ \\
\hline Nonresident & $\begin{array}{c}10117.3 * * * \\
(485.0)\end{array}$ & $\begin{array}{c}10625.0^{* * * *} \\
(522.1)\end{array}$ & $\begin{array}{c}12548.2 * * * \\
(602.8)\end{array}$ & $\begin{array}{c}14840.9 * * * \\
(729.4)\end{array}$ & $\begin{array}{c}13518.3^{* * * *} \\
(627.9)\end{array}$ & $\begin{array}{c}13371.3^{* * * *} \\
(577.0)\end{array}$ & $\begin{array}{c}13516.5^{* * * *} \\
(583.6)\end{array}$ & $\begin{array}{c}13862.6 * * * \\
(655.8)\end{array}$ & $\begin{array}{c}14036.7 \text { *** } \\
(684.1)\end{array}$ \\
\hline Asian & $\begin{array}{l}-998.7 \\
(538.8)\end{array}$ & $\begin{array}{l}-903.2 \\
(527.4)\end{array}$ & $\begin{array}{c}-1384.6^{*} \\
(588.1)\end{array}$ & $\begin{array}{c}-2418.1^{* * *} \\
(727.2)\end{array}$ & $\begin{array}{c}-1765.0^{* *} \\
(642.6)\end{array}$ & $\begin{array}{l}-856.6 \\
(587.4)\end{array}$ & $\begin{array}{l}-676.1 \\
(595.7)\end{array}$ & $\begin{array}{c}-583.2 \\
(711.1)\end{array}$ & $\begin{array}{l}-1221.1 \\
(850.2)\end{array}$ \\
\hline URM & $\begin{array}{l}-299.7 \\
(231.9)\end{array}$ & $\begin{array}{l}-340.7 \\
(240.1)\end{array}$ & $\begin{array}{c}-648.1^{* *} \\
(242.7)\end{array}$ & $\begin{array}{l}-632.0^{*} \\
(257.6)\end{array}$ & $\begin{array}{c}-846.4 * * * \\
(246.1)\end{array}$ & $\begin{array}{l}-313.1 \\
(223.6)\end{array}$ & $\begin{array}{l}-200.0 \\
(218.6)\end{array}$ & $\begin{array}{l}-103.3 \\
(239.5)\end{array}$ & $\begin{array}{l}-460.5 \\
(260.2)\end{array}$ \\
\hline Constant & $\begin{array}{c}-7556.6^{* * * *} \\
(348.6)\end{array}$ & $\begin{array}{c}-8812.6^{* * * *} \\
(376.4)\end{array}$ & $\begin{array}{c}-9447.4 * * * \\
(417.1)\end{array}$ & $\begin{array}{c}-12004.0 * * * \\
(493.3)\end{array}$ & $\begin{array}{c}-12756.4^{* * * *} \\
(471.3)\end{array}$ & $\begin{array}{c}-12813.3 * * * \\
(446.9)\end{array}$ & $\begin{array}{c}-12642.5^{* * *} \\
(432.7)\end{array}$ & $\begin{array}{c}-13887.1^{* * * *} \\
(477.6)\end{array}$ & $\begin{array}{c}-15292.3^{* * * *} \\
(515.6)\end{array}$ \\
\hline Constant & $\begin{array}{c}3121.1 * * * \\
(70.22)\end{array}$ & $\begin{array}{c}3347.8^{* * *} \\
(73.67)\end{array}$ & $\begin{array}{c}3490.1 * * * \\
(76.04)\end{array}$ & $\begin{array}{c}4059.4 * * * \\
(85.96)\end{array}$ & $\begin{array}{c}4215.1 * * * \\
(84.05)\end{array}$ & $\begin{array}{c}4415.9^{* * *} \\
(81.53)\end{array}$ & $\begin{array}{c}4469.0 * * * \\
(79.84)\end{array}$ & $\begin{array}{c}4981.2 * * * \\
(88.20)\end{array}$ & $\begin{array}{c}5457.1 * * * \\
(95.45)\end{array}$ \\
\hline $\mathbf{N}$ & 11521 & 12064 & 12114 & 12656 & 12768 & 13198 & 13096 & 12946 & 12688 \\
\hline r2 & 0.15 & 0.16 & 0.16 & 0.16 & 0.16 & 0.15 & 0.15 & 0.15 & 0.15 \\
\hline
\end{tabular}

Standard errors in parentheses

$* \mathbf{p}<0.05 * * \mathbf{p}<0.01 * * * \mathbf{p}<0.001$ 
Appendix Table 9: Pooled Tobit Regression Table for Non Need-Meeting Aid

\begin{tabular}{|c|c|c|c|c|c|c|c|c|c|}
\hline & 2005-07 & 2006-09 & 2007-10 & 2008-11 & 2009-12 & 2010-13 & 2011-14 & 2012-15 & 2013-15 \\
\hline First Gen. & $\begin{array}{l}-45.82 \\
(83.09)\end{array}$ & $\begin{array}{c}33.97 \\
(82.19)\end{array}$ & $\begin{array}{l}-8.375 \\
(85.42)\end{array}$ & $\begin{array}{l}-20.60 \\
(91.37)\end{array}$ & $\begin{array}{l}-156.5 \\
(93.49)\end{array}$ & $\begin{array}{l}-175.9 \\
(96.22)\end{array}$ & $\begin{array}{l}-70.91 \\
(105.0)\end{array}$ & $\begin{array}{l}-42.81 \\
(117.2)\end{array}$ & $\begin{array}{c}16.55 \\
(129.6)\end{array}$ \\
\hline SQIS Quartile 2 & $\begin{array}{c}2848.4 * * * \\
(131.3)\end{array}$ & $\begin{array}{c}3015.3 * * * * \\
(136.1)\end{array}$ & $\begin{array}{c}3465.6 * * * \\
(152.5)\end{array}$ & $\begin{array}{c}4530.7 * * * \\
(169.9)\end{array}$ & $\begin{array}{c}5159.7 * * * \\
(177.9)\end{array}$ & $\begin{array}{c}5822.3 * * * * \\
(187.3)\end{array}$ & $\begin{array}{c}5426.0 * * * \\
(194.7)\end{array}$ & $\begin{array}{c}5909.6 * * * \\
(215.1)\end{array}$ & $\begin{array}{c}6722.0 * * * \\
(234.0)\end{array}$ \\
\hline SQIS Quartile 3 & $\begin{array}{c}5558.4 * * * \\
(129.8)\end{array}$ & $\begin{array}{c}5933.7 * * * \\
(134.4)\end{array}$ & $\begin{array}{c}6529.8 * * * \\
(151.7)\end{array}$ & $\begin{array}{c}7623.4 * * * \\
(170.4)\end{array}$ & $\begin{array}{c}8130.7 * * * \\
(178.9)\end{array}$ & $\begin{array}{c}8807.0^{* * * *} \\
(188.3)\end{array}$ & $\begin{array}{c}8801.7 * * * \\
(194.2)\end{array}$ & $\begin{array}{c}9945.5 * * * \\
(213.7)\end{array}$ & $\begin{array}{c}11265.8 * * * \\
(229.9)\end{array}$ \\
\hline SQIS Quartile 4 & $\begin{array}{c}7294.4 * * * \\
(133.1)\end{array}$ & $\begin{array}{c}7849.2 * * * \\
(137.9)\end{array}$ & $\begin{array}{c}8693.6^{* * * *} \\
(155.2)\end{array}$ & $\begin{array}{c}9916.8^{* * *} \\
(174.0)\end{array}$ & $\begin{array}{c}10481.6 * * * \\
(181.5)\end{array}$ & $\begin{array}{c}11427.3 * * * \\
(190.6)\end{array}$ & $\begin{array}{c}11981.1 * * * \\
(196.2)\end{array}$ & $\begin{array}{c}13624.4 * * * \\
(215.5)\end{array}$ & $\begin{array}{c}15184.6^{* * * *} \\
(230.9)\end{array}$ \\
\hline Student EFC & $\begin{array}{c}-7.610^{* * * *} \\
(1.857)\end{array}$ & $\begin{array}{l}-4.237^{*} \\
(1.719)\end{array}$ & $\begin{array}{l}-1.185 \\
(1.758)\end{array}$ & $\begin{array}{l}-0.647 \\
(1.847)\end{array}$ & $\begin{array}{l}-2.457 \\
(1.893)\end{array}$ & $\begin{array}{l}-2.966 \\
(1.896)\end{array}$ & $\begin{array}{l}-2.462 \\
(1.939)\end{array}$ & $\begin{array}{l}1.106 \\
(1.923)\end{array}$ & $\begin{array}{l}-0.859 \\
(1.967)\end{array}$ \\
\hline Student Need & $\begin{array}{c}-773.7 * * * \\
(23.93)\end{array}$ & $\begin{array}{c}-715.6 * * * \\
(21.57)\end{array}$ & $\begin{array}{c}-705.2 * * * \\
(20.76)\end{array}$ & $\begin{array}{c}-728.9 * * * \\
(19.53)\end{array}$ & $\begin{array}{c}-756.2 * * * \\
(18.20)\end{array}$ & $\begin{array}{c}-756.2 * * * \\
(16.57)\end{array}$ & $\begin{array}{c}-746.4 * * * \\
(16.56)\end{array}$ & $\begin{array}{c}-678.1 * * * \\
(15.65)\end{array}$ & $\begin{array}{c}-663.0^{* * * *} \\
(15.36)\end{array}$ \\
\hline Pell Recipient & $\begin{array}{l}-207.4^{*} \\
(104.0)\end{array}$ & $\begin{array}{l}-150.9 \\
(103.1)\end{array}$ & $\begin{array}{l}-145.7 \\
(104.4)\end{array}$ & $\begin{array}{l}-186.3 \\
(107.2)\end{array}$ & $\begin{array}{l}-153.9 \\
(106.1)\end{array}$ & $\begin{array}{l}-10.73 \\
(108.1)\end{array}$ & $\begin{array}{c}185.4 \\
(116.7)\end{array}$ & $\begin{array}{c}38.43 \\
(127.1)\end{array}$ & $\begin{array}{l}-76.64 \\
(136.5)\end{array}$ \\
\hline Female & $\begin{array}{c}82.80 \\
(69.10)\end{array}$ & $\begin{array}{c}88.98 \\
(68.13)\end{array}$ & $\begin{array}{c}110.2 \\
(69.72)\end{array}$ & $\begin{array}{c}64.42 \\
(73.45)\end{array}$ & $\begin{array}{l}-27.77 \\
(74.11)\end{array}$ & $\begin{array}{l}-119.0 \\
(75.17)\end{array}$ & $\begin{array}{l}-116.6 \\
(80.34)\end{array}$ & $\begin{array}{c}-244.2^{* *} \\
(88.81)\end{array}$ & $\begin{array}{c}-257.3^{* *} \\
(97.02)\end{array}$ \\
\hline Nonresident & $\begin{array}{c}2215.7 * * * \\
(87.95)\end{array}$ & $\begin{array}{c}2501.6^{* * * *} \\
(86.21)\end{array}$ & $\begin{array}{c}2953.2 * * * \\
(89.53)\end{array}$ & $\begin{array}{c}3467.1 * * * \\
(96.05)\end{array}$ & $\begin{array}{c}3794.3 * * * \\
(98.43)\end{array}$ & $\begin{array}{c}4299.6^{* * * *} \\
(99.69)\end{array}$ & $\begin{array}{c}4721.8 * * * \\
(105.8)\end{array}$ & $\begin{array}{c}5879.7 * * * \\
(117.5)\end{array}$ & $\begin{array}{c}7151.7 * * * \\
(130.4)\end{array}$ \\
\hline Asian & $\begin{array}{l}-323.5 \\
(265.8)\end{array}$ & $\begin{array}{l}-275.6 \\
(263.8)\end{array}$ & $\begin{array}{l}-230.5 \\
(276.1)\end{array}$ & $\begin{array}{l}-46.64 \\
(306.9)\end{array}$ & $\begin{array}{l}-53.38 \\
(306.4)\end{array}$ & $\begin{array}{c}502.5 \\
(303.2)\end{array}$ & $\begin{array}{l}-25.96 \\
(330.2)\end{array}$ & $\begin{array}{l}-393.5 \\
(354.7)\end{array}$ & $\begin{array}{l}-804.6^{*} \\
(402.0)\end{array}$ \\
\hline URM & $\begin{array}{c}626.4 * * * \\
(160.9)\end{array}$ & $\begin{array}{l}467.1 * * \\
(156.7)\end{array}$ & $\begin{array}{c}275.4 \\
(157.7)\end{array}$ & $\begin{array}{l}306.8^{*} \\
(155.9)\end{array}$ & $\begin{array}{c}198.5 \\
(149.6)\end{array}$ & $\begin{array}{c}147.9 \\
(142.0)\end{array}$ & $\begin{array}{l}-51.02 \\
(147.2)\end{array}$ & $\begin{array}{l}-250.7 \\
(158.2)\end{array}$ & $\begin{array}{l}-422.7^{*} \\
(170.2)\end{array}$ \\
\hline Constant & $\begin{array}{c}-4686.9^{* * * *} \\
(138.9)\end{array}$ & $\begin{array}{c}-5323.7 * * * \\
(145.0)\end{array}$ & $\begin{array}{c}-6256.1 * * * \\
(164.4)\end{array}$ & $\begin{array}{c}-7274.2 * * * \\
(184.0)\end{array}$ & $\begin{array}{c}-7453.0^{* * * *} \\
(190.7)\end{array}$ & $\begin{array}{c}-7959.5 * * * \\
(199.3)\end{array}$ & $\begin{array}{c}-8158.0 * * * \\
(205.9)\end{array}$ & $\begin{array}{c}-9418.0 * * * \\
(226.2)\end{array}$ & $\begin{array}{c}-10440.5^{* * *} \\
(243.1)\end{array}$ \\
\hline Constant & $\begin{array}{c}3008.1 * * * \\
(29.91)\end{array}$ & $\begin{array}{c}2997.3 * * * \\
(29.44)\end{array}$ & $\begin{array}{c}3019.9 * * * \\
(29.79)\end{array}$ & $\begin{array}{c}3224.8^{* * *} \\
(31.17)\end{array}$ & $\begin{array}{c}3307.4 * * * \\
(30.99)\end{array}$ & $\begin{array}{c}3461.6^{* * * *} \\
(31.05)\end{array}$ & $\begin{array}{c}3723.1 * * * \\
(33.26)\end{array}$ & $\begin{array}{c}4132.1 * * * \\
(37.04)\end{array}$ & $\begin{array}{c}4567.8^{* * * *} \\
\quad(40.14)\end{array}$ \\
\hline $\mathbf{N}$ & 11521 & 12064 & 12114 & 12656 & 12768 & 13198 & 13096 & 12946 & 12688 \\
\hline r2 & 0.06 & 0.06 & 0.07 & 0.07 & 0.07 & 0.07 & 0.07 & 0.07 & 0.07 \\
\hline
\end{tabular}

Standard errors in parentheses

$* \mathbf{p}<0.05 * * \mathbf{p}<0.01 * * * \mathbf{p}<0.001$ 
Appendix Table 10: Tobit Aggregate Institutional Aid Regression Results - Marginal Effects on the Avg. Award

\begin{tabular}{|c|c|c|c|c|c|c|c|c|c|c|c|}
\hline & $\begin{array}{l}\text { ME } 2005 \\
\text { b/se }\end{array}$ & $\begin{array}{l}\text { ME } 2006 \\
\text { b/se }\end{array}$ & $\begin{array}{l}\text { ME } 2007 \\
\text { b/se }\end{array}$ & $\begin{array}{l}\text { ME } 2008 \\
\text { b/se }\end{array}$ & $\begin{array}{l}\text { ME } 2009 \\
\text { b/se }\end{array}$ & $\begin{array}{l}\text { ME } 2010 \\
\text { b/se }\end{array}$ & $\begin{array}{l}\text { ME } 2011 \\
\text { b/se }\end{array}$ & $\begin{array}{l}\text { ME } 2012 \\
\text { b/se }\end{array}$ & $\begin{array}{l}\text { ME } 2013 \\
\text { b/se }\end{array}$ & $\begin{array}{l}\text { ME } 2014 \\
\text { b/se }\end{array}$ & $\begin{array}{l}\text { ME } 2015 \\
\text { b/se }\end{array}$ \\
\hline \multirow{2}{*}{ First Gen. } & 14.02 & -31.53 & -12.14 & 39.54 & -63.38 & -44.95 & 10.65 & -52.17 & $157.44 *$ & -59.67 & 46.683 \\
\hline & -50.1 & -49.48 & -48.3 & -47.33 & -50.02 & -57.59 & -60.02 & -68.52 & -77.9 & -93.59 & -114.08 \\
\hline \multirow{2}{*}{ SQIS Quartile 2} & $1288.83 * * *$ & $1159.67 * * *$ & $1237.55^{* * *}$ & $1310.91 * * *$ & $1405.09^{* * *}$ & $2127.33 * * *$ & $2384.11 * * *$ & $2590.56 * * *$ & $2058.50 * * *$ & $3302.69 * * *$ & $4801.900^{* * *}$ \\
\hline & -70.04 & -69.53 & -75.02 & -70.68 & -74.27 & -86.61 & -92.57 & -100.35 & -114.81 & -137.41 & -165.95 \\
\hline \multirow{2}{*}{ SQIS Quartile 3} & $2276.45^{* * *}$ & $2269.91 * * *$ & $2383.89 * * *$ & $2552.63 * * *$ & $2609.45^{* * * *}$ & $3439.03 * * *$ & $3828.07 * * *$ & $4218.82 * * *$ & $3968.07 * * *$ & $5655.6^{* * *}$ & $7300.218^{* * *}$ \\
\hline & -67.27 & -66.2 & -71.02 & -65.58 & -69.63 & -82.81 & -88.13 & -96.53 & -107.02 & -127.96 & -156.34 \\
\hline \multirow[t]{2}{*}{ SQIS Quartile 4} & $2819.5^{* * *}$ & $2858.65^{* * *}$ & $3142.3^{* * *}$ & $3294.35^{* * *}$ & $3394.4 * * *$ & $4290.21^{* * *}$ & $4734.05^{* * * *}$ & $5453.69^{* * *}$ & $5568.24 * * *$ & $7242.87 * * *$ & $9067.554 * * *$ \\
\hline & -69.97 & -68.94 & -72.66 & -68.18 & -71.34 & -84.45 & -89.78 & -98.9 & -108.45 & -130.68 & -159.02 \\
\hline \multirow[t]{2}{*}{ Student EFC } & $-3.179^{*}$ & $-4.077 * * *$ & -1.965 & 0.391 & -0.99 & -1.221 & -1.812 & $-3.041 *$ & -0.484 & 0.736 & $-5.887 * * *$ \\
\hline & -1.27 & -1.12 & -1.16 & -1 & -1.11 & -1.33 & -1.28 & -1.41 & -1.47 & -1.42 & -1.78 \\
\hline \multirow[t]{2}{*}{ Student Need } & -9.805 & -10.221 & $32.053 * * *$ & $33.724 * * *$ & 10.588 & 9.788 & 5.53 & 2.129 & $40.150 * * *$ & $58.820 * * *$ & -6.268 \\
\hline & -10.05 & -9.19 & -8.44 & -7.23 & -7.48 & -8.2 & -7.99 & -8.21 & -8.65 & -9.93 & -11.27 \\
\hline \multirow[t]{2}{*}{ Pell Recipient } & -16.441 & $-124.642^{*}$ & -28.626 & 46.317 & -102.095 & -92.613 & 110.666 & 11.306 & 82.187 & -181.978 & 31.356 \\
\hline & -61.29 & -60.71 & -59.49 & -57.8 & -57.83 & -65.41 & -68.28 & -77.41 & -84.93 & -98.69 & -118.21 \\
\hline \multirow[t]{2}{*}{ Female } & 61.559 & 73.646 & 6.997 & $93.325^{*}$ & 57.382 & -41.297 & -42.346 & -35.022 & -42.949 & $-186.666^{*}$ & $-229.967 * *$ \\
\hline & -42.18 & -41.98 & -41.06 & -39.62 & -40.85 & -47.43 & -48.73 & -54.07 & -60.71 & -72.71 & -86.03 \\
\hline \multirow[t]{2}{*}{ Nonresident } & $838.46^{* * *}$ & $823.07^{* * *}$ & $933.91 * * *$ & $1094.99^{* * *}$ & $1224.46^{* * *}$ & $1422.64^{* * *}$ & $1683.91 * * *$ & $2064.02 * * *$ & $2091.55^{* * *}$ & $3202.01 * * *$ & $4381.715^{* * *}$ \\
\hline & -57.33 & -56.48 & -55.55 & -53.11 & -57.82 & -68.78 & -70.48 & -78.14 & -86.21 & -106.52 & -130.51 \\
\hline \multirow[t]{2}{*}{ Asian } & -161.19 & -251.32 & -131.46 & -66.57 & -232.77 & -137.15 & -268.8 & 328.9 & $-636.71^{*}$ & $-592.66^{*}$ & -1.589 \\
\hline & -176 & -160.23 & -149.31 & -161.12 & -168.49 & -196.66 & -188.38 & -211.6 & -268.69 & -273.43 & -379.29 \\
\hline \multirow[t]{2}{*}{ URM } & $204.52 *$ & $264.54 * *$ & -50.55 & 115.26 & 71.38 & -138.48 & $-288.78^{* *}$ & 141.29 & $-207.56^{*}$ & $-275.86^{*}$ & -216.485 \\
\hline & -91.12 & -94.93 & -84.63 & -81.85 & -83.94 & -84.76 & -88.99 & -89.34 & -98.81 & -121.33 & -139.96 \\
\hline $\mathbf{n}$ & 3716 & 3944 & 3861 & 4259 & 3994 & 4403 & 4371 & 4424 & 4301 & 4221 & 4166 \\
\hline pr2 & 0.04 & 0.05 & 0.05 & 0.05 & 0.06 & 0.06 & 0.06 & 0.06 & 0.06 & 0.06 & 0.07 \\
\hline
\end{tabular}


Appendix Table 11: Tobit Regression Results for Aggregate Institutional Aid - Marginal Effect on the Probability of Receiving an Inst. Aid Award

\begin{tabular}{|c|c|c|c|c|c|c|c|c|c|c|c|}
\hline & $\begin{array}{l}2005 \\
\text { b/se }\end{array}$ & $\begin{array}{l}2006 \\
\text { b/se }\end{array}$ & $\begin{array}{l}2007 \\
\text { b/se }\end{array}$ & $\begin{array}{c}2008 \\
\text { b/se }\end{array}$ & $\begin{array}{l}2009 \\
\text { b/se }\end{array}$ & $\begin{array}{l}2010 \\
\text { b/se }\end{array}$ & $\begin{array}{l}2011 \\
\text { b/se }\end{array}$ & $\begin{array}{l}2012 \\
\text { b/se }\end{array}$ & $\begin{array}{l}2013 \\
\text { b/se }\end{array}$ & $\begin{array}{l}2014 \\
\text { b/se }\end{array}$ & $\begin{array}{l}2015 \\
\text { b/se }\end{array}$ \\
\hline \multirow[t]{2}{*}{ First Gen. } & 0.01 & -0.01 & 0.00 & 0.01 & -0.02 & -0.01 & 0.00 & -0.01 & $0.036^{*}$ & -0.01 & 0.01 \\
\hline & $(0.02)$ & $(0.02)$ & $(0.02)$ & $(0.02)$ & $(0.02)$ & $(0.02)$ & $(0.02)$ & $(0.02)$ & $(0.02)$ & $(0.02)$ & $(0.02)$ \\
\hline \multirow[t]{2}{*}{ SQIS Quartile 2} & $0.46^{* * *}$ & $0.41^{* * * *}$ & $0.45 * * *$ & $0.48 * * *$ & $0.51 * * *$ & $0.64 * * *$ & $0.67 * * *$ & $0.66^{* * *}$ & $0.48^{* * *}$ & $0.62 * * *$ & $0.71 * * *$ \\
\hline & $(0.03)$ & $(0.03)$ & $(0.03)$ & $(0.03)$ & $(0.03)$ & $(0.03)$ & $(0.03)$ & $(0.03)$ & $(0.03)$ & $(0.03)$ & $(0.03)$ \\
\hline \multirow[t]{2}{*}{ SQIS Quartile 3} & $0.81^{* * *}$ & $0.80 * * *$ & $0.87 * * *$ & $0.93 * * *$ & $0.95^{* * *}$ & $1.023 * * *$ & $1.08 * * *$ & $1.07 * * *$ & $0.92 * * *$ & $1.07 * * *$ & $1.08 * * *$ \\
\hline & $(0.03)$ & $(0.02)$ & $(0.03)$ & $(0.03)$ & $(0.03)$ & $(0.03)$ & $(0.03)$ & $(0.03)$ & $(0.03)$ & $(0.03)$ & $(0.03)$ \\
\hline \multirow[t]{2}{*}{ SQIS Quartile 4} & $1.01 * * *$ & $1.01 * * *$ & $1.15^{* * *}$ & $1.20 * * *$ & $1.23^{* * *}$ & $1.28^{* * *}$ & $1.33^{* * *}$ & $1.39^{* * *}$ & $1.29^{* * *}$ & $1.36^{* * * *}$ & $1.34 * * *$ \\
\hline & $(0.03)$ & $(0.03)$ & $(0.03)$ & $(0.03)$ & $(0.03)$ & $(0.03)$ & $(0.03)$ & $(0.03)$ & $(0.03)$ & $(0.03)$ & $(0.03)$ \\
\hline \multirow[t]{2}{*}{ Student EFC } & $-0.001 *$ & $-0.001 * * *$ & 0.00 & 0.00 & 0.00 & 0.00 & 0.00 & $-0.001 *$ & 0.00 & 0.00 & $-0.001 * * *$ \\
\hline & $(0.00)$ & $(0.00)$ & $(0.00)$ & $(0.00)$ & $(0.00)$ & $(0.00)$ & $(0.00)$ & $(0.00)$ & $(0.00)$ & $(0.00)$ & $(0.00)$ \\
\hline \multirow[t]{2}{*}{ Student Need } & 0.00 & 0.00 & $0.01 * * *$ & $0.01 * * *$ & 0.00 & 0.00 & 0.00 & 0.00 & $0.01 * * *$ & $0.01 * * *$ & 0.00 \\
\hline & $(0.00)$ & $(0.00)$ & $(0.00)$ & $(0.00)$ & $(0.00)$ & $(0.00)$ & $(0.00)$ & $(0.00)$ & $(0.00)$ & $(0.00)$ & $(0.00)$ \\
\hline Pell Recipient & $(0.02)$ & $(0.02)$ & $(0.02)$ & $(0.02)$ & $(0.02)$ & $(0.02)$ & $(0.02)$ & $(0.02)$ & $(0.02)$ & $(0.02)$ & $(0.02)$ \\
\hline \multirow[t]{2}{*}{ Female } & 0.02 & 0.03 & 0.00 & $0.034 *$ & 0.02 & -0.01 & -0.01 & -0.01 & -0.01 & $-0.035^{*}$ & $-0.034 * *$ \\
\hline & $(0.02)$ & $(0.01)$ & $(0.02)$ & $(0.01)$ & $(0.01)$ & $(0.01)$ & $(0.01)$ & $(0.01)$ & $(0.01)$ & $(0.01)$ & $(0.01)$ \\
\hline \multirow[t]{2}{*}{ Nonresident } & $0.30^{* * *}$ & $0.29 * * *$ & $0.34 * * *$ & $0.40 * * *$ & $0.45 * * *$ & $0.43 * * *$ & $0.47 * * *$ & $0.53 * * *$ & $0.49 * * *$ & $0.60^{* * * *}$ & $0.65^{* * *}$ \\
\hline & $(0.02)$ & $(0.02)$ & $(0.02)$ & $(0.02)$ & $(0.02)$ & $(0.02)$ & $(0.02)$ & $(0.02)$ & $(0.02)$ & $(0.02)$ & $(0.02)$ \\
\hline \multirow[t]{2}{*}{ Asian } & -0.06 & -0.09 & -0.05 & -0.02 & -0.09 & -0.04 & -0.08 & 0.08 & $-0.148 *$ & $-0.112 *$ & 0.00 \\
\hline & $(0.06)$ & $(0.06)$ & $(0.05)$ & $(0.06)$ & $(0.06)$ & $(0.06)$ & $(0.05)$ & $(0.05)$ & $(0.06)$ & $(0.05)$ & $(0.06)$ \\
\hline \multirow[t]{2}{*}{ URM } & $0.07 *$ & $0.09 * *$ & -0.02 & 0.04 & 0.03 & -0.04 & $-0.08^{* *}$ & 0.04 & $-0.05^{*}$ & $-0.05^{*}$ & -0.03 \\
\hline & $(0.03)$ & $(0.03)$ & $(0.03)$ & $(0.03)$ & $(0.03)$ & $(0.03)$ & $(0.03)$ & $(0.02)$ & $(0.02)$ & $(0.02)$ & $(0.02)$ \\
\hline $\mathbf{N}$ & 3716 & 3944 & 3861 & 4259 & 3994 & 4403 & 4371 & 4424 & 4301 & 4221 & 4166 \\
\hline $\operatorname{Pr} 2$ & 0.04 & 0.05 & 0.05 & 0.05 & 0.06 & 0.06 & 0.06 & 0.06 & 0.06 & 0.06 & .07 \\
\hline
\end{tabular}

Standard errors in parentheses

$* \mathbf{p}<0.05 * * \mathbf{p}<0.01 * * * \mathbf{p}<0.001$ 
Appendix Table 12: Tobit Need-Meeting Institutional Aid Regression Results - Marginal Effects on the Avg. Award

\begin{tabular}{|c|c|c|c|c|c|c|c|c|c|c|c|}
\hline & $\begin{array}{l}2005 \\
\text { b/se }\end{array}$ & $\begin{array}{l}2006 \\
\text { b/se }\end{array}$ & $\begin{array}{l}2007 \\
\text { b/se }\end{array}$ & $\begin{array}{l}2008 \\
\text { b/se }\end{array}$ & $\begin{array}{l}2009 \\
\text { b/se }\end{array}$ & $\begin{array}{l}2010 \\
\text { b/se }\end{array}$ & $\begin{array}{l}2011 \\
\text { b/se }\end{array}$ & $\begin{array}{l}2012 \\
\text { b/se }\end{array}$ & $\begin{array}{l}2013 \\
\text { b/se }\end{array}$ & $\begin{array}{l}2014 \\
\text { b/se }\end{array}$ & $\begin{array}{l}2015 \\
\text { b/se }\end{array}$ \\
\hline First Gen. & $\begin{array}{c}1.74 \\
(42.16)\end{array}$ & $\begin{array}{l}-28.40 \\
(41.78)\end{array}$ & $\begin{array}{c}-7.62 \\
(39.17)\end{array}$ & $\begin{array}{c}66.29 \\
(37.69)\end{array}$ & $\begin{array}{l}-63.05 \\
(40.26)\end{array}$ & $\begin{array}{l}-12.59 \\
(42.35)\end{array}$ & $\begin{array}{l}-37.04 \\
(44.69)\end{array}$ & $\begin{array}{l}-88.58 \\
(51.12)\end{array}$ & $\begin{array}{c}97.41 \\
(62.07)\end{array}$ & $\begin{array}{l}-38.17 \\
(69.93)\end{array}$ & $\begin{array}{c}27.89 \\
(85.68)\end{array}$ \\
\hline SQIS Quartile 2 & $\begin{array}{c}866.457 * * * \\
(61.70)\end{array}$ & $\begin{array}{c}812.881 * * * \\
(61.03)\end{array}$ & $\begin{array}{c}789.131 * * * \\
(64.54)\end{array}$ & $\begin{array}{c}963.910 * * * \\
(63.06)\end{array}$ & $\begin{array}{c}1009.277 * * * \\
(67.34)\end{array}$ & $\begin{array}{c}1469.830^{* * * *} \\
(70.93)\end{array}$ & $\begin{array}{c}1557.475^{* * * *} \\
(75.91)\end{array}$ & $\begin{array}{c}1810.933 * * * * \\
(86.48)\end{array}$ & $\begin{array}{c}1255.527^{* * * *} \\
(100.62)\end{array}$ & $\begin{array}{c}2334.766^{* * * *} \\
(115.44)\end{array}$ & $\begin{array}{c}3336.877 \text { *** } \\
(138.46)\end{array}$ \\
\hline SQIS Quartile 3 & $\begin{array}{c}1590.689 * * * \\
(57.75)\end{array}$ & $\begin{array}{c}1613.311^{* * *} \\
\quad(56.89)\end{array}$ & $\begin{array}{c}1586.158^{* * * *} \\
(59.57)\end{array}$ & $\begin{array}{c}1804.828 * * * \\
(56.30)\end{array}$ & $\begin{array}{c}1802.681 * * * \\
(61.31)\end{array}$ & $\begin{array}{c}2217.707^{* * * * *} \\
(65.92)\end{array}$ & $\begin{array}{c}2373.666^{* * *} \\
\quad(70.27)\end{array}$ & $\begin{array}{c}2724.078 * * * \\
(79.71)\end{array}$ & $\begin{array}{c}2551.593^{* * * *} \\
(89.69)\end{array}$ & $\begin{array}{c}3802.014 * * * \\
(102.40)\end{array}$ & $\begin{array}{c}4955.399 * * * \\
(124.35)\end{array}$ \\
\hline SQIS Quartile 4 & $\begin{array}{l}2017.028 * * * \\
\quad(59.23)\end{array}$ & $\begin{array}{c}2075.485 * * * \\
\quad(58.72)\end{array}$ & $\begin{array}{c}2189.811 * * * * \\
\quad(59.83)\end{array}$ & $\begin{array}{c}2349.470 * * * * \\
(57.04)\end{array}$ & $\begin{array}{c}2371.085 * * * \\
\quad(61.77)\end{array}$ & $\begin{array}{c}2849.920^{* * * *} \\
(65.44)\end{array}$ & $\begin{array}{c}3031.595 * * * \\
\quad(69.55)\end{array}$ & $\begin{array}{c}3618.099 * * * \\
(77.65)\end{array}$ & $\begin{array}{c}3773.158^{* * * *} \\
\quad(87.57)\end{array}$ & $\begin{array}{c}5085.224 * * * \\
\quad(100.08)\end{array}$ & $\begin{array}{c}6360.441 * * * \\
\quad(121.51)\end{array}$ \\
\hline Student EFC & $\begin{array}{c}-2.128^{*} \\
(1.00)\end{array}$ & $\begin{array}{c}-3.043 * * * \\
(0.88)\end{array}$ & $\begin{array}{l}-1.17 \\
(0.88)\end{array}$ & $\begin{array}{c}0.43 \\
(0.74)\end{array}$ & $\begin{array}{l}-0.70 \\
(0.81)\end{array}$ & $\begin{array}{l}-0.48 \\
(0.89)\end{array}$ & $\begin{array}{l}-1.07 \\
(0.87)\end{array}$ & $\begin{array}{l}-1.61 \\
(0.95)\end{array}$ & $\begin{array}{c}0.00 \\
(1.07)\end{array}$ & $\begin{array}{c}1.15 \\
(0.99)\end{array}$ & $\begin{array}{c}-3.619 * * \\
(1.24)\end{array}$ \\
\hline Student Need & $\begin{array}{c}-255.203^{* * *} \\
(11.55)\end{array}$ & $\begin{array}{c}-232.865^{* * *} \\
(11.14)\end{array}$ & $\begin{array}{c}-188.518^{* * *} \\
(8.97)\end{array}$ & $\begin{array}{c}-185.785^{* * *} \\
(7.93)\end{array}$ & $\begin{array}{c}-185.067^{* * * *} \\
(8.16)\end{array}$ & $\begin{array}{c}-196.371 \text { *** } \\
(7.19)\end{array}$ & $\begin{array}{c}-225.712^{* * *} \\
(7.17)\end{array}$ & $\begin{array}{c}-213.287 * * * \\
(7.10)\end{array}$ & $\begin{array}{c}-214.692^{* * * *} \\
(8.22)\end{array}$ & $\begin{array}{c}-217.130^{* * * *} \\
(8.15)\end{array}$ & $\begin{array}{c}-272.199^{* * *} \\
(9.00)\end{array}$ \\
\hline Pell Recipient & $\begin{array}{l}-14.49 \\
(52.78)\end{array}$ & $\begin{array}{c}-128.997 * \\
(52.27)\end{array}$ & $\begin{array}{l}-18.48 \\
(49.10)\end{array}$ & $\begin{array}{c}17.69 \\
(47.46)\end{array}$ & $\begin{array}{c}-109.325 * \\
(46.39)\end{array}$ & $\begin{array}{l}-73.18 \\
(47.84)\end{array}$ & $\begin{array}{c}49.67 \\
(50.45)\end{array}$ & $\begin{array}{c}41.42 \\
(57.06)\end{array}$ & $\begin{array}{c}88.91 \\
(67.77)\end{array}$ & $\begin{array}{l}-88.65 \\
(73.90)\end{array}$ & $\begin{array}{l}-73.75 \\
(87.61)\end{array}$ \\
\hline Female & $\begin{array}{c}60.25 \\
(34.81)\end{array}$ & $\begin{array}{c}31.63 \\
(34.71)\end{array}$ & $\begin{array}{l}-16.77 \\
(32.83)\end{array}$ & $\begin{array}{c}58.35 \\
(30.85)\end{array}$ & $\begin{array}{c}41.71 \\
(31.69)\end{array}$ & $\begin{array}{l}-47.71 \\
(33.94)\end{array}$ & $\begin{array}{c}-9.47 \\
(35.17)\end{array}$ & $\begin{array}{l}-57.66 \\
(38.71)\end{array}$ & $\begin{array}{l}-36.01 \\
(46.66)\end{array}$ & $\begin{array}{c}-126.678^{*} \\
(53.15)\end{array}$ & $\begin{array}{c}-134.829^{*} \\
(62.83)\end{array}$ \\
\hline Nonresident & $\begin{array}{c}619.878 * * * \\
(44.61)\end{array}$ & $\begin{array}{c}610.844 * * * \\
(44.08)\end{array}$ & $\begin{array}{c}693.336 * * * \\
(41.84)\end{array}$ & $\begin{array}{c}802.375 * * * \\
(38.93)\end{array}$ & $\begin{array}{c}856.358 * * * \\
(42.17)\end{array}$ & $\begin{array}{c}1012.241^{* * * *} \\
(46.08)\end{array}$ & $\begin{array}{c}1156.006^{* * * *} \\
(47.63)\end{array}$ & $\begin{array}{c}1442.715^{* * * *} \\
\quad(52.87)\end{array}$ & $\begin{array}{c}1567.951^{* * * *} \\
(62.23)\end{array}$ & $\begin{array}{c}2546.629 * * * \\
\quad(75.26)\end{array}$ & $\begin{array}{c}3391.339 \text { *** } \\
(92.82)\end{array}$ \\
\hline Asian & $\begin{array}{c}-84.43 \\
(140.97)\end{array}$ & $\begin{array}{l}-152.43 \\
(134.86)\end{array}$ & $\begin{array}{c}-48.20 \\
(119.08)\end{array}$ & $\begin{array}{c}-22.59 \\
(127.17)\end{array}$ & $\begin{array}{c}-99.33 \\
(133.33)\end{array}$ & $\begin{array}{c}96.22 \\
(143.50)\end{array}$ & $\begin{array}{c}-57.00 \\
(140.83)\end{array}$ & $\begin{array}{c}340.867 * \\
(151.02)\end{array}$ & $\begin{array}{l}-363.92 \\
(210.02)\end{array}$ & $\begin{array}{c}-404.232 * \\
(196.72)\end{array}$ & $\begin{array}{c}85.34 \\
(278.49)\end{array}$ \\
\hline URM & $\begin{array}{c}164.607 * \\
(82.81)\end{array}$ & $\begin{array}{c}358.522 * * * \\
(84.63)\end{array}$ & $\begin{array}{c}65.22 \\
(72.35)\end{array}$ & $\begin{array}{c}29.64 \\
(71.05)\end{array}$ & $\begin{array}{l}138.59 \\
(72.41)\end{array}$ & $\begin{array}{c}30.44 \\
(64.36)\end{array}$ & $\begin{array}{l}-42.08 \\
(69.18)\end{array}$ & $\begin{array}{c}94.60 \\
(70.14)\end{array}$ & $\begin{array}{r}-120.67 \\
(81.01)\end{array}$ & $\begin{array}{c}-199.814^{*} \\
(95.67)\end{array}$ & $\begin{array}{l}-108.03 \\
(108.86)\end{array}$ \\
\hline $\mathbf{N}$ & 3716 & 3944 & 3861 & 4259 & 3994 & 4403 & 4371 & 4424 & 4301 & 4221 & 4166 \\
\hline Pr2 & 0.05 & 0.06 & 0.06 & 0.07 & 0.07 & 0.07 & 0.07 & 0.07 & 0.07 & 0.07 & 0.07 \\
\hline
\end{tabular}

Standard errors in parentheses

$* \mathbf{p}<0.05 * * \mathbf{p}<0.01 * * * \mathbf{p}<0.001$ 
Appendix Table 13: Tobit Regression Results for Need-Meeting Institutional Aid - Marginal Effects on the Probability of Receiving an Inst. Aid Award

\begin{tabular}{|c|c|c|c|c|c|c|c|c|c|c|c|}
\hline & $\begin{array}{l}2005 \\
\text { b/se }\end{array}$ & $\begin{array}{l}2006 \\
\text { b/se }\end{array}$ & $\begin{array}{l}2007 \\
\text { b/se }\end{array}$ & $\begin{array}{l}2008 \\
\text { b/se }\end{array}$ & $\begin{array}{l}2009 \\
\text { b/se }\end{array}$ & $\begin{array}{l}2010 \\
\text { b/se }\end{array}$ & $\begin{array}{l}2011 \\
\mathrm{~b} / \mathrm{se}\end{array}$ & $\begin{array}{l}2012 \\
\text { b/se }\end{array}$ & $\begin{array}{l}2013 \\
\text { b/se }\end{array}$ & $\begin{array}{l}2014 \\
\text { b/se }\end{array}$ & $\begin{array}{l}2015 \\
\text { b/se }\end{array}$ \\
\hline \multirow[t]{2}{*}{ First Gen. } & 0.00 & 0.00 & 0.00 & 0.00 & 0.00 & 0.00 & 0.00 & 0.00 & 0.00 & 0.00 & 0.00 \\
\hline & $(0.00)$ & $(0.00)$ & $(0.00)$ & $(0.00)$ & $(0.00)$ & $(0.00)$ & $(0.00)$ & $(0.00)$ & $(0.00)$ & $(0.00)$ & $(0.00)$ \\
\hline \multirow[t]{2}{*}{ SQIS Quartile 2} & 0.00 & 0.00 & 0.00 & 0.00 & 0.00 & 0.00 & 0.00 & 0.00 & 0.00 & 0.00 & $0.01 *$ \\
\hline & $(0.00)$ & $(0.00)$ & $(0.00)$ & $(0.00)$ & $(0.00)$ & $(0.00)$ & $(0.00)$ & $(0.00)$ & $(0.00)$ & $(0.00)$ & $(0.01)$ \\
\hline \multirow[t]{2}{*}{ SQIS Quartile 3} & 0.00 & 0.00 & 0.00 & 0.00 & 0.00 & 0.00 & 0.00 & 0.00 & 0.00 & 0.01 & $0.02^{*}$ \\
\hline & $(0.00)$ & $(0.00)$ & $(0.00)$ & $(0.00)$ & $(0.00)$ & $(0.00)$ & $(0.00)$ & $(0.00)$ & $(0.00)$ & $(0.00)$ & $(0.01)$ \\
\hline \multirow[t]{2}{*}{ SQIS Quartile 4} & 0.00 & 0.00 & 0.00 & 0.00 & 0.00 & 0.00 & 0.00 & 0.00 & 0.00 & 0.01 & $0.02 *$ \\
\hline & $(0.00)$ & $(0.00)$ & $(0.00)$ & $(0.00)$ & $(0.00)$ & $(0.00)$ & $(0.00)$ & $(0.00)$ & $(0.00)$ & $(0.00)$ & $(0.01)$ \\
\hline \multirow[t]{2}{*}{ Student EFC } & 0.00 & 0.00 & 0.00 & 0.00 & 0.00 & 0.00 & 0.00 & 0.00 & 0.00 & 0.00 & $-0.00 * *$ \\
\hline & $(0.00)$ & $(0.00)$ & $(0.00)$ & $(0.00)$ & $(0.00)$ & $(0.00)$ & $(0.00)$ & $(0.00)$ & $(0.00)$ & $(0.00)$ & $(0.00)$ \\
\hline \multirow[t]{2}{*}{ Student Need } & 0.00 & 0.00 & 0.00 & 0.00 & 0.00 & 0.00 & $-0.00 *$ & $-0.00 *$ & 0.00 & 0.00 & 0.00 \\
\hline & $(0.00)$ & $(0.00)$ & $(0.00)$ & $(0.00)$ & $(0.00)$ & $(0.00)$ & $(0.00)$ & $(0.00)$ & $(0.00)$ & $(0.00)$ & $(0.00)$ \\
\hline \multirow[t]{2}{*}{ Pell Recipient } & 0.00 & 0.00 & 0.00 & 0.00 & 0.00 & 0.00 & 0.00 & 0.00 & 0.00 & 0.00 & $-0.01 *$ \\
\hline & $(0.00)$ & $(0.00)$ & $(0.00)$ & $(0.00)$ & $(0.00)$ & $(0.00)$ & $(0.00)$ & $(0.00)$ & $(0.00)$ & $(0.00)$ & $(0.00)$ \\
\hline \multirow{2}{*}{ Female } & 0.00 & 0.00 & 0.00 & 0.00 & 0.00 & 0.00 & 0.00 & 0.00 & 0.00 & 0.00 & 0.00 \\
\hline & $(0.00)$ & $(0.00)$ & $(0.00)$ & $(0.00)$ & $(0.00)$ & $(0.00)$ & $(0.00)$ & $(0.00)$ & $(0.00)$ & $(0.00)$ & $(0.00)$ \\
\hline \multirow[t]{2}{*}{ Nonresident } & 0.00 & 0.00 & 0.00 & 0.00 & 0.00 & 0.00 & 0.00 & 0.00 & 0.00 & 0.01 & $0.02^{*}$ \\
\hline & $(0.00)$ & $(0.00)$ & $(0.00)$ & $(0.00)$ & $(0.00)$ & $(0.00)$ & $(0.00)$ & $(0.00)$ & $(0.00)$ & $(0.00)$ & $(0.01)$ \\
\hline \multirow[t]{2}{*}{ Asian } & 0.00 & 0.00 & 0.00 & 0.00 & 0.00 & 0.00 & 0.00 & 0.00 & 0.00 & 0.00 & 0.00 \\
\hline & $(0.00)$ & $(0.00)$ & $(0.00)$ & $(0.00)$ & $(0.00)$ & $(0.00)$ & $(0.00)$ & $(0.00)$ & $(0.00)$ & $(0.00)$ & $(0.00)$ \\
\hline \multirow[t]{2}{*}{ URM } & 0.00 & 0.00 & 0.00 & 0.00 & 0.00 & 0.00 & 0.00 & 0.00 & 0.00 & 0.00 & 0.00 \\
\hline & $(0.00)$ & $(0.00)$ & $(0.00)$ & $(0.00)$ & $(0.00)$ & $(0.00)$ & $(0.00)$ & $(0.00)$ & $(0.00)$ & $(0.00)$ & $(0.00)$ \\
\hline $\mathbf{N}$ & 3716 & 3944 & 3861 & 4259 & 3994 & 4403 & 4371 & 4424 & 4301 & 4221 & 4166 \\
\hline Pr2 & 0.04 & 0.05 & 0.05 & 0.05 & 0.06 & 0.06 & 0.06 & 0.06 & 0.06 & 0.06 & 0.06 \\
\hline
\end{tabular}


Appendix Table 14: Annual Tobit Need-Meeting Institutional Aid Results - Marginal Effects on The Probability of Receiving an Institutional Aid Award

\begin{tabular}{|c|c|c|c|c|c|c|c|c|c|c|c|}
\hline & $\begin{array}{l}2005 \\
\text { b/se }\end{array}$ & $\begin{array}{l}2006 \\
\text { b/se }\end{array}$ & $\begin{array}{l}2007 \\
\text { b/se }\end{array}$ & $\begin{array}{l}2008 \\
\text { b/se }\end{array}$ & $\begin{array}{l}2009 \\
\text { b/se }\end{array}$ & $\begin{array}{l}2010 \\
\text { b/se }\end{array}$ & $\begin{array}{l}2011 \\
\text { b/se }\end{array}$ & $\begin{array}{l}2012 \\
\text { b/se }\end{array}$ & $\begin{array}{l}2013 \\
\text { b/se }\end{array}$ & $\begin{array}{l}2014 \\
\text { b/se }\end{array}$ & $\begin{array}{l}2015 \\
\text { b/se }\end{array}$ \\
\hline First Gen. & $\begin{array}{l}4.135 \\
(7.10)\end{array}$ & $\begin{array}{l}-3.215 \\
(9.12)\end{array}$ & $\begin{array}{c}11.15 \\
(12.26)\end{array}$ & $\begin{array}{l}1.206 \\
(7.72)\end{array}$ & $\begin{array}{c}3.979 \\
(10.57)\end{array}$ & $\begin{array}{l}-11.97 \\
(19.06)\end{array}$ & $\begin{array}{l}11.521 \\
(14.81)\end{array}$ & $\begin{array}{l}-5.134 \\
(17.24)\end{array}$ & $\begin{array}{l}39.783^{*} \\
(20.05)\end{array}$ & $\begin{array}{l}-19.613 \\
(22.47)\end{array}$ & $\begin{array}{l}-21.108 \\
(29.93)\end{array}$ \\
\hline SQIS Quartile 2 & $\begin{array}{c}129.47 * * * \\
(17.46)\end{array}$ & $\begin{array}{c}137.43 * * * \\
(20.73)\end{array}$ & $\begin{array}{c}175.4^{* * * *} \\
(26.01)\end{array}$ & $\begin{array}{c}122.03 * * * \\
(18.59)\end{array}$ & $\begin{array}{c}141.87 * * * \\
(21.19)\end{array}$ & $\begin{array}{c}326.69 * * * \\
(39.14)\end{array}$ & $\begin{array}{c}333 . * * * \\
(34.82)\end{array}$ & $\begin{array}{c}362.74 * * * \\
(38.90)\end{array}$ & $\begin{array}{c}359.94 * * * \\
(42.40)\end{array}$ & $\begin{array}{c}496.71 * * * \\
(53.75)\end{array}$ & $\begin{array}{c}799.71 * * * \\
(74.81)\end{array}$ \\
\hline SQIS Quartile 3 & $\begin{array}{c}193.44 * * * \\
(23.34)\end{array}$ & $\begin{array}{c}244.4 * * * \\
(30.89)\end{array}$ & $\begin{array}{c}317.74 * * * \\
(37.18)\end{array}$ & $\begin{array}{c}210.67 * * * \\
(27.96)\end{array}$ & $\begin{array}{c}278.22 * * * \\
(33.36)\end{array}$ & $\begin{array}{c}572.22 * * * \\
(56.46)\end{array}$ & $\begin{array}{c}576.15^{* * *} \\
(50.47)\end{array}$ & $\begin{array}{c}626.97 * * * \\
(57.07)\end{array}$ & $\begin{array}{c}605.48 * * * \\
(59.84)\end{array}$ & $\begin{array}{c}859.20^{* * * *} \\
(78.37)\end{array}$ & $\begin{array}{c}1133.65^{* * *} \\
(95.01)\end{array}$ \\
\hline SQIS Quartile 4 & $\begin{array}{c}213.8 * * * \\
(25.61)\end{array}$ & $\begin{array}{c}273.83^{* * * *} \\
(34.30)\end{array}$ & $\begin{array}{c}350.49 * * * \\
(40.40)\end{array}$ & $\begin{array}{c}244.06 * * * \\
(31.99)\end{array}$ & $\begin{array}{c}328.48 * * * \\
(38.04)\end{array}$ & $\begin{array}{c}645.71 * * * \\
(61.72)\end{array}$ & $\begin{array}{c}622.24 * * * \\
(53.33)\end{array}$ & $\begin{array}{c}710.22 * * * \\
(63.40)\end{array}$ & $\begin{array}{c}698.39 * * * * \\
(66.10)\end{array}$ & $\begin{array}{c}908.37 * * * \\
(81.35)\end{array}$ & $\begin{array}{c}1182.20^{* * * *} \\
(97.84)\end{array}$ \\
\hline Student EFC & $\begin{array}{c}-31.32 * * * \\
(1.50)\end{array}$ & $\begin{array}{c}-29.94 * * * \\
(1.40)\end{array}$ & $\begin{array}{c}-35.45^{* * *} \\
(1.49)\end{array}$ & $\begin{array}{c}-28.55^{* * *} \\
(1.33)\end{array}$ & $\begin{array}{c}-29.72 * * * \\
(1.48)\end{array}$ & $\begin{array}{c}-45.42 * * * \\
(2.18)\end{array}$ & $\begin{array}{c}-40.93^{* * *} \\
(1.49)\end{array}$ & $\begin{array}{c}45.99 * * * \\
(1.63)\end{array}$ & $\begin{array}{c}-43.45^{* * *} \\
(1.67)\end{array}$ & $\begin{array}{c}-47.09 * * * \\
(1.83)\end{array}$ & $\begin{array}{c}-57.37 * * * \\
(2.22)\end{array}$ \\
\hline Student Need & $\begin{array}{c}-17.613 * * * \\
(2.02)\end{array}$ & $\begin{array}{c}-14.071^{* * * *} \\
(2.64)\end{array}$ & $\begin{array}{c}-9.667 * \\
(3.87)\end{array}$ & $\begin{array}{c}-13.155^{* * * *} \\
(2.11)\end{array}$ & $\begin{array}{c}-11.995 * * * \\
(2.92)\end{array}$ & $\begin{array}{l}-6.837 \\
(5.81)\end{array}$ & $\begin{array}{c}-12.094 * * \\
(3.75)\end{array}$ & $\begin{array}{c}-13.517 * * * * \\
(4.09)\end{array}$ & $\begin{array}{l}-3.267 \\
(5.10)\end{array}$ & $\begin{array}{r}11.257 \\
(6.42)\end{array}$ & $\begin{array}{c}2.24 \\
(6.85)\end{array}$ \\
\hline Pell Recipient & $\begin{array}{c}-92.26 * * * \\
(9.95)\end{array}$ & $\begin{array}{c}-97.68^{* * * *} \\
(12.55)\end{array}$ & $\begin{array}{c}-118.37 * * * \\
(17.16)\end{array}$ & $\begin{array}{c}-99.07 * * * \\
(11.13)\end{array}$ & $\begin{array}{c}-138.9^{* * *} \\
(15.90)\end{array}$ & $\begin{array}{c}-261.13^{* * * *} \\
(27.24)\end{array}$ & $\begin{array}{c}-157.97 \text { *** } \\
(20.40)\end{array}$ & $\begin{array}{c}-223.81 * * * \\
(22.77)\end{array}$ & $\begin{array}{c}-231.23 * * * \\
(25.08)\end{array}$ & $\begin{array}{c}-318.5^{* * * *} \\
(28.18)\end{array}$ & $\begin{array}{c}-299.27 * * * \\
(36.31)\end{array}$ \\
\hline Female & $\begin{array}{l}-0.684 \\
(6.56)\end{array}$ & $\begin{array}{c}22.246^{*} \\
(8.83)\end{array}$ & $\begin{array}{c}0.261 \\
(11.49)\end{array}$ & $\begin{array}{l}10.41 \\
(7.34)\end{array}$ & $\begin{array}{l}13.01 \\
(9.86)\end{array}$ & $\begin{array}{l}10.217 \\
(17.33)\end{array}$ & $\begin{array}{l}-13.116 \\
(13.39)\end{array}$ & $\begin{array}{c}1.739 \\
(15.39)\end{array}$ & $\begin{array}{l}16.035 \\
(17.75)\end{array}$ & $\begin{array}{l}-36.746 \\
(19.69)\end{array}$ & $\begin{array}{c}-56.092 * \\
(25.63)\end{array}$ \\
\hline Nonresident & $\begin{array}{c}379.56^{* * * *} \\
(25.19)\end{array}$ & $\begin{array}{c}432.73 * * * \\
(29.93)\end{array}$ & $\begin{array}{c}540.42^{* * * *} \\
(33.44)\end{array}$ & $\begin{array}{c}464.27 * * * \\
(31.29)\end{array}$ & $\begin{array}{c}588.69 * * * \\
(37.55)\end{array}$ & $\begin{array}{c}909.49 * * * \\
(48.35)\end{array}$ & $\begin{array}{c}787.9 * * * \\
(38.47)\end{array}$ & $\begin{array}{c}897.30 * * * \\
(43.36)\end{array}$ & $\begin{array}{c}906.15 * * * \\
(44.36)\end{array}$ & $\begin{array}{c}905.28 * * * \\
(46.23)\end{array}$ & $\begin{array}{c}1229.61 * * * \\
(58.80)\end{array}$ \\
\hline Asian & $\begin{array}{l}-71.67 \\
(46.82)\end{array}$ & $\begin{array}{l}-27.59 \\
(32.26)\end{array}$ & $\begin{array}{l}-49.33 \\
(44.26)\end{array}$ & $\begin{array}{l}-29.81 \\
(30.19)\end{array}$ & $\begin{array}{l}-90.58 * \\
(44.99)\end{array}$ & $\begin{array}{c}-211.643 \\
(85.22)\end{array}$ & $\begin{array}{l}-53.35 \\
(47.46)\end{array}$ & $\begin{array}{c}18.50 \\
(56.58)\end{array}$ & $\begin{array}{l}-114.89 \\
(83.90)\end{array}$ & $\begin{array}{l}-26.10 \\
(82.76)\end{array}$ & $\begin{array}{c}-93.03 \\
(119.92)\end{array}$ \\
\hline URM & $\begin{array}{c}12.13 \\
(11.43)\end{array}$ & $\begin{array}{c}-4.98 \\
(16.38)\end{array}$ & $\begin{array}{c}-66.06^{* *} \\
(22.66)\end{array}$ & $\begin{array}{c}6.40 \\
(11.82)\end{array}$ & $\begin{array}{l}-32.8^{*} \\
(16.21)\end{array}$ & $\begin{array}{l}-63.03 * \\
(26.66)\end{array}$ & $\begin{array}{l}-52.71 * \\
(20.53)\end{array}$ & $\begin{array}{c}23.34 \\
(21.29)\end{array}$ & $\begin{array}{l}-16.65 \\
(24.63)\end{array}$ & $\begin{array}{l}-47.61 \\
(27.67)\end{array}$ & $\begin{array}{l}-50.24 \\
(34.98)\end{array}$ \\
\hline $\mathbf{N}$ & 3716 & 3944 & 3861 & 4259 & 3994 & 4403 & 4371 & 4424 & 4301 & 4221 & 4166 \\
\hline Pr2 & 0.16 & 0.16 & 0.15 & 0.17 & 0.17 & 0.15 & 0.16 & 0.15 & 0.15 & 0.16 & 0.14 \\
\hline
\end{tabular}

Standard errors in parentheses

$\mathbf{p}<0.05 * * \mathbf{p}<0.01 * * * p<0.001$ 
Appendix Table 15: Tobit Non-Need-Meeting Regression Results - Probability of Receiving an Institutional Aid Award

\begin{tabular}{|c|c|c|c|c|c|c|c|c|c|c|c|}
\hline & 2005 & 2006 & 2007 & 2008 & 2009 & 2010 & 2011 & 2012 & 2013 & 2014 & 2015 \\
\hline & b/se & b/se & b/se & b/se & b/se & b/se & b/se & b/se & b/se & b/se & b/se \\
\hline \multirow[t]{2}{*}{ First Gen. } & 0.00 & -0.01 & 0.00 & 0.03 & -0.03 & -0.01 & -0.02 & -0.03 & 0.03 & -0.01 & 0.01 \\
\hline & $(0.02)$ & $(0.02)$ & $(0.02)$ & $(0.02)$ & $(0.02)$ & $(0.02)$ & $(0.02)$ & $(0.02)$ & $(0.02)$ & $(0.02)$ & $(0.02)$ \\
\hline \multirow[t]{2}{*}{ SQIS Quartile 2} & $0.37 * * *$ & $0.34 * * *$ & $0.36^{* * * *}$ & $0.43^{* * *}$ & $0.41 * * *$ & $0.57 * * *$ & $0.62 * * *$ & $0.64 * * *$ & $0.9 * * *$ & $0.64 * * *$ & $0.76^{* * *}$ \\
\hline & $(0.03)$ & $(0.03)$ & $(0.03)$ & $(0.03)$ & $(0.03)$ & $(0.03)$ & $(0.03)$ & $(0.03)$ & $(0.03)$ & $(0.03)$ & $(0.04)$ \\
\hline \multirow[t]{2}{*}{ SQIS Quartile 3} & $0.68 * * *$ & $0.67 * * *$ & $0.72 * * *$ & $0.80 * * *$ & $0.73 * * *$ & $0.87 * * *$ & $0.94 * * *$ & $0.96^{* * *}$ & $0.78 * * *$ & $1.05^{* * *}$ & $1.14 * * *$ \\
\hline & $(0.03)$ & $(0.02)$ & $(0.03)$ & $(0.03)$ & $(0.03)$ & $(0.03)$ & $(0.03)$ & $(0.03)$ & $(0.03)$ & $(0.03)$ & $(0.04)$ \\
\hline \multirow[t]{2}{*}{ SQIS Quartile 4} & $0.86^{* * *}$ & $0.86^{* * *}$ & $0.99 * * *$ & $1.04 * * *$ & $0.96^{* * *}$ & $1.11 * * *$ & $1.20 * * *$ & $1.28 * * *$ & $1.16^{* * *}$ & $1.40 * * *$ & $1.46^{* * *}$ \\
\hline & $(0.03)$ & $(0.02)$ & $(0.03)$ & $(0.03)$ & $(0.03)$ & $(0.03)$ & $(0.03)$ & $(0.03)$ & $(0.03)$ & $(0.03)$ & $(0.04)$ \\
\hline \multirow[t]{2}{*}{ Student EFC } & $-0.001 *$ & $-0.001 * * *$ & 0.00 & 0.00 & 0.00 & 0.00 & 0.00 & 0.00 & 0.00 & 0.00 & $-0.001 * *$ \\
\hline & $(0.00)$ & $(0.00)$ & $(0.00)$ & $(0.00)$ & $(0.00)$ & $(0.00)$ & $(0.00)$ & $(0.00)$ & $(0.00)$ & $(0.00)$ & $(0.00)$ \\
\hline \multirow[t]{2}{*}{ Student Need } & $-0.11 * * *$ & $-0.10 * * *$ & $-0.089 * * *$ & $-0.08 * * *$ & $-0.078 * * *$ & $-0.08 * * *$ & $-0.09 * * *$ & $-0.08 * * *$ & $-0.07 * * *$ & $-0.06^{* * *}$ & $-0.06 * * *$ \\
\hline & $(0.01)$ & $(0.00)$ & $(0.00)$ & $(0.00)$ & $(0.00)$ & $(0.00)$ & $(0.00)$ & $(0.00)$ & $(0.00)$ & $(0.00)$ & $(0.00)$ \\
\hline \multirow[t]{2}{*}{ Pell Recipient } & -0.01 & $-0.053^{*}$ & -0.01 & 0.01 & $-0.044^{*}$ & -0.03 & 0.02 & 0.02 & 0.03 & -0.02 & -0.02 \\
\hline & $(0.02)$ & $(0.02)$ & $(0.02)$ & $(0.02)$ & $(0.02)$ & $(0.02)$ & $(0.02)$ & $(0.02)$ & $(0.02)$ & $(0.02)$ & $(0.02)$ \\
\hline \multirow[t]{2}{*}{ Female } & 0.03 & 0.01 & -0.01 & 0.03 & 0.02 & -0.02 & 0.00 & -0.02 & -0.01 & $-0.035^{*}$ & $-0.031^{*}$ \\
\hline & $(0.01)$ & $(0.01)$ & $(0.01)$ & $(0.01)$ & $(0.01)$ & $(0.01)$ & $(0.01)$ & $(0.01)$ & $(0.01)$ & $(0.01)$ & $(0.01)$ \\
\hline \multirow[t]{2}{*}{ Nonresident } & $0.27 * * *$ & $0.25 * * *$ & $0.32 * * *$ & $0.36^{* * * *}$ & $0.36 * * *$ & $0.40 * * *$ & $0.46^{* * * *}$ & $0.51 * * *$ & $0.48 * * *$ & $0.70 * * *$ & $0.78^{* * *}$ \\
\hline & $(0.02)$ & $(0.02)$ & $(0.02)$ & $(0.02)$ & $(0.02)$ & $(0.02)$ & $(0.02)$ & $(0.02)$ & $(0.02)$ & $(0.02)$ & $(0.02)$ \\
\hline \multirow[t]{2}{*}{ Asian } & -0.04 & -0.06 & -0.02 & -0.01 & -0.04 & 0.04 & -0.02 & $0.120^{*}$ & -0.11 & $-0.111^{*}$ & 0.02 \\
\hline & $(0.06)$ & $(0.06)$ & $(0.05)$ & $(0.06)$ & $(0.05)$ & $(0.06)$ & $(0.06)$ & $(0.05)$ & $(0.06)$ & $(0.05)$ & $(0.06)$ \\
\hline \multirow[t]{2}{*}{ URM } & $0.07 *$ & $0.15^{* * *}$ & 0.03 & 0.01 & 0.06 & 0.01 & -0.02 & 0.03 & -0.04 & $-0.06^{*}$ & -0.03 \\
\hline & $(0.04)$ & $(0.03)$ & $(0.03)$ & $(0.03)$ & $(0.03)$ & $(0.03)$ & $(0.03)$ & $(0.02)$ & $(0.02)$ & $(0.03)$ & $(0.02)$ \\
\hline $\mathbf{N}$ & 3716 & 3944 & 3861 & 4259 & 3994 & 4403 & 4371 & 4424 & 4301 & 4221 & 4166 \\
\hline Pr2 & 0.04 & 0.05 & 0.05 & 0.05 & 0.06 & 0.06 & 0.06 & 0.06 & 0.06 & 0.06 & 0.06 \\
\hline
\end{tabular}

$* \mathbf{p}<0.05 * * \mathbf{p}<0.01 * * * \mathbf{p}<0.001$ 